\title{
FINAL REPORT - \\ HYBRID-MIXING TESTS SUPPORTING THE CONCENTRATE RECEIPT VESSEL (CRV-VSL-00002A/2B) CONFIGURATION (U)
}

SEPTEMBER 2004

ENGINEERING DEVELOPMENT LABORATORY

HANFORD RIVER PROTECTION PROJECT - WTP

SAVANNAH RIVER NATIONAL LABORATORY

Westinghouse Savannah River Company

Savannah River Site

Aiken, SC 29808

Prepared for the U.S. Department of Energy Under Contract Number DEAC09-96SR18500

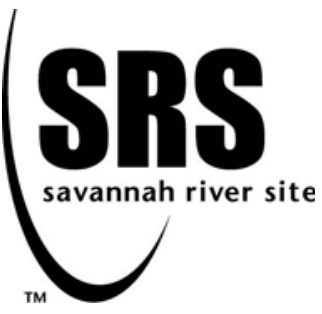


This document was prepared in conjunction with work accomplished under Contract No. DE-AC09-96SR18500 with the U. S. Department of Energy.

\section{DISCLAIMER}

This report was prepared as an account of work sponsored by an agency of the United States Government. Neither the United States Government nor any agency thereof, nor any of their employees, makes any warranty, express or implied, or assumes any legal liability or responsibility for the accuracy, completeness, or usefulness of any information, apparatus, product or process disclosed, or represents that its use would not infringe privately owned rights. Reference herein to any specific commercial product, process or service by trade name, trademark, manufacturer, or otherwise does not necessarily constitute or imply its endorsement, recommendation, or favoring by the United States Government or any agency thereof. The views and opinions of authors expressed herein do not necessarily state or reflect those of the United States Government or any agency thereof.

This report has been reproduced directly from the best available copy.

Available for sale to the public, in paper, from: U.S. Department of Commerce, National Technical Information Service, 5285 Port Royal Road, Springfield, VA 22161, phone: (800) 553-6847, fax: (703) 605-6900

email: orders@ntis.fedworld.gov

online ordering: http://www.ntis.gov/help/index.asp

Available electronically at http://www.osti.gov/bridge

Available for a processing fee to U.S. Department of Energy and its contractors, in paper, from: U.S. Department of Energy, Office of Scientific and Technical Information, P.O. Box 62, Oak Ridge, TN 37831-0062,

phone: (865)576-8401,

fax: (865)576-5728

email: $\underline{\text { reports@ adonis.osti.gov }}$ 
Key Words:

Pulse Jet Mixers

Non-Newtonian fluid

Mixing

Retention:

Permanent

Key WTP R\&T References:

Test Specification

24590-HLW-TSP-RT-03-008, Rev. 0

Test Plan WSRC-TR-2003-00410

Test Exceptions

24590-WTP-TEF-RT-04-001

24590-WTP-TEF-RT-04-006

Scoping Statement S-200

\section{FINAL REPORT - \\ HYBRID-MIXING TESTS SUPPORTING THE CONCENTRATE RECEIPT VESSEL (CRV-VSL-00002A/2B) CONFIGURATION (U)}

Hector N. Guerrero 786-5A

Kurt R. Eberl 773-A

September 2004

Westinghouse Savannah River Company Savannah River Site

Aiken, SC 29808

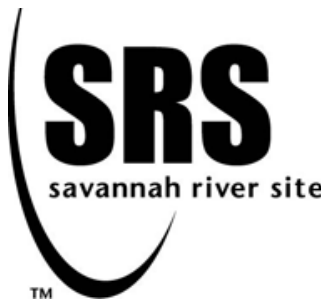


This page was intentionally left blank 


\section{TABLE OF CONTENTS}

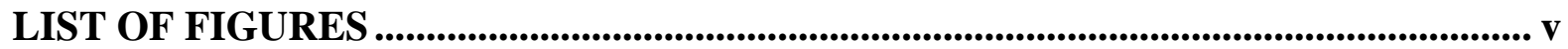

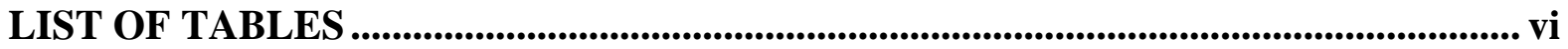

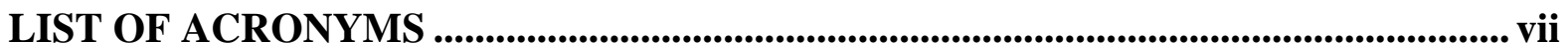

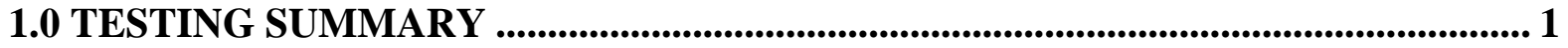

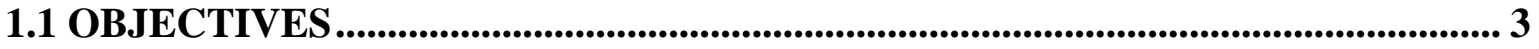

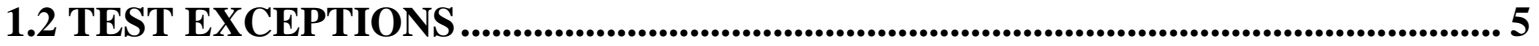

1.3 RESULTS AND PERFORMANCE AGAINST SUCCESS CRITERIA ................ 6

1.4 QUALITY REQUIREMENTS................................................................................. 8

1.5 R\&T TEST CONDITIONS .......................................................................................... 8

1.5.1 Test Specification Test Conditions................................................................... 8

1.5.2 Test Exception 24590-WTP-TEF-RT-04-001 Test Conditions ........................ 11

1.5.3 Test Exception 24590-WTP-TEF-RT-04-0006 Test Conditions ....................... 12

1.6 SIMULANT USE ............................................................................................ 14

1.6.1 Plant Bounding Conditions ............................................................................ 14

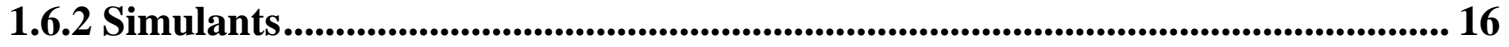

1.7 DISCREPANCIES AND FOLLOW-ON TESTS ..................................................... 19

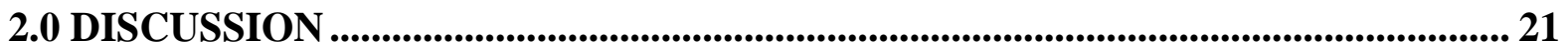

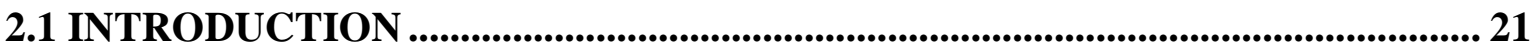

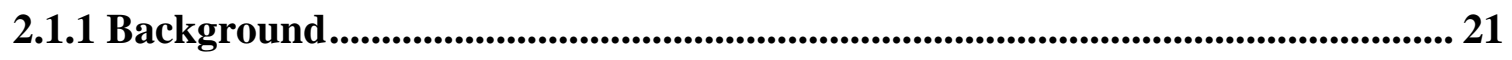

2.1.2 Design Goals for the Phase II PJM Hybrid Mixing Systems .............................. 21

2.1.3 Operational Scenarios............................................................................... 22

2.1.4 Overview of the PJM-Hybrid Mixing Systems Design Approach .................... 24

2.1.5 Overview of the Scaled Testing Methodology........................................................... 26

2.2 TEST STAND AND EXPERIMENTAL METHODS............................................... 26

2.2.1 CRV Prototype Vessel and Alternative PJM Configurations .......................... 27

2.2.2 System Operation and Data Acquisition......................................................... 37

2.3 TESTING METHODS FOR DETERMINING MIXING EFFECTIVENESS ..... 40

2.3.1 Visual Means...................................................................................................... 40

2.3.2 Dye Method...................................................................................................................... 40

2.3.3 Ultrasonic Velocity Probe........................................................................... 44

2.3.4 Solids Mixing Method ........................................................................................ 46

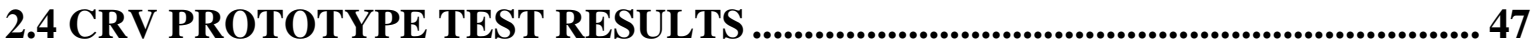

2.4.1 Phase I - PJM Configuration Selection Process ...................................................... 47

2.4.2 Phase II - Final CRV Configuration Validation ................................................ 49

2.5 SELECTION AND DESCRIPTION OF FINAL CRV CONFIGURATION........ 63

2.5.1 Comparison of Test Results of Final CRV Configurations............................. 63

2.5.2 Description of Final Selected CRV Configuration ................................................. 64

3.0 REFERENCES...................................................................................................................69 69

APPENDIX A. TECHNICAL BASIS FOR SCALED TESTING OF WTP MIXING VESSELS WITH NON-NEWTONIAN SLURRIES ........................... 71

A-1 INTRODUCTION ............................................................................................ 71

A-2 PRINCIPLES OF PJM OPERATION.................................................................. 71

A-3 IMPORTANT PROPERTIES, PARAMETERS, AND NON-DIMENSIONAL

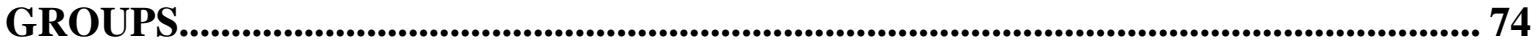

A-4 GEOMETRIC SCALING APPROACH.......................................................... 76 
A-5 SCALING NON-DIMENSIONAL PARAMETERS ......................................... 77

A-6 SUMMARY OF SCALED TEST APPROACH ............................................... 78

APPENDIX B. NOZZLE VELOCITY VALIDATION AND VERIFICATION........... 81

APPENDIX C. DYE METHOD AND RESULTS ........................................................ 89

C-1 DYE METHOD DESCRIPTION ................................................................. 89

C-2 DYE TEST RESULTS ................................................................................. 92

APPENDIX D. ULTRASONIC VELOCITY PROBE ...........................................99

APPENDIX E. STATISTICAL ANALYSIS OF SOLIDS MIXING TESTS............... 113 
WSRC-TR-2004-00398, REVISION 0

SRNL-RPP-2004-00060, REVISION 0

\section{LIST OF FIGURES}

Figure 1-1. Rheogram of Actual HLW Pretreated Sludge Samples with Upper Bound Rheological Curve.

Figure 1-2. Flow Behavior Comparison of PJM Simulants and Actual HLW Pretreated

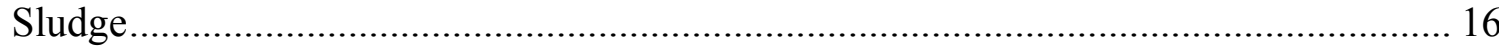

Figure 2-1. PJM-Hybrid Mixing Approach. Central cluster PJMs mix the lower region of

the vessel and a secondary system mixes the upper region.

Figure 2-2. Scaled Concentrate Receipt Vessel Test Stand (Baseline PJM Configuration installed).

Figure 2-3. Overall View of Concentrate Receipt Vessel Test Facility showing Subsystems

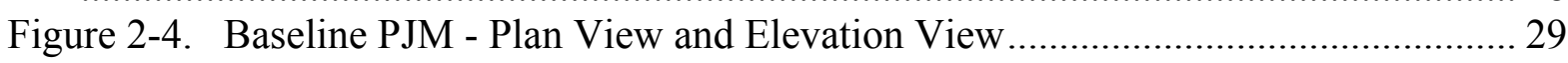

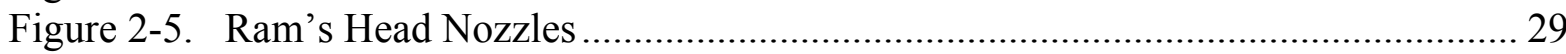

Figure 2-6. Modified Baseline PJM Configuration .............................................................. 30

Figure 2-7. Chandelier PJM Configuration - Plan View and Elevation View...................... 31

Figure 2-8. Spider PJM Configuration - Plan View and Elevation View.............................. 31

Figure 2-9. Top View of the CRV Prototypic Test Stand Showing Nominal Dimensions .. 32

Figure 2-10. Plan View of the CRV Test Stand Showing Nominal Dimensions ................. 33

Figure 2-11. Final 8-inch diameter Chandelier PJM and charge vessel assembly (1.5-in.

diameter Nozzles installed) .................................................................................... 34

Figure 2-12. Center Nozzle Showing Nominal Dimensions for 1-inch Nozzle .................... 34

Figure 2-13. $45^{\circ}$ Nozzle; Showing Nominal Dimensions for 1-inch Nozzle ........................ 35

Figure 2-14. $135^{\circ}$ Nozzle Showing Nominal Dimensions for 1-inch Nozzle........................ 35

Figure 2-15. Sparger and Sample Line Locations in Final Chandelier Arrangement .......... 36

Figure 2-16. Level Probe Installation inside a PJM............................................................ 38

Figure 2-17. Isometric Drawing of the CRV Test Stand with Compressed Air and Vacuum

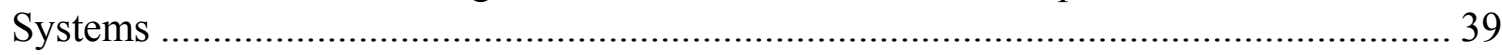

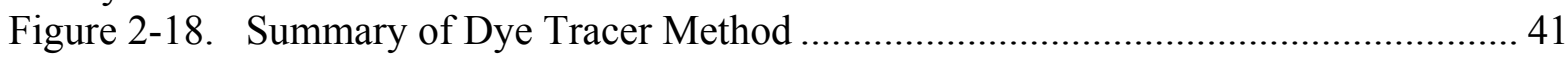

Figure 2-19. Typical Ultrasonic Velocity Probe Velocity Measurements............................. 45

Figure 2-20. Plot of Cavern Height vs. Nozzle Velocity for Test Group A .......................... 50

Figure 2-21. Cavern Height vs. Yield Reynolds Number for CRV Tank, Downward Nozzles

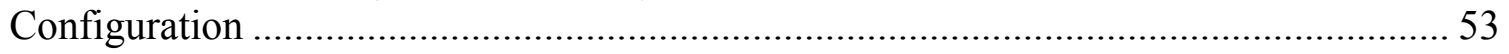

Figure 2-22. Amplitude of Velocity Oscillations for Various Conditions of Air Sparging

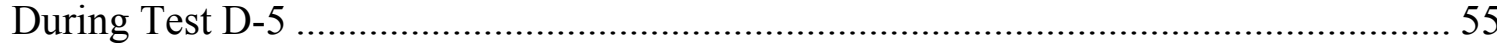

Figure 2-23. HCP-VSL-00001/2 Mixing System Layout - Plan View .................................. 65

Figure 2-24. HCP-VSL-00001/2 Mixing System Layout - Elevation View ............................ 65

Figure 2-25. Sparge Air Requirements and Resulting ZOIs - HCP-VSL-00001/2 ............... 66

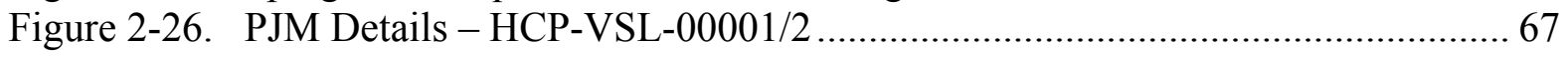

Figure 2-27. Outer PJM Nozzle Detail - HCP-VSL-00001/2 ……………………................ 67 


\section{LIST OF TABLES}

Table 1-1. Test Objectives .................................................................................. 3

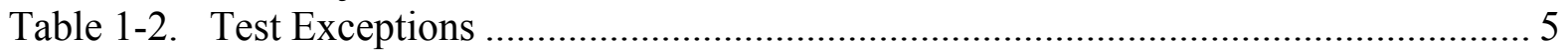

Table 1-3. Results and Performance against Success Criteria ............................................ 6

Table 1-4. Test Specification 24590-HLW-TSP-RT-03-008, Rev. 0, Test Matrix ............... 9

Table 1-5. Specific Test Conditions for Test Specification 24590-HLW-TSP-RT-03-008, Rev. 0 and Test Plan WSRC-TR-2003-00410, Rev. 0................................................ 10

Table 1-6. Test Conditions for Test Exception 24590-WTP-TEF-RT-04-001, UVP Probe

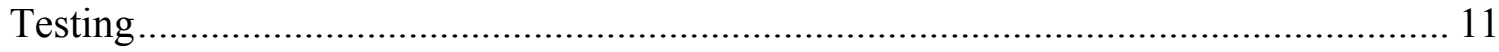

Table 1-7. Test Conditions for Test Exception 24590-WTP-TEF-RT-04-001, UVP Probe

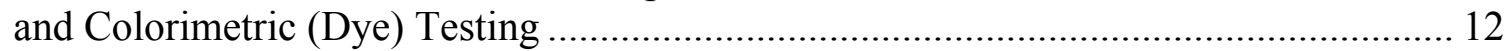

Table 1-8. Test Conditions for Test Exception 24590-WTP-TEF-RT-04-006................... 13

Table 1-9. Physical and Rheological Properties that Help Define Simulants for Rating or Qualifying Fluidic Mixing Systems ...................................................................... 15

Table 1-10. Rheological Model Fits for CRV Prototype PJM Laponite Simulant at Ambient

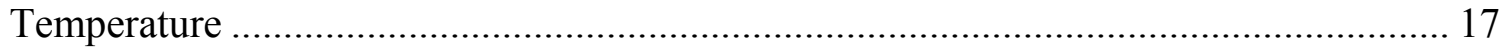

Table 1-11. Rheological Model Fits for CRV Prototype PJM Kaolin:Bentonite Simulants at

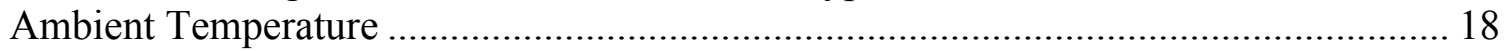

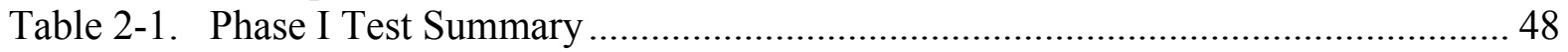

Table 2-2. Scoping Test (Test Group A) Results.......................................................... 50

Table 2-3. Cavern Heights for Chandelier PJM Configuration with 1-inch Downward Facing Nozzles (Test Group C Results) ........................................................... 52

Table 2-4. Percent Tank Volume Mixed as Measured by UVP Probe and Dye Methods

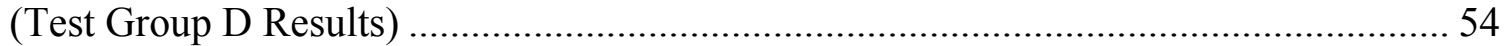

Table 2-5. Percent Tank Volume Mixed for Final CRV Configurations (Test Group E

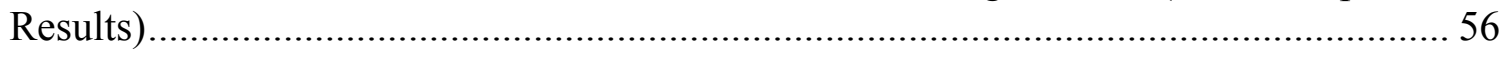

Table 2-6. Test Conditions and Results of Solids Lift Tests Performed in CRV Prototypic Test Stand ..................................................................................................... 57

Table 2-7. Solids Mixing Test Results for 1-inch Downward Nozzle Configuration with

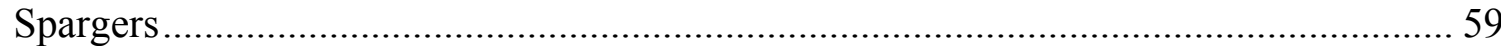

Table 2-8. Solids Mixing Test Results for 1.5-inch Up/Down Nozzle Configuration with No

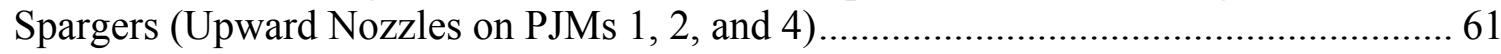

Table 2-9. Solids Mixing Test Results for 1.5-inch Up/Down Nozzle Configuration with No

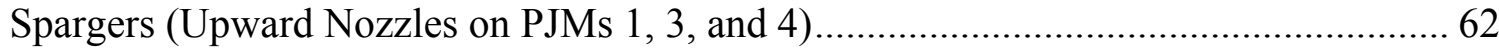

Table 2-10. Concentrate Receipt Vessels (HCP-VSL-00001/2)...................................... 64 
WSRC-TR-2004-00398, REVISION 0

SRNL-RPP-2004-00060, REVISION 0

\section{LIST OF ACRONYMS}

\begin{tabular}{|c|c|}
\hline AEA & PJM contractor \\
\hline APEL & Applied Process Engineering Laboratory \\
\hline BHRG & BHR Group \\
\hline $\mathrm{BNI}$ & Bechtel National, Inc. \\
\hline $\mathrm{CCN}$ & correspondence control number \\
\hline CFD & computational fluid dynamics \\
\hline CRV & concentrate receipt vessel \\
\hline DACS & data acquisition and control software \\
\hline DBE & design basis event \\
\hline gpm & gallons per minute \\
\hline GFC & glass former chemicals \\
\hline GFFH & glass former facility handling \\
\hline GR\&R & gas retention and release \\
\hline IHLW & immobilized high-level waste \\
\hline $\mathrm{H}_{\mathrm{c}}$ & cavern height \\
\hline $\mathrm{H} / \mathrm{D}$ & ratio of slurry height to vessel diameter \\
\hline HLP & HLW Lag Storage and Feed Blending Process System \\
\hline HLW & high-level waste \\
\hline ID & inner diameter \\
\hline ITS & important to safety \\
\hline JPP & jet pump pair \\
\hline LAW & low-activity waste \\
\hline LS & lag storage \\
\hline MFPV & melter feed process vessel \\
\hline MFV & melter feed vessel \\
\hline MTG & metric ton glass \\
\hline OD & outer diameter \\
\hline PJM & pulse jet mixer \\
\hline $\mathrm{R} \& \mathrm{D}$ & research and development \\
\hline $\mathrm{R} \& \mathrm{~T}$ & research and technology \\
\hline RFD & reverse flow diverter \\
\hline $\mathrm{ROB}$ & region of bubbles \\
\hline $\mathrm{scfm}$ & standard cubic feet per minute \\
\hline SRNL & Savannah River National Laboratory \\
\hline TRU & transuranics \\
\hline $\mathrm{U}$ & nozzle velocity \\
\hline $\mathrm{U}_{\mathrm{BT}}$ & breakthrough velocity \\
\hline $\mathrm{U}_{\min }$ & minimum nozzle velocity for detectable cavern \\
\hline $\mathrm{U}_{\mathrm{P}}$ & Protoypic PJM nozzle design velocity $(12 \mathrm{~m} / \mathrm{s})$ \\
\hline UFP & ultrafiltration feed process vessel \\
\hline UVP & Ultrasonic Velocity Probe \\
\hline VVV & Validate, Verify, nozzle Velocity \\
\hline WTP & Waste Treatment Plant \\
\hline ZOI & zone of influence \\
\hline
\end{tabular}


WSRC-TR-2004-00398, REVISION 0

SRNL-RPP-2004-00060, REVISION 0

This page intentionally left blank.

- viii - 
WSRC-TR-2004-00398, REVISION 0

SRNL-RPP-2004-00060, REVISION 0

\subsection{TESTING SUMMARY}

The Savannah River National Laboratory (SRNL) has performed scaled physical modeling of Pulse Jet Mixing Systems applicable to the Concentrate Receipt Vessel (CRV) of Hanford's Waste Treatment Plant (WTP) as part of the overall effort to validate PJM mixing in WTP vessels containing non-Newtonian fluids. The strategy developed by the Pulse Jet Mixing Task Team (R\&T, Engineering, Bechtel R\&D, SRNL, and mixing consultants) was to construct a quarter-scale model of the CRV, utilize a clear simulant to understand PJM mixing behavior, and down-select from a number of PJM configurations to a "best design" configuration. This "best design" would undergo final validation testing using a particulate simulant that has rheological properties closely similar to WTP waste streams. The scaled PJM mixing tests were to provide information on the operating parameters critical for the uniform movement (total mobilization) of these non-Newtonian slurries. Overall, 107 tests were performed during Phase I and Phase II testing.

Phase I testing (Section 2.4.1) included tests of the baseline PJM configuration composed of (6) 6-inch (scaled) diameter PJMs and (2) Rams Head PJMs, and two alternative PJM designs. Parameters that were varied were: number of PJMs (6-8), nozzle size and orientation, simulant yield stress, and PJM firing order. Due to the desire to reduce the number of PJMs back to the original number (6) to minimize the impact on plant piping, the alternative PJMs had larger 8-inch (scaled) diameter PJMs. These were arranged into the Spider and Chandelier configurations. A transparent simulant, Laponite, was used to evaluate the percent volume mixed by visual means. The boundaries of the cavern or turbulent flow region could be visually distinguished from the unyielded region. Phase I testing indicated that the baseline design with 8 PJMs met the mixing criteria imposed with the clear simulant, with just PJM mixing, but the impact on plant design was severe due to increased piping and air consumption. Both alternative designs (Spider and Chandelier) had greater potential than the baseline design, but the Chandelier design was selected as best design due to practical advantages.

Initial testing of the Chandelier design with particulate simulant (Section 2.4.2.1), a solution of kaolin and bentonite, was performed with PJM mixing only for various simulant yield stresses and at tank levels of 40 inches (full level) and 30 inches. A correlation of the dimensionless cavern height was determined as a function of Yield Reynolds number. The cavern height was measured with the Ultrasonic Velocity Probe (UVP) probe. Here, the criteria for the minimum velocity of $80 \mathrm{~mm} / \mathrm{sec}$ was based on correlating the tank level at which breakthrough of the pulse jet at the surface when the tank level is lowered slowly with the PJMs were operating. This also corresponded to the minimum detectable velocity pulse above the turbulent noise recorded by the UVP. 
To reduce the impact on the overall cost and schedule, hybrid mixing designs were investigated. These involved the use of both: PJMs, which are excellent in sweeping wastes off the tank bottom and suspending it, and air spargers, which are designed to fully mix the suspended wastes up to the surface of the vessel. Phase II of the PJM program (Section 2.4.2) investigated further alternative configurations to assess the effects of slurry rheology changes, reduced tank volume, PJM jet velocity and nozzle size, configuration and sparging. Both the colorimetric (dye) and UVP methods were used to determine the percent mixed tank volume. The criterion for full mixing was when both methods indicate $100 \%$ mixing. The results show that a number of alternate mixing designs met the WTP mixing criterion when air sparging in all 5 PJM sectors of up to $2 \mathrm{scfm}$ per sparger was utilized.

This however required that the full volume of the 8-inch PJM be fully driven at nozzle velocities up to $12 \mathrm{~m} / \mathrm{s}$, which require development of a new Jet Pump Pair (JPP). Consequently, two new configurations were tested. One of the new configurations utilized 1-inch downward nozzles and air sparging in all 5 sectors of up to $3 \mathrm{scfm}$ per sparger, and the other utilized both upward and downward pointing 1-inch nozzles and 5 spargers at $2 \mathrm{scfm}$ each. The configuration with 1-inch downward pointing nozzles and 5 spargers was selected.

The final verification test was performed in conjunction with the assessment of the capability of the hybrid mixing design to uniformly mix the contents of the CRV when solids that are known to exist in the waste are also simulated. The solids were simulated with 210-300 micron sized glass beads mixed with the kaolin:bentonite simulant. The PJMs and air spargers were turned on for the same number of cycles as in the plant before the CRV contents are transferred. Grab samples were then taken at two elevations to correspond to upper and lower tank volumes. Pump samples were also obtained from the tank heel. Statistical analysis was used to determine any significant differences in tracer concentrations between tank upper, lower, and heel volumes. The results of the solids mixing test for the 1-inch downward nozzles with sparging and $30 \mathrm{~Pa}$ yield stress show that the upper and lower tank volumes did not significantly differ from each other, but that the heel tracer concentration obtained close to the sampling charge vessel, had a statistically significant difference from the two other tank volumes. This could be due to a low flow region in the vicinity of the sampling vessels or that the sampling technique needs improvement, such as the use of grab samples in the heel area.

While the sampling technique could be improved and testing of the 1-inch downward nozzles with sparging could be repeated, the WTP project decided that the air flow requirement of the spargers was too high. A second configuration was chosen which utilized 1.5 inch nozzles arranged in upward and downward facing configuration, but with no sparging. The solid mixing results for this configuration at $30 \mathrm{~Pa}$ was significantly worse than for the previous case, where the tracer mean concentrations for random grab samples in the heel were clearly different from the upper and lower tank grab samples. 
A third PJM configuration, essentially similar to the second one, but with one upward nozzle and one downward nozzle relocated to minimize the flow obstruction effect of the sampling vessels. This test resulted in a deviation from the experimental "true" tank average concentration of less than $4.77 \%$ for $30 \mathrm{~Pa}$ simulant. It is possible that with further work, the deviation from tank average could be reduced to less than $4 \%$.

The final PJM configuration selected was the 1-inch downward nozzles with sparging.

\subsection{OBJECTIVES}

The objectives of this task are embodied in Test Specification 24590-HLW-TSP-RT-03-008, Rev. 0, Test Plan WSRC-TR-2003-00410, and Test Exceptions: 24590-WTP-TEF-RT-04001 and 24590-WTP-TEF-RT-04-006. These are summarized in Table 1-1.

Table 1-1. Test Objectives

\begin{tabular}{|l|c|l|}
\hline \multicolumn{1}{|c|}{ Test Objective } & $\begin{array}{l}\text { Objective } \\
\text { Met (Y/N) }\end{array}$ & \multicolumn{1}{|c|}{ Discussion } \\
\hline $\begin{array}{l}\text { 1. Provide design information on } \\
\text { the operating parameters } \\
\text { critical for the uniform } \\
\text { movement (total mobilization) } \\
\text { of the tank contents. }\end{array}$ & Y & $\begin{array}{l}\text { The specific objective was to provide } \\
\text { data, such as cavern height or } \% \\
\text { volume mixed, on the mobilization of } \\
\text { non-Newtonian simulants for the } \\
\text { assessment of PJM mixing system } \\
\text { designs for the CRV vessel. The non- } \\
\text { Newtonian simulant was to possess } \\
\text { target rheological characteristics that } \\
\text { were similar to those measured for } \\
\text { WTP waste streams. } \\
\text { The data reported for the scaled } \\
\text { prototype testing will eventually be } \\
\text { used to generate the scaling, } \\
\text { engineering, and bounding parametric } \\
\text { correlations which will be used to } \\
\text { ensure the WTP Project has a } \\
\text { functional fluidic mixing systems } \\
\text { design for the CRV non-Newtonian } \\
\text { vessel. } \\
\text { This objective was met with each of } \\
\text { the CRV PJM configurations } \\
\text { requested by WTP Project, and } \\
\text { resulted in selection of the Chandelier } \\
\text { design. See Sections 2.4.1 and } 2.4 .2 .\end{array}$ \\
\hline
\end{tabular}


WSRC-TR-2004-00398, REVISION 0

SRNL-RPP-2004-00060, REVISION 0

Table 1.1 - Test Objectives - continued

\begin{tabular}{|c|c|c|}
\hline Test Objective & $\begin{array}{c}\text { Objective } \\
\text { Met (Y/N) }\end{array}$ & Discussion \\
\hline $\begin{array}{l}\text { 2. Develop mixing correlation } \\
\text { (\% volume mixed) curves as a } \\
\text { function of Rheology using } \\
\text { clay simulant with yield stress } \\
\text { at } 4 \text { data points over the range } \\
\text { of } 40-10 \mathrm{~Pa} \text {. Tests to be done } \\
\text { at } 8 \text { and } 12 \mathrm{~m} / \mathrm{s} \text { velocities. }\end{array}$ & Y & $\begin{array}{l}\text { Test Plan WSRC-TR-2003-00410 has } \\
\text { led to a final best design } \\
\text { configuration. Testing will be } \\
\text { finished to demonstrate mixing using } \\
\text { a particulate simulant with } \\
\text { rheological properties deemed closer } \\
\text { to actual waste. } \\
\text { This objective was met by testing } \\
\text { with various nozzle sizes and } \\
\text { orientations. See Sections } 2.4 .2 .1 \text { and } \\
\text { 2.4.2.2. }\end{array}$ \\
\hline $\begin{array}{l}\text { 3. Obtain revised test matrix data } \\
\text { with hybrid mixing designs to } \\
\text { demonstrate a mixing solution } \\
\text { exists using a particulate } \\
\text { simulant with rheological } \\
\text { properties deemed closer to } \\
\text { actual waste. }\end{array}$ & $\mathrm{Y}$ & $\begin{array}{l}\text { WTP Project decided it would be best } \\
\text { to lower the amount of air used in the } \\
\text { best design configuration. Testing to } \\
\text { be conducted with the baseline } \\
\text { number of pulse tubes or less } \\
\text { combined with spargers and } \\
\text { recirculation pumps. } \\
\text { This objective was met by testing two } \\
\text { PJM configurations with glass beads } \\
\text { as solid phase tracers. See Section } \\
\text { 2.4.2.3. }\end{array}$ \\
\hline
\end{tabular}


WSRC-TR-2004-00398, REVISION 0

SRNL-RPP-2004-00060, REVISION 0

\subsection{TEST EXCEPTIONS}

Table 1-2. Test Exceptions

\begin{tabular}{|l|l|}
\hline List Test Exceptions & Describe Test Exceptions \\
\hline 1.24590-WTP-TEF-RT-04-001 & $\begin{array}{l}\text { Reconfigure and perform revised test } \\
\text { matrix in final down selected Chandelier } \\
\text { configuration to develop mixing } \\
\text { correlation (\% volume mixed) curves as a } \\
\text { function of rheology, nozzle velocity and } \\
\text { use of spargers. }\end{array}$ \\
\hline 2.24590-WTP-TEF-RT-04-0006 & $\begin{array}{l}\text { Testing will be performed with } \\
\text { kaoline:bentonite clay mixture with } \\
\text { rheological properties approximating a } \\
\text { Bingham Plastic with a Yield Stress of } \\
\text { 30 Pa and consistency of 30 cP, followed } \\
\text { by tests with simulant with Yield stress of } \\
6 \text { Pa and whatever consistency results } \\
\text { after dilution of the 30 Pa simulant. } \\
\text { Methods for measuring mixing } \\
\text { effectiveness will include colorimetric dye } \\
\text { method, Radio-frequency tags, } \\
\text { Polycarbonate beads, and ultrasonic } \\
\text { probe. The mixing capability in the solid } \\
\text { phase will also be assessed by using glass } \\
\text { beads to simulate high density materials in } \\
\text { the radioactive waste. }\end{array}$ \\
\hline
\end{tabular}


WSRC-TR-2004-00398, REVISION 0

SRNL-RPP-2004-00060, REVISION 0

\subsection{RESULTS AND PERFORMANCE AGAINST SUCCESS CRITERIA}

\section{Table 1-3. Results and Performance against Success Criteria}

\begin{tabular}{|c|c|}
\hline List Success Criteria & $\begin{array}{l}\text { Explain How the Tests Did or Did Not } \\
\text { Meet the Success Criteria }\end{array}$ \\
\hline $\begin{array}{l}\text { 1. A test stand was to be procured/ } \\
\text { fabricated for concentrate receipt vessel } \\
\text { (CRV) class of tanks with non- } \\
\text { Newtonian slurries. A flexible, easily } \\
\text { re-configurable design for the PJMs } \\
\text { and internals would be developed and } \\
\text { fabricated. The scope included design, } \\
\text { procurement/ fabrication, assembly, } \\
\text { shakedown testing, prototypical testing, } \\
\text { data analysis, and reporting. To meet } \\
\text { the mixing criteria, testing was to } \\
\text { assess a number of operating } \\
\text { parameters, e.g., AEA Technology base } \\
\text { design; nozzle velocity; nozzle size; } \\
\text { modifying pulse frequency; number of } \\
\text { PJM tubes; different orientations/ } \\
\text { elevations of PJM tubes; flow } \\
\text { reversers; pulse tube firing order, until } \\
\text { mixing success was achieved. The } \\
\text { successful mixing parameters will be } \\
\text { provided to WTP Engineering to } \\
\text { release fabrication of the CRV vessel. }\end{array}$ & $\begin{array}{l}\text { 1. A quarter scale CRV test platform was } \\
\text { constructed with } 6 \text { baseline PJMs (6-inch } \\
\text { diameter) and } 2 \text { Ram's Head PJMs. } \\
\text { Testing with various combinations of } \\
\text { nozzle size and velocity, number of PJM } \\
\text { tubes, orientations of nozzles, pulse tube } \\
\text { firing order suggested better mixing } \\
\text { designs were required. Two other basic } \\
\text { PJM configurations were built using } \\
\text { 8-inch diameter PJMs that had the } \\
\text { capability to be easily reconfigured. These } \\
\text { were the Spider and the Chandelier } \\
\text { designs. Visual observations were used } \\
\text { with the clear Laponite simulant to } \\
\text { determine mixing effectiveness. The } \\
\text { Spider and the Chandelier designs were } \\
\text { judged acceptable, with the Chandelier } \\
\text { design chosen for its fabricability and } \\
\text { robust design. }\end{array}$ \\
\hline $\begin{array}{l}\text { 2. Determination of pulsed jet mixer } \\
\text { operating conditions and physical fluidics } \\
\text { systems internal vessel arrangement to } \\
\text { achieve flow velocities great enough to } \\
\text { mix the entire vessel contents uniformly to } \\
\text { meet WTP operational constraints. This } \\
\text { would be demonstrated with a transparent } \\
\text { waste simulant, at a minimum, with shear } \\
\text { strength near the bounding } 30 \mathrm{~Pa} \text { Bingham } \\
\text { Plastic yield stress value and potentially } \\
\text { with a representative particulate simulant. }\end{array}$ & $\begin{array}{l}\text { Transparent Laponite was used up to a } \\
\text { Yield Stress of } 70 \mathrm{~Pa} \text { for final selection of } \\
\text { various PJM configurations. Kaolin: } \\
\text { bentonite solution which exhibited a } \\
\text { Bingham Plastic yield stress up to } 30 \mathrm{~Pa} \\
\text { and consistency of } 30 \mathrm{cP} \text { was used for the } \\
\text { particulate simulant. }\end{array}$ \\
\hline
\end{tabular}


WSRC-TR-2004-00398, REVISION 0

SRNL-RPP-2004-00060, REVISION 0

Table 1.3 - Results and Performance against Success Criteria - continued

\begin{tabular}{|l|}
\hline List Success Criteria \\
\hline 3. A diagnostic technique (or techniques) will be \\
used to demonstrate that the necessary mixing \\
criterion is achieved. This may include direct \\
measurement of velocity, detection of mixed \\
versus relatively stagnant regions via \\
chemical or thermal tracer, or some form of \\
visual confirmation, (e.g., flow followers, or \\
dye observations). [Note: It was recognized \\
that the requirement for flow in $100 \%$ of the \\
vessel contents may be impractical (and \\
extremely difficult to experimentally \\
confirm). The requirement may be relaxed by \\
the PJM Steering Committee (say to 95\%) \\
after observation of actual mixing behavior.]
\end{tabular}

4. Collecting performance data using the scaled prototypic platforms with a simulant exhibiting non-Newtonian behavior representative of that measured for selected WTP waste streams. The simulants and required properties will be defined by the WTP PJM Steering Committee and specified in the test procedures and test instructions used to define and conduct specific test operations.

\section{Explain How the Tests Did or Did Not Meet the Success Criteria}

The colorimetric (dye) method and the Ultrasonic Velocity probe were used to obtain \% mixed volume of various hybrid mixing designs. A design is said to have $100 \%$ mixed volume when both methods indicate $100 \%$ mixing.

Data from various PJM configurations were obtained with non-Newtonian kaolin:bentonite solutions representative of selected WTP waste streams. In addition, high density solids in the waste streams were simulated with glass beads to determine the ability of the mixing systems to lift the solid particles off the bottom and distribute them over the tank volume.

5. Determine the extent of solids mixing in the final best design configuration and verify that the degree of uniformity required can be accomplished.

Solids mixing tests using glass bead tracers were performed with two nozzle configurations and two simulant rheologies. Uniformity of three CRV tank volumes was determined using statistical methods in one configuration and using a true experimental glass beads mean in the other. At this point, the WTP Project decided to cancel the CRV. 


\subsection{QUALITY REQUIREMENTS}

This work was conducted in accordance with the RPP-WTP QA requirements specified for work conducted by SRTC as identified in DOE IWO M0SRLE60. SRTC has provided matrices to WTP demonstrating compliance of the SRTC QA program with the requirements specified by WTP. Specific information regarding the compliance of the SRTC QA program with RW-0333P, Revision 10, NQA-1 1989, Part 1, Basic and Supplementary Requirements and NQA-2a 1990, Subpart 2.7 is contained in these matrices.

\subsection{R\&T TEST CONDITIONS}

The Test Specification establishes conditions to ensure that results are valid for project needs. This section lists those conditions and indicates whether they were followed. It describes the circumstances and consequences where deviations may have been necessary

\begin{tabular}{|l|c|}
\hline List R\&T Test Conditions & Were Test Conditions Followed? \\
\hline $\begin{array}{l}\text { 1. Test Specification 24590-HLW-TSP- } \\
\text { RT-03-008, Rev. 0 }\end{array}$ & See Comment in Sec. 1.5.1 \\
\hline 2. Test Exception -24590-WTP-TEF-RT-04- & Yes \\
\hline 3. Test Exception 24590-WTP-TEF-RT-04- & Yes \\
\hline
\end{tabular}

\subsubsection{Test Specification Test Conditions}

Test Specification 24590-HLW-TSP-RT-03-008, Rev. 0, and Test Plan WSRC-TR-200300410, Rev. 0, provided a Test Matrix for Scaled CRV PJM testing, which is given in Table 1-4. This is basically a general approach to testing. A detailed test matrix was provided by WTP by email or verbal instructions and the test conditions are summarized in Table 1-5. All of these tests were of the CRV1 (Constant Volume) type. Due to schedule requirements, CRV2 tests were dropped, and these were supplanted by later tests with the final configuration. Some of the tests were of the CRV3 type. 
WSRC-TR-2004-00398, REVISION 0

SRNL-RPP-2004-00060, REVISION 0

Table 1-4. Test Specification 24590-HLW-TSP-RT-03-008, Rev. 0, Test Matrix

\begin{tabular}{|c|c|}
\hline Test Series & CRV Prototypic Vessel \\
\hline CRV1 & $\begin{array}{l}\text { Constant Drive Volume Test - Baseline PJM Configuration } \\
\text { - Nominal } \mathrm{d}_{0} \\
\text { - } \text { Find } \mathrm{U}_{\mathrm{Min}} \\
\text { - Increase U } \\
\text { - Determine } \mathrm{U}_{\mathrm{BT}} \\
\text { - If break-through, observe mixing* } \\
\text { - Possibly increase U } \\
\text { - Measure breakthrough - look at simulant height as } \\
\text { a function of U }\end{array}$ \\
\hline CRV2 & $\begin{array}{l}\text { Mixing Time Test - Baseline PJM Configuration } \\
\text { - If } \mathrm{U}_{\mathrm{BT}}>\mathrm{U}_{\mathrm{P}} \text {, use } \mathrm{U}_{\mathrm{BT}} \\
\text { - } \text { If } \mathrm{U}_{\mathrm{BT}}<\mathrm{U}_{\mathrm{P}} \text {, use } \mathrm{U}_{\mathrm{P}} \\
\text { - } \text { Measure } \mathrm{Hc}(\mathrm{t}) \\
\text { - } \text { Time to break-through } \\
\text { - } \text { Time to fully mixed }\end{array}$ \\
\hline CRV3 & TBD - likely CRV1 with maximum, optional pulse tubes \\
\hline \multicolumn{2}{|c|}{$\begin{array}{l}\text { * Breakthrough is noted when the mobilized simulant fraction reaches the } \\
\text { surface of the stagnant region of the simulant. Observation and notes will } \\
\text { be documented on the size of the opening, as a function of time through } \\
\text { which the mobilized simulant reaches the surface will be noted along with } \\
\text { the effects on the stagnant region. }\end{array}$} \\
\hline
\end{tabular}


WSRC-TR-2004-00398, REVISION 0

SRNL-RPP-2004-00060, REVISION 0

Table 1-5. Specific Test Conditions for Test Specification 24590-HLW-TSP-RT-03008, Rev. 0 and Test Plan WSRC-TR-2003-00410, Rev. 0

\begin{tabular}{|c|c|c|c|c|c|c|c|c|c|c|c|}
\hline \multirow[b]{2}{*}{$\begin{array}{c}\text { Test } \\
\text { Num- } \\
\text { ber }\end{array}$} & \multicolumn{3}{|c|}{ CONFIGURATION } & \multicolumn{3}{|c|}{$\begin{array}{c}\text { NOZZLE SIZE } \\
\text { (INCHES) }\end{array}$} & \multicolumn{2}{|c|}{$\begin{array}{l}\text { CYCLE } \\
\text { TIME }\end{array}$} & \multirow[b]{2}{*}{$\begin{array}{c}\text { Nom. } \\
\text { Noz. } \\
\text { Velo- } \\
\text { city } \\
\text { (m/sec) }\end{array}$} & \multirow[b]{2}{*}{$\begin{array}{c}\text { Shear } \\
\text { Strength } \\
\text { (Pa) }\end{array}$} & \multirow[b]{2}{*}{$\begin{array}{l}\text { Firing Order } \\
\text { (Syn/ Asyn) }\end{array}$} \\
\hline & $\begin{array}{c}\# \\
\text { Normal } \\
\text { Nozzle } \\
\text { (Tube } \\
\text { Size- } \\
\text { Inches) } \\
\end{array}$ & $\begin{array}{c}\# \\
\text { Rams } \\
\text { Head } \\
\text { (Tube } \\
\text { Size - } \\
\text { Inches) }\end{array}$ & $\begin{array}{c}\# \\
\text { Down- } \\
\text { ward } \\
\text { (Tube } \\
\text { Size- } \\
\text { Inches) } \\
\end{array}$ & $\begin{array}{c}\text { Normal } \\
\text { Nozzle }\end{array}$ & $\begin{array}{l}\text { Rams } \\
\text { Head }\end{array}$ & $\begin{array}{c}\text { Down- } \\
\text { ward }\end{array}$ & $\begin{array}{l}\text { Drive } \\
\text { Time } \\
\text { (sec) }\end{array}$ & $\begin{array}{l}\text { Total } \\
\text { Cycle } \\
\text { Time } \\
\text { (sec) } \\
\end{array}$ & & & \\
\hline $\mathrm{I}-1$ & NA & NA & $6(6)$ & NA & NA & 1 & 3.1 & 15 & 6 & 84 & SYN \\
\hline $\mathrm{I}-2$ & NA & NA & $6(6)$ & NA & NA & 1 & 2.1 & 13 & 8 & 85 & SYN \\
\hline I-3 & NA & NA & $6(6)$ & NA & NA & 1 & 2.4 & 20 & 12 & 86 & SYN \\
\hline $\mathrm{I}-4$ & NA & NA & $6(6)$ & NA & NA & 1 & 5.4 & 20 & 6 & 34 & SYN \\
\hline I-5 & NA & NA & $6(6)$ & NA & NA & 1 & 3.7 & 20 & 8 & 36 & SYN \\
\hline I-6 & NA & NA & $6(6)$ & NA & NA & 1 & 2.2 & 20 & 12 & 36 & SYN \\
\hline I-7 & NA & $2(6)$ & $6(6)$ & NA & NA & 1 & 5 & 20 & 6 & 72 & SYN \\
\hline I-8 & NA & $2(6)$ & $6(6)$ & NA & NA & 1 & 3.3 & 20 & 8 & 72 & SYN \\
\hline I-9 & NA & $2(6)$ & $6(6)$ & NA & NA & 1 & 2 & 20 & 12 & 71 & SYN \\
\hline $\mathrm{I}-10$ & NA & $2(6)$ & $6(6)$ & NA & NA & 1 & 5.7 & 22 & 6 & 40 & SYN \\
\hline $\mathrm{I}-11$ & NA & $2(6)$ & $6(6)$ & NA & NA & 1 & 3 & 22 & 8 & 43 & SYN \\
\hline $\mathrm{I}-12$ & NA & $2(6)$ & $6(6)$ & NA & NA & 1 & 2 & 22 & 11 & 40 & SYN \\
\hline $\mathrm{I}-13$ & $4(6)$ & NA & NA & 1 & NA & NA & 3.1 & 18 & 8 & 42.8 & SYN \\
\hline I-14 & $4(6)$ & NA & NA & 1 & NA & NA & 2.2 & 18 & 12 & 44.8 & SYN \\
\hline $\mathrm{I}-15$ & $4(6)$ & $2(6)$ & NA & 1 & 0.71 & NA & 3.1 & 25 & 8 & 49.3 & SYN \\
\hline $\mathrm{I}-16$ & $4(6)$ & $2(6)$ & NA & 1 & 0.71 & NA & 2.2 & 25 & 12 & 51.8 & SYN \\
\hline $\mathrm{I}-17$ & $6(6)$ & NA & NA & 1 & NA & NA & 3.1 & 25 & 8 & 42.4 & SYN \\
\hline I-18 & $6(6)$ & NA & NA & 1 & NA & NA & 2.2 & 25 & 12 & 43.6 & SYN \\
\hline $\mathrm{I}-19$ & $6(6)$ & $2(6)$ & NA & 1 & 0.71 & NA & 3.1 & 25 & 8 & 50 & SYN \\
\hline $\mathrm{I}-20$ & $6(6)$ & $2(6)$ & NA & 1 & 0.71 & NA & 2.2 & 25 & 12 & 52.3 & SYN \\
\hline $\mathrm{I}-21$ & $6(6)$ & NA & NA & 1 & NA & NA & 3.1 & 20 & 8 & 80 & SYN \\
\hline $\mathrm{I}-22$ & $6(6)$ & NA & NA & 1 & NA & NA & 2.2 & 20 & 12 & 80 & SYN \\
\hline $\mathrm{I}-23$ & $6(6)$ & $2(6)$ & NA & 1 & NA & 1 & 3.1 & 27 & 8 & 85 & ASYN \\
\hline $\mathrm{I}-24$ & $6(6)$ & $2(6)$ & NA & 1 & NA & 1 & 2.2 & 27 & 12 & 85 & ASYN/SYN \\
\hline $\mathrm{I}-25$ & $3(6)$ & $2(6)$ & $3(6)$ & 1 & 0.71 & NA & 3.1 & 25 & 8 & 90 & ASYN \\
\hline $\mathrm{I}-26$ & $3(6)$ & $2(6)$ & $3(6)$ & 1 & 0.71 & NA & 2.2 & 25 & 12 & 90 & ASYN/SYN \\
\hline $\mathrm{I}-27$ & $2(6)$ & $2(6)$ & $4(6)$ & 1.5 & 0.8 & 1.5 & 1.4 & 18 & 8 & 70 & ASYN/SYN \\
\hline $\mathrm{I}-28$ & $2(6)$ & $2(6)$ & $4(6)$ & 1.5 & 0.8 & 1.5 & 1 & 18 & 12 & 70 & ASYN/ SYN \\
\hline $\mathrm{I}-29$ & $5(8)$ & NA & $1(8)$ & 1.5 & N/A & 1.5 & 2.37 & 18 & 8 & 70 & ASYN/SYN \\
\hline $\mathrm{I}-30$ & $5(8)$ & NA & $1(8)$ & 1.5 & $\mathrm{~N} / \mathrm{A}$ & 1.5 & 1.66 & 18 & 12 & 70 & ASYN/SYN \\
\hline $\mathrm{I}-31$ & $5(8)$ & NA & $1(8)$ & 1.5 & N/A & 1.5 & 2.37 & 18 & 8 & 70 & SYN \\
\hline $\mathrm{I}-32$ & $5(8)$ & NA & $1(8)$ & 1.5 & N/A & 1.5 & 1.66 & 18 & 12 & 70 & SYN \\
\hline $\mathrm{I}-33$ & NA & $2(6)$ & $4(8)$ & N/A & 0.8 & 1.5 & 2.37 & 18 & 8 & 70 & ASYN/SYN \\
\hline $\mathrm{I}-34$ & NA & $2(6)$ & $4(8)$ & N/A & 0.8 & 1.5 & 1.66 & 18 & 12 & 70 & ASYN/SYN \\
\hline
\end{tabular}




\subsubsection{Test Exception 24590-WTP-TEF-RT-04-001 Test Conditions}

Table 1-6 specified test conditions from Test Exception 24590-WTP-TEF-RT-04-001 to determine cavern height as a function of nozzle velocity and kaolin/bentonite simulant yield stress. Cavern is described as the well-mixed region in the vicinity of the pulse jet nozzles, distinct from the unyielded region. The primary method of determining this cavern region was the Ultrasonic Velocity Probe (UVP) and by lowering the tank level during PJM operation to determine breakthrough. The Chandelier configuration, with 6 PJMs (8-inch dia.) and (5) 1-inch downward (45 deg.) nozzles and (1) center downward nozzle, was to be used for the purpose of determining a mixing correlation.

Table 1-6. Test Conditions for Test Exception 24590-WTP-TEF-RT-04-001, UVP Probe Testing

\begin{tabular}{|c|c|c|c|c|c|c|c|c|c|}
\hline \multirow[b]{2}{*}{$\begin{array}{c}\text { Test } \\
\text { Group }\end{array}$} & \multirow[b]{2}{*}{$\begin{array}{c}\text { Test } \\
\text { Sequence }\end{array}$} & \multirow[b]{2}{*}{$\begin{array}{l}\text { Test } \\
\text { type }\end{array}$} & \multicolumn{3}{|c|}{ Nozzle Configuration } & \multirow{2}{*}{$\begin{array}{l}\text { Nozzle } \\
\text { I.D., } \\
\text { inches }\end{array}$} & \multirow{2}{*}{$\begin{array}{c}\text { Nominal } \\
\text { Nozzle } \\
\text { Velocity } \\
\text { m/s } \\
\end{array}$} & \multirow{2}{*}{$\begin{array}{c}\# \\
\text { Spargers } \\
\text { @ scfm } \\
\text { tot. }\end{array}$} & \multirow{2}{*}{$\begin{array}{c}\text { Nominal } \\
\text { Yield } \\
\text { Stress } \\
(\mathbf{P a}) \\
\end{array}$} \\
\hline & & & $\begin{array}{l}\# 45 \\
\text { deg. }\end{array}$ & $\begin{array}{c}\text { \# } 135 \\
\text { deg. }\end{array}$ & $\begin{array}{c}\text { \# Ver- } \\
\text { tical }\end{array}$ & & & & \\
\hline $\mathrm{C}$ & 1 & $\mathrm{TL}$ & 5 & N/A & 1 & 1 & 8,12 & N/A & 15 \\
\hline & & $\begin{array}{l}30 ", \\
20 ", \\
15 "\end{array}$ & & & & & 8,12 & (5) 8 & \\
\hline $\mathrm{C}$ & 2 & TL & 5 & N/A & 1 & 1 & 8,12 & N/A & 30 \\
\hline & & $\begin{array}{l}30 ", \\
20 ", \\
15 "\end{array}$ & & & & & 8,12 & (5) 8 & \\
\hline $\mathrm{C}$ & 3 & $\mathrm{TL}$ & 5 & N/A & 1 & 1 & 8,12 & N/A & 20 \\
\hline & & $\begin{array}{l}30 ", \\
20 ", \\
15 "\end{array}$ & & & & & 8,12 & (5) 8 & \\
\hline $\mathrm{C}$ & 4 & TL & 5 & N/A & 1 & 1 & 8,12 & N/A & 10 \\
\hline & & $\begin{array}{l}30 ", \\
20 ", \\
15 "\end{array}$ & & & & & 8,12 & (5) 8 & \\
\hline
\end{tabular}

Table 1-7 specifies test conditions from Test Exception 24590-WTP-TEF-RT-04-001 using both the UVP and Colorimetric (Dye) methods to determine the degree of mixing. Nozzle sizes, including 1-inch, 1.25-inch, and 1.5-inch nozzles were to be tested. In addition to the above PJM configuration, a second configuration, consisting of (3) 135 deg. (upwards), (2) 45 deg. (downwards), and 1 center (downwards) nozzles, was to be tested. Nozzle velocities of 8 and $12 \mathrm{~m} / \mathrm{s}$ and air sparge flow rates of 4 and $8 \mathrm{scfm}$ were to be included. 
WSRC-TR-2004-00398, REVISION 0

SRNL-RPP-2004-00060, REVISION 0

Table 1-7. Test Conditions for Test Exception 24590-WTP-TEF-RT-04-001, UVP Probe and Colorimetric (Dye) Testing

\begin{tabular}{|c|c|c|c|c|c|c|c|c|c|}
\hline \multirow[b]{2}{*}{$\begin{array}{l}\text { Test } \\
\text { Group }\end{array}$} & \multirow[b]{2}{*}{$\begin{array}{c}\text { Test } \\
\text { Sequence }\end{array}$} & \multirow[b]{2}{*}{ Test type } & \multicolumn{3}{|c|}{ Nozzle Configuration } & \multirow[b]{2}{*}{$\begin{array}{l}\text { Nozzle } \\
\text { I.D., } \\
\text { inches }\end{array}$} & \multirow{2}{*}{$\begin{array}{c}\text { Nominal } \\
\text { Nozzle } \\
\text { Velocity } \\
\text { m/s } \\
\end{array}$} & \multirow{2}{*}{$\begin{array}{c}\# \\
\text { Spargers } \\
\text { @ scfm } \\
\text { tot. }\end{array}$} & \multirow{2}{*}{$\begin{array}{c}\text { Nominal } \\
\text { Yield } \\
\text { Stress } \\
\text { (Pa) } \\
\end{array}$} \\
\hline & & & $\begin{array}{l}\# 45 \\
\text { deg. }\end{array}$ & $\begin{array}{c}\# 135 \\
\text { deg. }\end{array}$ & $\begin{array}{c}\# \\
\text { Ver- } \\
\text { tical }\end{array}$ & & & & \\
\hline $\mathrm{D}$ & $1 \mathrm{a}$ & Mixing & 5 & $\mathrm{~N} / \mathrm{A}$ & 1 & 1 & 8 & $\mathrm{~N} / \mathrm{A}$ & 24 \\
\hline $\mathrm{D}$ & $1 \mathrm{~b}$ & Mixing & 5 & $\mathrm{~N} / \mathrm{A}$ & 1 & 1 & 12 & $\mathrm{~N} / \mathrm{A}$ & 24 \\
\hline $\mathrm{D}$ & $1 \mathrm{c}$ & Mixing & 5 & $\mathrm{~N} / \mathrm{A}$ & 1 & 1 & 12 & (2) 4 & 24 \\
\hline $\mathrm{D}$ & $1 d$ & Mixing & 5 & $\mathrm{~N} / \mathrm{A}$ & 1 & 1 & 12 & (5) 8 & 24 \\
\hline $\mathrm{D}$ & $3 a$ & Mixing & 5 & N/A & 1 & 1.5 & 8 & N/A & 11 \\
\hline $\mathrm{D}$ & $3 b$ & Mixing & 5 & $\mathrm{~N} / \mathrm{A}$ & 1 & 1.5 & 12 & N/A & 11 \\
\hline $\mathrm{D}$ & $3 c$ & Mixing & 5 & $\mathrm{~N} / \mathrm{A}$ & 1 & 1.5 & 12 & (2) 4 & 11 \\
\hline $\mathrm{D}$ & $3 d$ & Mixing & 5 & N/A & 1 & 1.5 & 12 & (5) 8 & 11 \\
\hline $\mathrm{D}$ & $4 a$ & Mixing & 5 & N/A & 1 & 1.5 & 8 & N/A & 24 \\
\hline $\mathrm{D}$ & $4 \mathrm{~b}$ & Mixing & 5 & $\mathrm{~N} / \mathrm{A}$ & 1 & 1.5 & 12 & N/A & 24 \\
\hline $\mathrm{D}$ & $4 \mathrm{c}$ & Mixing & 5 & $\mathrm{~N} / \mathrm{A}$ & 1 & 1.5 & 12 & (2) 4 & 24 \\
\hline $\mathrm{D}$ & $4 d$ & Mixing & 5 & $\mathrm{~N} / \mathrm{A}$ & 1 & 1.5 & 12 & (5) 8 & 24 \\
\hline $\mathrm{D}$ & $5 \mathrm{a}$ & Mixing & 5 & N/A & 1 & 1.5 & 8 & $\mathrm{~N} / \mathrm{A}$ & 30 \\
\hline D & $5 b$ & Mixing & 5 & $\mathrm{~N} / \mathrm{A}$ & 1 & 1.5 & 12 & $\mathrm{~N} / \mathrm{A}$ & 30 \\
\hline $\mathrm{D}$ & $5 c$ & Mixing & 5 & N/A & 1 & 1.5 & 12 & (2) 4 & 30 \\
\hline $\mathrm{D}$ & $5 \mathrm{~d}$ & Mixing & 5 & $\mathrm{~N} / \mathrm{A}$ & 1 & 1.5 & 12 & (5) 8 & 30 \\
\hline $\mathrm{D}$ & $6 a$ & Mixing & 2 & 3 & 1 & 1 & 8 & $\mathrm{~N} / \mathrm{A}$ & 30 \\
\hline $\mathrm{D}$ & $6 \mathrm{~b}$ & Mixing & 2 & 3 & 1 & 1 & 12 & N/A & 30 \\
\hline $\mathrm{D}$ & $6 c$ & Mixing & 2 & 3 & 1 & 1 & 12 & (2) 4 & 30 \\
\hline $\mathrm{D}$ & $6 \mathrm{~d}$ & Mixing & 2 & 3 & 1 & 1 & 12 & (5) 10 & 30 \\
\hline $\mathrm{D}$ & $7 a$ & Mixing & 5 & N/A & 1 & 1.25 & 8 & N/A & 30 \\
\hline $\mathrm{D}$ & $7 \mathrm{~b}$ & Mixing & 5 & $\mathrm{~N} / \mathrm{A}$ & 1 & 1.25 & 12 & N/A & 30 \\
\hline $\mathrm{D}$ & $7 \mathrm{c}$ & Mixing & 5 & $\mathrm{~N} / \mathrm{A}$ & 1 & 1.25 & 12 & (2) 4 & 30 \\
\hline $\mathrm{D}$ & $7 \mathrm{~d}$ & Mixing & 5 & $\mathrm{~N} / \mathrm{A}$ & 1 & 1.25 & 12 & (5) 10 & 30 \\
\hline
\end{tabular}

\subsubsection{Test Exception 24590-WTP-TEF-RT-04-0006 Test Conditions}

Test Exception 24590-WTP-TEF-RT-04-006 provided the test conditions for the final selection of the CRV PJM configuration. The UVP, dye, and solids mixing tests were used to determine the mixing effectiveness. The original Test Exception specified tests up to Test Sequence 6A and 6B in Table 1-8. Additional tests, Test Sequence 7 through 7D were requested to determine if a configuration that did not require sparging would be successful in achieving $100 \%$ mixing. 
WSRC-TR-2004-00398, REVISION 0

SRNL-RPP-2004-00060, REVISION 0

Table 1-8. Test Conditions for Test Exception 24590-WTP-TEF-RT-04-006

\begin{tabular}{|c|c|c|c|c|c|c|c|c|c|}
\hline \multirow[b]{2}{*}{$\begin{array}{l}\text { Test } \\
\text { Group }\end{array}$} & \multirow[b]{2}{*}{$\begin{array}{c}\text { Test } \\
\text { Sequence }\end{array}$} & \multirow[b]{2}{*}{$\begin{array}{c}\text { PJM } \\
\text { Configuration }\end{array}$} & \multicolumn{3}{|c|}{ CRV Nozzle Configuration } & \multirow{2}{*}{$\begin{array}{c}\text { Nozzle } \\
\text { Velocity } \\
\text { m/s }\end{array}$} & \multirow[b]{2}{*}{$\begin{array}{c}\text { \# of } \\
\text { Spargers }\end{array}$} & \multirow[b]{2}{*}{$\begin{array}{l}\text { Pump } \\
\text { Recirc. }\end{array}$} & \multirow[b]{2}{*}{ Simulant } \\
\hline & & & DW & $\begin{array}{c}45 \\
4 E G\end{array}$ & $\begin{array}{c}135 \\
\text { DEG }\end{array}$ & & & & \\
\hline $\mathrm{E}$ & 1 & Chandelier & $1(4 ")$ & $5(4 ")$ & 0 & 8 & $2(\# 3 \& 5)$ & No & $\begin{array}{c}>30 \mathrm{~Pa} \\
\text { Clay }\end{array}$ \\
\hline E & $1 \mathrm{~A}$ & Chandelier & $1(4 ")$ & $5(4 ")$ & 0 & 8 & $3(\# 1,3,5)$ & No & $\begin{array}{c}>30 \mathrm{~Pa} \\
\text { Clay }\end{array}$ \\
\hline E & 1B & Chandelier & $1(4 ")$ & $5(4 ")$ & 0 & 8 & $5(\# 1-5)$ & No & $\begin{array}{c}>30 \mathrm{~Pa} \\
\text { Clay }\end{array}$ \\
\hline E & $1 \mathrm{C}$ & Chandelier & $1(4 ")$ & $5(4 ")$ & 0 & $\begin{array}{c}12 \text { (Add } \\
\text { Dye) }\end{array}$ & $2(\# 3 \& 5)$ & No & $\begin{array}{c}>30 \mathrm{~Pa} \\
\text { Clay }\end{array}$ \\
\hline E & $1 \mathrm{D}$ & Chandelier & $1(4 ")$ & $5(4 ")$ & 0 & 12 & $3(\# 1,3,5)$ & No & $\begin{array}{c}>30 \mathrm{~Pa} \\
\text { Clay }\end{array}$ \\
\hline E & $1 \mathrm{E}$ & Chandelier & $1(4 ")$ & $5(4 ")$ & 0 & 12 & $5(\# 1-5)$ & No & $\begin{array}{c}>30 \mathrm{~Pa} \\
\text { Clay } \\
\end{array}$ \\
\hline E & 2 & Chandelier & $1(4 ")$ & $5(4 ")$ & 0 & $8 \& 12$ & $\mathrm{NO}$ & No & $\begin{array}{c}>30 \mathrm{~Pa} \\
\text { Clay }\end{array}$ \\
\hline E & 3 & Chandelier & $1(4 ")$ & $2(4 ")$ & $3(4 ")$ & 8 & $2(\# 3 \& 5)$ & No & $\begin{array}{c}>30 \mathrm{~Pa} \\
\text { Clay }\end{array}$ \\
\hline $\mathrm{E}$ & $3 \mathrm{~A}$ & Chandelier & $1(4 ")$ & $2(4 ")$ & $3(4 ")$ & 8 & $3(\# 1,3,5)$ & No & $\begin{array}{c}>30 \mathrm{~Pa} \\
\text { Clay }\end{array}$ \\
\hline $\mathrm{E}$ & $3 \mathrm{~B}$ & Chandelier & $1(4 ")$ & $2(4 ")$ & $3(4 ")$ & 8 & $5(\# 1-5)$ & No & $\begin{array}{c}>30 \mathrm{~Pa} \\
\text { Clay }\end{array}$ \\
\hline E & $3 \mathrm{C}$ & Chandelier & $1(4 ")$ & $2(4 ")$ & $3(4 ")$ & $\begin{array}{l}12 \text { (Add } \\
\text { Dye) }\end{array}$ & $2(\# 3 \& 5)$ & No & $\begin{array}{c}>30 \mathrm{~Pa} \\
\text { Clay }\end{array}$ \\
\hline E & $3 \mathrm{D}$ & Chandelier & $1(4 ")$ & $2(4 ")$ & $3(4 ")$ & 12 & $3(\# 1,3,5)$ & No & $\begin{array}{c}>30 \mathrm{~Pa} \\
\text { Clay }\end{array}$ \\
\hline E & $3 \mathrm{E}$ & Chandelier & $1(4 ")$ & $2(4 ")$ & $3(4 ")$ & 12 & $5(\# 1-5)$ & No & $\begin{array}{c}>30 \mathrm{~Pa} \\
\text { Clay }\end{array}$ \\
\hline $\mathrm{E}$ & 4 & Chandelier & $1(4 ")$ & $2(4 ")$ & $3(4 ")$ & $8 \& 12$ & NO & No & $\begin{array}{c}>30 \mathrm{~Pa} \\
\quad \text { Clay }\end{array}$ \\
\hline E & 5 & Chandelier & $\begin{array}{l}\text { Best } \\
\text { Result }\end{array}$ & $\begin{array}{l}\text { Best } \\
\text { Result }\end{array}$ & $\begin{array}{l}\text { Best } \\
\text { Result }\end{array}$ & $\begin{array}{c}\text { Just Off } \\
\text { Bottom } \\
\text { Velocity }\end{array}$ & $2 \& 5$ & No & $\mathrm{H} 2 \mathrm{O}$ \\
\hline $\mathrm{E}$ & $6 \mathrm{~A}$ & Chandelier & $\begin{array}{c}\text { Best } \\
\text { Result }\end{array}$ & $\begin{array}{c}\text { Best } \\
\text { Result }\end{array}$ & $\begin{array}{c}\text { Best } \\
\text { Result }\end{array}$ & $8 \& 12$ & $5(\# 1-5)$ & No & $30 \mathrm{~Pa}$ \\
\hline E & $6 \mathrm{~B}$ & Chandelier & $\begin{array}{l}\text { Best } \\
\text { Result }\end{array}$ & $\begin{array}{c}\text { Best } \\
\text { Result }\end{array}$ & $\begin{array}{l}\text { Best } \\
\text { Result }\end{array}$ & $8 \& 12$ & $5(\# 1-5)$ & No & $6 \mathrm{~Pa}$ \\
\hline $\mathrm{E}$ & 7 & Chandelier & $1(4 ")$ & $2(4 ")$ & $3(4 ")$ & $\begin{array}{l}\text { Just Off } \\
\text { Bottom } \\
\text { Velocity }\end{array}$ & N/A & No & N/A \\
\hline $\mathrm{E}$ & $7 \mathrm{~A}$ & Chandelier & $1\left(4^{\prime \prime}\right)$ & $2(4 ")$ & $3(4 ")$ & $8 \& 12$ & N/A & No & $30 \mathrm{~Pa}$ \\
\hline E & $7 \mathrm{~B}$ & Chandelier & $1(4 ")$ & $2(4 ")$ & $3(4 ")$ & $8 \& 12$ & N/A & No & $6 \mathrm{~Pa}$ \\
\hline $\mathrm{E}$ & $7 C^{*}$ & Chandelier & $1(4 ")$ & $2\left(4^{\prime \prime}\right)$ & $3(4 ")$ & $8 \& 12$ & N/A & No & $30 \mathrm{~Pa}$ \\
\hline E & $7 D^{*}$ & Chandelier & $1\left(4^{\prime \prime}\right)$ & $2(4 ")$ & $3(4 ")$ & $8 \& 12$ & N/A & No & $6 \mathrm{~Pa}$ \\
\hline
\end{tabular}

* Tests 7C and 7D differ from Tests 7A and 7B in that one downward and one 135 deg. Nozzles were interchanged. 
WSRC-TR-2004-00398, REVISION 0

SRNL-RPP-2004-00060, REVISION 0

\subsection{SIMULANT USE}

\subsubsection{Plant Bounding Conditions}

For all seven WTP vessels that will contain non-Newtonian fluids, it was assumed that the HLW pretreated sludge bounding physical and rheological properties would hold (CCNs 069099, 065607, and 082255).

\subsubsection{Normal Plant Operation Rheological Bound}

Data from actual radioactive and simulant waste rheograms combined with general engineering principles were used to define a set of bounding physical and rheological properties that agree well with actual data (Poloski et al. 2003). The non-Newtonian HLW pretreated sludge rheological properties were fit using a linear Bingham plastic model. The bounding conditions were used to develop the waste simulants used in the PJM program. Figure 1-1 is a plot of actual pretreated waste rheograms and the upper bounding rheological properties curve. The linear Bingham plastic model fit parameters are yield stress (y-axis intercept) of $30 \mathrm{~Pa}$ and consistency (slope) of $30 \mathrm{cP}$. Table 1-9 contains a summary of expected physical and rheological properties.

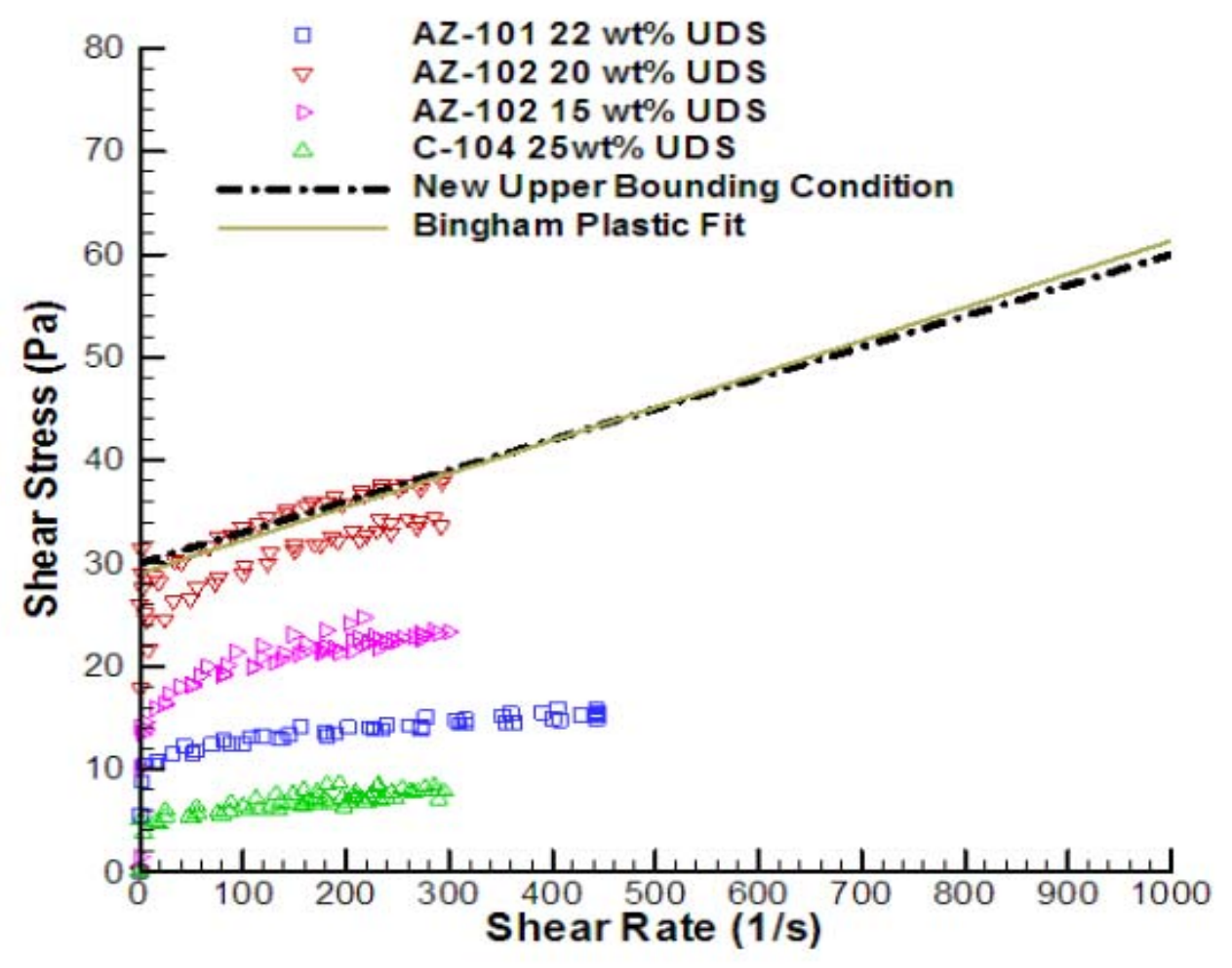

Figure 1-1. Rheogram of Actual HLW Pretreated Sludge Samples with Upper Bound Rheological Curve 
WSRC-TR-2004-00398, REVISION 0

SRNL-RPP-2004-00060, REVISION 0

Table 1-9. Physical and Rheological Properties that Help Define Simulants for Rating or Qualifying Fluidic Mixing Systems

\begin{tabular}{|l|c|}
\hline \multicolumn{1}{|c|}{ Property } & HLW Pretreated Sludge \\
\hline $\mathrm{pH}$ & $\approx 12^{(\mathrm{a})}-14$ \\
\hline Particle size distribution $\left(\mathrm{D}_{50}\right)^{(\mathrm{b})}$ & $2 \mu \mathrm{m}$ \\
\hline Particle size distribution $\left(\mathrm{D}_{95}\right)^{(\mathrm{c})}$ & $20 \mu \mathrm{m}$ \\
\hline Bulk density & $1.1-1.6$ \\
\hline Supernatant liquid density & $\approx 1.0$ \\
\hline Vol\% settled solids & $10 \%-90 \%$ \\
\hline $\mathrm{Wt} \%$ total dried solids & $5 \%-25 \%$ \\
\hline $\mathrm{Wt} \%$ total oxide & $7 \%-15 \%{ }^{(\mathrm{d})}$ \\
\hline Shear stress versus shear rate $\left(\right.$ ambient and $\left.40^{\circ} \mathrm{C}\right)$ & $\mathrm{Bingham} \mathrm{Plastic}$ \\
\hline $\begin{array}{l}\text { (a) Expected pH after washing leaching in } 0.01 \mathrm{M} \text { NaOH. } \\
\text { (b) } 50 \% \text { of particles are smaller than the indicated value. } \\
\text { (c) } 95 \% \text { of particles are smaller than the indicated value. } \\
\text { (d) Based on simulant data. }\end{array}$ \\
\hline
\end{tabular}

Because the rheological window is based on only four samples from three tanks, it is possible that slurries from other tanks could exceed the rheological boundary. It has been estimated that 20 to $30 \%$ of HLW tanks may have rheological properties higher (yield stress and consistency higher than $30 \mathrm{~Pa}$ and $30 \mathrm{cP}$, respectively) than those documented in the three active tank samples analyzed to date (CCN 082255). This uncertainty will be addressed by laboratory testing prior to receipt of the waste at the WTP to define the extent to which the slurry may be concentrated and stay below the rheological boundary.

\subsubsection{Plant Upset Operation Rheological Bound}

It is important to note that measured maximum shear strength values (an actual physical property that must be overcome in order for these fluids to flow) for actual HLW pretreated sludge samples when allowed to stand in an unmixed condition, that is, post-DBE, the waste will gel and reach shear strength values greater than $30 \mathrm{~Pa}$. For this reason, a bounding shear strength value of $70 \mathrm{~Pa}$ should be used (CCN 065607). In addition, the gel time (the time required for the actual waste to reach its maximum shear strength value) of actual waste samples will need to be taken into account along with the maximum shear strength values for plant operation considerations. 


\subsubsection{Simulants}

One transparent simulant and one opaque simulant were used in the PJM program. The transparent simulant was Laponite RD (Southwestern Clay Products), a thixotropic colloidal synthetic clay that forms stable gel networks when unsheared. Due to the thixotropic nature of Laponite, the flow behavior of the simulant is dynamic, and it was allowed to gel and reach a target shear strength. Speers et al. (1987) demonstrated that the shear strength of clay drilling muds increases over time following first-order rate kinetics. Laponite shear strength behavior was observed to agree with the Speers et al. (1987) correlation for drilling muds. At this point the PJM system was started and a mixing cavern formed as defined by the gel's shear strength. After constant shearing, a steady-state flow behavior was approached. Unfortunately, this flow behavior was lower than the bounding rheology of WTP waste streams. This is illustrated in Figure 1-2, where actual HLW pretreated sludge rheograms are compared with PJM simulants. The bounding rheological parameters of the HLW pretreated sludge (Poloski et al. 2003) are defined as Bingham plastic consistency of $30 \mathrm{cP}$ and yield stress of $30 \mathrm{~Pa}$.

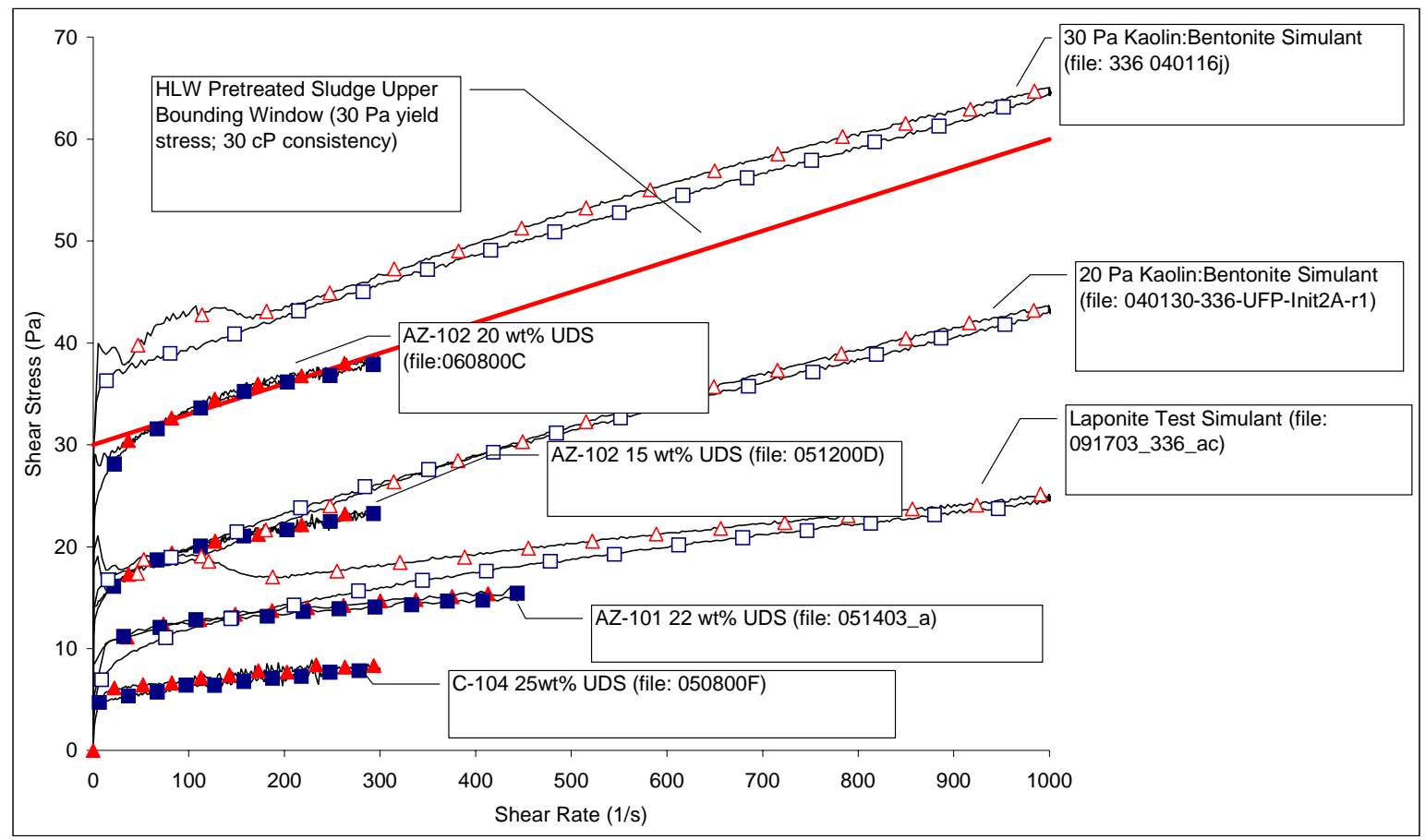

Figure 1-2. Flow Behavior Comparison of PJM Simulants and Actual HLW Pretreated Sludge 
In addition to not possessing the target rheological parameters desired for PJM testing, the Laponite composition also does not match other target values given in Table 1-9. The Laponite recipe calls for 1-2 wt\% Laponite RD in water where the actual waste is in the 15 to $25 \mathrm{wt} \%$ undissolved solids range. And the Laponite simulant consists of particles on the order of tens of nanometers, whereas the actual waste consists of particles in the tens of microns range. These differences may result in varying turbulent flow behavior in the PJM mixing cavern. For these reasons, a more representative particulate slurry was developed to enhance confidence in the PJM testing results. Unfortunately, this simulant is opaque.

The particulate simulant developed consists of a mixture of kaolin clay (EPK Feldspar Pulverized) and bentonite clay (WYO-Ben Big Horn CH-200) in water. To meet the WTP bounding parameters of Bingham plastic consistency of $30 \mathrm{cP}$ and yield stress $30 \mathrm{~Pa}$, a recipe was developed using these two clays. The recipe calls for a composite of $80 \%$ kaolin and $20 \%$ bentonite mixed with water to a loading of approximately $27 \mathrm{wt} \%$. Water is then added to the simulant to adjust the rheological parameters to other target values. Figure 1-2 compares these simulants with actual waste at various solids loadings to target $30+$ and $20 \mathrm{~Pa}$ yield stress. In addition, the bentonite/kaolin simulant shear strength behavior was observed to agree with Speers et al. (1987) correlation for drilling muds.

The measured rheological properties of Laponite and kaolin:bentonite simulants used in the tests are summarized in Table 1-10 and Table 1-11, respectively.

\section{Table 1-10. Rheological Model Fits for CRV Prototype PJM Laponite Simulant at Ambient Temperature}

\begin{tabular}{|c|c|c|c|c|c|c|c|}
\hline \multirow[b]{2}{*}{$\begin{array}{l}\text { Test } \\
\text { Date } \\
\end{array}$} & \multirow[b]{2}{*}{$\begin{array}{c}\text { Test } \\
\text { Number } \\
\end{array}$} & \multirow{2}{*}{$\begin{array}{c}\text { Yield } \\
\text { Stress } \\
\text { (Vane) } \\
\text { Pa } \\
\end{array}$} & \multicolumn{2}{|c|}{ Bingham Plastic } & \multicolumn{3}{|c|}{ Herschel-Bulkely } \\
\hline & & & $\begin{array}{r}\tau_{\mathrm{BP}} \\
(\mathbf{P a}) \\
\end{array}$ & $\begin{array}{c}\eta_{\mathrm{BP}} \text { (Pa- } \\
\mathbf{s}) \\
\end{array}$ & $\begin{array}{r}\tau_{\mathrm{HB}} \\
(\mathbf{P a}) \\
\end{array}$ & $\begin{array}{c}\mathrm{K}_{\mathrm{HB}}(\mathrm{Pa}- \\
\left.\mathbf{s}^{\mathrm{n}}\right) \\
\end{array}$ & $\mathbf{m}$ \\
\hline $10 / 1 / 03$ & $\mathrm{I}-1,2,3$ & 84.2 & 11.13 & 0.01 & 5.4 & 0.97 & 0.41 \\
\hline $10 / 4 / 03$ & $\mathrm{I}-4,5,6$ & 35.5 & 2.78 & 0.01 & 0.12 & 0.29 & 0.52 \\
\hline $10 / 11 / 03$ & $\mathrm{I}-7,8,9$ & 70.8 & 9.33 & 0.01 & 4.4 & 0.77 & 0.43 \\
\hline $10 / 13 / 03$ & $\mathrm{I}-10,11,12$ & 41 & 4.17 & 0.01 & 0.76 & 0.45 & 0.47 \\
\hline $10 / 24 / 03$ & $\mathrm{I}-13,14,15$ & 44,9 & 4.52 & 0.01 & 1.04 & 0.49 & 0.46 \\
\hline $10 / 27 / 03$ & $\mathrm{I}-16,17$ & 50.8 & 3.88 & 0.01 & 0.87 & 0.4 & 0.47 \\
\hline $10 / 25 / 03$ & $\mathrm{I}-18,19,20$ & 48.6 & 4.1 & 0.01 & 0.95 & 0.42 & 0.47 \\
\hline $11 / 1 / 03$ & $\mathrm{I}-21,22$ & 76.2 & 4.42 & 0.01 & 1.35 & 0.41 & 0.47 \\
\hline $11 / 6 / 03$ & $\mathrm{I}-23,24$ & 84.6 & 8.83 & 0.01 & 4.76 & 0.61 & 0.44 \\
\hline $11 / 9 / 03$ & $\mathrm{I}-25,26$ & 89.9 & 10 & 0.01 & 6.64 & 0.43 & 0.48 \\
\hline $11 / 14 / 03$ & $\mathrm{I}-27,28$ & 69.3 & 8.11 & 0.0092 & 5.23 & 0.326 & 0.514 \\
\hline $11 / 18 / 03$ & $\begin{array}{c}\mathrm{I}- \\
29,30,33,32 \\
\end{array}$ & 83.4 & 8.38 & 0.01 & 5.98 & 0.24 & 0.55 \\
\hline $11 / 21 / 03$ & $\mathrm{I}-33,34$ & 81 & 9.37 & 0.0091 & 22.3 & 0.17 & 0.6 \\
\hline
\end{tabular}


WSRC-TR-2004-00398, REVISION 0

SRNL-RPP-2004-00060, REVISION 0

Table 1-11. Rheological Model Fits for CRV Prototype PJM Kaolin:Bentonite Simulants at Ambient Temperature

\begin{tabular}{|c|c|c|c|c|c|c|c|}
\hline Test Date & Test Number & Test type & $\begin{array}{c}\text { Bingham } \\
\text { plastic YS }\end{array}$ & $\begin{array}{c}\mathbf{B P} \\
\text { consistency, } \\
\text { cP } \\
\end{array}$ & $\begin{array}{c}\mathbf{H}-\mathrm{B} \mathbf{t}_{\mathrm{HB}}, \\
\mathbf{P a}\end{array}$ & $\begin{array}{c}\text { H-B } \\
\text { Khb, } \\
\text { CP } \\
\end{array}$ & H-B, m \\
\hline $11 / 30 / 2003$ & $\begin{array}{c}\text { A-1a, A-1b, A- } \\
1 \mathrm{c}, \mathrm{A}-1 \mathrm{~d}, \mathrm{~A}-1 \mathrm{e}, \mathrm{A}-2\end{array}$ & Mixing/UVP & 21.02 & 19.82 & 18.97 & 0.109 & 0.762 \\
\hline $12 / 2 / 2003$ & A-3 & Mixing/Visual & 17.85 & 20.41 & 15.35 & 0.142 & 0.728 \\
\hline $12 / 3 / 2003$ & A-4 & Mixing/Visual & 12.08 & 17.01 & 10.05 & 0.142 & 0.704 \\
\hline $12 / 4 / 2003$ & A-5 & Mixing/Dye\#A & 15.93 & 20.2 & 13.2 & 0.158 & 0.714 \\
\hline $12 / 5 / 2003$ & A-6 & Mixing/dye\#B & 16.8 & 20.6 & 14 & 0.161 & 0.707 \\
\hline $1 / 9 / 2004$ & $\mathrm{C}-1 \mathrm{a}$ & Mixing 40" TL (UVP) & 16.4 & 28.5 & 17.1 & 0.089 & 0.665 \\
\hline $1 / 10 / 2004$ & $\mathrm{C}-1 \mathrm{~b}$ & Mixing 30" TL (UVP) & 16.4 & 28.5 & 17.1 & 0.089 & 0.665 \\
\hline $1 / 10 / 2004$ & $\mathrm{C}-2 \mathrm{a}$ & Mixing 40" TL (UVP) & 35.4 & 20.7 & 35.2 & 0.022 & 0.998 \\
\hline $1 / 11 / 2004$ & $\mathrm{C}-2 \mathrm{~b}$ & Mixing 30" TL (UVP) & 35.4 & 20.7 & 35.2 & 0.022 & 0.998 \\
\hline $1 / 12 / 2004$ & $\mathrm{C}-3 \mathrm{a}$ & Mixing 40" TL (UVP) & 28 & 18.6 & 25.6 & 0.142 & 0.727 \\
\hline $1 / 13 / 2004$ & $\mathrm{C}-3 \mathrm{~b}$ & Mixing 30" TL (UVP) & 28 & 18.6 & 25.6 & 0.142 & 0.727 \\
\hline $1 / 14 / 2004$ & $\mathrm{C}-4 \mathrm{a}$ & Mixing 40" TL (UVP) & 4.4 & 6.8 & 3.31 & 0.069 & 0.68 \\
\hline $1 / 15 / 2004$ & $\mathrm{C}-4 \mathrm{~b}$ & Mixing 30" TL (UVP) & 11.45 & 18.1 & 9.12 & 0.136 & 0.72 \\
\hline $1 / 14 / 2004$ & $\begin{array}{c}\text { D-1a, D-1b, D-1c, } \\
\text { D-1d }\end{array}$ & Dye 1 & 11.45 & 18.1 & 9.12 & 0.136 & 0.72 \\
\hline $1 / 15 / 2004$ & $\begin{array}{c}\text { D-2a, D-2b, D-2c, } \\
\text { D-2d }\end{array}$ & Dye 2 & 27.4 & 16.2 & 29.8 & 0.073 & 0.796 \\
\hline $1 / 27 / 2004$ & $\begin{array}{c}\text { D-3a, D-3b, D-3c, } \\
\text { D-3d }\end{array}$ & Dye 3 & 10.2 & 17.7 & 7.4 & 2.08 & 0.68 \\
\hline $1 / 28 / 2004$ & $\begin{array}{l}\text { D-4a, D-4b, D-4c, } \\
\text { D-4d }\end{array}$ & Dye4/UVP/video & 32.6 & 19.6 & 26.8 & 0.842 & 0.474 \\
\hline $1 / 29 / 2004$ & $\begin{array}{c}\text { D-5a, D-5b, D-5c, } \\
\text { D-5d }\end{array}$ & Dye5/UVP/video & 31.2 & 18.4 & 26.6 & 0.6 & 0.515 \\
\hline $1 / 31 / 2004$ & $\begin{array}{c}\text { D-6a, D-6b, D-6c, } \\
\text { D-6d }\end{array}$ & Dye6/UVP/video & 28.2 & 19.7 & 23.5 & 0.565 & 0.53 \\
\hline $2 / 6 / 2004$ & $\begin{array}{c}\text { D-7a, D-7b, D-7c, } \\
\text { D-7d }\end{array}$ & Dye7/UVP/video & 32.4 & 17.1 & 26.6 & 0.395 & 0.55 \\
\hline $2 / 9 / 2004$ & E-1, E-1a, E-1b & Dye 8 & 30.2 & 16.2 & 24 & 0.574 & 0.535 \\
\hline $2 / 10 / 2004$ & E-1c, E-1d, E-1e & Dye 9 & 30 & 18 & 25.4 & 0.3 & 0.619 \\
\hline $2 / 12 / 2004$ & E-3, E-3a, E-3b & Dye10/UVP & 32.9 & 18.5 & 29 & 0.22 & 0.676 \\
\hline $2 / 13 / 2004$ & E-3c, E-3d, E-3e & Dye11/UVP & 32.8 & 17.2 & 26.4 & 0.522 & 0.544 \\
\hline $2 / 24 / 2004$ & E-6a & Solids mixing Dye12 & 28.9 & 19.7 & 24.2 & 0.326 & 0.614 \\
\hline $2 / 25 / 2004$ & E-6b & Solids mixing Dye 13 & 6.1 & 13.4 & 4.18 & 0.08 & 0.758 \\
\hline $3 / 15 / 2004$ & E-7aa & Dye 14 & 30.9 & 17.3 & 22.7 & 0.888 & 0.525 \\
\hline $3 / 18 / 2004$ & E-7a & solids & 27.7 & 16.6 & 23.6 & 0.307 & 0.6 \\
\hline $3 / 22 / 2004$ & E-7bb & Dye 15 & 5.94 & 16.7 & 4.75 & 0.0914 & 0.742 \\
\hline $3 / 25 / 2004$ & $E-7 b$ & Solids mixing & 9.58 & 20.4 & 7.86 & 0.129 & 0.724 \\
\hline $3 / 29 / 2004$ & $E-7 c$ & Solids mixing & 9.58 & 20.4 & 7.86 & 0.129 & 0.724 \\
\hline $4 / 1 / 2004$ & E-7d & Solids mixing & 34.1 & 20.2 & 28.7 & 0.432 & 0.579 \\
\hline $5 / 12 / 2004$ & G-1 & VVV & 29.33 & 41.9 & 12.3 & 6.06 & 0.272 \\
\hline $5 / 19 / 2004$ & G-2 & VVV & 5.73 & 19.96 & 4.34 & 0.119 & 0.726 \\
\hline $6 / 14 / 2004$ & G-3 & VVV & 5.73 & 19.96 & 4.34 & 0.119 & 0.726 \\
\hline $6 / 16 / 2004$ & G-4 & VVV & 26 & 31.4 & 20.4 & 0.494 & 0.602 \\
\hline $6 / 18 / 2004$ & G-5 & VVV & 26 & 31.4 & 20.4 & 0.494 & 0.602 \\
\hline
\end{tabular}




\subsection{DISCREPANCIES AND FOLLOW-ON TESTS}

No discrepancies are apparent with respect to meeting specified test requirements and also with respect to the data obtained. 
WSRC-TR-2004-00398, REVISION 0

SRNL-RPP-2004-00060, REVISION 0

This page intentionally left blank. 
WSRC-TR-2004-00398, REVISION 0

SRNL-RPP-2004-00060, REVISION 0

\subsection{DISCUSSION}

\subsection{INTRODUCTION}

\subsubsection{Background}

The Pulse Jet Mixer (PJM) Task Team (R\&T, Engineering, Bechtel R\&D, Savannah River National Laboratory, and mixing consultants) developed an integrated strategy for scaled testing to validate PJM mixing in Waste Treatment Plant (WTP) vessels containing nonNewtonian fluids in June 2003 (Smith, et al. 2003). The scaled PJM mixing tests were to provide information on the operating parameters critical for the uniform movement (total mobilization) of these non-Newtonian slurries.

Initial (physical) scaled testing confirmed in October 2003 that the baseline pulse jet designs in these vessels did not mix the non-Newtonian slurries to the extent necessary to meet WTP design requirements. Phase I of the PJM program developed an alternative PJM-only configuration that mixed the vessels containing non-Newtonian slurries in accordance with WTP design requirements toward the end of November 2003. While the alternative PJM configuration was acceptable, implementation of the PJM-only mixing systems severely impacted the WTP facility designs due to increased numbers of PJMs, additional piping, and the significantly increased air consumption necessary to operate these systems.

To minimize the impact to the overall project cost and schedule, the PJM Task Team was directed to develop PJM hybrid mixing systems to reduce the WTP impact. Phase II of the PJM program investigated further alternative configurations to assess the effects of slurry rheology changes, reduced tank volume, PJM jet velocity and nozzle size, and sparging. Phase II testing of PJM hybrid mixing systems confirmed that the modified configurations do mix non-Newtonian slurries in accordance with WTP design requirements.

This document describes the PJM hybrid mixing systems goals, mixing operation modes, test stands and experimental methods, selected configuration, and testing data supporting the HLW concentrate receipt vessel (HCP-VSL-00001/00002) configuration selected by the HLW Vitrification Facility Team and Central Engineering (CCN 086662).

\subsubsection{Design Goals for the Phase II PJM Hybrid Mixing Systems}

In conjunction with Engineering, Pretreatment and HLW Vitrification Facilities, and Project Management personnel, the PJM Task Team conducted the hybrid mixing systems testing program with the following success criteria and constraints:

- Achieve complete mixing (i.e., no stagnant regions) with turbulent conditions in the majority of the slurry volume. Turbulent mixing conditions enhance heat transfer within the vessel. Turbulent mixing facilitates the suspension of waste particles.

- Use the baseline PJMs to mix in the bottom of the vessels; supplemental mixing would be used to mix the upper portion of the vessels. 
- Limit the PJMs to the original baseline design (24590-WTP-MV-M59T-00004), which includes a 4-inch exit nozzle; however, the standard jet pump pairs (JPPs), which use compressed air as the motive force to drive the pulse tubes, will be upgraded to allow for a nozzle velocity of $12 \mathrm{~m} / \mathrm{s}$. The number of PJMs is limited to six in the HLW concentrate receipt vessel (CRV).

- Target the non-Newtonian slurry rheology in terms of yield stress from 5 to $30 \mathrm{~Pa}$ based on actual pretreated waste data from Tanks C-104 and AZ-102, respectively.

- Mix the CRV vessel to the required H/D ratio of 1.0, with pretreated waste slurries having a yield stress of $30 \mathrm{~Pa}$.

- Operate the air sparge systems within the constraints of the HLW Vitrification Facility vessel vent system; i.e., total additional air flow of approximately $230 \mathrm{scfm}$.

- Consider supplemental mixing technologies that are technically mature above emerging technologies. Eventually, PJMs, sparging, and steady jets (flow provided by recirculation pumps) were selected as the only options.

- Provide robust mixing systems, i.e., provide for a 40-year operation life in a configuration that can be fabricated readily.

- Keep gas holdup (how much gas is retained at steady state in the mixed waste during normal, continuous PJM operation) as low as possible.

- Control gas release rate (how quickly gas is released upon PJM restart after a period of no mixing) after a post DBE or non-mixing period.

- Minimize air consumption requirements on both the supply and vessel ventilation systems.

- Minimize the number of vessel penetrations.

- Minimize the overall risk to the project.

- Minimize the overall cost and schedule impact to the project.

\subsubsection{Operational Scenarios}

\subsubsection{Operational Processing Modes}

The HLW melter feed process receives HLW concentrate from the Pretreatment Facility in the concentrate receipt vessels (CRV) (HCP-VSL-00001/00002), mixes the waste slurry concentrate (solids from ultrafiltration, strontium/TRU precipitate, cesium concentrate, technetium concentrate) with glass-formers in the melter feed process vessel (MFPV), then pumps the melter feed slurry to the HLW melter feed vessel (MFV). The MFVs then meter the feed to the melters at a specified rate. The CRVs provide waste slurry concentrate to two feed process trains which operate independently of each other and are dedicated to a specific melter. The concentrate receipt system is designed for a throughput of $6 \mathrm{MTG} /$ day. 
Each of the two HLW concentrate receipt vessels has four reverse flow diverters (RFDs) for pumping feed to the HLW MFPV, six pulse jet fluidic mixers, and two RFDs for sampling. The process control samples are collected from these vessels and analyzed to determine glass formulation. Each CRV contains enough pretreated waste to transfer two batches to the HLW melter feed preparation vessels (HFP-VSL-00001/00005). The HLW MFPVs mix the glass-former chemicals from the GFFHs with the HLW pretreated waste sludge from the HLW CRVs using mechanical agitators. Each MFPV has two mechanical pumps to transfer waste to the associated HLW MFV, with a side stream diverted to an autosampler. The MFV vessels have a mechanical agitator for mixing.

The HLW CRVs operate with one vessel receiving and sampling, and the other vessel transferring to the MFPVs. When a CRV is designated to receive concentrate, volumes are verified and the requirement transmitted to the Pretreatment Facility.

After a HLW pretreated sludge waste transfer, the line is flushed with three line volumes of demineralized water. The first two volumes flow to the CRV, the third flush of approximately 270 gallons flows back to the Pretreatment Facility.

Pulse jet mixers (PJM) operate at all times during sampling and transfers, to maintain a consistent pretreated sludge slurry composition. This ensures representative sampling of the waste slurry concentrate material. Sampling occurs after batch transfer and line flush. Samples are collected using one of two RFDs that recirculate concentrate for about 2 hours during the sampling process. A sample turnaround time of 29.4 hours is required for complete sample analysis and glass former determination.

The concentrate is transferred to the MFPVs when it has sufficient capacity to receive 5,500 gallons of waste concentrate and glass-formers. CRVs can transfer to both MFPVs and to vessel washdown, RLD-VSL-00008.

- Concentrate Receipt Vessel Data: HCP-VSL-00001/00002 (24590-HLW-M6C-HCP00001)

o Overflow volume: 16,978 gal

o Operating volume (with PJMs): 13,140 gal

o Filled volume: $11,585 \mathrm{gal}$

o Batch volume: $9,000 \mathrm{gal}$

o Heel volume: 2,585 gal

o Influent flowrate (from PT): 140 gpm

o Effluent flowrate (to MFPV): $44 \mathrm{gpm}$ 
WSRC-TR-2004-00398, REVISION 0

SRNL-RPP-2004-00060, REVISION 0

- Operating Logic: HCP-VSL-00001/00002 (24590-HLW-3YD-HCP-00001)

0 Initial tank fill requires transfer of 11,585 gallons of slurry from the Pretreatment Facility.

o Batch volume is 9,000 gallons, of which approximately 500 gallons are contributed from line flushing.

o PJMs operate continuously, displacing an additional 1,555 gallons. Operating volume is equivalent to 13,140 gallons.

o Sampling occurs via an RFD on continuous recycle. Sampling time is 2 hours.

o Sample processing requires 35 hours (including sampling time).

o Transfer to the MFPV occurs when required. Volume transferred is approximately 4,500 gallons. Actual volume is stipulated by calculations based on waste loading, solids content, and glass-former constituent volumes.

o Transfer rate for the RFD is $44 \mathrm{gpm}$. Total transfer time is approximately 102 minutes. Refill vessel after completion of second transfer. Low set point to enable refill is 5,859 gallons.

o Approximately 87 gallons of demineralized water are used to flush the lines from the CRV to the MFPV.

\subsubsection{Mixing Operation Modes}

This section discusses the normal and post-DBE mixing operation modes. Normal mixing is that required for routine or normal plant operation. Post-DBE mixing refers to the mixing modes that will be available after a plant upset.

Normal Mixing: The hybrid mixing system will provide for complete mixing of the nonNewtonian slurry within the constraints of the HLW Vitrification Facility vessel ventilation system. Gas holdup in the waste slurry during normal operation will be low, i.e., gas release will be effective. Normal operations mixing can use a combination of PJMs and sparging system.

Post-DBE Mixing: After a DBE, sparging air can be diverted to the cell ventilation system and the incremental air flow constraint of approximately $230 \mathrm{scfm}$ is lifted. Normal mixing uses equipment that is not rated for important-to-safety (ITS) use. Post DBE, the hybrid mixing system will use ITS-rated systems only and provide for complete mixing of the nonNewtonian slurry to ensure gas release from the slurry. Post-DBE mixing and gas release is limited to PJM and sparger operation.

\subsubsection{Overview of the PJM-Hybrid Mixing Systems Design Approach}

The hybrid mixing systems considered in this work involves the combined use of PJMs and air sparging. The mixing technologies were combined to take advantage of their respective strengths. 
PJMs are used for mixing the lower region of the vessel contents and facilitating off-bottom suspension of solids. PJMs are ideally suited for these tasks because they discharge downward with nozzles near the vessel floor. The ideal PJM configuration for hybrid systems is one that creates a well-defined, highly turbulent cavern. The material in the upper region of the vessel is then transported to the turbulent cavern by the other system (spargers) where it is mixed as illustrated in Figure 2-1.

Having a high degree of turbulence is important to encourage both adequate mixing and gas removal, as well as to minimize scaling issues for prototypic test results that will be applied at full scale. (Scale-up is discussed in more detail in Appendix A.) Additionally, having an obstruction-free interface between the mixed and unmixed regions simplifies the specification of spargers.

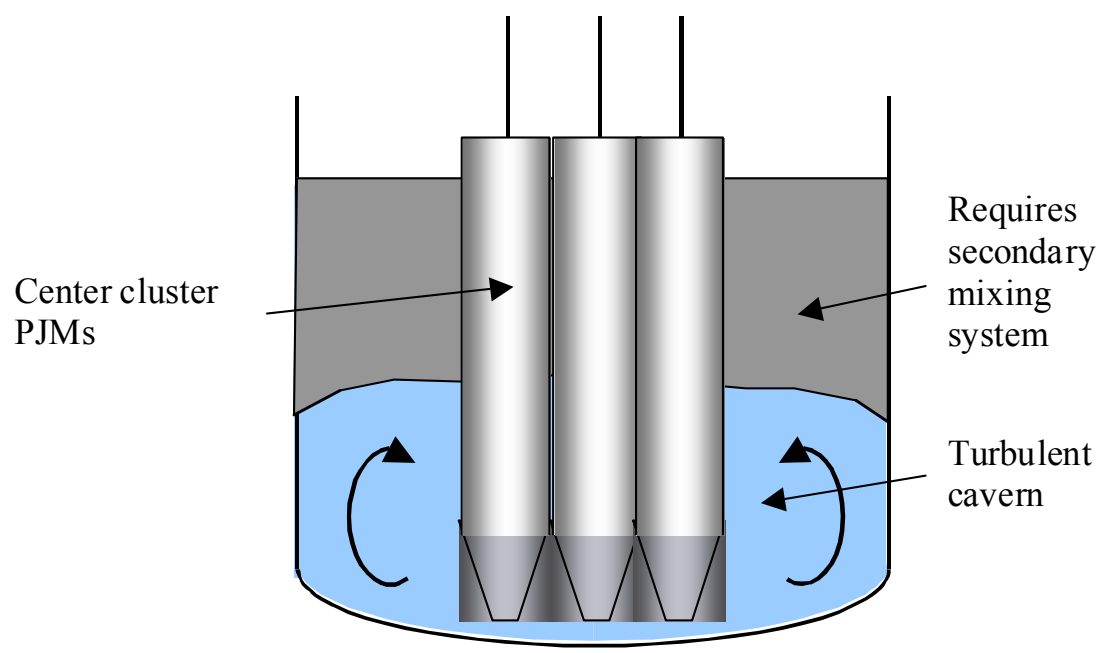

Figure 2-1. PJM-Hybrid Mixing Approach. Central cluster PJMs mix the lower region of the vessel and a secondary system mixes the upper region.

A centralized cluster of PJMs with nozzles angled toward the tank wall was found to be the most effective at creating a distinct mixing cavern. Tests with a distributed array of PJMs were also conducted and found to provide good overall mixing (determined by the dye method); however, the uniformity of the cavern was found to be highly sensitive to nozzle impingement angle, and the quality of the turbulence was suspect.

Air sparge tubes provide an alternative mechanism for mixing. Rising air bubbles produce drag on surrounding fluid, creating an upward pumping effect. Once at the surface, fluid must recirculate downward. The net result is an upward bubble zone of mixing (in this document, this region is referred to as the region of bubbles [ROB]), surrounded by a larger, downward zone (in this document, this region is referred to as the zone of influence [ZOI]). Sparge ZOIs will interact in beneficial ways if neighboring sparge points are spaced close enough. However, these interactions for non-Newtonian fluids are not fully understood and are not addressed in this document. Locating the outlet of the sparge tube near the bottom of the tank and well inside the PJM cavern should provide the capability to completely mix the tank contents. 
WSRC-TR-2004-00398, REVISION 0

SRNL-RPP-2004-00060, REVISION 0

\subsubsection{Overview of the Scaled Testing Methodology}

The scaled testing methodology involved conducting tests in a scaled version of the full-scale $\mathrm{CRV}$ vessel. Information on sparger scaling was obtained with a single large-scale sparge tube (PJM Task Team, 2004). Scale-up and application of the mixing technologies are based on a mix of well-known theory and developments by the PJM mixing program.

As described in Section 1.6, the two primary simulants were Laponite and a mixture of kaolin/bentonite clay. Laponite is a thixotropic colloidal synthetic clay that forms a transparent gel when left unsheared. This simulant was used for assessing the scale-up behavior of the PJMs and visualizing the flow behavior in the scaled prototypes. The kaolin/bentonite clay mixture exhibits a Bingham plastic rheology that closely represents the rheology of actual waste slurries. This simulant was used to investigate the scale-up behavior of PJMs and GR\&R characteristics. It was also used to assess the performance of the scaled prototypes.

The scale-up of the PJM mixing performance and the GR\&R characteristics was investigated at three different scales with geometrically scaled test stands containing four PJMs. The largest test stand (described in PJM Task Team, 2004) is the 12,000 gallon vessel in the Hanford 336 building which is similar in size to the actual concentrate receipt vessel. The intermediate sized test stand (described in PJM Task Team, 2004) is located in the Applied Process Engineering Laboratory (APEL). It is approximately one-quarter scale (based on linear dimensions) relative to the large tank with a total volume of about 250 gallons. The small-scale tank, which is about one-half scale relative to the APEL test stand, is located at the Savannah River National Laboratory. These tests will not be described in this report, but can be found in (Wilson, 2004).

The basis for scale-up of the mixing induced by PJMs is based on modifications to turbulent jet theory to account for the non-Newtonian rheology and non-steady jets from the PJMs. Dimensional analysis (Appendix A) was used to identify the important dimensionless parameters and guide the experimental design. The configuration for the sparging systems was based on the results of nearly full-scale tests with a single sparge tube (PJM Task Team, 2004).

The CRV vessel (described in Section 2.2.1) has a scale factor of four (4). Approximately 107 separate runs were conducted in the prototypic CRV platform containing various configurations of PJMs, recirculation pumps, and spargers.

\subsection{TEST STAND AND EXPERIMENTAL METHODS}

This section contains a description of the CRV test stand and the experimental methods. The scaled CRV prototype is a geometrically scaled model of the full-scale CRV tanks. The prototype was used to evaluate various mixing configurations. Section 2.4.2.1 describes the equipment and methods used to obtain performance data for sparging in non-Newtonian slurries. Section 2.3 describes the methods used to assess the extent of mixing. 
WSRC-TR-2004-00398, REVISION 0

SRNL-RPP-2004-00060, REVISION 0

\subsubsection{CRV Prototype Vessel and Alternative PJM Configurations}

This section describes the scaled CRV vessel and the various candidate PJM configurations. The 168-inch-diameter, full-scale CRV tank was represented by a 40.125 -inch-ID clear acrylic vessel. The geometric scale factor was $\sim 4.0$. The scaled CRV prototypic test vessel was $76 \pm 1$ inches tall with a 2:1 elliptical dish head made out of stainless steel. Figure 2-2 shows a picture of the CRV vessel and test stand with the Baseline configuration. Compressed air and vacuum manifolds with solenoid valves can also be seen in the picture. An overall view of the CRV Test Facility is shown in Figure 2-3.

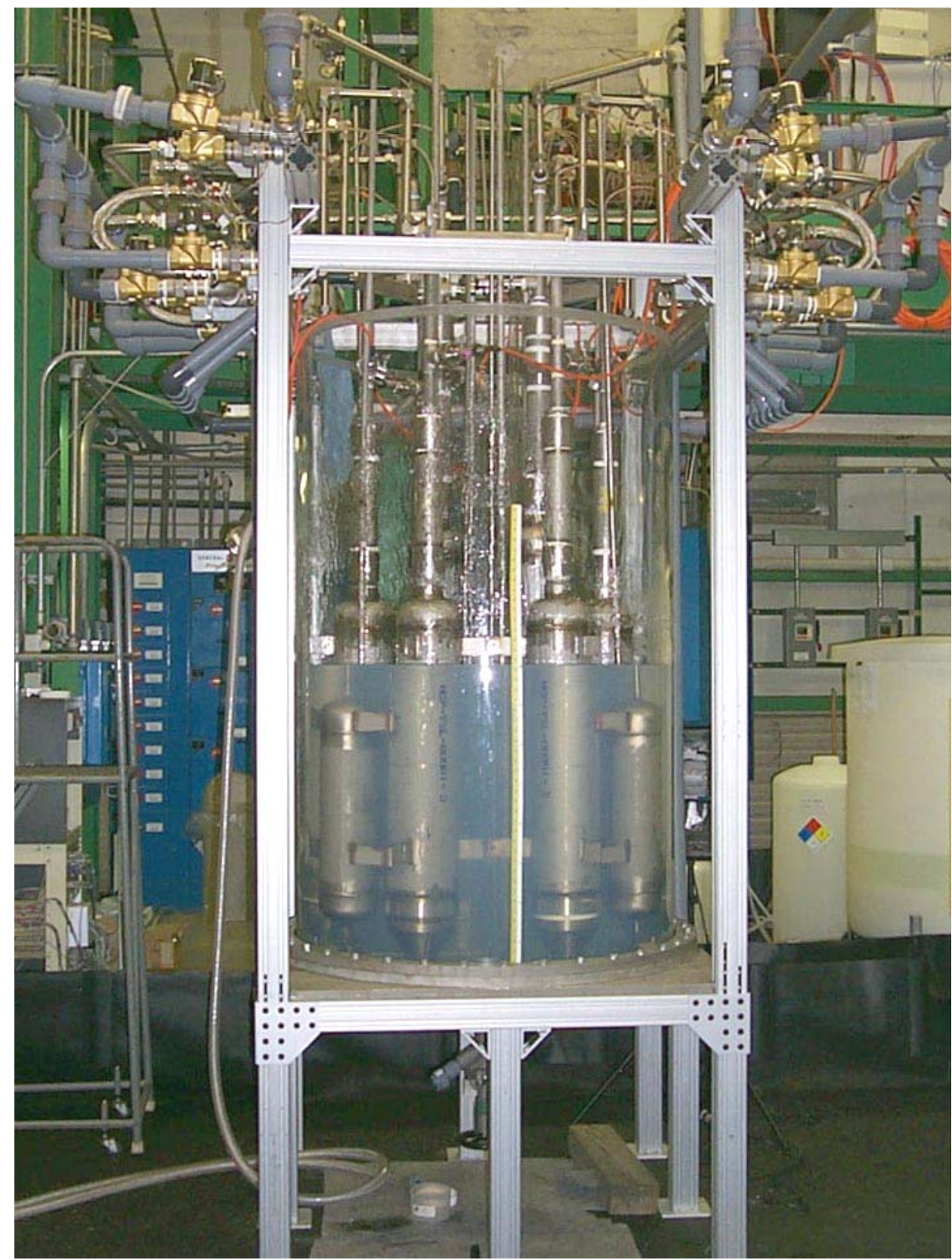

Figure 2-2. Scaled Concentrate Receipt Vessel Test Stand (Baseline PJM Configuration installed) 


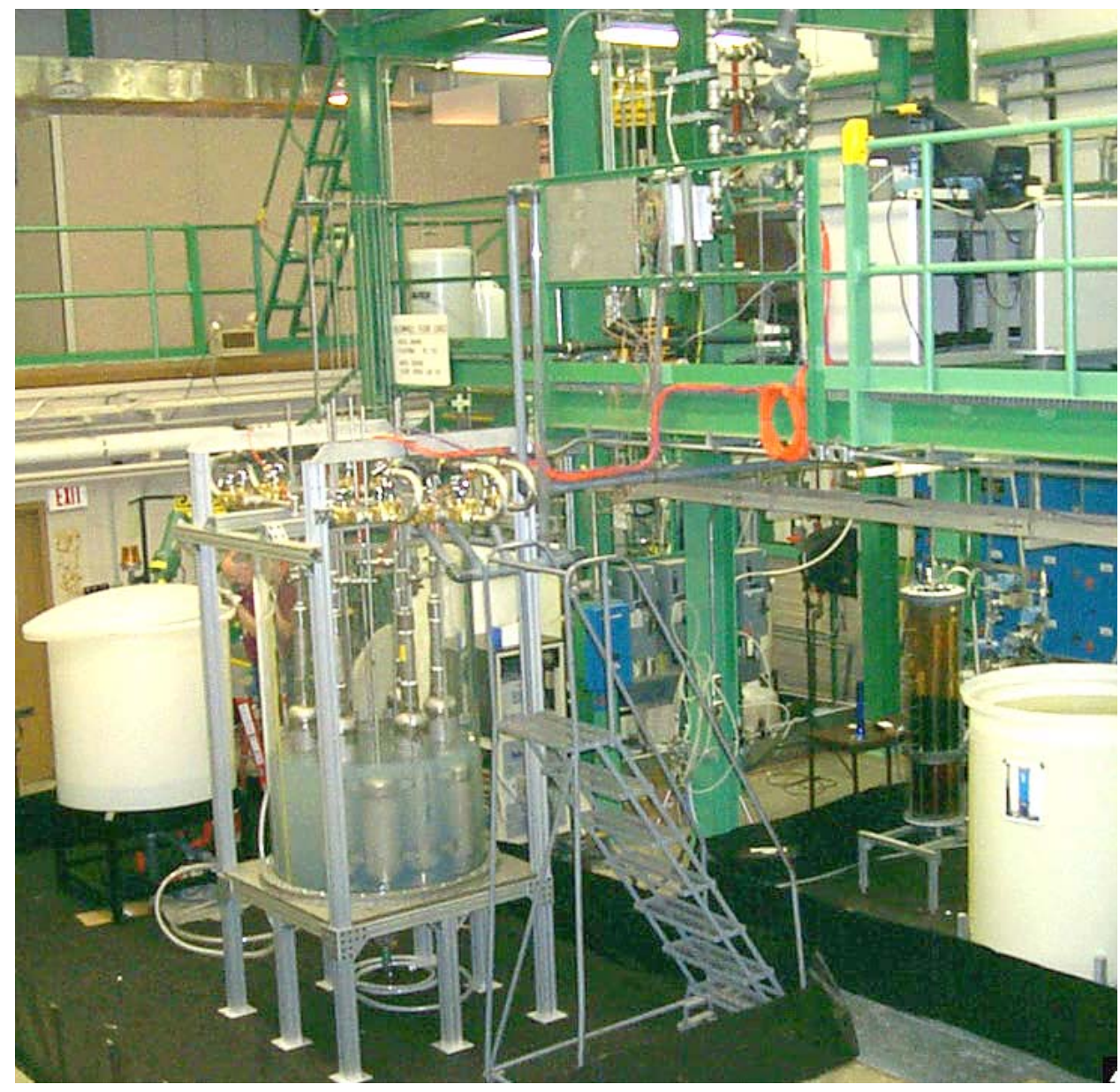

Figure 2-3. Overall View of Concentrate Receipt Vessel Test Facility showing Subsystems

\subsubsection{PJM Assembly Configurations}

\subsection{Baseline Design}

The baseline design is shown in Figure 2-4. Six 6-inch-diameter scaled PJMs and two additional Ram's Head PJMs can be inserted or taken out. Four large charge vessels (for operating the RFD transfer pump system) and two small charge vessels (for operating the RFD sampling system) are also simulated in the mockup. The arrangement of the components in this design is shown in Figure 2-4. An elevation view of the PJMs is also shown in Figure 2-4.

The PJMs for the Baseline design were constructed from 6-inch-diameter (6.625-inch ID) schedule 40 stainless steel pipes with the end connected to an approximately $60^{\circ}$ angle cone terminating in two types of nozzles as shown in Figure 2-4. One type is a downward facing nozzle and the other, a nozzle perpendicular to the bottom head. The cylindrical section of the PJMs was $37 \pm 1$ inches tall; this corresponds to a PJM height scale factor of $\sim 4.32$. 
The difference between the CRV tank dimension scale factor and the pulse tube dimension scale factor was due to the need to use standard pipe sizes for procurement expediency. However, the volume expelled from the PJMs was consistent with the CRV vessel scale factor of $\sim 4.0$. The Ram's Head PJMs, which direct flow to the outer wall region, are shown in Figure 2-5.

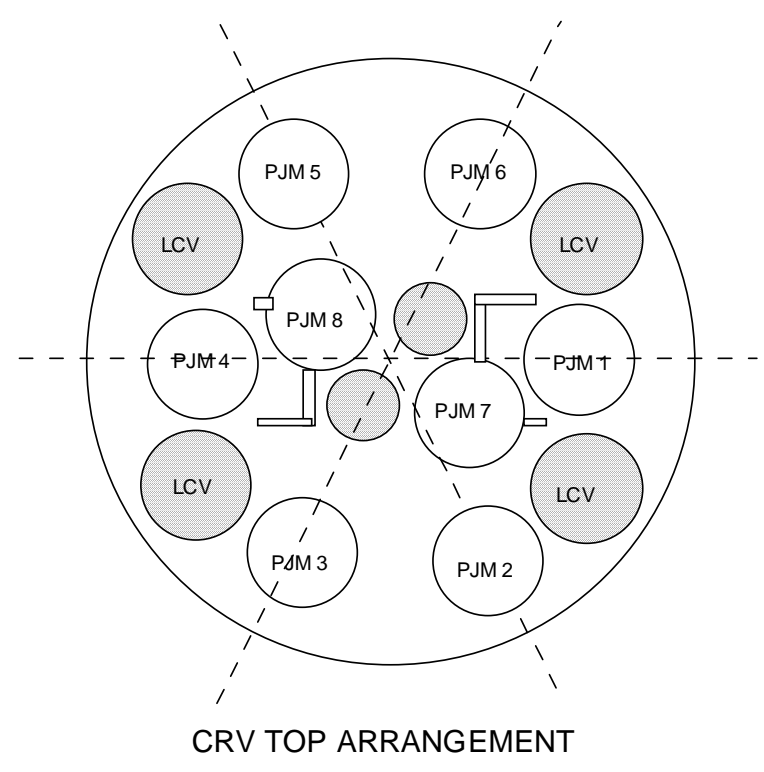

Plan View

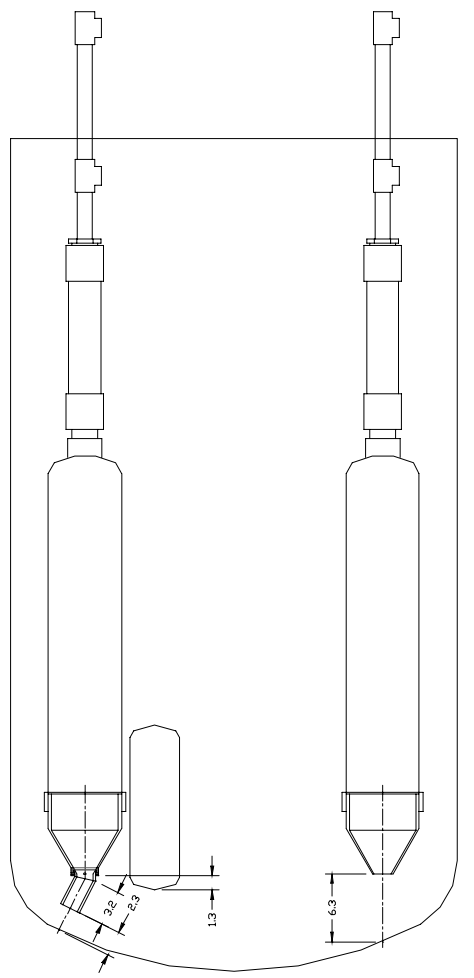

Elevation View

Figure 2-4. Baseline PJM - Plan View and Elevation View

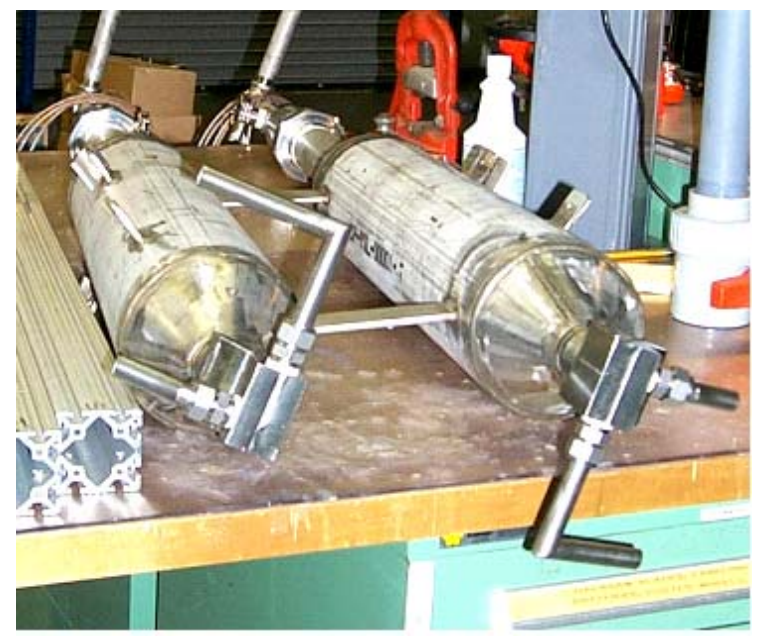

Figure 2-5. Ram's Head Nozzles 


\subsection{PJMs plus 2 Ram's Head Arrangement}

A modified baseline design (Figure 2-6) moves the small charge vessels (located at the bottom central position in the vessel in the baseline design) toward the wall. This allows less flow restriction for jet flow from the PJMs to be directed into the central region of the vessel. The Ram's Head nozzles were relocated and the flow directed closer to the vessel wall.

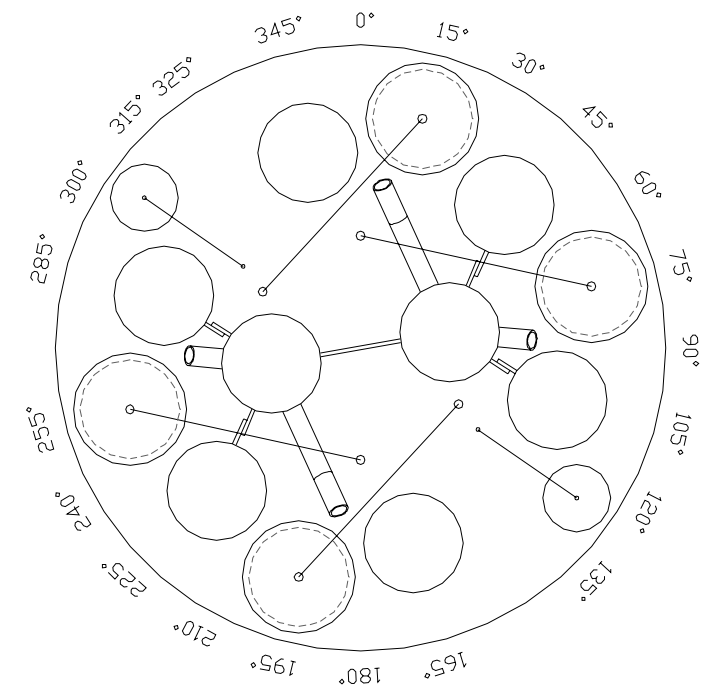

Figure 2-6. Modified Baseline PJM Configuration

\subsection{Initial Chandelier Arrangement}

Due to the desire to reduce the number of PJMs to the baseline number of 6 , a third arrangement uses six larger 8-inch-diameter PJMs clustered closely in a chandelier-like arrangement, Figure 2-7. The large and small charge vessels are located close to the vessel wall.

\subsection{Spider Arrangement}

A variation of the Baseline design, the Spider arrangement uses four large (8-in. diameter) PJMs and two 6-in. diameter PJMs. The two inner PJMs have four pipe nozzles each where the flow from each nozzle is directed at a gap between the PJMs and charge vessels. See Figure 2-8. 


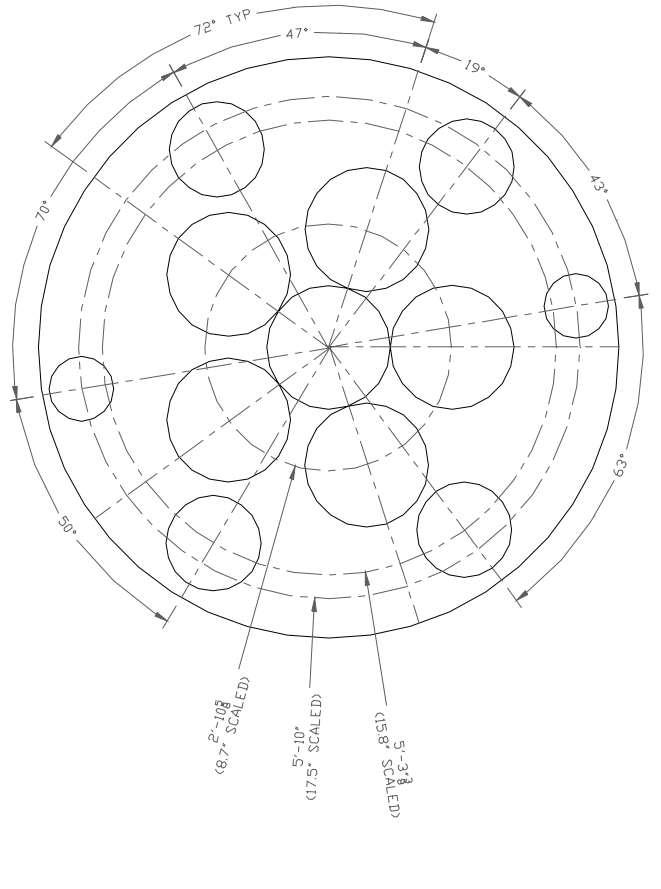

Plan View

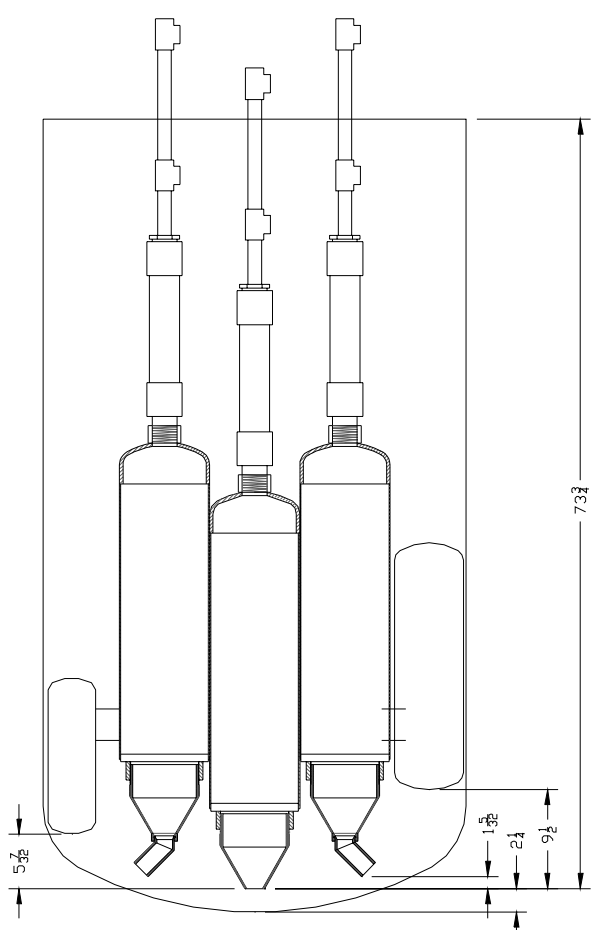

Elevation View

Figure 2-7. Chandelier PJM Configuration - Plan View and Elevation View

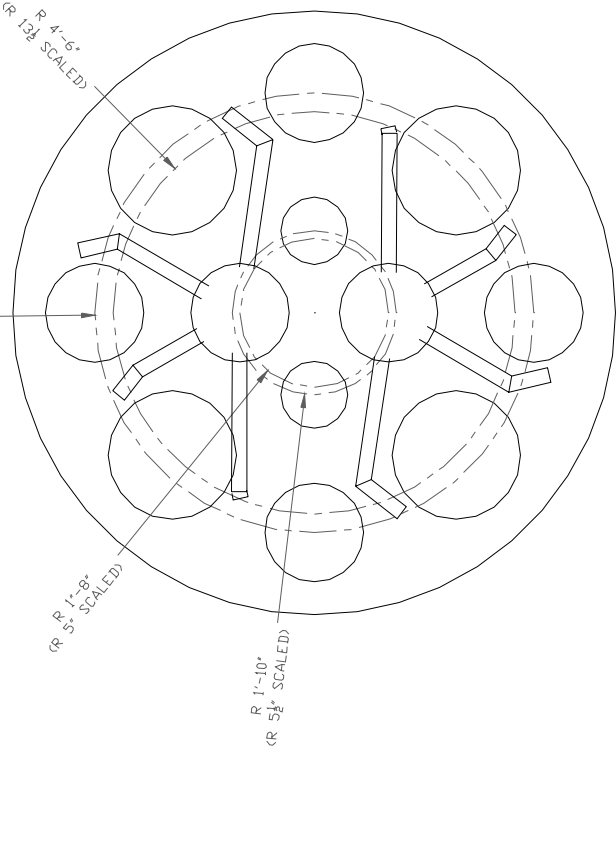

Plan View

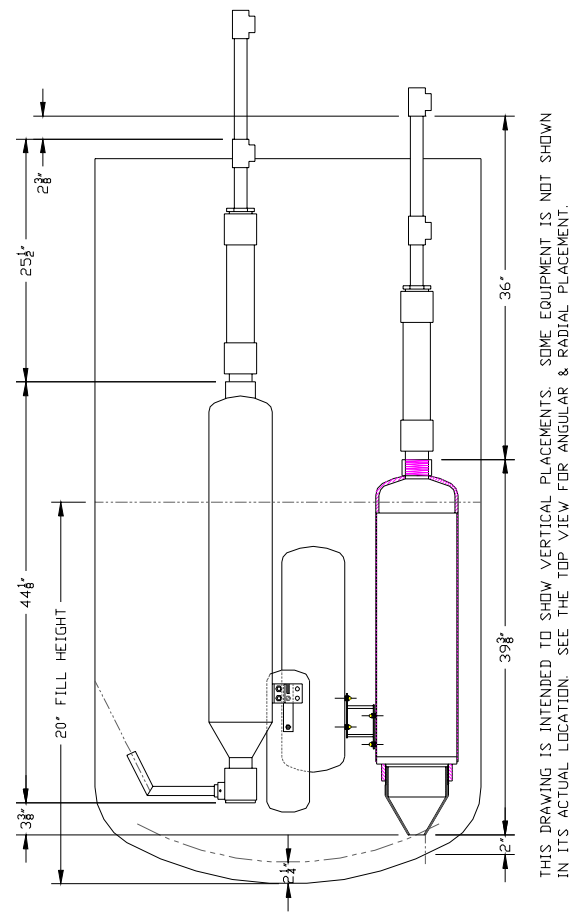

Elevation View

Figure 2-8. Spider PJM Configuration - Plan View and Elevation View 
WSRC-TR-2004-00398, REVISION 0

SRNL-RPP-2004-00060, REVISION 0

\subsection{Final Chandelier PJM Arrangement}

The final, selected PJM arrangement is the so called Chandelier arrangement, Figure 2-9.

This is a modification of Figure 2-7, where the charge vessels are positioned along the vessel wall along radial centerlines between PJMs. This is to ensure a flow distribution as close to symmetrical as possible.

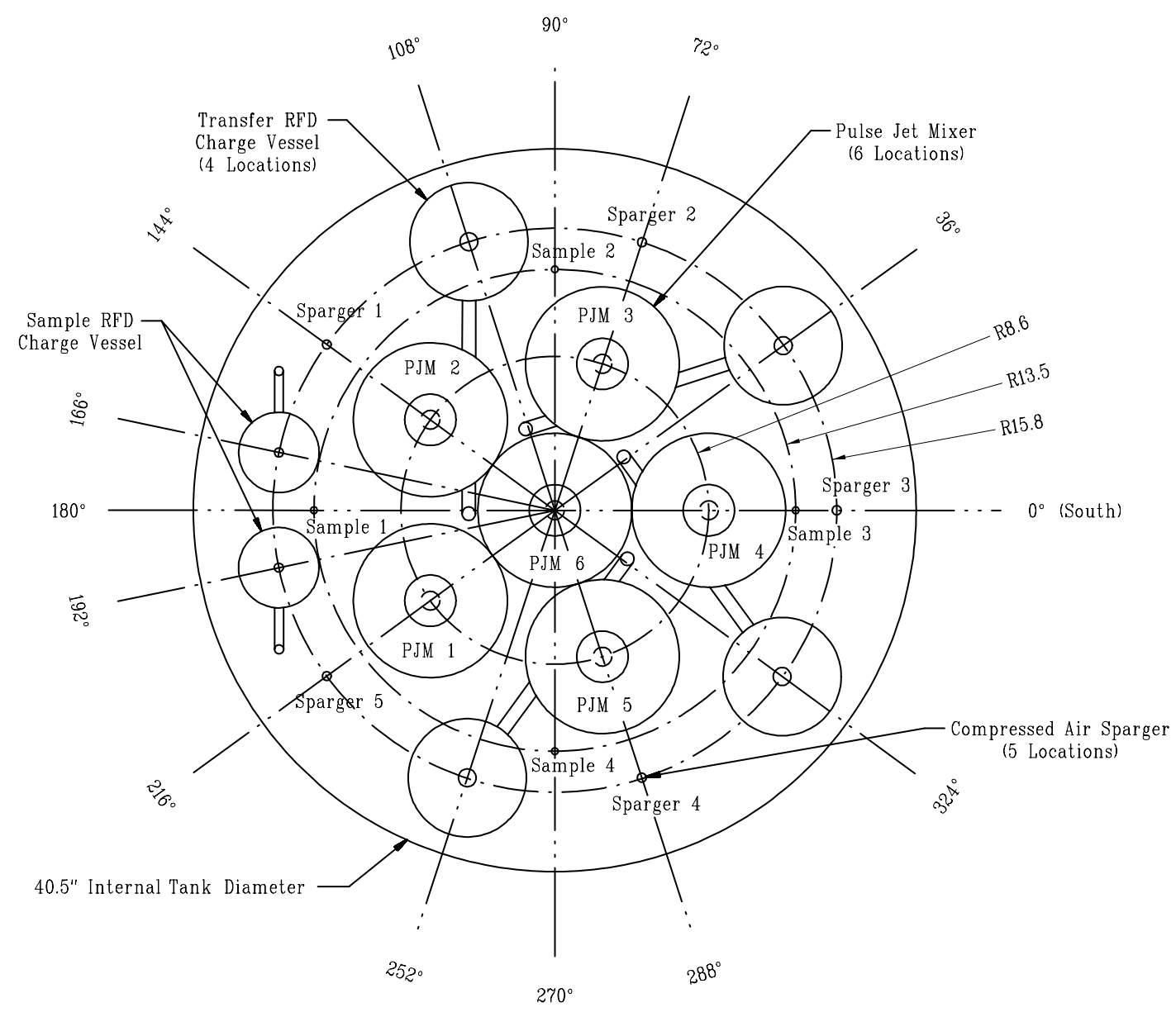

Figure 2-9. Top View of the CRV Prototypic Test Stand Showing Nominal Dimensions

All PJMs for the final, selected CRV prototype of the Chandelier arrangement were constructed from 8-inch-diameter (8.329-inch ID) schedule 10 stainless steel pipes with the end connected to an approximately $60^{\circ}$ angle cone truncated to a 1.5 -inch-diameter collar to which the nozzles were fitted. Figure 2-10 is a drawing of the PJM assembly; Figure 2-11 is a photograph of the entire assembly inside the CRV tank. The cylindrical section of the PJMs was $37 \pm 1$ inches tall; this corresponds to a PJM height scale factor of $\sim 4.32$. The difference between the CRV tank dimension scale factor and the pulse tube dimension scale factor was due to the need to use standard pipe sizes for procurement expediency. However, the volume expelled from the PJMs was consistent with the CRV vessel scale factor of $\sim 4.0$. 


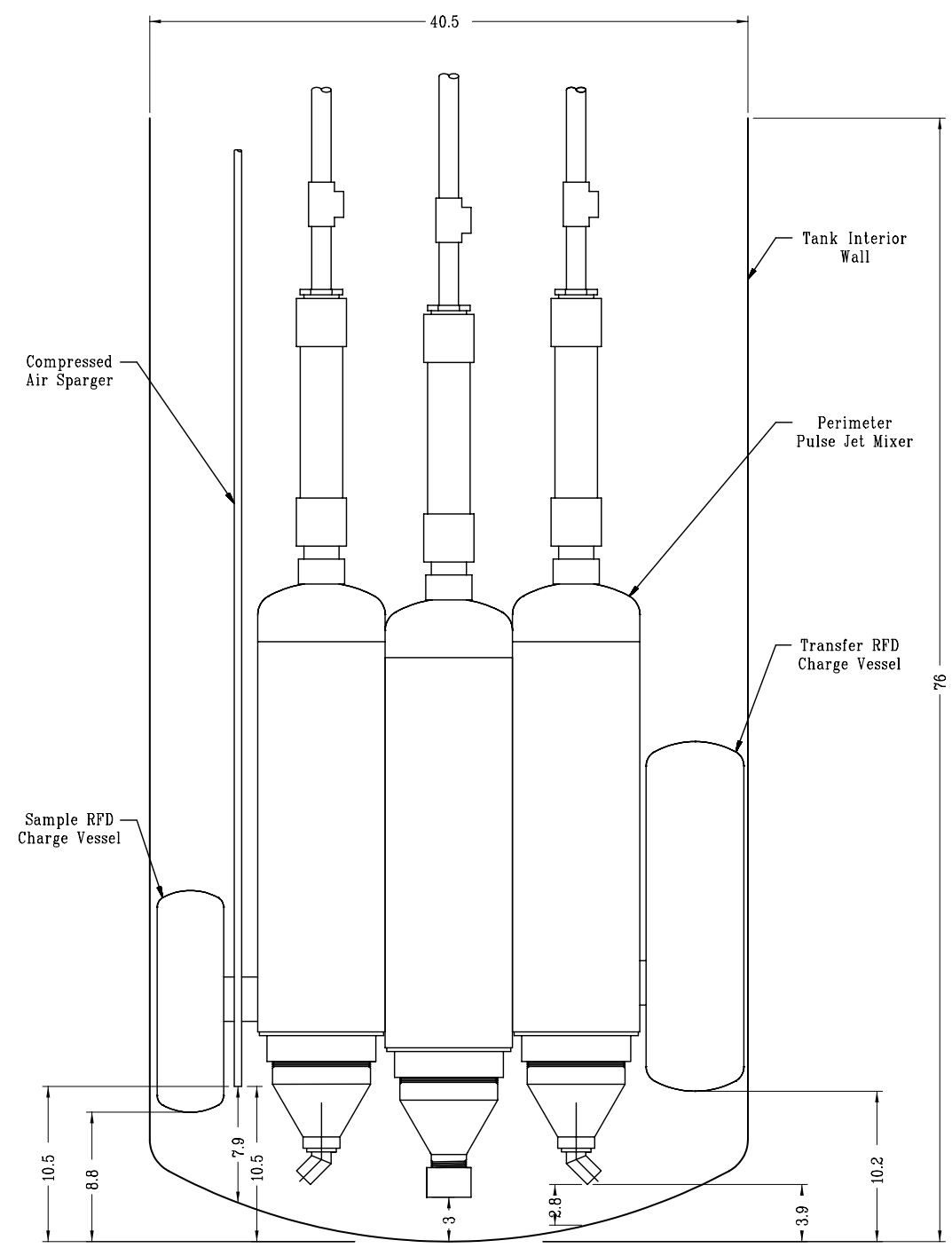

Figure 2-10. Plan View of the CRV Test Stand Showing Nominal Dimensions

The center PJM nozzle (Figure 2-12) was constructed from a drilled stainless steel pipe cap attached to a $60^{\circ}$ cone and was pointed straight down toward the center of the tank bottom and raised approximately 2 inches off the bottom. Two types of perimeter PJM nozzles were used. One, (Figure 2-13 - 1.05-inch ID shown) was angled $45^{\circ}$ (using welded pipe sections) from the vertical; and the other (Figure 2-14) was angled $135^{\circ}$ from the vertical. Both were directed radially outward from the tank center and raised approximately 2 inches off the tank floor. Only two combinations of nozzles were used. The first, called the Down Nozzle Configuration, consisted of (5) $45^{\circ}$ downward facing nozzles and (1) center down nozzle. The second, called the Up/Down Nozzle Configuration, consisted of (3) $135^{\circ}$ Nozzles at PJMs 1, 2, and 4, (2) $45^{\circ}$ down nozzles and (1) center down nozzle. 
WSRC-TR-2004-00398, REVISION 0

SRNL-RPP-2004-00060, REVISION 0

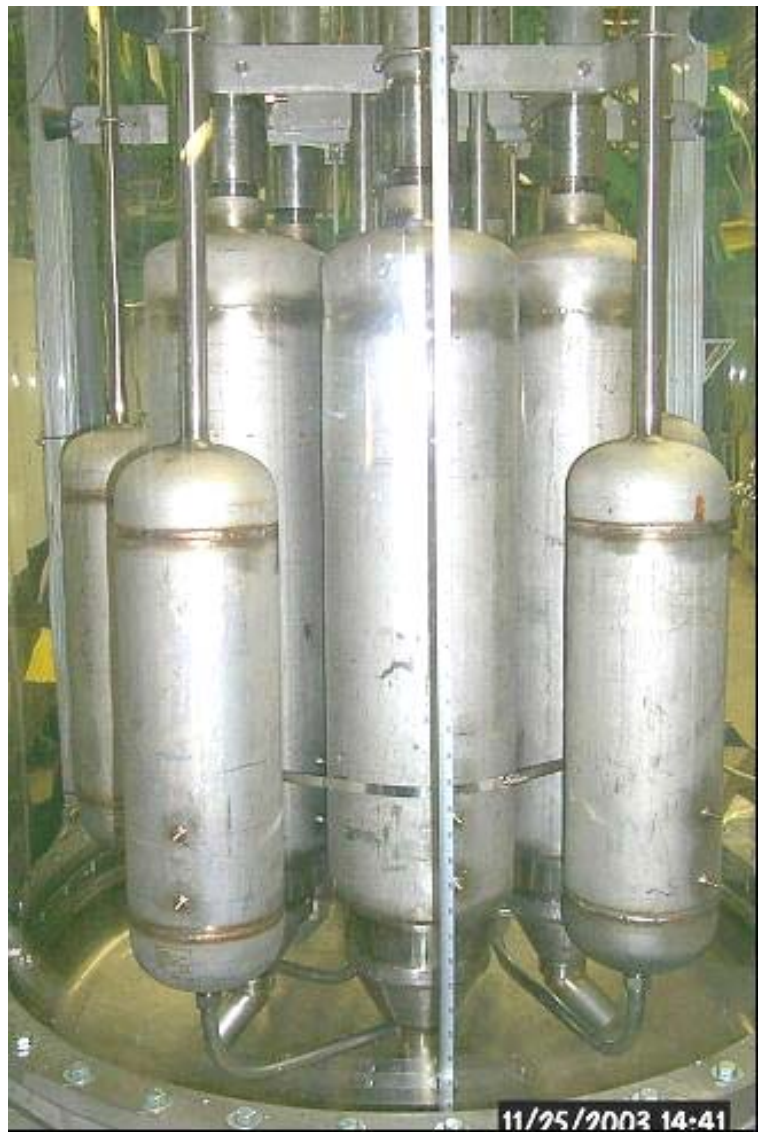

Figure 2-11. Final 8-inch diameter Chandelier PJM and charge vessel assembly (1.5-in. diameter Nozzles installed)

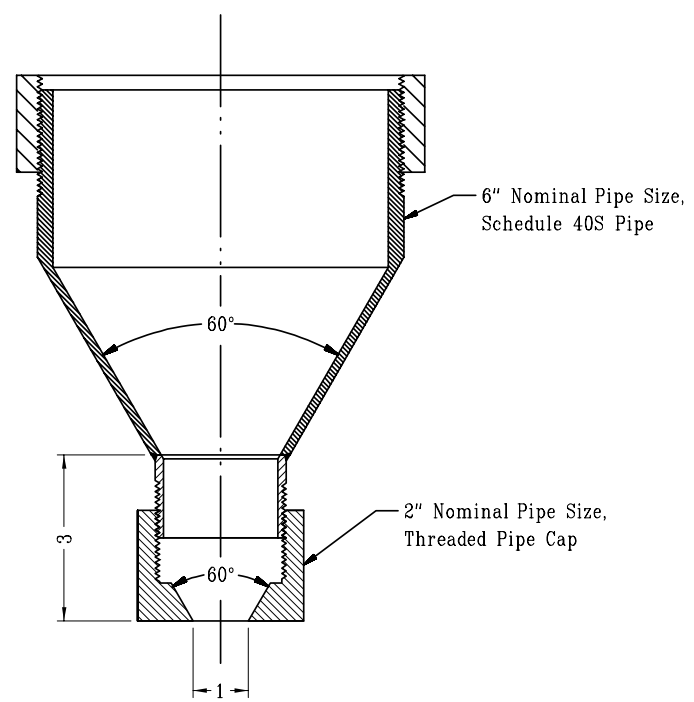

Figure 2-12. Center Nozzle Showing Nominal Dimensions for 1-inch Nozzle 
WSRC-TR-2004-00398, REVISION 0

SRNL-RPP-2004-00060, REVISION 0

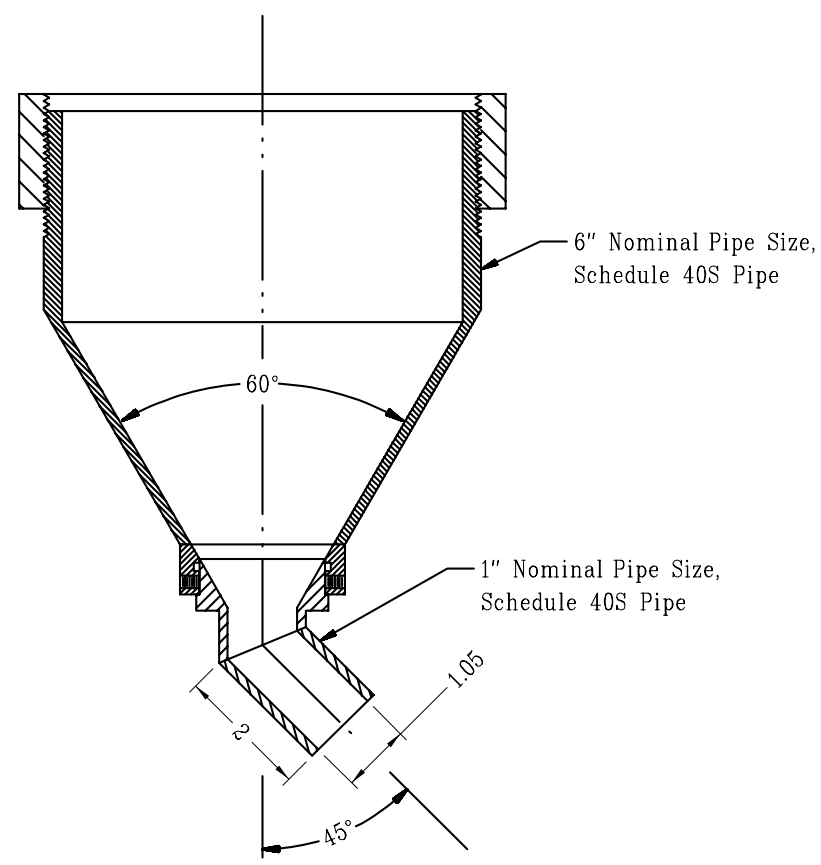

Figure 2-13. $45^{\circ}$ Nozzle; Showing Nominal Dimensions for 1-inch Nozzle

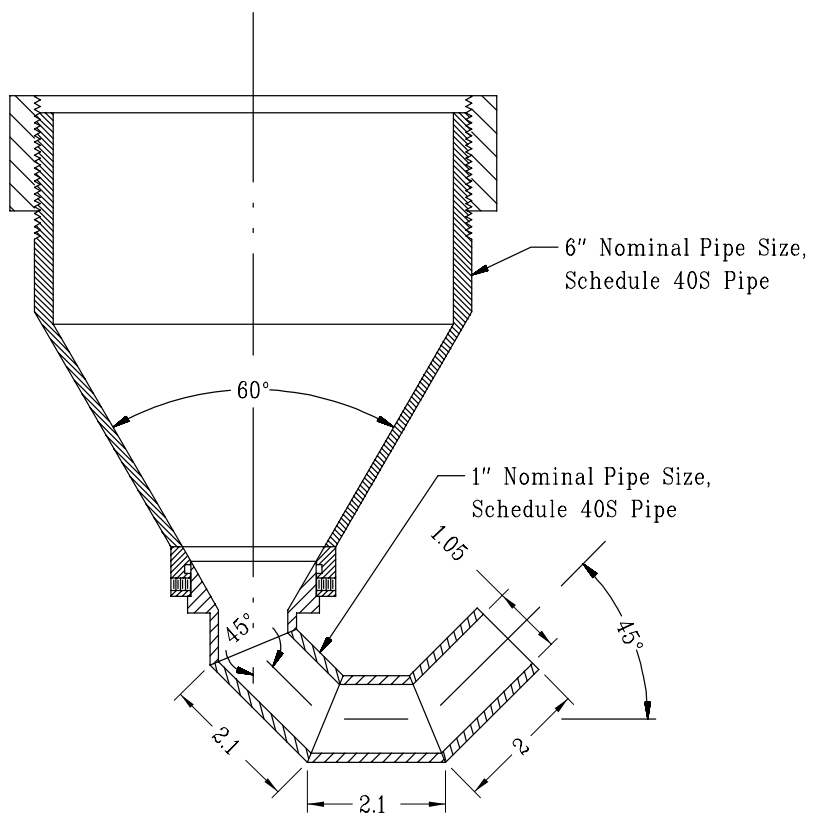

Figure 2-14. $135^{\circ}$ Nozzle Showing Nominal Dimensions for 1-inch Nozzle 


\subsubsection{Sparger Configuration}

Tests using spargers were performed using an array of 5 spargers at a pitch circle of 31.6 in. The spargers were located approximately at the center of the open regions between the charge vessels, as shown in Figure 2-15. The sparger tubes were made from 0.5-inch-OD (0.37-inch ID) stainless steel tubing, and the lower ends of the sparger tubes were approximately 10.5 inches above the bottom of the tank as measured from the tank bottom. The sparger flow rates were individually controlled with throttle valves and measured with rotameters for equal flows. The total air flow was measured with a Kurz mass air flowmeter and recorded on the data acquisition system.

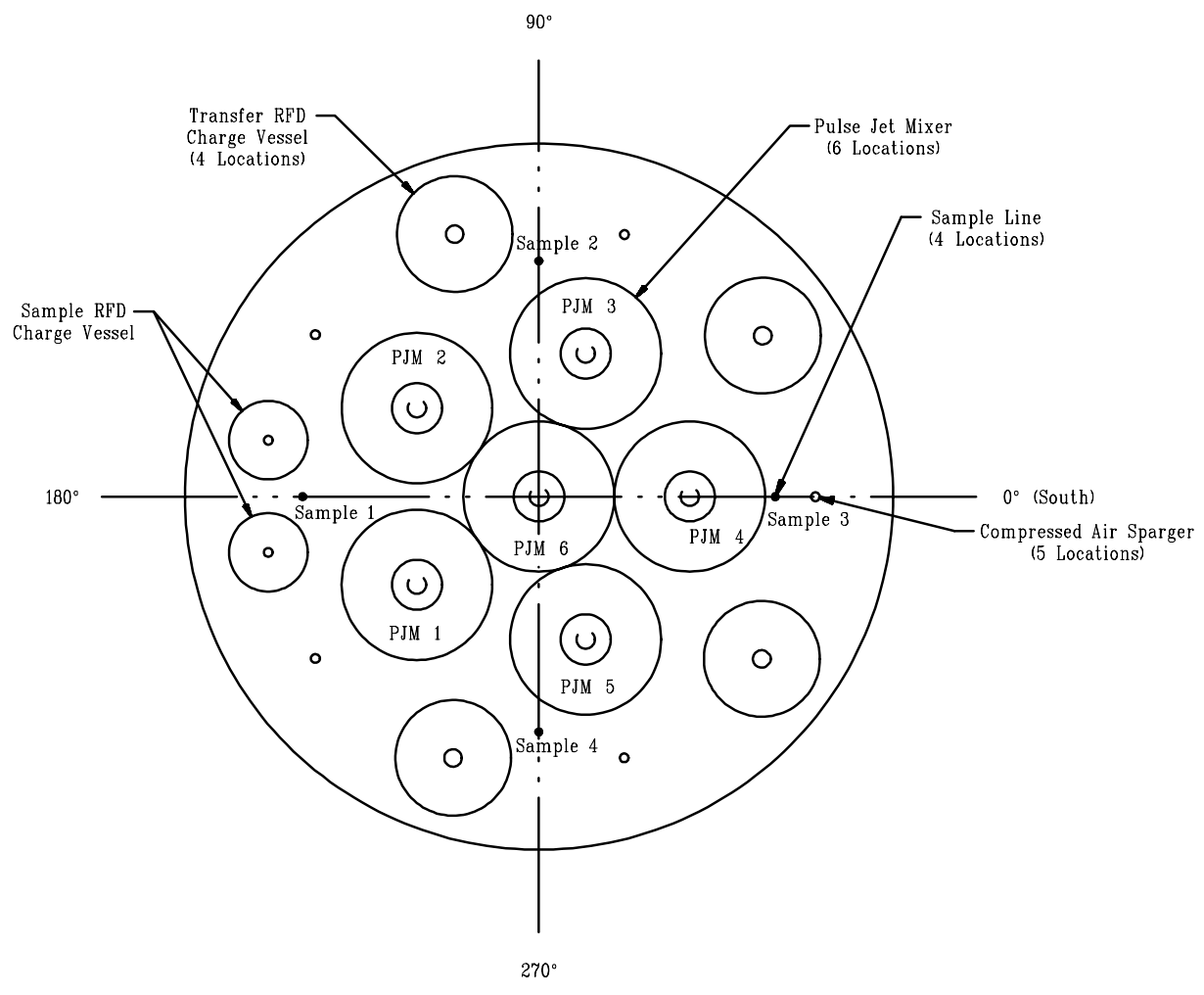

Figure 2-15. Sparger and Sample Line Locations in Final Chandelier Arrangement 


\subsubsection{System Operation and Data Acquisition}

Unlike conventional PJMs, whose operation is regulated by JPPs driven by compressed air, the prototype test systems used a series of solenoid valves and a combination of an air compressor and a vacuum pump to simulate the drive and suction phases of PJM operation. These operations were controlled through a control logic program using Labview software that turns the appropriate solenoid valves on and off at specified time intervals. The duration of each phase, the applied pressure, and the vacuum are all variables that can be independently varied to simulate the operation of the PJMs. The PJMs were operated at a specific average nozzle velocity $\left(\overline{\mathrm{u}}_{\text {disch }}\right)$, which is defined as

\section{Equation 2-1}

$$
\bar{u}_{\text {disch }}=\frac{\Delta H}{\Delta t} * A R
$$

where $\Delta H$ is the length of the PJM stroke, $\Delta t$ is the time for achieving the stroke, and $A R$ is the area ratio of the PJM to the nozzle.

This equation is the same as Equation A- 6 in Appendix A. The drive distance was based on volume scaling to the plant, given the linearly scaled PJM diameter. The drive distance was approximately 27-inches. When the 8-inch PJM was used to simulate the 6-inch PJM, the drive distance was reduced to 16-inches. During the drive portion of the cycle, the drive time was set so that the nominal velocity was achieved, knowing the initial and final simulant levels inside the PJM. The cycle time was controlled to be one over the scale factor of the plant cycle time and includes times for venting and quiescent periods.

Figure 2-16 gives a schematic of the PJM and level probe installation (6-inch PJM shown). A one-inch tee at the top provides an air inlet and vent. The compressed air and vacuum manifold systems are shown in Figure 2-17. Pressurized air source, vacuum, and venting are controlled by individual solenoid valves for each PJM.

During each mixing test, several variables such as PJM liquid levels and pressures, tank temperatures, air supply pressure, and total sparger air flow rate were monitored continuously and recorded digitally on a computer. The liquid/slurry level inside each of the PJMs was measured using Drexelbook capacitance level probes and transmitters. Figure 2-16 shows the level probe installation inside the PJM. The level probes were calibrated against a tape measure on the side of the tank whenever there was a change of simulant (slurry yield stress changed). Compressor and vacuum supply pressures and the pressure inside each PJM were monitored using flush-diaphragm Endress + Hauser ceramic pressure transducers, installed at a pipe Tee fitting near the top of the PJM. Data from all the sensors were recorded on a laboratory computer, running Labview software at sampling times of approximately 0.1 seconds. 
WSRC-TR-2004-00398, REVISION 0

SRNL-RPP-2004-00060, REVISION 0

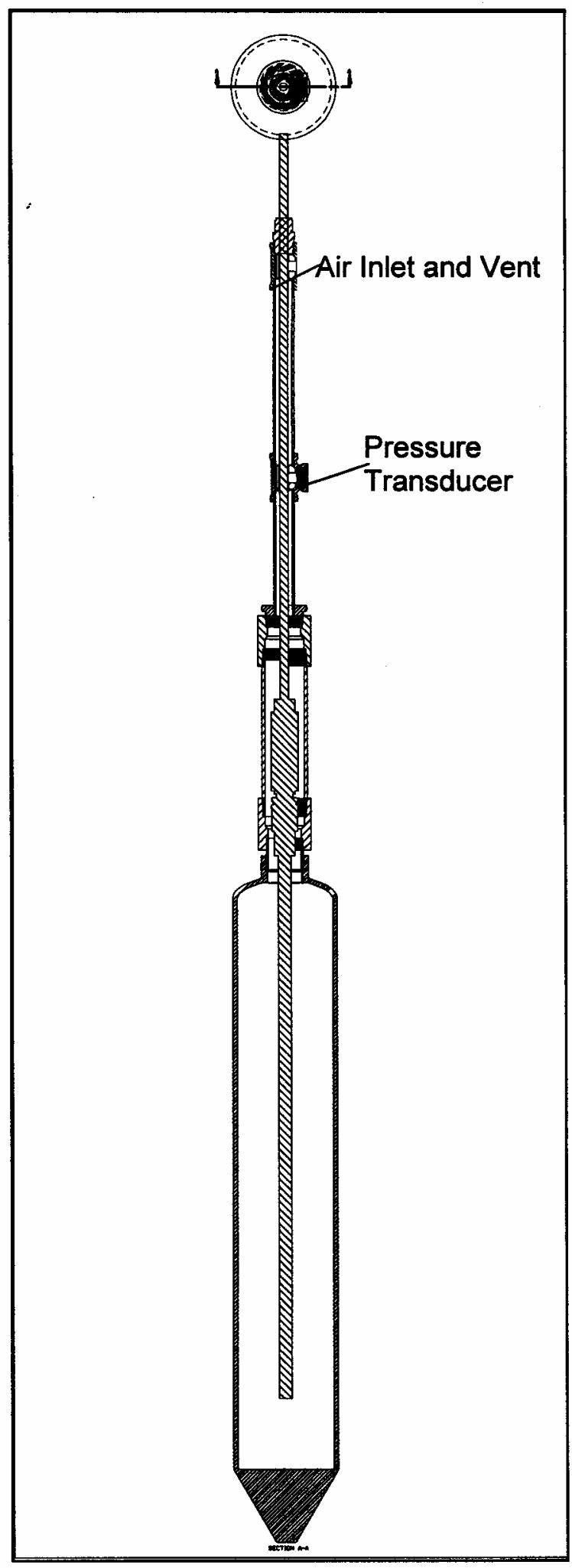

Figure 2-16. Level Probe Installation inside a PJM 
WSRC-TR-2004-00398, REVISION 0

SRNL-RPP-2004-00060, REVISION 0

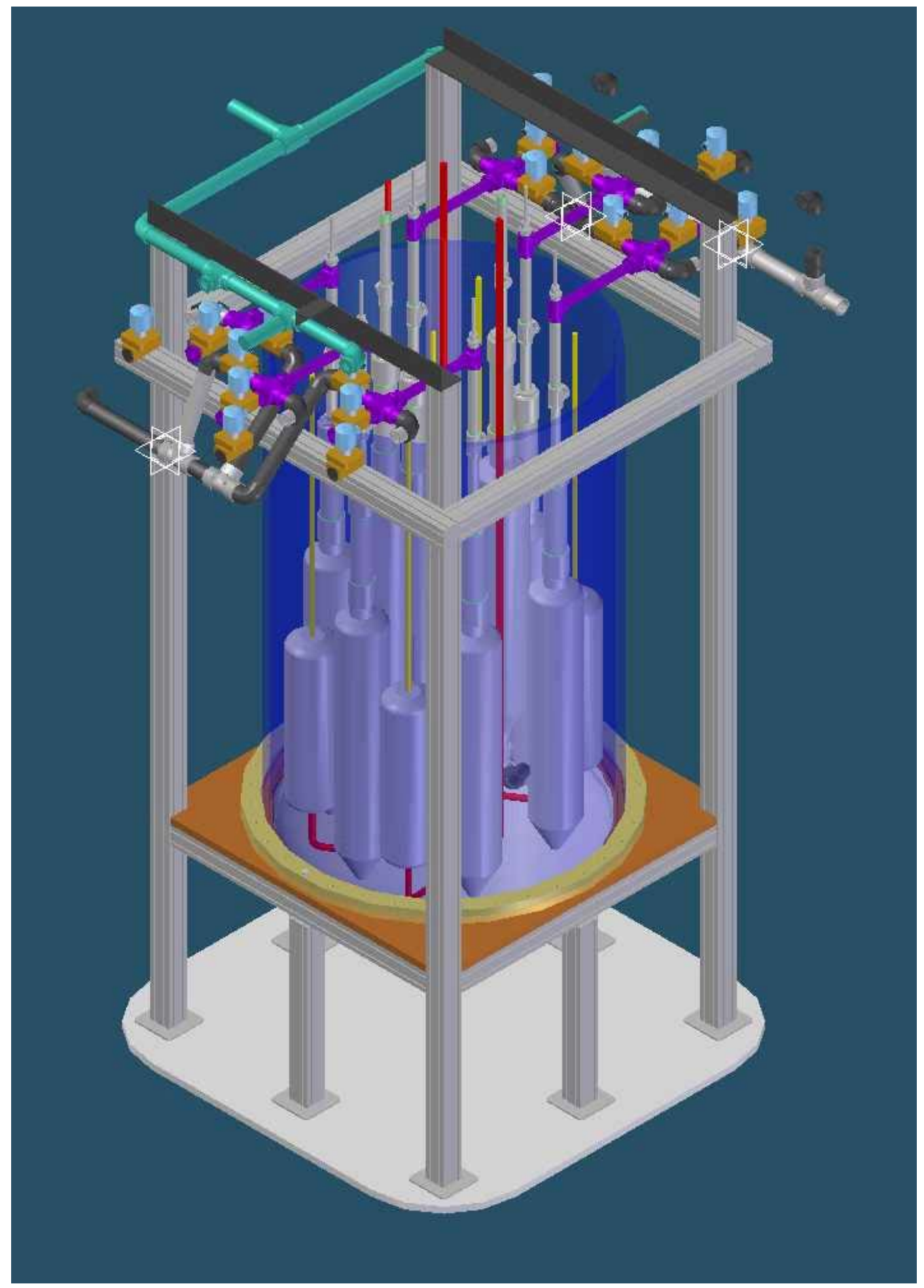

Figure 2-17. Isometric Drawing of the CRV Test Stand with Compressed Air and Vacuum Systems 
WSRC-TR-2004-00398, REVISION 0

SRNL-RPP-2004-00060, REVISION 0

\subsection{TESTING METHODS FOR DETERMINING MIXING EFFECTIVENESS}

The primary measurement in the scaled prototypic CRV test platform was the size and extent of the mobilization cavern resulting from PJM operations and PJMs combined with sparging. This was achieved by one or a combination of four methods:

1) visual means during the early scoping runs with Laponite;

2) a chemical (dye) tracer method, discussed in detail in Section 2.3.2 and Appendix C

3) an ultrasonic velocity probe (UVP), described in Appendix D

4) glass bead tracers, described in Section 2.3.3

Methods 2, 3, and 4 were used for the Kaolin/Bentonite simulant. For this case, complete and successful mixing was defined as $100 \%$ as indicated by both the chemical tracer and velocity probe methods. This was true for the simulant solution. However, for the situation where solids in the waste must be simulated, then the ultimate test was the solids mixing test.

\subsubsection{Visual Means}

During the PJM Configuration Selection process, the Dye, ultrasonic velocity probe, and solids mixing methods had not been developed. However, in these tests, the clear simulant, Laponite, was used. The transparency of Laponite enabled one to determine the boundaries between moving fluid (entrained bubbles were clearly visible) and stagnant or jelled material. This allowed a somewhat quantitative assessment of how much of the simulant was mixed. Video recordings were extensively used. Also, the shape of the cavern and the mechanism of producing it are defined as follows. Two types of mixing may exist simultaneously in the tank.

- Type 1 mixing is where a cavern is carved out at the bottom of the tank by the high velocity jets and a distinct upper region that is still un-sheared exists.

- Type 2 mixing is when most of the jet flow goes to the center and a breakthrough occurs at the top surface of the simulant.

- Type 3 mixing is when the moving fluid at the top center spills over to the outer wall and pushes down gelled material into the cavern in a ratcheting action.

- Type 4 mixing is when highly turbulent motion is produced.

\subsubsection{Dye Method}

Mixing performance in the CRV test vessel was assessed in the Dye method through the use of Brilliant Blue dye as a tracer. A summary of the technique used is shown in Figure 2-18. First the baseline dye concentration in the simulant was obtained by taking an initial sample. The dye tracer was injected during the initial stages of the PJM test. Samples of the simulant were taken from several locations during each mixing test to determine the changes in dye concentration as a function of time and operating parameters. At the end of a test cycle, the test vessel was homogenized and a final sample collected. Determination of the fraction of tank volume mixed was based on the assumption that a contiguous volume of well sheared material or cavern is formed throughout which the dye is uniformly mixed. It was also assumed that a steady state dye concentration has been reached at the time a sample is taken. 


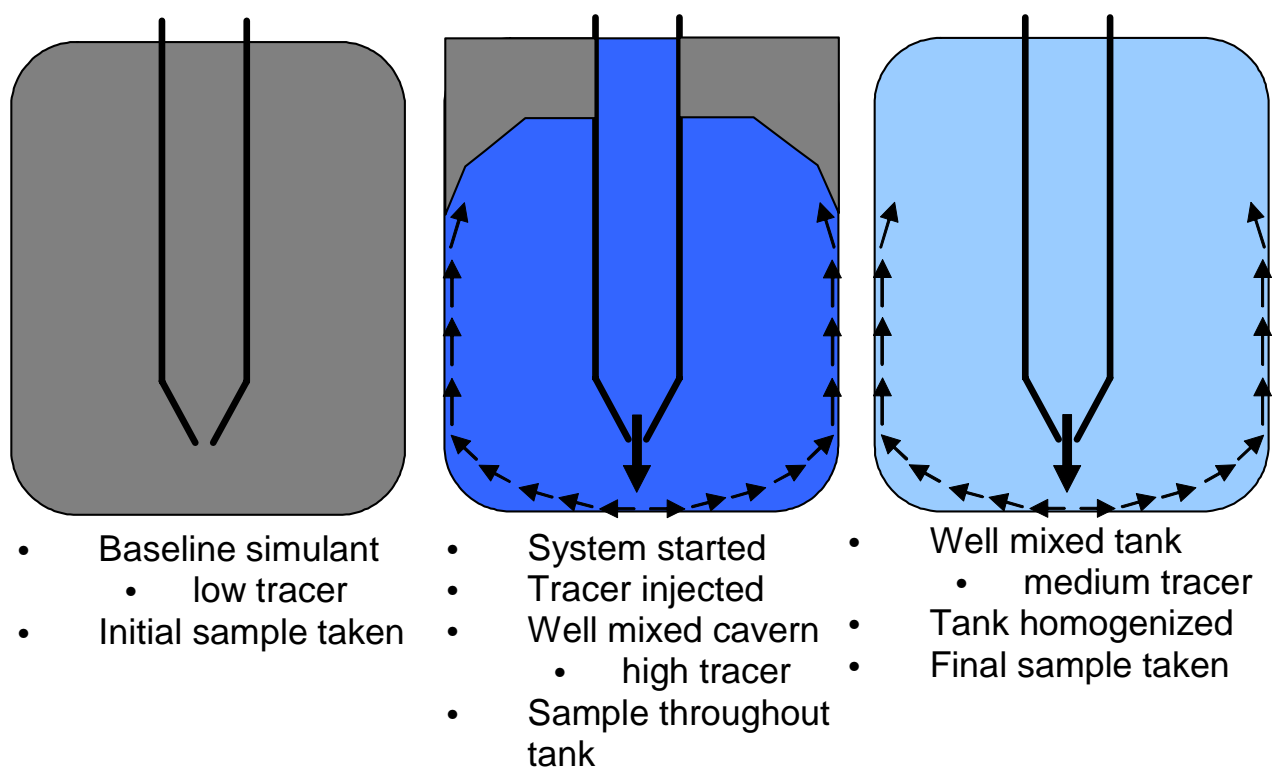

\section{Figure 2-18. Summary of Dye Tracer Method}

The required amount of dye ( $\sim 5$ g per 100 gal of clay simulant in the tank) was mixed with $\sim 2$ liters of the same clay simulant that was used in the testing. The concentrated tracer/clay mixture was injected prior to the start of a sequence of tests at lowest nozzle velocity of that test sequence. The concentrated tracer slurry was injected into the center PJM during the vacuum phase of the PJM cycle over a period of approximately 10 minutes. Once tracer injection was completed, the tracer injection line was purged with clean clay to ensure complete transfer of the tracer into the PJM. Once the line was purged, the experimental clock was started.

Four simulant samples from the tank at simulant lines located in the annulus between the PJM and the tank wall (as shown in Figure 2-15) were collected over a period of at least 45 minutes of PJM operation. Three of these samples (Samples 1, 2, and 3) were drawn near the bottom of the tank, and Sample 4 was drawn near the top of the tank, respectively. These samples were withdrawn at 10 minute intervals to correspond to different PJM and sparger operating conditions, starting at the lowest energy mixing conditions, then progressing to more vigorous mixing conditions. For example, these conditions would typically be: $8 \mathrm{~m} / \mathrm{s}$, $12 \mathrm{~m} / \mathrm{s}$, then $12 \mathrm{~m} / \mathrm{s}$ with $4 \mathrm{scfm}$ of air sparging, and then finally $12 \mathrm{~m} / \mathrm{s}$ nozzle velocity and $6 \mathrm{scfm}$ of air sparging.

After completion of the specified run conditions, the tank was completely homogenized and final homogenized samples collected. Comparison of the tracer concentration in the various samples with the final homogenized samples provides the percent mixed as a function of time and run conditions. Complete details of the Dye method can be found in Appendix C. 
Multiple run conditions were typically achieved for each tracer injection. The tracer test started with the lowest mixing energy condition to form the initial well mixed cavern. An additional mixing system (sparging tubes) or increased pulse tube velocities were then used as subsequent run conditions to form larger mixing caverns.

Samples were drawn using a peristaltic pump system. When sampling, the lines were initially purged of simulant into a separate beaker. Then the pump was run at full speed $(170 \mathrm{ml} / \mathrm{min})$ to collect a $20 \mathrm{ml}$ sample in 57 secs. A clean beaker was used to collect the sample and sealed. Due to the tendency of sample lines to plug, the pump was operated continuously to ensure free flow of the simulant and the line was continuously purged. The next sample was taken at the appropriate time.

The concentration of dye was measured using a UV-VIS spectrometer. This instrument requires a transparent sample. To overcome this limitation, the opaque kaolin:bentonite simulant was centrifuged, and the analysis was performed on the centrifuged liquid portion of the sample. The spectrometer measures the optical absorbance of the sample at multiple wavelengths of light. When the dye is present in the system a peak absorbance is observed at approximately $630 \mathrm{~nm}$. According to Beer's law, the magnitude of this absorbance peak is directly proportional to the concentration of dye in the system.

Equation 2-2 is used to calculate the fraction mixed.

Equation 2-2

$$
X_{j}=\frac{C_{f}-C_{0}}{C_{j}-C_{0}}
$$

where

$X_{j} \quad$ is the fraction mixed of the $\mathrm{j}$-th tank sample

$C_{f} \quad$ is the tracer concentration of the final homogenized simulant

$C_{0} \quad$ is the tracer concentration of the initial baseline simulant

$C_{j} \quad$ is the tracer concentration of the $\mathrm{j}$-th tank sample

When the aqueous phase tracer does not absorb onto the solid phase, the liquid phase concentration can be measured with the techniques above, and Equation 2-2 can be used to directly calculate the fraction of the tank mixed. The chloride ion did not appear to absorb onto the simulant particles, and this equation is used for the $\mathrm{NaCl}$ tracer. 
Because the spectrometer measures absorbance, which is proportional to concentration, Equation 2-2 can be rewritten for the dye tracer as follows:

Equation 2-3

$$
X_{j}=\frac{A_{f}-A_{0}}{A_{j}-A_{0}}
$$

where

$X_{j} \quad$ is the fraction mixed of the $\mathrm{j}$-th tank sample

$A_{f} \quad$ is the optical absorbance of the final homogenized simulant

$A_{0} \quad$ is the optical absorbance of the initial baseline simulant

$A_{j} \quad$ is the optical absorbance of the $\mathrm{j}$-th tank sample

Unfortunately, the dye tracer absorbs onto the clay particles in significant quantity. In this situation Equation 2-2 still applies, but the concentrations used in the equation must account for both the liquid and solid phases. This is accomplished using Equation 2-4.

$$
\text { Equation 2-4 } \quad C=Y_{l} C_{l}+Y_{s} C_{S}
$$

where

$$
\begin{array}{ll}
C & \text { is the tracer concentration } \\
C_{l} & \text { is the tracer concentration of the liquid phase } \\
C_{S} & \text { is the tracer concentration of the solid phase } \\
Y_{l} & \text { is the liquid phase mass fraction } \\
Y_{S} & \text { is the solid phase mass fraction }
\end{array}
$$

The distribution of tracer between the liquid and solid phases is typically described using a distribution coefficient (Equation 2-5).

$$
\text { Equation 2-5 } \quad C_{s}=K_{d} C_{l}
$$

where $K_{d}$ is the distribution coefficient. 
To complicate matters further, the distribution coefficient is also a function of liquid phase dye concentration. When Equation 2-3 and Equation 2-4 are substituted in Equation 2-2, the following equation results:

Equation 2-6

$$
X_{j}=\frac{Y_{l}\left(A_{f}-A_{o}\right)+Y_{s}\left(K_{d f} A_{f}-K_{d o} A_{o}\right)}{Y_{l}\left(A_{j}-A_{o}\right)+Y_{s}\left(K_{d j} A_{j}-K_{d o} A_{o}\right)}
$$

where

$K_{d f} \quad$ is the distribution coefficient at the homogenized tank tracer concentration

$K_{d o} \quad$ is the distribution coefficient at the initial baseline tracer concentration

$K_{d j} \quad$ is the distribution coefficient at the j-th tank sample tracer concentration

When $\mathrm{K}_{\mathrm{d}}$ is null or constant, Equation 2-6 reduces to Equation 2-3. Over the small dye concentration ranges observed in the prototype testing, the assumption of a constant distribution coefficient is valid, and Equation 2-2 can be used. Note that as $A_{j}$ approaches $A_{f}$, $\mathrm{K}_{\mathrm{dj}}$ approaches $\mathrm{K}_{\mathrm{df}}$, and the error associated in using Equation 2-2 approaches zero. In addition, the distribution coefficient function varies from batch to batch of simulant, and other factors such as temperature and contact time will also affect the distribution coefficient function. Lastly, the solids loading of the simulant was often varied for rheological purposes. For these reasons, Equation 2-6 is used to estimate the fraction mixed using the dye tracer. Estimates of the uncertainty of this method are given in Appendix C.

\subsubsection{Ultrasonic Velocity Probe}

One method of assessing mixing effectiveness is to measure fluid velocities in the simulant. The Ultrasonic Velocity Probe (UVP) was used in this experiment to perform these fluid velocity measurements. It is essentially an ultrasonic sensor that propagates a pulse of ultrasound of 1-2 MHz frequency through a narrow beam in the fluid. The clay particles in the simulant reflect part of this beam back to the sensor. The reflected beam frequency is Doppler-shifted by an amount proportional to the speed of the clay particles. This method relies on first principles, but requires knowledge of the speed of sound in the simulant.

The question is: what is the minimum velocity that should be considered necessary for effective mixing. Turbulent flow would suggest effective mixing, as also laminar flow if there is sufficient folding and stretching of streamlines. This is a highly debatable issue unless there is experimental data to justify a minimum velocity criteria. No such data was available for conditions of this test. However, for the purpose of this report, the required minimum velocity was set at a value that seemed to correspond to the value at which the velocity of the pulse jet decays at the boundary of the cavern. Detailed flow mapping was performed in the middle of the annular region between the PJM and the tank wall opposite a downward ( $45^{\circ}$ angled) PJM nozzle for the case of a 1-inch nozzle and using both upward and downward directed nozzles. Results are illustrated in Figure 2-19. 


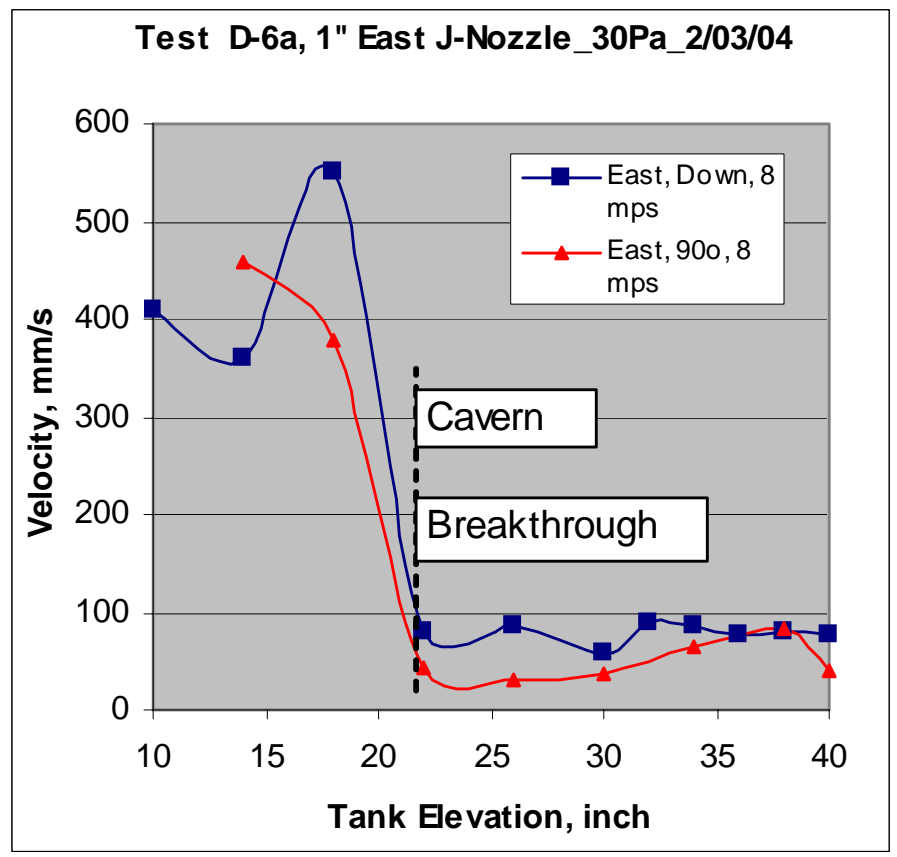

Figure 2-19. Typical Ultrasonic Velocity Probe Velocity Measurements

The velocity plotted is the peak value of the velocity pulse during the drive phase of the cycle. This indicates that the vertical velocity (measured with a downward looking probe) starts at a high initial value near the bottom of the tank, decays, and flattens out near the top surface of the simulant. A second probe, directed 90 degrees from the first probe towards the center of the tank, shows the horizontal velocity following the behavior of the horizontal velocity, decreasing from the lower regions towards the top and also flattening out at close to the same tank elevation of 21 -inches. This breakpoint elevation correlates closely with the observation of the breakthrough of the pulse jet when the tank level is lowered with the PJMs operating.

The flat portion of the curve (near the top of the tank) seems to correlate with a flat top pulse, not a sharp pulse, that may be associated with a piston like movement of the simulant near the top. The velocity at the top of the cavern, or minimum required mixing velocity, was therefore set at $80 \mathrm{~mm} / \mathrm{sec}$ for the horizontal component. An adequately high horizontal or radial flow component would suggest that the flow is not entirely piston-like and some mixing is going on. Also, the $80 \mathrm{~mm} / \mathrm{sec}$ value can still be distinguished clearly above the noise level in the UVP signal. It is also above the average peak velocity of $60 \mathrm{~mm} / \mathrm{sec}$ in the tank corresponding to a $12 \mathrm{~m} / \mathrm{sec}$ nozzle velocity.

The UVP measurements differ from Figure 2-19 for different tank locations, e.g., location of an upward nozzle, sampling vessel, or an operating sparger, but the criteria of $80 \mathrm{~mm} / \mathrm{sec}$ for the horizontal probe was adopted for the cavern height measurements. In the case of air sparging, the minimum velocity was set at $60 \mathrm{~mm} / / \mathrm{sec}$, since the flow oscillations were regular or continuous, indicating good mixing conditions. A more detailed discussion of the UVP probe cavern measurement technique, typical UVP signals, and plots of the velocity distributions for various nozzle configurations is given in Appendix D. 


\subsubsection{Solids Mixing Method}

The mixing capability of PJMs for the liquid phase was validated as above through dye tracer studies and ultrasonic velocity probes. However, validation of acceptable degree of mixing of the solids phase was also required. The solids phase in the UFP, LS, and CRV vessels could contain a certain amount of high density particles such as rutile $(\rho=4.25 \mathrm{~g} / \mathrm{ml})$ from the glass former solids that may be carried over to the filter solids in the recycle streams. Based on the available data (CCN 052912; Poloski et al. 2003) these large particles may be on the order of 175 microns in size and have a density as high as $4.25 \mathrm{~g} / \mathrm{ml}$.

The solids mixing tests utilized tracer glass beads in the size range of $210-300$ microns (50X70 mesh) in 2 simulants with $30 \mathrm{~Pa}$ and $6 \mathrm{~Pa}$ yield stress, respectively. The concentration of the tracer beads did not exceed $0.3 \%$ by volume of the inventory of simulant in the CRV tank in order not to affect the simulant rheology significantly. The CRV tank was first filled with simulant to a level corresponding to the top of the heel (elliptical bottom) and $11.5 \mathrm{lbs}$ of glass beads were distributed over the simulant surface. Then the tank was filled to the 40-inch level. Because the 8-inch-diameter PJMs were used to simulate the baseline (scaled) 6-inch-diameter PJMs, the PJM stroke was limited to 15 inches to simulate the same PJM expelled volume as for a full-stroke 6-inch PJM. The PJMs were then operated for a total of 66 cycles, equal to the same number of cycles for 1.5-hour plant operation.

At the end of the mixing period with the simulant in a static condition, the upper and the lower halves of the CRV were sampled at 10 random locations each. A grab sampler was used for this purpose, consisting of a 2-inch-diameter rotating cylinder attached to two upper and lower fixed cylinders by rubber sleeves. By rotating the movable cylinder, a $250 \mathrm{ml}$ sample was trapped between the twisted rubber sleeves. In addition to this, the CRV heel was sampled multiple times (10 samples) at a single location near the bottom of one of the RFDs, using a peristaltic pump. This was at Sample Pt. No. 1 in Figure 2-15, where a 0.5inch OD (0.37-in ID) tube was used to draw the samples.

The solids concentration in each sample was determined by sieving, washing and drying the tracer solids from a known weight of the sample. This concentration is expressed as mass percent dry tracer solids in wet sample. In addition to this, the grab sampler was calibrated to determine any bias in collecting the tracer solids. Also, the initial clay solid concentration in the same size range as the glass bead tracers was determined as a correction to the measured sample solids concentration. 


\subsection{CRV PROTOTYPE TEST RESULTS}

The test results presented in this section are organized to conform to the test matrices given in Section 1.5. The reported nozzle velocities are average or nominal velocities defined by Equation A- 3, Appendix A, which are within 13\% of the area average velocity (Equation A- 5), as verified by the verification tests in Appendix B.

\subsubsection{Phase I - PJM Configuration Selection Process}

Table 2-1 summarizes the mixing results for the different PJM configurations, Test Series I-1 to I-34. This test series investigated various configurations of PJM size and number, nozzle size and orientation, nozzle velocity, simulant rheology, cycle time and PJM firing sequence, as listed in Table 2-1. The clear simulant Laponite was used and the method of determining the degree of mixing was purely visual. In Table 2-1, four different types of mixing are indicated. In Type 1, a small distinct cavern is formed, surrounded on the sides and on top by un-sheared material. In Type 2 , most of the flow from the pulse jets is concentrated in the central open area and the sheared material has extended or broken through to the top surface. In Type 3, the breakthrough area has increased at the top so that the flow at the center overflows to the side, which forces the jelled material downwards to be consumed by the high velocity jets at the bottom of the tank. Type 4 regions of the tank are highly turbulent. The total volume mixed is considered as the sum of all four different mixing type regions.

Tests I-1 to I-6 were tests utilizing the base configuration of six 6-inch PJM and 1-inch downward nozzles, Figure 2-4. The maximum volume mixed of 99\% (Types 3 and 4 added together) was observed at $11 \mathrm{~m} / \mathrm{s}$ nozzle velocity and $36 \mathrm{~Pa}$ yield stress. When the Rams Head PJMs were added, Tests I-7 to I-13, 100\% mobilization was observed at $11 \mathrm{~m} / \mathrm{s}$. In Tests I-14 to I-22, the nozzles on the perimeter PJMs were replaced with nozzles that were normal to the elliptical bottom head. Different combinations of six and eight PJMs (including Rams Head PJMs) were tried. A maximum mobilization of 98\% was reached at a yield stress of 52.3 Pa. In Tests I-2 to I-26, the yield stress was increased to 85-90 Pa and combinations of alternating normal and downward nozzles were utilized. A mobilization of only $85 \%$ was achieved at the high yield stress of $85 \mathrm{~Pa}$. In Tests I-27 to I-29, the nozzle diameters were increased to 1.5 -inches. Essentially $100 \%$ mobilization was reached for a yield stress of $70 \mathrm{~Pa}$. 
Table 2-1. Phase I Test Summary

\begin{tabular}{|c|c|c|c|c|c|c|c|c|c|c|c|}
\hline \multirow[b]{2}{*}{$\begin{array}{c}\text { Test } \\
\text { Number }\end{array}$} & \multicolumn{3}{|c|}{ Configuration } & \multirow[b]{2}{*}{$\begin{array}{l}\text { Nozzle } \\
\text { Dia. } \\
\text { (inches) }\end{array}$} & \multirow[b]{2}{*}{$\begin{array}{c}\text { Nozzle } \\
\text { Velocity } \\
\text { m/s }\end{array}$} & \multirow[b]{2}{*}{$\begin{array}{l}\text { Laponite } \\
\text { Yield } \\
\text { Stress (Pa) }\end{array}$} & \multirow[b]{2}{*}{$\begin{array}{c}\text { Firing } \\
\text { Order } \\
\text { Syn } \\
\text { /Asyn }\end{array}$} & \multirow[b]{2}{*}{$\begin{array}{c}\text { Mixing } \\
\text { Type } \\
1,2,3,4\end{array}$} & \multirow[b]{2}{*}{$\begin{array}{c}\text { Type } 4 \\
\text { Volume \% }\end{array}$} & \multirow[b]{2}{*}{$\begin{array}{c}\text { Type } 3 \\
\text { Volume } \\
\%\end{array}$} & \multirow[b]{2}{*}{$\begin{array}{c}\text { Total } \\
\text { Volume } \\
\text { Mixed }\end{array}$} \\
\hline & $\begin{array}{l}\text { \# Normal } \\
\text { Nozzle } \\
\text { (Tube } \\
\text { Dia.-inch) }\end{array}$ & $\begin{array}{c}\text { \# RAMS } \\
\text { Head } \\
\text { (Tube } \\
\text { Dia.-inch) }\end{array}$ & $\begin{array}{l}\text { \# Down- } \\
\text { ward } \\
\text { (Tube } \\
\text { size- } \\
\text { inch) }\end{array}$ & & & & & & & & \\
\hline $\mathrm{I}-1$ & NA & NA & $6(6)$ & 1 & 7.93 & 84 & Syn & 1 & \multicolumn{2}{|c|}{ Cavern Below Flange } & $\mathrm{N} / \mathrm{A}$ \\
\hline $\mathrm{I}-2$ & NA & NA & $6(6)$ & 1 & 7.7 & 85 & Syn & 2 & 10 & 35 & 45 \\
\hline $\mathrm{I}-3$ & NA & NA & $6(6)$ & 1 & 11.5 & 86 & Syn & 2 & 20 & 55 & 75 \\
\hline $\mathrm{I}-4$ & NA & NA & $6(6)$ & 1 & 4.9 & 34 & Syn & 2 & 20 & 55 & 75 \\
\hline $\mathrm{I}-5$ & NA & NA & $6(6)$ & 1 & 7.7 & 36 & Syn & 3 & 25 & 65 & 90 \\
\hline $\mathrm{I}-6$ & NA & NA & $6(6)$ & 1 & 11.8 & 36 & Syn & 3 & 40 & 59 & 99 \\
\hline $\mathrm{I}-7$ & NA & $2(6)$ & $6(6)$ & 1 & 4.2 & 72 & Syn & 1 & 10 & & 10 \\
\hline $\mathrm{I}-8$ & NA & $2(6)$ & $6(6)$ & 1 & 6.85 & 72 & Syn & 2 & 30 & 45 & 75 \\
\hline I-9 & NA & $2(6)$ & $6(6)$ & 1 & 10.5 & 71 & Syn & 3 & 50 & 49 & 99 \\
\hline $\mathrm{I}-10$ & NA & $2(6)$ & $6(6)$ & 1 & 3.94 & 40 & Syn & 3 & 50 & 40 & 90 \\
\hline $\mathrm{I}-11$ & NA & $2(6)$ & $6(6)$ & 1 & 6.84 & 43 & Syn & 4 & 60 & 35 & 95 \\
\hline I-12 & NA & $2(6)$ & $6(6)$ & 1 & 10.3 & 40 & Syn & 4 & 70 & 30 & 100 \\
\hline $\mathrm{I}-13$ & $4(6)$ & NA & NA & 1 & 8 & 42.8 & Syn & $\begin{array}{c}\text { 2(revers } \\
\mathrm{e})\end{array}$ & 20 & 20 & 40 \\
\hline $\mathrm{I}-14$ & $4(6)$ & NA & NA & 1 & 10.7 & 44.8 & Syn & 2 & 40 & 35 & 75 \\
\hline $\mathrm{I}-15$ & $4(6)$ & $2(6)$ & NA & 1 & 7.87 & 49.3 & Syn & 3 & 45 & 40 & 85 \\
\hline I-16 & $4(6)$ & $2(6)$ & NA & 1 & 11.2 & 51.8 & Syn & 4 & 55 & 40 & 95 \\
\hline $\mathrm{I}-17$ & $6(6)$ & NA & NA & 1 & 8 & 42.4 & Syn & 3 & 50 & 40 & 90 \\
\hline I-18 & $6(6)$ & NA & NA & 1 & 11.5 & 43.6 & Syn & 4 & 55 & 40 & 95 \\
\hline I-19 & $6(6)$ & $2(6)$ & NA & 1 & 7.77 & 50 & Syn & 3 & 40 & 45 & 85 \\
\hline $\mathrm{I}-20$ & $6(6)$ & 2(6) & NA & 1 & 11.2 & 52.3 & Syn & 4 & 60 & 38 & 98 \\
\hline $\mathrm{I}-21$ & $6(6)$ & NA & NA & 1 & 6.87 & 80 & Syn & 2 & 20 & 20 & 40 \\
\hline $\mathrm{I}-22$ & $6(6)$ & NA & NA & 1 & 10.9 & 80 & Syn & 2 & 25 & 50 & 75 \\
\hline $\mathrm{I}-23$ & $6(6)$ & $2(6)$ & NA & 1 & 7.37 & 85 & Asyn & $1(40 \%)$ & N/A & N/A & 40 \\
\hline $\mathrm{I}-24$ & $6(6)$ & $2(6)$ & NA & 1 & 10.2 & 85 & Asyn/Syn & 3 & 40 & 45 & 85 \\
\hline $\mathrm{I}-25$ & $3(6)$ & $2(6)$ & $3(6)$ & 1 & 8.8 & 90 & Asyn & 2 & 25 & 35 & 60 \\
\hline $\mathrm{I}-26$ & $3(6)$ & $2(6)$ & $3(6)$ & 1 & 9.52 & 90 & Asyn/Syn & 3 & 35 & 45 & 80 \\
\hline $\mathrm{I}-27$ & $2(6)$ & $2(6)$ & $4(6)$ & 1.5 & 7.4 & 70 & Asyn/Syn & 4 & 80 & 20 & 100 \\
\hline $\mathrm{I}-28$ & $2(6)$ & $2(6)$ & $4(6)$ & 1.5 & 10.6 & 70 & Asyn/Syn & 4 & 90 & 10 & 100 \\
\hline $\mathrm{I}-29$ & $5(8)$ & NA & $1(8)$ & 1.5 & 8 & 70 & Asyn/Syn & 4 & 90 & 10 & 100 \\
\hline $\mathrm{I}-30$ & $5(8)$ & NA & $1(8)$ & 1.5 & 12.2 & 70 & Asyn/Syn & 4 & 95 & 5 & 100 \\
\hline $\mathrm{I}-31$ & $5(8)$ & NA & $1(8)$ & 1.5 & 8.63 & 70 & Syn & 4 & 50 & 50 & 100 \\
\hline $\mathrm{I}-32$ & $5(8)$ & NA & $1(8)$ & 1.5 & 12 & 70 & Syn & 4 & 60 & 40 & 100 \\
\hline I-33 & NA & $2(6)$ & $4(8)$ & 1.5 & 8.37 & 70 & Asyn/Syn & 4 & 95 & 5 & 100 \\
\hline $\mathrm{I}-34$ & NA & $2(6)$ & $4(8)$ & 1.5 & 12.2 & 70 & Asyn/Syn & 4 & 100 & N/A & 100 \\
\hline
\end{tabular}


During Tests I-23 to I-28, the procedure for operating the PJMs was changed from synchronous to asynchronous, to determine if better mixing could be obtained with asynchronous operation. Here, the PJMs were divided into 3 groups; each group being fired in sequence a third of the total cycle after the previous group, and so on. It was found that asynchronous firing made the mixing worse and that the PJMs needed to be fired simultaneously to get the maximum effect.

In Tests I-29 to I-32, the CRV III PJM or Chandelier configuration, Figure 2-7, was utilized. Essentially complete mixing was achieved, with $95 \%$ of the turbulent Type 4 mixing and 5\% of the less vigorous Type 3, at a nozzle velocity of $12 \mathrm{~m} / \mathrm{s}$ and $70 \mathrm{~Pa}$ yield stress. The last series of tests, Tests I-33 and I-34, were run with the CRV II or Spider PJM configuration, Figure 2-8. Here, the mixing was slightly better than the Chandelier, where the mixing was all Type 4.

The PJM configuration selected by Bechtel Engineering was the Chandelier arrangement. Although CRV III configuration had slightly better performance, it was deemed more difficult to construct and the spider nozzles would tend to break off. The final PJM configuration was a slight modification of the initial Chandelier arrangement where the charge vessels were repositioned to have better flow distribution

\subsubsection{Phase II - Final CRV Configuration Validation}

The objectives of the Phase II tests were to determine what hybrid mixing system or combinations of nozzle size, nozzle orientation (downwards, or combination of upwards and downwards facing nozzles), number of spargers and total air flow was required to fully mix the vessel, and then to perform a final solids mixing study of two final configurations.

\subsubsection{Cavern Height Measurement}

These tests addressed the requirement of determining the breakthrough nozzle velocity as specified in the Test Plan.

\subsection{Test Group A Results}

Test Group A runs were initial scoping tests performed with kaolin:bentonite simulant and with 1.5-inch $45^{\circ}$ downward nozzles installed. The UVP probe was operational at this time and cavern height measurements were obtained at nozzle velocities up to the maximum achievable with the maximum air manifold supply pressure of 94 psig. Here, the velocity criteria was $100 \mathrm{~mm} / \mathrm{sec}$ with the horizontal probe. The results are summarized in Table 2-2. A plot of the cavern height vs. nozzle velocity, given in Figure 2-20, shows a close to linear relationship between the cavern height and the nozzle velocity in the velocity range tested. 
WSRC-TR-2004-00398, REVISION 0

SRNL-RPP-2004-00060, REVISION 0

Table 2-2. Scoping Test (Test Group A) Results

\begin{tabular}{|c|c|c|c|c|c|c|c|c|c|c|}
\hline \multirow[b]{2}{*}{$\begin{array}{c}\text { Test } \\
\text { Group }\end{array}$} & \multirow[b]{2}{*}{$\begin{array}{c}\text { Test } \\
\text { Sequence }\end{array}$} & \multicolumn{3}{|c|}{ Nozzle Configuration } & \multirow{2}{*}{$\begin{array}{l}\text { Nozzle } \\
\text { I.D., } \\
\text { inches }\end{array}$} & \multirow{2}{*}{$\begin{array}{c}\text { Nozzle } \\
\text { Velo- } \\
\text { city } \\
\text { m/s } \\
\end{array}$} & \multirow{2}{*}{$\begin{array}{c}\# \\
\text { Spargers } \\
\text { @ scfm } \\
\text { tot. }\end{array}$} & \multirow{2}{*}{$\begin{array}{c}\text { Yield } \\
\text { Stress } \\
(\mathbf{P a})\end{array}$} & \multirow{2}{*}{$\begin{array}{c}\text { Cavern } \\
\text { Hgt., } \\
\text { in. }\end{array}$} & \multirow[b]{2}{*}{ Visual Results } \\
\hline & & $\begin{array}{l}\# 45 \\
\text { deg. }\end{array}$ & $\begin{array}{c}\text { \# } 135 \\
\text { deg. }\end{array}$ & $\begin{array}{c}\# \\
\text { Vertical }\end{array}$ & & & & & & \\
\hline A & $1 \mathrm{a}$ & 5 & NA & 1 & 1.5 & 9.1 & N/A & 21 & 25.5 & N/A \\
\hline A & $1 \mathrm{~b}$ & 5 & NA & 1 & 1.5 & 11.9 & $\mathrm{~N} / \mathrm{A}$ & 21 & 29.5 & $\mathrm{~N} / \mathrm{A}$ \\
\hline A & $1 \mathrm{c}$ & 5 & NA & 1 & 1.5 & 14.5 & $\mathrm{~N} / \mathrm{A}$ & 21 & 33 & $\mathrm{~N} / \mathrm{A}$ \\
\hline A & $1 \mathrm{~d}$ & 5 & NA & 1 & 1.5 & 16.3 & N/A & 21 & 36 & N/A \\
\hline $\mathrm{A}$ & $1 \mathrm{e}$ & 5 & NA & 1 & 1.5 & 17.9 & $\mathrm{~N} / \mathrm{A}$ & 21 & 40 & N/A \\
\hline A & 2 & 5 & NA & 1 & 1.5 & 8.86 & (5) 2.1 & 21 & N/A & $\begin{array}{l}\text { Outer ring had } \\
\text { better mixing } \\
\text { than inner ring }\end{array}$ \\
\hline A & 3 & 2 & 3 & 1 & 1.5 & 8.97 & (5) 5 & 17.8 & N/A & $\begin{array}{l}\text { Outer ring had } \\
\text { better mixing } \\
\text { than inner ring }\end{array}$ \\
\hline
\end{tabular}

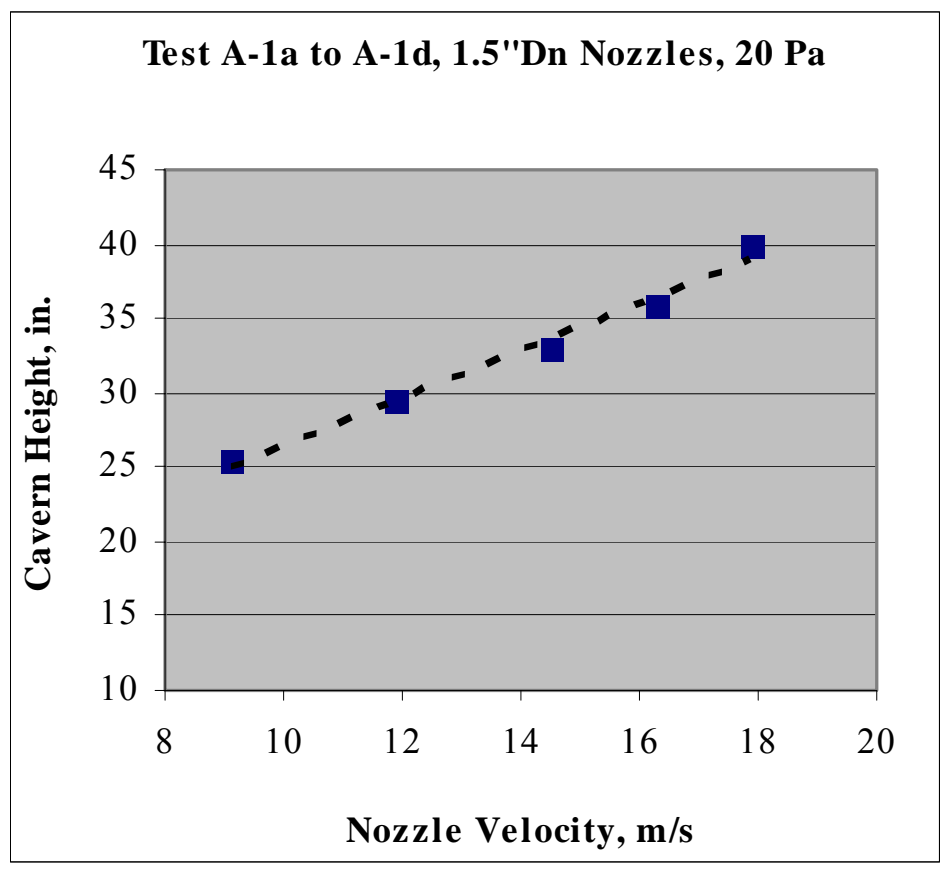

Figure 2-20. Plot of Cavern Height vs. Nozzle Velocity for Test Group A 
In Test A-2, two rings of spargers, one ring located adjacent to the PJMs and the other located at the present location of spargers in Figure 2-15 were installed. Air was injected into each ring separately at a total air flow of $2.2 \mathrm{scfm}$, while the PJMs were operating at $8 \mathrm{~m} / \mathrm{s}$. Good mixing was observed with the outer ring of spargers. In Test A-3, the nozzle arrangement was changed to a combination of (3) upward, (2) $45^{\circ}$ downward, and (1) centerdown nozzles. The test with the outer and inner rings of spargers was repeated with similar results as in the tests with downward nozzles. The sparger locations were then finalized as in Figure 2-15.

\subsection{Test Group C Results}

In these tests, the 1-inch Down Nozzles configuration was used with several Kaolin/bentonite solutions having yield stresses from $10 \mathrm{~Pa}$ to $30 \mathrm{~Pa}$. The objective was to provide a correlation of cavern height as a function of nozzle velocity and yield stress. The original intent was to utilize different tank levels (40", 30", 20", and 15") to observe the nozzle velocity at breakthrough to determine the cavern height. However, the UVP probe was utilized for this purpose and only the 40" and 30" tank levels were tested. For some conditions, the cavern was also detected by slowly lowering the tank level with the PJMs operating to determine the point of breakthrough. The results are summarized in Table 2-3.

The cavern height data in Table 2-3 can be correlated as a function of Yield Stress Reynolds number, $\mathrm{Re}_{\mathrm{Y}}$, as suggested by Art Etchells, PJM Team Consultant. His correlation is given in Equation 2-7.

\section{Equation 2-7}

$$
\frac{H}{T}=0.065 * \operatorname{Re}_{Y}^{0.25}
$$

The data plotted with predictions of the above correlation are shown in Figure 2-21. This also includes data obtained with other nozzles (See Test Group A results, Table 2-2, and Test Group D, Table 2-4). The data for the 1.25" and 1.5-inch nozzles are higher than for the 1-inch nozzles, indicating a dependence on nozzle size. This could be explained by the fact that cavern size would depend on energy considerations. A larger nozzle with the same velocity as a smaller one would of course deliver more energy for mobilizing the nonNewtonian simulant. The UVP probe method became more developed as testing progressed, i.e., flow mapping of more tank sectors was done later. Data for similar conditions but different dates may not agree closely. 
WSRC-TR-2004-00398, REVISION 0

SRNL-RPP-2004-00060, REVISION 0

Table 2-3. Cavern Heights for Chandelier PJM Configuration with 1-inch Downward Facing Nozzles (Test Group C Results)

\begin{tabular}{|c|c|c|c|c|c|c|c|c|c|c|}
\hline $\begin{array}{l}\text { Test } \\
\text { Group }\end{array}$ & $\begin{array}{c}\text { Test } \\
\text { Sequ- } \\
\text { ence }\end{array}$ & Test type & $\begin{array}{c}\text { Nozzle } \\
\text { Direction }\end{array}$ & $\begin{array}{c}\text { Nozzle } \\
\text { Diam. } \\
\text { in. }\end{array}$ & $\begin{array}{c}\text { Nozzle } \\
\text { Velocity, } \\
\text { fps }\end{array}$ & $\begin{array}{c}\# \\
\text { Spargers } \\
\text { @ scfm } \\
\text { tot. }\end{array}$ & $\begin{array}{c}\text { Yield } \\
\text { Stress } \\
\text { (Pa) }\end{array}$ & $\begin{array}{c}\text { UVP } \\
\text { Cavern } \\
\text { Height, } \\
\text { in. }\end{array}$ & $\begin{array}{c}\text { Cavern } \\
\text { Hgt. (in) } \\
\text { by level } \\
\text { lowering }\end{array}$ & $\begin{array}{c}\text { \%Tank } \\
\text { Volume } \\
\text { Mixed }\end{array}$ \\
\hline \multirow[t]{4}{*}{$\mathrm{C}$} & $1 \mathrm{a}$ & \multirow{2}{*}{$\begin{array}{l}\text { Mixing, } \\
40 " \text { Tank } \\
\text { Level }\end{array}$} & Down & 1 & 8.3 & N/A & 16.4 & 23 & & $55 \%$ \\
\hline & & & & & 12.53 & N/A & & 26 & & $62 \%$ \\
\hline & & & & & 8.3 & (5) 8.33 & & 26 & & $62 \%$ \\
\hline & & & & & 12.53 & (5) 7.49 & & 30 & & $73 \%$ \\
\hline \multirow[t]{4}{*}{$\mathrm{C}$} & $1 b$ & \multirow{2}{*}{$\begin{array}{l}\text { Mixing, } \\
30 " \text { Tank } \\
\text { Level }\end{array}$} & Down & 1 & 8.64 & N/A & 16.4 & 23 & & $55 \%$ \\
\hline & & & & & 12.46 & N/A & & 25 & & $60 \%$ \\
\hline & & & & & 8.64 & (5) 7.55 & & 26 & & $62 \%$ \\
\hline & & & & & 12.46 & (5) 7.55 & & 26 & & $62 \%$ \\
\hline \multirow[t]{4}{*}{$\mathrm{C}$} & $2 \mathrm{a}$ & \multirow{2}{*}{$\begin{array}{l}\text { Mixing, } \\
40 " \text { Tank } \\
\text { Level }\end{array}$} & Down & 1 & 8.65 & $\mathrm{~N} / \mathrm{A}$ & 35.4 & 18 & & $42 \%$ \\
\hline & & & & & 12.46 & N/A & & 23 & & $55 \%$ \\
\hline & & & & & 8.65 & (5) 7.55 & & 23 & & $55 \%$ \\
\hline & & & & & 12.46 & (5) 7.55 & & 37 & & $91 \%$ \\
\hline \multirow[t]{4}{*}{$\mathrm{C}$} & $2 b$ & \multirow{2}{*}{$\begin{array}{l}\text { Mixing, } \\
30 " \text { Tank } \\
\text { Level }\end{array}$} & Down & 1 & 9.01 & N/A & 35.4 & 18.5 & & $43 \%$ \\
\hline & & & & & 12.7 & N/A & & 19 & & $44 \%$ \\
\hline & & & & & 9.01 & (5) 7.68 & & 19.5 & & $45 \%$ \\
\hline & & & & & 12.7 & (5) 7.68 & & 23.5 & & $56 \%$ \\
\hline \multirow[t]{3}{*}{$\mathrm{C}$} & $3 a$ & \multirow{2}{*}{$\begin{array}{l}\text { Mixing, } \\
40 " \text { Tank } \\
\text { Level }\end{array}$} & Down & 1 & 8.18 & N/A & 28 & 19 & 24 & $44 \%$ \\
\hline & & & & & 11.49 & N/A & & 25 & 25 & $60 \%$ \\
\hline & & & & & 8.19 & (5) 7.52 & & 18 & & $42 \%$ \\
\hline \multirow[t]{2}{*}{$\mathrm{C}$} & $3 b$ & \multirow{2}{*}{$\begin{array}{l}\text { Mixing, } \\
\text { 30" Tank } \\
\text { Level }\end{array}$} & Down & 1 & 7.95 & N/A & 28 & 18 & & $42 \%$ \\
\hline & & & & & 12.93 & N/A & & 27 & & $65 \%$ \\
\hline \multirow[t]{3}{*}{ C } & $4 a$ & \multirow{2}{*}{$\begin{array}{l}\text { Mixing, } \\
40 " \text { Tank } \\
\text { Level }\end{array}$} & Down & 1 & 8.49 & N/A & 11.5 & 23.5 & 24 & $56 \%$ \\
\hline & & & & & 12.32 & N/A & & 28.5 & 30 & $69 \%$ \\
\hline & & & & & 12.32 & (5) 7.58 & & 28 & & $68 \%$ \\
\hline \multirow[t]{2}{*}{$\mathrm{C}$} & $4 \mathrm{~b}$ & \multirow{2}{*}{$\begin{array}{l}\text { Mixing, } \\
30 " \text { Tank } \\
\text { level }\end{array}$} & Down & 1 & 8.44 & N/A & 11.5 & 24 & & $57 \%$ \\
\hline & & & & & 13.2 & N/A & & 30 & & $73 \%$ \\
\hline
\end{tabular}




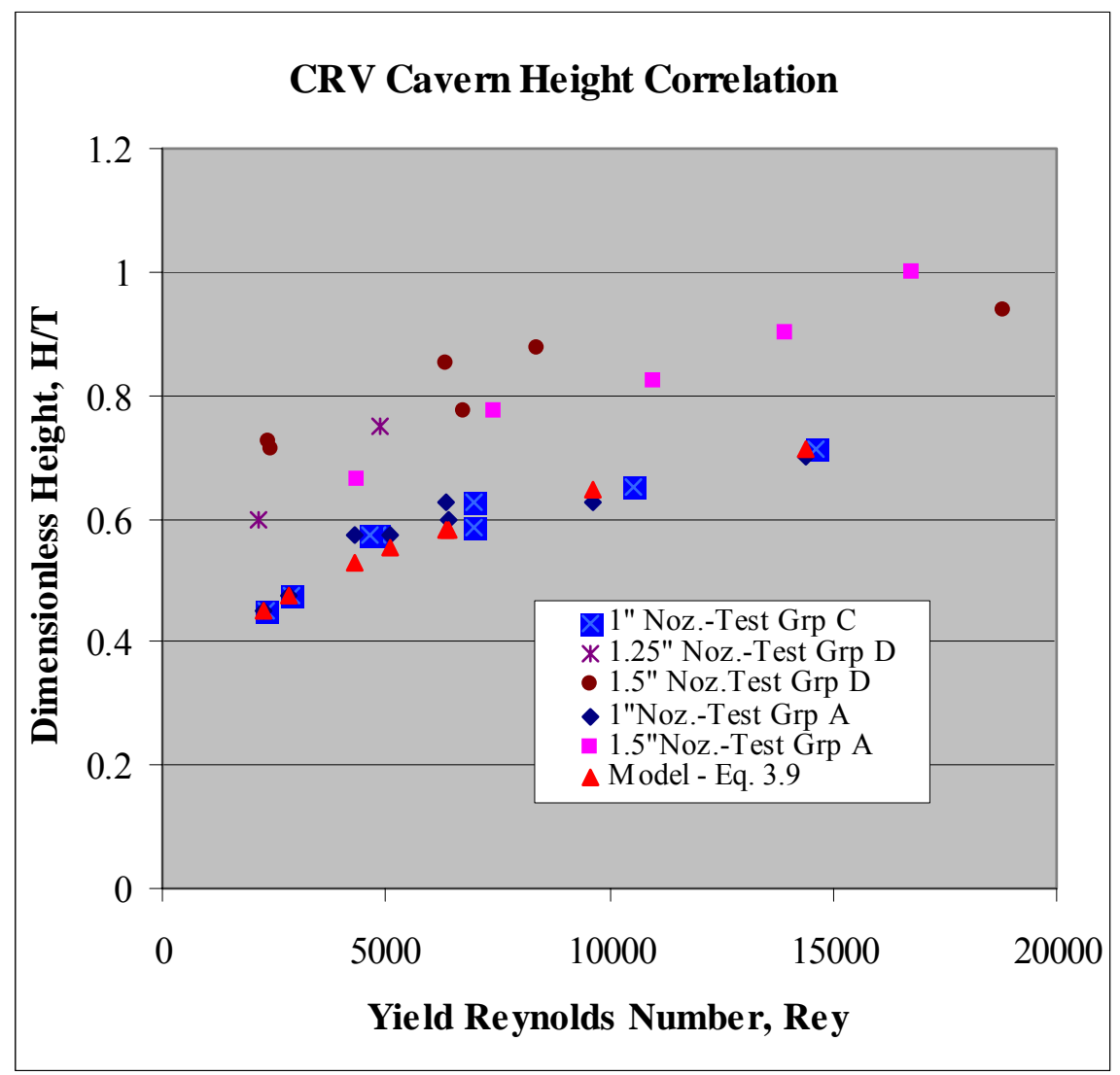

Figure 2-21. Cavern Height vs. Yield Reynolds Number for CRV Tank, Downward Nozzles Configuration

\subsubsection{Tank Mixed Volume Measurement}

\subsection{Test Group D Results}

The objective of Test Group D was to determine the percent mixed volume of the CRV tank under various nozzle sizes, directions, and number of spargers and total air flow conditions. Table 2-4 summarizes the results. The dye and UVP probe methods were used to determine the cavern height. Detailed sample absorbance plots and corresponding predictions by the Dye method are included in Appendix C. Detailed UVP velocity measurements are given in Appendix D.

In Table 2-4, the percent mixed volume could not be calculated by the Dye method in some instances because the sample absorbance was lower than the final, homogenized value. This suggests that the 45 minutes of mixing allotted for each mixing condition was insufficient to fully distribute the dye inside the cavern. Also, UVP measurements indicate a region of low flow around the sampling vessels near the bottom of the tank. 
WSRC-TR-2004-00398, REVISION 0

SRNL-RPP-2004-00060, REVISION 0

Table 2-4. Percent Tank Volume Mixed as Measured by UVP Probe and Dye Methods (Test Group D Results)

\begin{tabular}{|c|c|c|c|c|c|c|c|c|c|c|}
\hline $\begin{array}{c}\text { Test } \\
\text { Group } \\
\end{array}$ & \begin{tabular}{|c} 
Test Seq \\
uence
\end{tabular} & $\begin{array}{c}\text { Nozzle } \\
\text { Confi- } \\
\text { guration } \\
\end{array}$ & \begin{tabular}{|c|} 
Nozzle \\
Diam., in.
\end{tabular} & \begin{tabular}{|c|} 
Meas. \\
Nozzle \\
Velo-city \\
$\mathrm{m} / \mathrm{s}$ \\
\end{tabular} & $\begin{array}{c}\text { (\#) Spargers } \\
\text { @ scfm tot. }\end{array}$ & $\begin{array}{c}\text { Meas. } \\
\text { Yield } \\
\text { Stress } \\
(\mathrm{Pa}) \\
\end{array}$ & \begin{tabular}{|c} 
Cavern \\
Hgt. (UVP) \\
in. Dn/Up \\
Nozzle \\
\end{tabular} & \begin{tabular}{|c|} 
Cavern \\
Hgt., tank \\
level lower- \\
ing (in.) \\
\end{tabular} & $\begin{array}{c}\text { \% Tank } \\
\text { Volume } \\
\text { mixed, } \\
\text { UVP } \\
\end{array}$ & $\begin{array}{c}\text { \% Tank } \\
\text { Volume } \\
\text { mixed, } \\
\text { Dye } \\
\end{array}$ \\
\hline $\mathrm{D}$ & $1 \mathrm{a}$ & Down & 1 & 8.49 & N/A & 11.4 & 21.8 & 23.5 & $51 \%$ & $0 \%$ \\
\hline $\mathrm{D}$ & $1 \mathrm{~b}$ & Down & 1 & 12.32 & $\mathrm{~N} / \mathrm{A}$ & 11.4 & 26 & 24.2 & $62 \%$ & $67 \%$ \\
\hline $\mathrm{D}$ & $1 \mathrm{c}$ & Down & 1 & 12.32 & (2) 3.87 & 11.4 & 26 & & $77 \%$ & $67 \%$ \\
\hline $\mathrm{D}$ & $1 \mathrm{~d}$ & Down & 1 & 12.32 & (5) 7.6 & 11.4 & 26 & & $100 \%$ & $76 \%$ \\
\hline $\mathrm{D}$ & $2 \mathrm{a}$ & Down & 1 & 8.45 & N/A & 27.4 & 24.5 & 25 & $58 \%$ & $73 \%$ \\
\hline $\mathrm{D}$ & $2 \mathrm{~b}$ & Down & 1 & 13.2 & N/A & 27.4 & 29 & & $70 \%$ & $78 \%$ \\
\hline $\mathrm{D}$ & $2 \mathrm{c}$ & Down & 1 & 13.2 & (2) 3.8 & 27.4 & 29 & & $82 \%$ & $88 \%$ \\
\hline $\mathrm{D}$ & $2 \mathrm{~d}$ & Down & 1 & 13.2 & (5) 7.72 & 27.4 & 29 & & $100 \%$ & $91 \%$ \\
\hline $\mathrm{D}$ & $3 \mathrm{a}$ & Down & 1.5 & 8.82 & N/A & 10.2 & 35 & 35 & $90 \%$ & $*$ \\
\hline $\mathrm{D}$ & $3 b$ & Down & 1.5 & 13.2 & N/A & 10.2 & 37.5 & & $92 \%$ & * \\
\hline $\mathrm{D}$ & $3 \mathrm{c}$ & Down & 1.5 & 13.2 & (2) 3.88 & 10.2 & 40 & & $99 \%$ & $78 \%$ \\
\hline $\mathrm{D}$ & $3 \mathrm{~d}$ & Down & 1.5 & 13.2 & (5) 7.67 & 10.2 & 40 & & $100 \%$ & $86 \%$ \\
\hline $\mathrm{D}$ & $4 \mathrm{a}$ & Down & 1.5 & 8.54 & N/A & 32.6 & 28.5 & 32 & $69 \%$ & $*$ \\
\hline $\mathrm{D}$ & $4 \mathrm{~b}$ & Down & 1.5 & 13.7 & N/A & 32.6 & 34 & 36.5 & $91 \%$ & $98 \%$ \\
\hline $\mathrm{D}$ & $4 \mathrm{c}$ & Down & 1.5 & 13.7 & (2) 3.8 & 32.6 & 40 & & $99 \%$ & $100 \%$ \\
\hline $\mathrm{D}$ & $4 d$ & Down & 1.5 & 13.7 & (5) 7.6 & 32.6 & 40 & & $100 \%$ & $100 \%$ \\
\hline $\mathrm{D}$ & $5 \mathrm{a}$ & Down & 1.5 & 8.2 & $\mathrm{~N} / \mathrm{A}$ & 31.2 & 29 & 29 & $73 \%$ & $95 \%$ \\
\hline $\mathrm{D}$ & $5 b$ & Down & 1.5 & 13.77 & $\mathrm{~N} / \mathrm{A}$ & 31.2 & 31 & 34.5 & $83 \%$ & $94 \%$ \\
\hline $\mathrm{D}$ & $5 \mathrm{c}$ & Down & 1.5 & 13.77 & (2) 3.8 & 31.2 & 34 & & $90 \%$ & $93 \%$ \\
\hline $\mathrm{D}$ & $5 \mathrm{~d}$ & Down & 1.5 & 13.77 & (5) 7.6 & 31.2 & 34 & & $100 \%$ & $96 \%$ \\
\hline $\mathrm{D}$ & $6 a$ & Up/Down & 1 & 8.9 & $\mathrm{~N} / \mathrm{A}$ & 28.2 & $21 / 33$ & 22 & $68 \%$ & $\wedge 87 \%$ \\
\hline $\mathrm{D}$ & $6 \mathrm{~b}$ & Up/Down & 1 & 12 & N/A & 28.2 & $31 / 40$ & 33 & $90 \%$ & $\wedge 90 \%$ \\
\hline $\mathrm{D}$ & $6 \mathrm{c}$ & Up/Down & 1 & 12 & (2) 3.82 & 28.2 & $31 / 40$ & & $94 \%$ & $\wedge 90 \%$ \\
\hline $\mathrm{D}$ & $6 \mathrm{~d}$ & Up/Down & 1 & 12 & (5) 9.5 & 28.2 & $31 / 40$ & & $100 \%$ & $\wedge 90 \%$ \\
\hline $\mathrm{D}$ & $7 \mathrm{a}$ & Down & 1.25 & 7.5 & N/A & 32.4 & 30 & 30 & $73 \%$ & N/A \\
\hline $\mathrm{D}$ & $7 \mathrm{~b}$ & Down & 1.25 & 7.5 & (2) 3.8 & 32.4 & 34 & 33.5 & $83 \%$ & $99 \%$ \\
\hline $\mathrm{D}$ & $7 \mathrm{c}$ & Down & 1.25 & 7.5 & (3) 5.6 & 32.4 & 34 & & $90 \%$ & $98 \%$ \\
\hline $\mathrm{D}$ & $7 \mathrm{~d}$ & Down & 1.25 & 7.5 & (5) 9.5 & 32.4 & 34 & & $100 \%$ & $100 \%$ \\
\hline
\end{tabular}


In the UVP method, velocity measurements were made in two typical locations: a) in the annular flow area between PJM and tank wall opposite a downward facing nozzle; and b) annular flow area opposite an upwards facing nozzle. The cavern heights and mixed volumes for these regions are then used to determine the total percent tank volume mixed. In some runs, the cavern height is checked by lowering the tank level with the PJMs operating. This method confirms the UVP cavern height values. Overall, the dye method tends to give higher mixed volumes than the UVP probe since the dye can be mixed at lower velocities than the UVP velocity criterion of $80 \mathrm{~mm} / \mathrm{sec}$. Also, the dye was not confined to the cavern, but tended to find a path along the wall to the top surface layers.

Complete mixing is indicated in Table 2-4 by both the Dye and UVP methods for Test D-4d (1.5" Down Nozzles, $12 \mathrm{~m} / \mathrm{s}, 5$ spargers at $8 \mathrm{scfm}$ total air flow, $24 \mathrm{~Pa}$ ) and Test D-7d (1.25" Up/Down Nozzles, $8 \mathrm{~m} / \mathrm{s}, 5$ spargers at $10 \mathrm{scfm}$ total, $30 \mathrm{~Pa}$ ). The UVP method also indicates 100\% mixing for Tests D-1d, D-5d, and D-6d, although the Dye method shows less than $100 \%$ mixing. The UVP is considered a conservative method due to the high minimum velocity criteria; however, there may be low velocity pockets adjacent to the sampling vessels that were not measured. The Dye method, on the other hand, requires high skill to obtain accurate data. Also, mixing must be sustained for a sufficient period to insure uniform distribution of the tracer.

During Test D-5, additional tests were performed with the UVP, where air was sparged through 2 spargers (Spargers 1 and 5) at $4 \mathrm{scfm}$ and $10 \mathrm{scfm}$, respectively for two nozzle velocities [Figure 2-22 (a) and (b)], and also through all 5 spargers at $10 \mathrm{scfm}$ and $16 \mathrm{scfm}$ [See Figure 2-22 (b)]. The data plotted in Figure 2-22 (a) and (b) are the amplitudes of oscillations of the velocity due to the rising of the air bubbles. Due to the regular oscillations, the criterion for good mixing is arbitrarily set at $60 \mathrm{~mm} / \mathrm{sec}$.

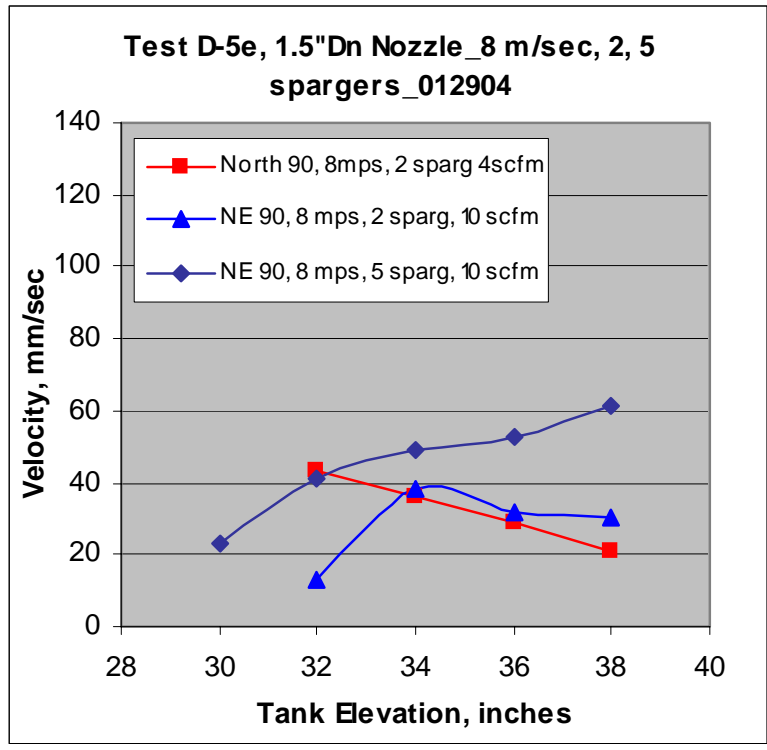

(a) $8 \mathrm{~m} / \mathrm{s}$ Nozzle Velocity

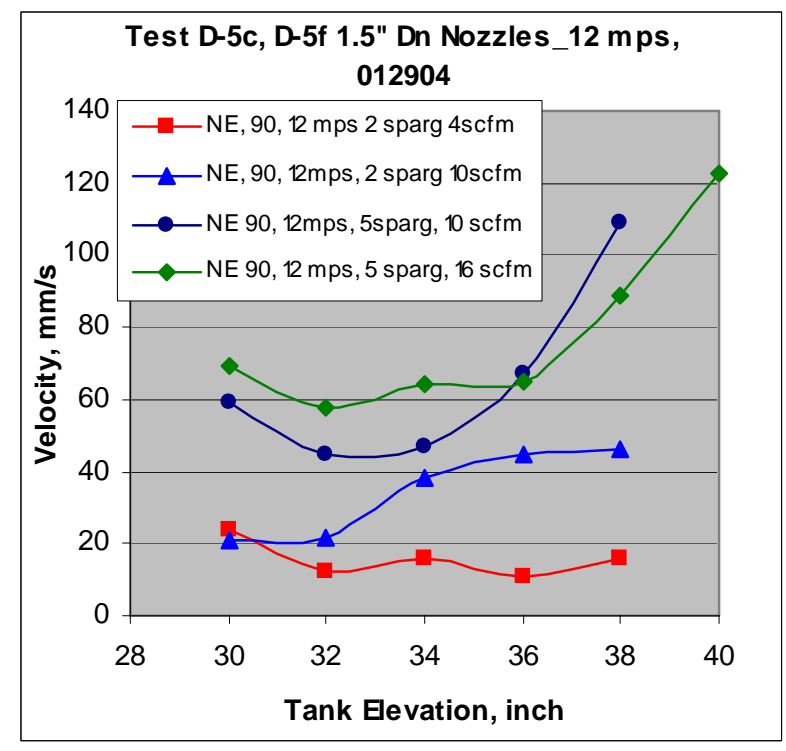

(b) $12 \mathrm{~m} / \mathrm{s}$ Nozzle Velocity

Figure 2-22. Amplitude of Velocity Oscillations for Various Conditions of Air Sparging During Test D-5 
WSRC-TR-2004-00398, REVISION 0

SRNL-RPP-2004-00060, REVISION 0

\subsubsection{Verifications of Final CRV Configurations}

\subsection{Test Group E Results}

In Test Group E, 1-inch nozzles were used in the Down and Up/Down Nozzle Configurations. Sparging with two, three, and five spargers at $2 \mathrm{scfm}$ each was also conducted. Percentage of Tank Volume Mixed was measured with the Dye and UVP methods. Table 2-5 summarizes the results. Test Sequence E-1e, E-3e, and E-7A show complete or close to $100 \%$ mixing.

Table 2-5. Percent Tank Volume Mixed for Final CRV Configurations (Test Group E Results)

\begin{tabular}{|c|c|c|c|c|c|c|c|c|c|}
\hline $\begin{array}{c}\text { Test } \\
\text { Group }\end{array}$ & \begin{tabular}{|c|} 
Test Seq- \\
uence
\end{tabular} & $\begin{array}{c}\text { Nozzle } \\
\text { Confi- } \\
\text { guration }\end{array}$ & $\begin{array}{c}\text { Nozzle } \\
\text { Diam., } \\
\text { in. }\end{array}$ & \begin{tabular}{|c|} 
Measured \\
Nozzle \\
Velocity \\
ft/s \\
\end{tabular} & $\begin{array}{c}\text { (\#) } \\
\text { Spargers } \\
\text { @ scfm } \\
\text { tot. }\end{array}$ & \begin{tabular}{|c|} 
Measured \\
Yield \\
Stress \\
(Pa) \\
\end{tabular} & $\begin{array}{c}\text { Cavern Hgt. } \\
\text { (UVP) in. } \\
\text { Dn/Up } \\
\text { Nozzle } \\
\end{array}$ & $\begin{array}{c}\text { \% Tank } \\
\text { Volume } \\
\text { Mixed, } \\
\text { UVP } \\
\end{array}$ & $\begin{array}{c}\text { \% Tank } \\
\text { Volume } \\
\text { Mixed, } \\
\text { Dye } \\
\end{array}$ \\
\hline E & 1 & Down & 1 & 8.17 & (2) 3.77 & 30.2 & 21 & 73 & $\wedge 98$ \\
\hline E & $1 \mathrm{a}$ & Down & 1 & 8.72 & (3) 5.64 & 30.2 & 21 & 80 & $\wedge$ ^98 \\
\hline E & $1 b$ & Down & 1 & 8.63 & (5) 9.56 & 30.2 & 40 & 95 & 100 \\
\hline $\mathrm{E}$ & $1 \mathrm{c}$ & Down & 1 & 12.7 & (2) 3.88 & 30 & 28 & 78 & 90 \\
\hline $\mathrm{E}$ & $1 d$ & Down & 1 & 11.84 & (3) 5.78 & 30 & 28 & 88 & 90 \\
\hline $\mathrm{E}$ & $1 \mathrm{e}$ & Down & 1 & 12.76 & (5) 9.56 & 30 & 40 & 98 & 100 \\
\hline $\mathrm{E}$ & 3 & Up/Down & 1 & 7.68 & (2) 3.89 & 32.9 & $20 / 31$ & 79 & $*$ \\
\hline E & $3 a$ & Up/Down & 1 & 8.3 & (3) 5.78 & 32.9 & $20 / 31$ & 83 & $*$ \\
\hline E & $3 b$ & Up/Down & 1 & 8.35 & (5) 9.47 & 32.9 & $40 / 40$ & 99 & $*$ \\
\hline $\mathrm{E}$ & $3 c$ & Up/Down & 1 & 12.01 & (2) 4.34 & 32.8 & $29 / 35.5$ & 89 & 94 \\
\hline E & $3 d$ & Up/Down & 1 & 11.6 & (3) 5.72 & 32.8 & $29 / 40$ & 91 & 99 \\
\hline E & $3 e$ & Up/Down & 1 & 11.4 & (5) 9.56 & 32.8 & $40 / 40$ & $100 \%$ & $*$ \\
\hline E & $6 \mathrm{~A}$ & Down & 1 & 12.35 & (5) 14.2 & 28.9 & $\mathrm{~N} / \mathrm{A}$ & $\mathrm{N} / \mathrm{A}$ & $83 \%$ \\
\hline E & $6 \mathrm{~B}$ & Down & 1 & 12.18 & (5) 15 & 6.1 & N/A & N/A & $89 \%$ \\
\hline $\mathrm{E}$ & $7 \mathrm{~A}$ & Up/Down & 1.5 & 12.27 & N/A & 27.7 & $40 / 40$ & $100 \%$ & $100 \%$ \\
\hline $\mathrm{E}$ & $7 \mathrm{~B}$ & Up/Down & 1.5 & 12.26 & N/A & 9.58 & $40 / 40$ & $100 \%$ & $100 \%$ \\
\hline$E$ & $7 \mathrm{C}$ & Up/Down & 1.5 & 13.07 & N/A & 9.58 & N/A & $\mathrm{N} / \mathrm{A}$ & N/A \\
\hline E & $7 \mathrm{D}$ & Up/Down & 1.5 & 11.9 & N/A & 34.1 & $\mathrm{~N} / \mathrm{A}$ & $\mathrm{N} / \mathrm{A}$ & N/A \\
\hline
\end{tabular}




\subsubsection{Solids Mixing Assessment Tests}

In order for the solids to be mixed adequately in the CRV vessel, the mixers must (1) have the ability to lift the heaviest (weight) particles off the bottom of the vessel and suspend it in the fluid phase, and (2) circulate the suspended solids sufficiently to obtain acceptable distribution of solids over the entire volume of the vessel. An acceptable distribution of solids is considered particularly critical to the function of the CRV tank. Given these demands on solids mixing, the following tests were carried out in the CRV prototypic vessel.

\subsection{Off-Bottom Mixing Tests}

The objective of this test was to determine, for the chosen PJM configuration, the jet velocity required to lift the heaviest particle off the bottom of the vessel and suspend it into the fluid phase. The tests used $5 \mathrm{~mm}$ diameter glass beads $(\rho=2.20-2.50 \mathrm{~g} / \mathrm{ml})$ as the test beads, based on an experimental correlation and recommendation by Art Etchells. Sufficient volume of beads in the vessel was used to cover the entire area of the dished head bottom with at least 1 layer of beads. Water was used in the test to allow visual examination of the bead behavior at the bottom.

During the solids lift tests, visual observations were made to assess whether at any moment during the drive phase all the solid glass beads were lifted off the floor. The ability of the PJMs to lift the beads is indicated by Yes or No in the last column of Table 2-6. The nozzle velocities are nominal values.

Table 2-6. Test Conditions and Results of Solids Lift Tests Performed in CRV Prototypic Test Stand

\begin{tabular}{|c|c|c|c|c|c|}
\hline $\begin{array}{c}\text { Test } \\
\text { Group }\end{array}$ & $\begin{array}{c}\text { Test } \\
\text { Sequence }\end{array}$ & Test Mode & $\begin{array}{c}\text { Noz. Vel. } \\
(\mathbf{m} / \mathbf{s})\end{array}$ & $\begin{array}{c}\text { Cycle } \\
\text { Time (sec) }\end{array}$ & $\begin{array}{c}\text { Solids Lift } \\
\text { (Yes/No) }\end{array}$ \\
\hline E & 5 & PJMs only & 6.2 & 20 & Yes \\
\hline E & 5 & PJMs only & 4.9 & 20 & Yes \\
\hline E & 5 & PJMs only & 4.1 & 20 & Yes \\
\hline E & 5 & PJMs only & 3.6 & 20 & No \\
\hline E & 5 & PJMs only & 4.5 & 20 & Yes \\
\hline E & 7 & PJMs only & 3.1 & 20 & No \\
\hline E & 7 & PJMs only & 3.8 & 20 & No \\
\hline$E$ & 7 & PJMs only & 3.4 & 20 & No \\
\hline$E$ & 7 & PJMs only & 3.9 & 20 & No \\
\hline$E$ & 7 & PJMs only & 4.86 & 20 & Yes \\
\hline
\end{tabular}


The data for the bead lift tests for Test Sequence E-7 (PJM configuration: (5) $45^{\circ}$ and (1) center downward 1" nozzles) indicates that the minimum velocity needed to lift the beads from the floor was between 3.6 and $4.1 \mathrm{~m} / \mathrm{s}$. This value is below the minimum jet velocity of $8 \mathrm{~m} / \mathrm{s}$ being considered for the PJMs. For Test Sequence E-7 (PJM configuration: (2) 45', (3) $135^{\circ}$, and (1) center downward $1.5^{\prime \prime}$ nozzles), the minimum lift off velocity is $4.86 \mathrm{~m} / \mathrm{s}$.

The above data only refers to whether solids are lifted off the tank bottom. How well they are distributed vertically and radially in the tanks depends on different factors with different functionalities. In the WTP Project, this has been studied with computational fluid dynamics (CFD) and has shown with slow settling particles that the solids are fairly well distributed. However CFD cannot currently determine whether the solids are lifted off the bottom; this requires the experimental verification discussed above.

\subsection{Solids Mixing Tests}

Solids mixing tests were conducted in the CRV prototype to determine the uniformity of solids distribution in the vessel and thus verify the adequacy of mixing in the CRV to meet the plant specification for solids uniformity. During operation of the plant, the HLW in the CRV is expected to be transferred to the MFPV in 2 equal batches of 4500 gallons each, represented by the upper and lower halves of the vessel and excluding the material in the heel of the vessel. Accordingly, the current acceptability criterion to confidently produce compliant glass is that the CRV must be mixed and sampled so that there is no difference between the means for the upper and lower halves of the CRV vessel within a specified confidence interval, given the sampled data.

\subsection{Plant CRV Operation}

In the WTP plant, the CRV vessel has a capacity of 11,585 gals. The vessel contents are mixed for 1.5 hours to obtain solids uniformity in the slurry. Eight to ten samples are then withdrawn from the heel of the tank through the RFD sampler system. These samples are then used to estimate the tank sample mean chemical concentration.

The contents of the CRV is then transferred in 2 equal batch transfers of 4500 gals each to the Melter Feed Preparation Vessel (MFPV) for the addition of glass former chemicals (GFC). The estimated tank sample mean concentration is used to determine the GFC requirements for both of the two batch transfers. Given this mode of operation, an additional criterion for verification is defined as the estimated tank sample mean concentration at a single location (RFD sampler in the heel of the tank) is an acceptable estimate of the batch sample mean concentration for the entire tank.

\subsection{Solids Mixing Test Results}

Table 2-7 presents the results for the solids mixing test utilizing 1-inch diameter nozzles in the Downward Nozzle Configuration for $30 \mathrm{~Pa}$ and $6 \mathrm{~Pa}$ simulant yield stresses. 
WSRC-TR-2004-00398, REVISION 0

SRNL-RPP-2004-00060, REVISION 0

Table 2-7. Solids Mixing Test Results for 1-inch Downward Nozzle Configuration with Spargers

\begin{tabular}{|c|c|c|c|c|c|c|c|c|}
\hline $\begin{array}{l}\text { Test } \\
\text { Group }\end{array}$ & $\begin{array}{l}\text { Test } \\
\text { sequ- } \\
\text { ence }\end{array}$ & $\begin{array}{l}\text { Nozzle } \\
\text { Diam. } \\
\text { (inch) }\end{array}$ & $\begin{array}{l}\text { Nozzle } \\
\text { Config- } \\
\text { uration }\end{array}$ & $\begin{array}{c}\text { Yield } \\
\text { stress } \\
(\mathbf{P a})\end{array}$ & $\begin{array}{c}\text { \#Spargers } \\
\text { at air } \\
\text { flow }\end{array}$ & $\begin{array}{c}\text { Sample } \\
\text { Description }\end{array}$ & $\begin{array}{c}\text { Glass bead } \\
\text { wt \% } \\
\text { (biases } \\
\text { incl.) }\end{array}$ & $\begin{array}{l}\text { Standard } \\
\text { deviation }\end{array}$ \\
\hline \multirow[t]{3}{*}{$\mathrm{E}$} & $6 \mathrm{~A}$ & 1 & Down & 30 & $\begin{array}{c}5 \text { spargers } \\
@ 3 \mathrm{scfm} \\
\text { ea } \\
\end{array}$ & $\begin{array}{c}\text { Upper tank grab } \\
\text { samples }\end{array}$ & $0.6740 \%$ & $0.0114 \%$ \\
\hline & & & & & & $\begin{array}{c}\text { Lower tank grab } \\
\text { samples }\end{array}$ & $0.6733 \%$ & $0.0052 \%$ \\
\hline & & & & & & $\begin{array}{l}\text { Heel (Charge } \\
\text { vessel) pump } \\
\text { samples }\end{array}$ & $0.6440 \%$ & $0.0116 \%$ \\
\hline \multirow[t]{3}{*}{$\mathrm{E}$} & $6 \mathrm{~B}$ & 1 & Down & 6 & $\begin{array}{c}5 \text { spargers } \\
\text { @3 } 3 \mathrm{scfm} \\
\text { ea }\end{array}$ & $\begin{array}{c}\text { Upper tank grab } \\
\text { samples }\end{array}$ & $0.6566 \%$ & $0.0095 \%$ \\
\hline & & & & & & $\begin{array}{c}\text { Lower tank grab } \\
\text { samples }\end{array}$ & $0.6735 \%$ & $0.0103 \%$ \\
\hline & & & & & & $\begin{array}{l}\text { Heel (Charge } \\
\text { vessel) pump } \\
\text { samples }\end{array}$ & $0.6474 \%$ & $0.0374 \%$ \\
\hline
\end{tabular}

For this test, the PJMs were operated for 66 cycles then stopped. Ten grab samples were obtained from upper tank level, and 10 samples from lower tank level, then 10 heel pump samples. Also, the 8-inch PJMs were used to simulate the same drive volumes as 6-inch PJMs, such that the drive length was limited to 16-inches, rather than the full stroke of 27 inches. Consequently, there is a problem of determining an absolute mixing efficiency, or deviation from a true mean based on the mass of glass beads added to the tank and the simulant volume. This is because not all of the simulant in the PJM participate in the mixing outside the PJM. While there was a certain amount of mixing inside the PJM, this was also unknown. Further, there were potential losses of glass beads in nooks and crannies in the CRV PJM assembly. For this reason, comparison of the glass beads means from the different tank volumes with an absolute glass bead concentration would not be appropriate.

\subsection{Statistical Data Analysis}

Statistical tests were performed to compare data samples from the three different locations: (i) samples from the upper half of the tank, (ii) samples from the lower half of the tank, and (iii) samples from the heel of the tank collected at the RFD sampler location. The complete analyses for the $30 \mathrm{~Pa}$ and $6 \mathrm{~Pa}$ simulant tests can be found in Appendix E. Explanations on what these various tests mean are also given. 


\subsection{Pa Simulant Test}

For the $30 \mathrm{~Pa}$ test, the Analysis of Variance (ANOVA) test (which assumes variances are equal) and the Welch test (which assumes variances can differ) both conclude that the three different means are not equal. The Levine test determines that the variances are equal. The Tukey-Kramer test then concludes that the means from the upper and lower grabs are different from the mean of the heel pump samples. This means that using a pump sampler in the heel at the RFD location can result in a sample analysis that does not represent the upper and lower tank halves. This may be due to the method of sampling (pump vs. grab sampling) or that the location of the heel sampler is unrepresentative of the heel simulant.

\subsection{Pa Simulant Test}

For the solids mixing test using a $6 \mathrm{~Pa}$ simulant, the ANOVA results suggest an indication of a difference in the mean glass beads wt $\%$ across the three sampling locations at slightly above a 5\% significance level. However, Levene's test suggests that the variances of the data across the three locations are not the same, and Welch's test concludes that the means are different with at least $95 \%$ confidence. For the variances, it appears that the variance of the heel is greater than those of the low and high grab data. The Tukey-Kramer comparisons among the means show a significant difference between the low grab and heel. When the heel samples are excluded from the comparison, an ANOVA tests suggest that there is a statistically significant difference between the mean solids $\mathrm{wt} \%$ for the high and low grab locations.

\subsection{Solids Mixing Test for 1.5-inch Up/Down Nozzle Configuration with No Spargers}

Solids mixing tests were also performed for the option of 1.5-inch Up/Down Nozzle Configuration with no spargers. The test data are given in Table 2-8. In Test E-7A, the test was performed with 8-in PJMs with full drive length. The PJMs were operated for 66 cycles then stopped. Ten grab samples were obtained from the upper tank level, and 10 samples from the lower tank level, then 10 heel pump samples.

In Test E-7B, the PJMs were operated for 66 cycles with full drive length, then stopped. Grab samples were taken sequentially from upper, lower, heel, and then peristaltic pump locations, then upper, lower, and heel locations for the next group of samples, and so forth. Ten heel grab samples were obtained at random locations. Then the tank was fully homogenized by over-blowing PJMs for 30 minutes and from the final samples an experimental true mean was determined. The column "Deviation from experimental "true" mean," provides a clear picture of the variation of the different set of samples from an experimental uniform concentration. For Test E-7B, the sample uniformity was within $1.88 \%$ of the true mean. 
WSRC-TR-2004-00398, REVISION 0

SRNL-RPP-2004-00060, REVISION 0

Table 2-8. Solids Mixing Test Results for 1.5-inch Up/Down Nozzle Configuration with No Spargers (Upward Nozzles on PJMs 1, 2, and 4)

\begin{tabular}{|c|c|c|c|c|c|c|c|c|c|}
\hline $\begin{array}{c}\text { Test } \\
\text { Group }\end{array}$ & $\begin{array}{c}\text { Test } \\
\text { sequ- } \\
\text { ence } \\
\end{array}$ & $\begin{array}{l}\text { Nozzle } \\
\text { Diam. } \\
\text { (inch) }\end{array}$ & $\begin{array}{l}\text { Nozzle } \\
\text { Config- } \\
\text { uration } \\
\end{array}$ & $\begin{array}{c}\text { Yield } \\
\text { stress } \\
(\mathbf{P a}) \\
\end{array}$ & $\begin{array}{l}\text { \#Spargers } \\
\text { at air flow } \\
\end{array}$ & $\begin{array}{c}\text { Sample } \\
\text { Description }\end{array}$ & $\begin{array}{c}\text { Glass bead } \\
\text { wt\% (biases } \\
\text { incl.) } \\
\end{array}$ & $\begin{array}{l}\text { Standard } \\
\text { deviation }\end{array}$ & $\begin{array}{c}\text { Deviation } \\
\text { from exp. } \\
\text { "true" } \\
\text { mean }\end{array}$ \\
\hline \multirow[t]{6}{*}{$\mathrm{E}$} & $7 \mathrm{~A}$ & 1.5 & Up/Down & 30 & N/A & $\begin{array}{l}\text { Upper tank } \\
\text { grab samples }\end{array}$ & $0.5734 \%$ & $0.0060 \%$ & N/A \\
\hline & & & & & & $\begin{array}{l}\text { Lower tank } \\
\text { grab samples }\end{array}$ & $0.5751 \%$ & $0.0055 \%$ & N/A \\
\hline & & & & & & $\begin{array}{l}\text { Heel } 1 \\
\text { (Charge vessel) } \\
\text { grab samples }\end{array}$ & $0.8105 \%$ & $0.1530 \%$ & N/A \\
\hline & & & & & & $\begin{array}{l}\text { Heel } 1 \text { (Charge } \\
\text { vessel) pump } \\
\text { samples }\end{array}$ & $0.6694 \%$ & $0.1214 \%$ & N/A \\
\hline & & & & & & $\begin{array}{l}\text { Heel } 4 \text { (PJM4) } \\
\text { grab samples }\end{array}$ & $0.5872 \%$ & $0.0989 \%$ & N/A \\
\hline & & & & & & $\begin{array}{l}\text { Heel } 4 \text { (PJM4) } \\
\text { pump samples }\end{array}$ & $0.5605 \%$ & $0.0110 \%$ & N/A \\
\hline \multirow[t]{6}{*}{$\mathrm{E}$} & $7 \mathrm{~B}$ & 1.5 & Up/Down & 6 & N/A & $\begin{array}{l}\text { Upper tank } \\
\text { grab samples }\end{array}$ & $0.6070 \%$ & $0.0429 \%$ & $-1.60 \%$ \\
\hline & & & & & & $\begin{array}{l}\text { Lower tank } \\
\text { grab samples }\end{array}$ & $0.6196 \%$ & $0.0106 \%$ & $0.44 \%$ \\
\hline & & & & & & $\begin{array}{l}\text { Heel grab } \\
\text { samples }\end{array}$ & $0.6285 \%$ & $0.0036 \%$ & $1.88 \%$ \\
\hline & & & & & & $\begin{array}{l}\text { Heel } 1 \text { (Charge } \\
\text { vessel) pump } \\
\text { samples }\end{array}$ & $0.6270 \%$ & $0.0272 \%$ & $1.64 \%$ \\
\hline & & & & & & $\begin{array}{l}\text { Heel } 4 \text { (PJM4) } \\
\text { pump samples }\end{array}$ & $0.6240 \%$ & $0.0130 \%$ & $1.15 \%$ \\
\hline & & & & & & $\begin{array}{l}\text { Final } \\
\text { homogenized } \\
\text { tank grab } \\
\text { samples }\end{array}$ & $0.6169 \%$ & $0.0095 \%$ & $0 \%$ \\
\hline
\end{tabular}


WSRC-TR-2004-00398, REVISION 0

SRNL-RPP-2004-00060, REVISION 0

Table 2-9. Solids Mixing Test Results for 1.5 -inch Up/Down Nozzle Configuration with No Spargers (Upward Nozzles on PJMs 1, 3, and 4)

\begin{tabular}{|c|c|c|c|c|c|c|c|c|c|}
\hline $\begin{array}{c}\text { Test } \\
\text { Group }\end{array}$ & $\begin{array}{r}\text { Test } \\
\text { sequ- } \\
\text { ence }\end{array}$ & $\begin{array}{l}\text { Nozzle } \\
\text { Diam. } \\
\text { (inch) }\end{array}$ & $\begin{array}{l}\text { Nozzle } \\
\text { Config- } \\
\text { uration } \\
\end{array}$ & $\begin{array}{l}\text { Yield } \\
\text { stress } \\
(\mathrm{Pa})\end{array}$ & $\begin{array}{c}\text { \#Spargers } \\
\text { at air } \\
\text { flow } \\
\end{array}$ & $\begin{array}{c}\text { Sample } \\
\text { Description }\end{array}$ & $\begin{array}{c}\text { Glass bead } \\
\text { wt \% (biases } \\
\text { incl.) } \\
\end{array}$ & $\begin{array}{l}\text { Standard } \\
\text { deviation }\end{array}$ & $\begin{array}{c}\text { Deviation } \\
\text { from exp. } \\
\text { "true" } \\
\text { mean } \\
\end{array}$ \\
\hline \multirow[t]{6}{*}{ E } & $7 \mathrm{C}$ & 1.5 & Up/Down & 6 & N/A & $\begin{array}{l}\text { Upper tank grab } \\
\text { samples }\end{array}$ & $0.6149 \%$ & $0.0064 \%$ & $0.77 \%$ \\
\hline & & & & & & $\begin{array}{l}\text { Lower tank grab } \\
\text { samples }\end{array}$ & $0.6154 \%$ & $0.0051 \%$ & $0.85 \%$ \\
\hline & & & & & & $\begin{array}{l}\text { Heel grab } \\
\text { samples }\end{array}$ & $0.6139 \%$ & $0.0080 \%$ & $0.60 \%$ \\
\hline & & & & & & $\begin{array}{l}\text { Heel } 1 \text { (Charge } \\
\text { vessel) pump } \\
\text { samples }\end{array}$ & $0.6012 \%$ & $0.0253 \%$ & $-1.47 \%$ \\
\hline & & & & & & $\begin{array}{l}\text { Heel } 4 \text { (PJM4) } \\
\text { pump samples }\end{array}$ & $0.6182 \%$ & $0.0103 \%$ & $1.30 \%$ \\
\hline & & & & & & $\begin{array}{l}\text { Final } \\
\text { homogenized } \\
\text { tank grab samples }\end{array}$ & $0.6102 \%$ & $0.0061 \%$ & $0 \%$ \\
\hline \multirow[t]{6}{*}{ E } & $7 \mathrm{D}$ & 1.5 & Up/Down & 30 & N/A & $\begin{array}{l}\text { Upper tank grab } \\
\text { samples }\end{array}$ & $0.6388 \%$ & $0.0058 \%$ & $-2.80 \%$ \\
\hline & & & & & & $\begin{array}{l}\text { Lower tank grab } \\
\text { samples }\end{array}$ & $0.6369 \%$ & $0.0132 \%$ & $-3.09 \%$ \\
\hline & & & & & & $\begin{array}{l}\text { Heel grab } \\
\text { samples }\end{array}$ & $0.6431 \%$ & $0.0251 \%$ & $-2.15 \%$ \\
\hline & & & & & & $\begin{array}{l}\text { Heel } 1 \text { (Charge } \\
\text { vessel) pump } \\
\text { samples }\end{array}$ & $0.8629 \%$ & $0.0885 \%$ & $31.29 \%$ \\
\hline & & & & & & $\begin{array}{l}\text { Heel } 4 \text { (PJM4) } \\
\text { pump samples }\end{array}$ & $0.6259 \%$ & $0.0268 \%$ & $-4.77 \%$ \\
\hline & & & & & & $\begin{array}{l}\text { Final } \\
\text { homogenized } \\
\text { tank grab samples }\end{array}$ & $0.6572 \%$ & $0.0330 \%$ & $0 \%$ \\
\hline
\end{tabular}


In Tests E-7C and E-7D (Table 2-9), the upward ( $135^{\circ}$ nozzles) were installed on PJMs 1, 3, and 4 . The concern was that in the previous nozzle configuration, the upward nozzles were located on either side of the small charge vessels, thus were not clearing solids underneath the charge vessels. Putting a downward nozzle on PJM 2 would seem to improve this situation. For both Tests E-7C and E-7D, the PJMs were operated for 66 cycles with full drive length, then stopped. Grab samples were taken sequentially and randomly from upper, lower, heel, and then peristaltic pump locations, then upper, lower, and heel locations for next group of samples, and so forth. A single PJM cycle was run between grab samples. Ten heel grab samples were obtained at random locations. Then the tank was fully homogenized by over-blowing PJMs for 30 minutes. The experimental true mean then determined. For the $6 \mathrm{~Pa}$ Test $\mathrm{E}-7 \mathrm{C}$, the maximum deviation from the experimental true was $1.47 \%$. For the $30 \mathrm{~Pa}$ Test E-7D, a high standard deviation was measured for the heel pump samples and the deviation from the experimental true mean was $31.29 \%$. If this is discounted as experimental error, the maximum deviation for the $30 \mathrm{~Pa}$ test would still be $4.77 \%$.

\subsection{SELECTION AND DESCRIPTION OF FINAL CRV CONFIGURATION}

This section provides a comparison of test results of the final CRV configurations and a description of the final CRV configuration for the plant.

\subsubsection{Comparison of Test Results of Final CRV Configurations}

Two PJM configurations were selected for final verification (Test Exception 24590-WTPTEF-RT-04-0006). The first, Configuration A, consisted of (5) $45^{\circ}$ downward and (1) center downward 1-inch nozzles and 5 spargers with $3 \mathrm{scfm}$ each. The 8-inch PJMs operated with delivered volume simulating a 6-inch PJM. The second, Configuration B, consisted of (2) $45^{\circ}$ downward, (3) $135^{\circ}$ upward and (1) center downward 1.5-inch nozzles, and no spargers. The UVP probe and dye method both indicated $100 \%$ mixing for these two configurations. Configuration A was selected based on the fact that air requirements for the 1.5-inch nozzles and 8-inch PJMs translated to a new development effort for a larger Jet Pump Pair (JPP) than is currently available.

Solids mixing tests were then performed with Configuration A, which determined that the upper and lower regions of the vessel had no significant statistical difference in glass bead tracer concentrations, but that the heel (pump) samples had a small but significant statistical difference with the upper and lower regions. A comparison of the tracer concentrations in the three regions with respect to a true mean was not available. The technique could have been improved, with homogenization of the tank after PJM/sparger mixing to obtain an experimental true mean and grab samples taken from the heel and a retest done. However, there was no opportunity to do so. It was felt however that Configuration A was a viable design. 
Since the sparger air requirements for Configuration A were deemed excessive for the plant, Configuration B (PJM only) was tested for solids mixing also for final verification. The Offbottom velocity tests showed a higher required nozzle velocity to clear the glass beads from the vessel bottom than for Configuration A. This was due to the unsymmetrical flow distribution of the downward facing nozzles, since the outer nozzles and the center nozzle were essentially in- line. The upward facing nozzles were also not arranged symmetrically. The results of the solids mixing test at $30 \mathrm{~Pa}$ showed a maximum probable deviation (excluding experimental error) of $4.77 \%$ for the sampled means from an experimental true mean. It was felt that given more time and adjustments of the PJM arrangements that this deviation could be reduced.

\subsubsection{Description of Final Selected CRV Configuration}

The PJM cluster configuration concept, that is, one central pulse tube with the remaining pulse tubes clustered around the central tube, was chosen for the HCP vessels. This configuration was selected to minimize the impact on the current HLW plant design based upon consultation with Engineering. See CCN 086662.

The PJM cluster configuration provides a mixed turbulent cavern in the bottom of the vessel that suspends waste particles and is scalable. Supplemental mixing used to mix the upper portion of the vessels relies on spargers. Based upon this direction, this section describes the recommended configuration for consideration. The following full-scale configuration is consistent with those tested. Table 2-10 summarizes the characteristics of this final design.

Table 2-10. Concentrate Receipt Vessels (HCP-VSL-00001/2)

\begin{tabular}{|l|l|}
\hline $\begin{array}{l}\text { Normal } \\
\text { operation }\end{array}$ & $\begin{array}{l}\text { The HCP vessel under normal conditions requires operation of PJMs and } \\
\text { continuous sparging. Varieties of sparge tube layouts were considered for } \\
\text { use. The configuration presented in this document was chosen by WTP } \\
\text { Engineering to minimize impact with consideration to the total air } \\
\text { requirement and the total number of sparger lines. The layout of PJMs, } \\
\text { sparge lines, and charge vessels is shown in Figure 2-23 and Figure 2-24. } \\
\text { Hatched circles overlaid on a plan view in Figure 2-25 indicate the size of the } \\
\text { ZOI of each particular sparge tube at the flow rates specified in the adjacent } \\
\text { table. }\end{array}$ \\
\hline Post-DBE & $\begin{array}{l}\text { Under post-DBE conditions, operation of PJMs and continuous sparging is } \\
\text { required. The required air sparge flow rates are as given in the table in } \\
\text { Figure 2-25. }\end{array}$ \\
\hline PJM & $\begin{array}{l}\text { The central PJM has a downward-pointing 4-inch nozzle that is 1.5 nozzle } \\
\text { diameters (6 inches) off the bottom of the vessel. The outer five PJMs are } \\
\text { located on a pitch circle diameter (PCD) of 70 inches. All of their exit } \\
\text { nozzles are pointed outward toward the vessel sidewall at 45 degrees; the } \\
\text { nozzle openings are also } 4 \text { inches and are } 6 \text { inches off the bottom of the } \\
\text { vessel. Elevation views of the pulse tubes are shown in Figure 2-24 and } \\
\text { Figure 2-26 with the outer pulse tube nozzle detail shown in Figure 2-27. }\end{array}$ \\
\hline $\begin{array}{l}\text { Sparge } \\
\text { Line Details }\end{array}$ & $\begin{array}{l}\text { The lower sparge lines are all } 6 \text { inches off the bottom of the vessel. The } \\
\text { spargers above the pulse tubes and charge vessels are 2 inches above the top } \\
\text { of the respective vessels. Elevation views of the spargers are shown in } \\
\text { Figure 2-24 and Figure 2-26. }\end{array}$ \\
\hline
\end{tabular}




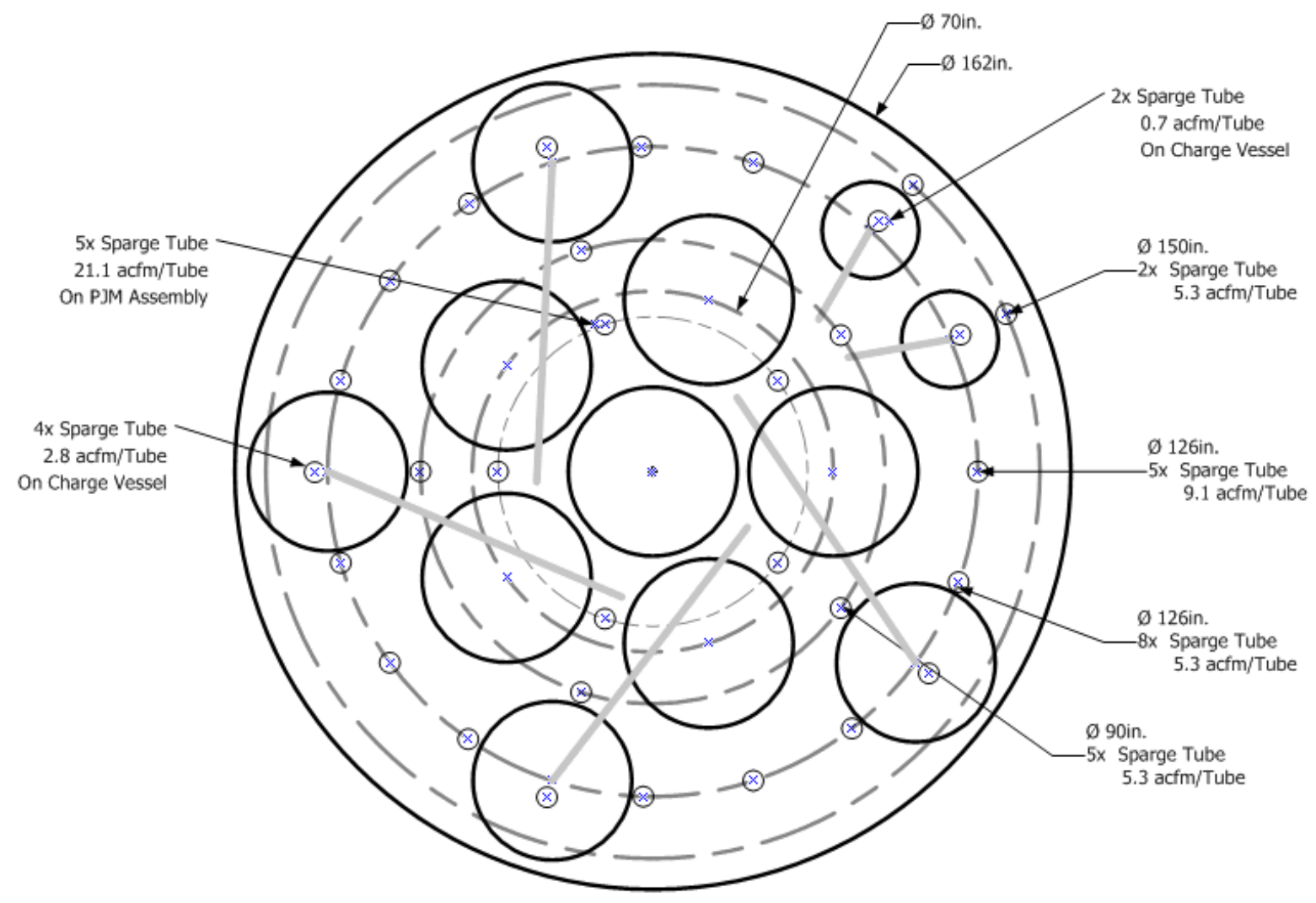

Figure 2-23. HCP-VSL-00001/2 Mixing System Layout - Plan View

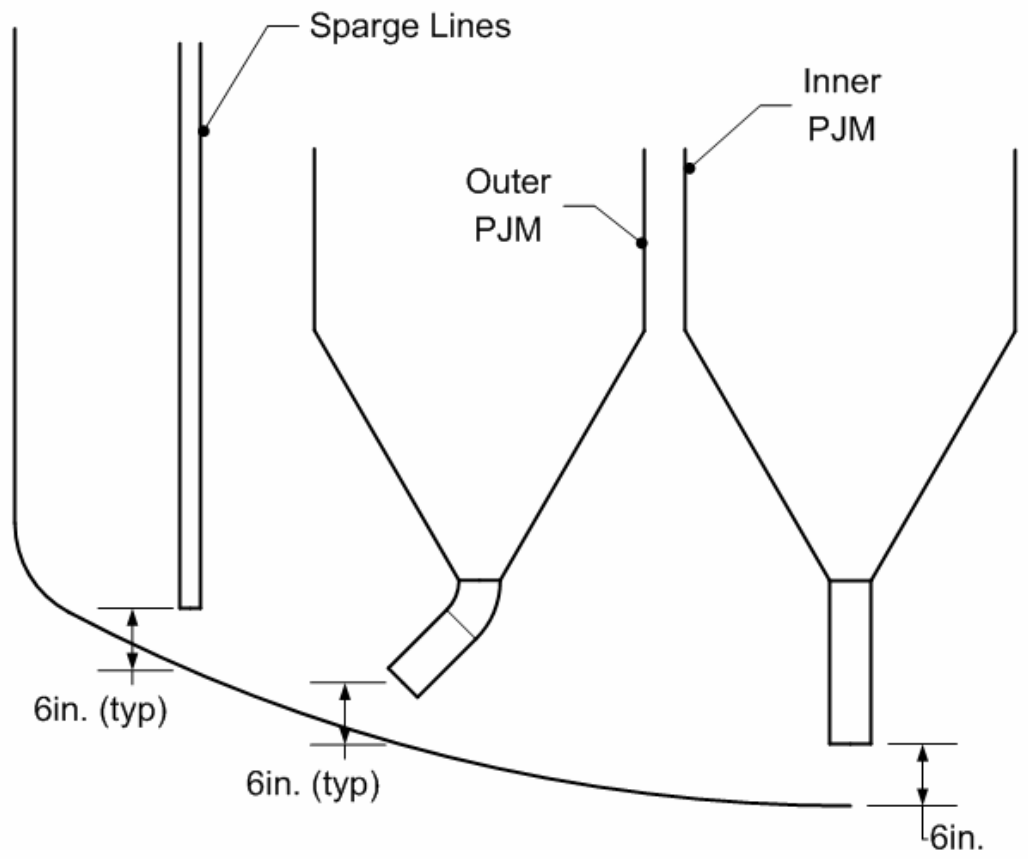

Figure 2-24. HCP-VSL-00001/2 Mixing System Layout - Elevation View 
WSRC-TR-2004-00398, REVISION 0

SRNL-RPP-2004-00060, REVISION 0

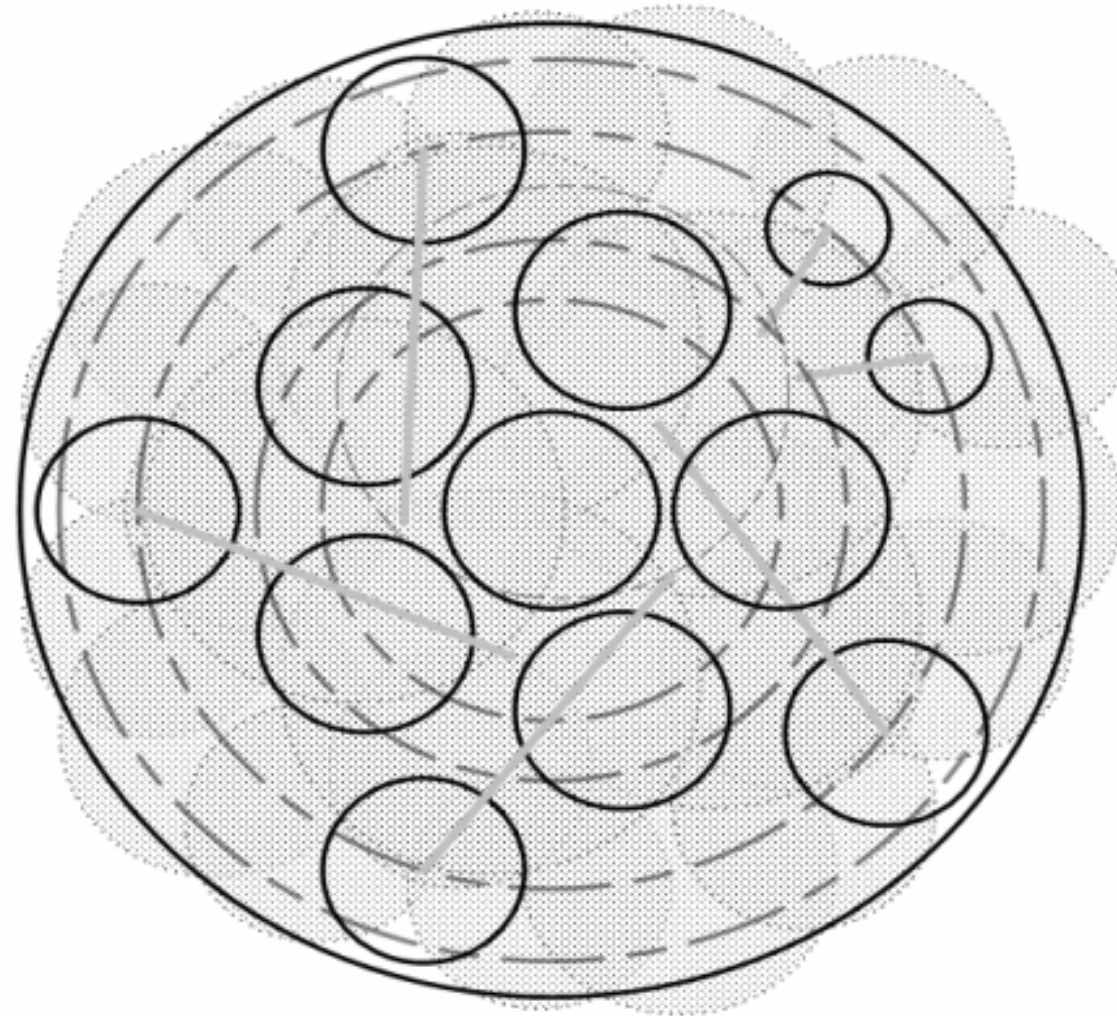

\begin{tabular}{|c|c|c|c|c|c|c|c|c|c|}
\hline \multirow{8}{*}{ 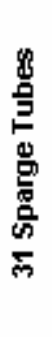 } & $\begin{array}{c}\text { \# OF } \\
\text { TUEE S }\end{array}$ & $\begin{array}{c}2 / 3 \mathrm{ZOI} \\
\text { (in.) }\end{array}$ & $\begin{array}{l}\text { flowt ube } \\
\text { (actri) }\end{array}$ & $\begin{array}{c}\text { subtotal } \\
\text { (acin) }\end{array}$ & $\begin{array}{l}\text { Radial } \\
\text { Position } \\
\text { (in) }\end{array}$ & $\begin{array}{c}\text { Nozzle } \\
\text { Elevation } \\
\text { (in) }\end{array}$ & $\begin{array}{l}\text { Pressure } \\
\text { Corr. Fador }\end{array}$ & $\begin{array}{c}\text { subtotal } \\
\text { (sctin) }\end{array}$ & \multirow{8}{*}{ 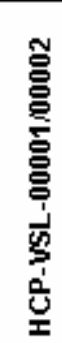 } \\
\hline & 5 & 48 & $\overline{9.1}$ & 45 & $\overline{63}$ & 19 & 1.60 & $\overline{73}$ & \\
\hline & 8 & 40 & 5.3 & 42 & 63 & 19 & 1.60 & 68 & \\
\hline & 2 & 40 & 5.3 & 11 & 75 & 24 & 1.58 & 17 & \\
\hline & 5 & 40 & 5.3 & 27 & 45 & 12 & 1.62 & 43 & \\
\hline & 5 & 64 & 21.1 & 106 & 37 & 162 & 1.13 & 119 & \\
\hline & 4 & 32 & 2.8 & 11 & 63 & 109 & 1.30 & 14 & \\
\hline & 2 & 20 & 0.7 & 1 & 63 & 109 & 1.30 & 2 & \\
\hline
\end{tabular}

Figure 2-25. Sparge Air Requirements and Resulting ZOIs - HCP-VSL-00001/2 
WSRC-TR-2004-00398, REVISION 0

SRNL-RPP-2004-00060, REVISION 0

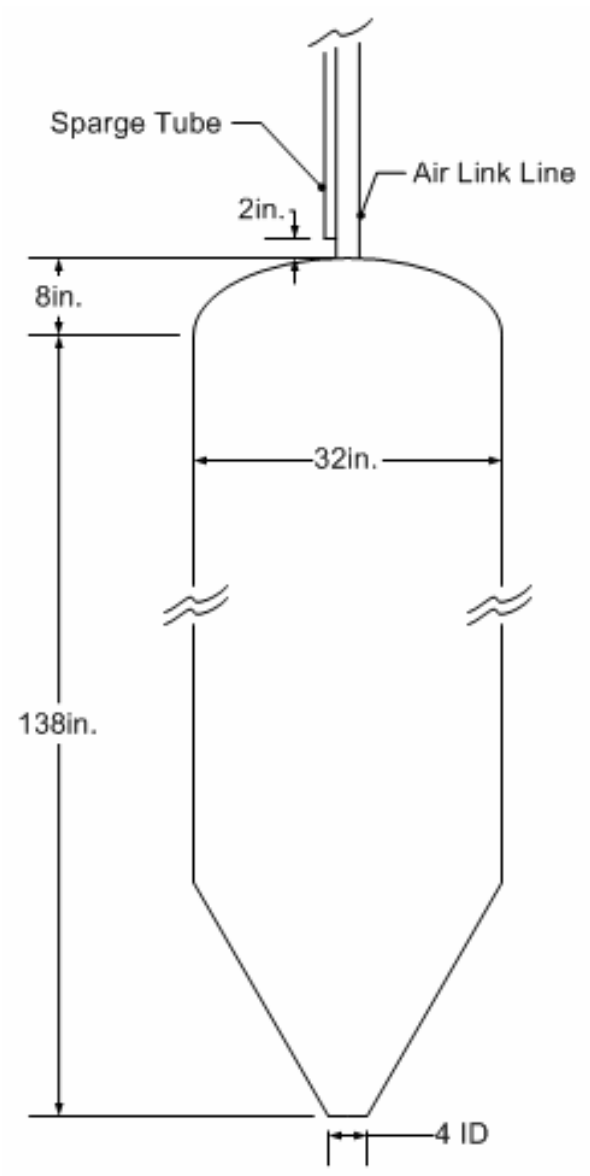

Figure 2-26. PJM Details - HCP-VSL-00001/2

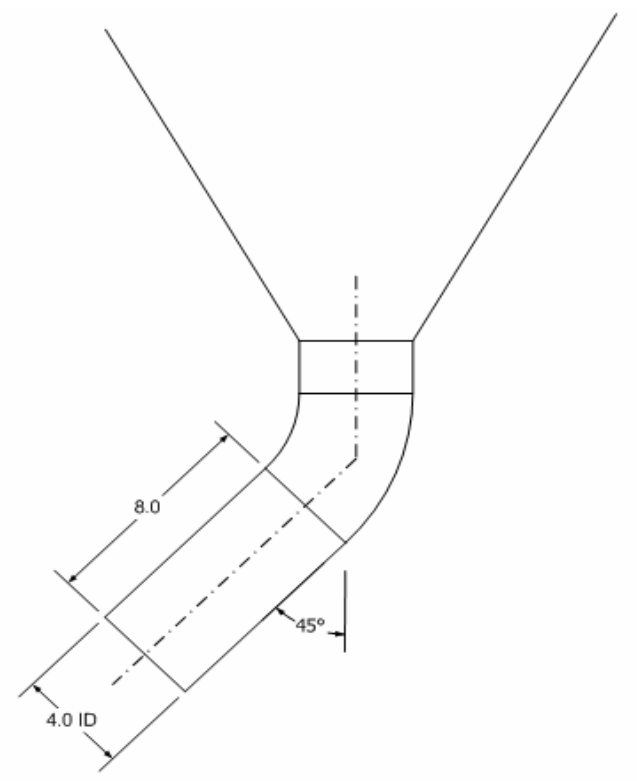

Figure 2-27. Outer PJM Nozzle Detail - HCP-VSL-00001/2 
WSRC-TR-2004-00398, REVISION 0

SRNL-RPP-2004-00060, REVISION 0

This page intentionally left blank. 
WSRC-TR-2004-00398, REVISION 0

SRNL-RPP-2004-00060, REVISION 0

\subsection{REFERENCES}

Test Specification 24590-HLW-TSP-RT-03-008, Rev. 0, "Development of Scaled

Performance Data for PJM Mixers in the HLW Concentrate Receipt Vessel (CRV)", by R. Longwell, August 26, 2003.

Test Plan WSRC-TR-2003-00410, Task Technical and Assurance Plan in Support of the RPP Test Specification, "Development of Scaled Performance Data for PJM Mixers in the HLW Concentrate Receipt Vessel (CRV)" by H. N. Guerrero, 9/15/03

Test Exception 24590-WTP-TEF-RT-04-001, "Test Exception to Test Plan WSRC-TR2003-00410, SRT-RPP-2003-198, Rev. 0, 'Revised Test Matrix and Direction to Reconfigure and Test in Final Down Selected 'Best' Mixing Configuration for the CRV Prototypic Test Platform'.

Test Exception 24590-WTP-TEF-RT-04-006, "Test Exception to Test Plan WSRC-TR-200300410, SRT-RPP-2003-198, Rev. 0, 'Revised Test Matrix and Direction to Reconfigure and Test in the HLW CRV Prototypic Test Platform to Understand Hybrid Mixing Designs .

WTP Project Memorandum CCN 052912 from C Bogaerts/JF Howell to S Khan/C Corriveau, "Fluid Properties for HFP Vessels," March 10, 2003

WTP Project Memorandum CCN 065607 from GM Duncan to TF Valentino, "Rheology Design Basis for non-Newtonian Treated Waste," November 17, 2003.

WTP Project Memorandum CCN 069099 from S Barnes to G Duncan, "R\&T Response to Engineering Review of AZ-102 HLW Pretreated Sludge Rheological Data and Rheological Recommendation for Consideration," October 17, 2003.

WSRC-TR-2004-00430, “One-Eighth Scale Pulse Jet Mixer Design Parameter, Scaling Law Testing," by D. Wilson, August, 2004.

PJM Task Team, "Hybrid Mixing System Test Data Supporting the Concentrate Receipt Vessel (CRV-VSL-00002A/2B) Configuration,” Interim report, April, 2004.

Poloski, A, O. Bredt, B. Calloway, G. Smith, and H. Smith. 2003. Technical Basis for HLW Vitrification Stream Physical and Rheological Property Bounding Conditions. WTP-RPT100 Rev. 0, Battelle - Pacific Northwest Division, Richland, WA.

Smith, G. L, H. Abodishish, P. Meyer, and A. Bronner, "Action Plan: WTP Pulsed Jet Mixing and Hydrogen Release for Process Vessels Containing Non-Newtonian Slurries," Effective Date: June 16, 2003. 
Speers R. A., K. R. Holme, M.A. Tung, and W. T. Williamson, 1987. "Drilling fluid shear stress overshoot behavior." Rheologica Acta, Vol. 26, pp. 447-452.

Zwietering, T. N., 1958. "Suspending of Solid Particles in Liquids." Chem. Eng. Sci., Vol. 8, p. 244. 


\section{APPENDIX A. \\ TECHNICAL BASIS FOR SCALED TESTING OF WTP MIXING VESSELS WITH NON-NEWTONIAN SLURRIES}

\section{A-1 INTRODUCTION}

Small-scale testing is a common approach used successfully in the many varied fields of applied fluid dynamics. The success of the approach depends greatly on the fact that system performance depends on certain non-dimensional groupings of physical parameters. If these parameter groupings can be preserved at different geometric scales (i.e., large and small), the essential behavior of the system will be the same at both scales. This principle is referred to as similarity in the theory of fluid dynamics engineering. Limitations of scaled testing are attributed to the inability to match important non-dimensional parameter groupings at both scales. In complex fluid dynamic problems, there can be many non-dimensional parameter groups; however, often the essential behavior of the phenomenon is dominated by only a few key groups. In this situation small-scale testing can produce results that are very close to large-scale behavior.

Appendix A presents the approach used to establish the scalability of the scaled prototypic mixing tests. Section A-2 gives a brief introduction to the basics of pulse jet mixer (PJM) operation. Section A-3 gives a summary of the important properties and parameters involved in PJM mixing of non-Newtonian materials. Section A-4 explains the geometric scaling approach and how velocities and time are scaled. Section A-5 discusses the important nondimensional parameters which, ideally, are to be preserved during scaled testing. Finally, Section A-6 summarizes the basis for scaled testing.

\section{A-2 PRINCIPLES OF PJM OPERATION}

A schematic of a typical PJM system in a vessel is shown in Figure A- 1. The tank has diameter $\mathrm{D}_{\mathrm{T}}$, volume $\mathrm{V}_{\mathrm{T}}$, and an operating level $\mathrm{H}$. There are N PJMs in the tank, each with diameter $\mathrm{D}_{\mathrm{PT}}$ and volume $\mathrm{V}_{\mathrm{PT}}$. Each PJM has a conical nozzle with diameter $\mathrm{d}_{0}$. For the baseline design, the total volume of the pulse tubes $\mathrm{N} \mathrm{V}_{\mathrm{PT}}$ is approximately $10 \%$ the operating volume of the vessel.

The operation of the PJM has three phases. During the drive phase, the tube is pressurized and a volume of slurry is discharged. The level change in the tube during discharge is $\Delta \mathrm{L}$. The corresponding increase in waste level is $\Delta \mathrm{H}$ where

Equation A- 1

$$
\Delta \mathrm{H}=\mathrm{N} \Delta \mathrm{L}\left(\frac{\mathrm{D}_{\mathrm{PT}}^{2}}{\mathrm{D}_{\mathrm{T}}^{2}-\mathrm{ND}_{\mathrm{PT}}^{2}}\right)
$$

(partially submerged PJMs)

or 
WSRC-TR-2004-00398, REVISION 0

SRNL-RPP-2004-00060, REVISION 0

Equation A- 2

$$
\Delta \mathrm{H}=\mathrm{N} \Delta \mathrm{L} \frac{\mathrm{D}_{\mathrm{PT}}^{2}}{\mathrm{D}_{\mathrm{T}}^{2}} \quad \text { (fully submerged PJMs) }
$$

Typical values of $\Delta \mathrm{H}$ are about $10 \%$ of the operating level $\mathrm{H}$. The average velocity $\mathrm{u}_{0}$ discharged during the drive phase is given by

Equation A- 3

$$
\mathrm{u}_{0}=\frac{\mathrm{D}_{\mathrm{PT}}^{2}}{\mathrm{~d}_{0}^{2}} \frac{\Delta \mathrm{L}}{\mathrm{t}_{\mathrm{D}}}
$$

where $t_{D}$ is the drive time or pressure pulse time. The average velocity is sometimes called nominal velocity.

The other two phases of PJM operation are the vent phase and suction phase. Immediately after the drive phase, a vent is opened and excess pressure is allowed to vent to the atmosphere. During the suction phase, vacuum is applied to the pulse tube. The tube fills due to a combination of the applied vacuum and the difference in hydrostatic head between the waste level and the level in the tube. The vent time and suction time are given by $t_{V}$ and $\mathrm{t}_{\mathrm{S}}$, respectively. The total cycle time for PJM operation is given by

\section{Equation A- $4 \quad t_{C}=t_{D}+t_{V}+t_{S}$}

It is important to emphasize that the average drive velocity given by Equation A- 3 is both spatially and temporally averaged. Spatially, the velocity will vary over the cross section of the nozzle. Temporally, the velocity varies due to inertial effects. When the drive phase is over, some fluid continues to discharge due to the inertia of the moving column of fluid. These inertial effects are dependent on the physical size of the system. The actual velocity varies somewhat over the operating cycle, as shown in Figure A- 2.

$$
\text { Equation A- } 5 \quad \bar{u}_{\text {area }}=\frac{1}{t_{P}-t_{m}} \int_{t_{m}}^{t_{D}} u d t
$$

Another is the true average velocity given by

Equation A- 6

$$
\overline{\mathrm{u}}_{\mathrm{disch}}=\frac{\mathrm{D}_{\mathrm{PT}}^{2}}{\mathrm{~d}_{0}^{2}} \frac{\Delta \mathrm{L}_{\mathrm{A}}}{\mathrm{t}_{\mathrm{DA}}}
$$

where $\Delta \mathrm{L}_{\mathrm{A}}$ and $\mathrm{t}_{\mathrm{DA}}$ are the actual measured level change and drive times in the pulse tube. Generally, Equation A- 5 will produce higher velocities than Equation A- 6 . 
The difficulty with Equation A- 6 is that due to transient effects, there is a lag between the actual level in the PJM tube and the level as measured by the capacitance probe. This is due to electronic delay and delay of draining the slurry coating on the capacitance probe, as discussed in Appendix B. The slowly changing levels at the start and end of the stroke results in a large uncertainty in the actual drive time. For this reason, the pulse time, or pressure time of the applied air pressure is used in Equation A- 6, and the nominal velocity is validated against a nozzle velocity obtained by measuring the tank level with laser sensors.

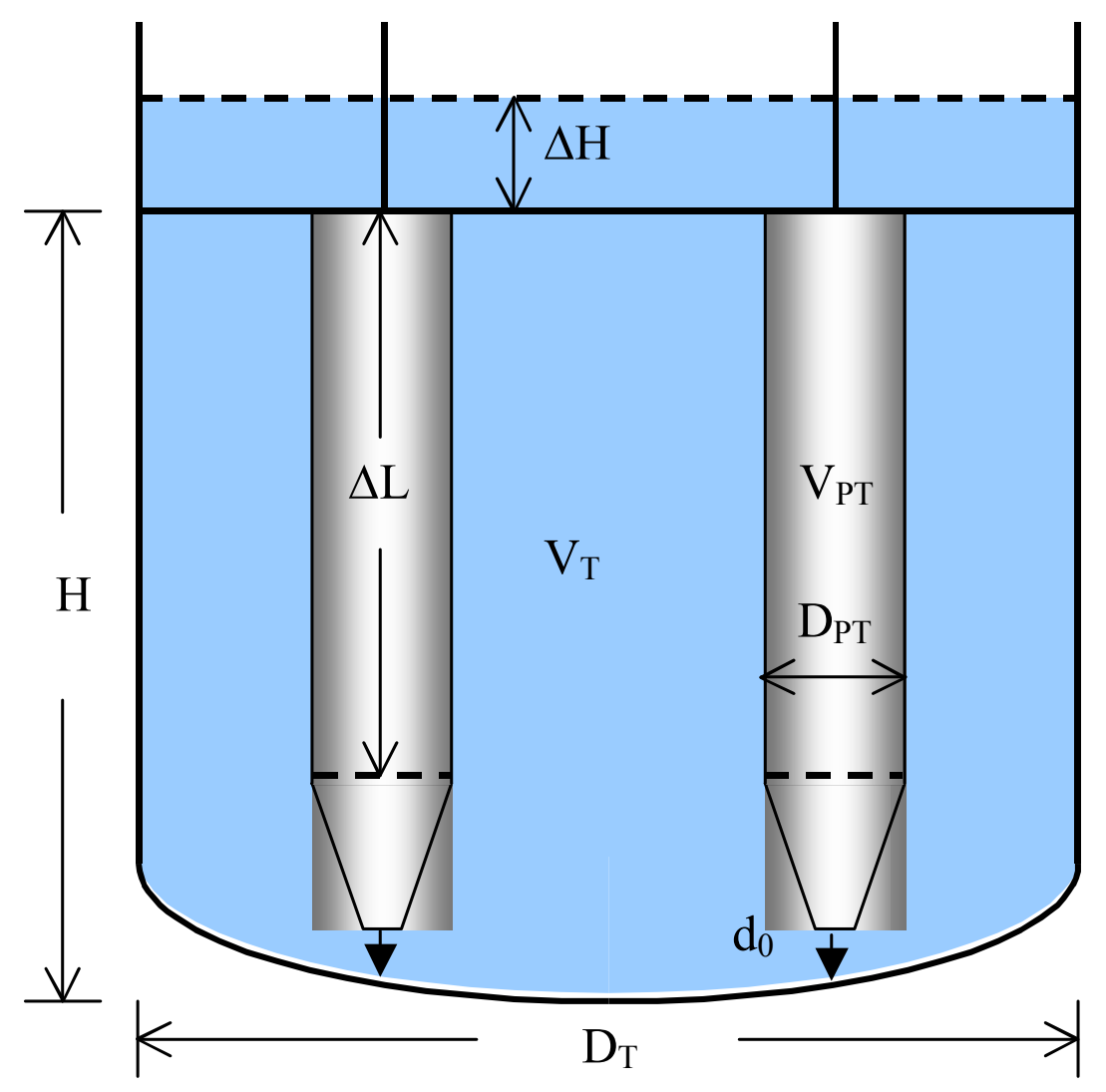

Figure A- 1. Illustration of a Typical PJM System in a Waste Treatment Plant Vessel 
WSRC-TR-2004-00398, REVISION 0

SRNL-RPP-2004-00060, REVISION 0

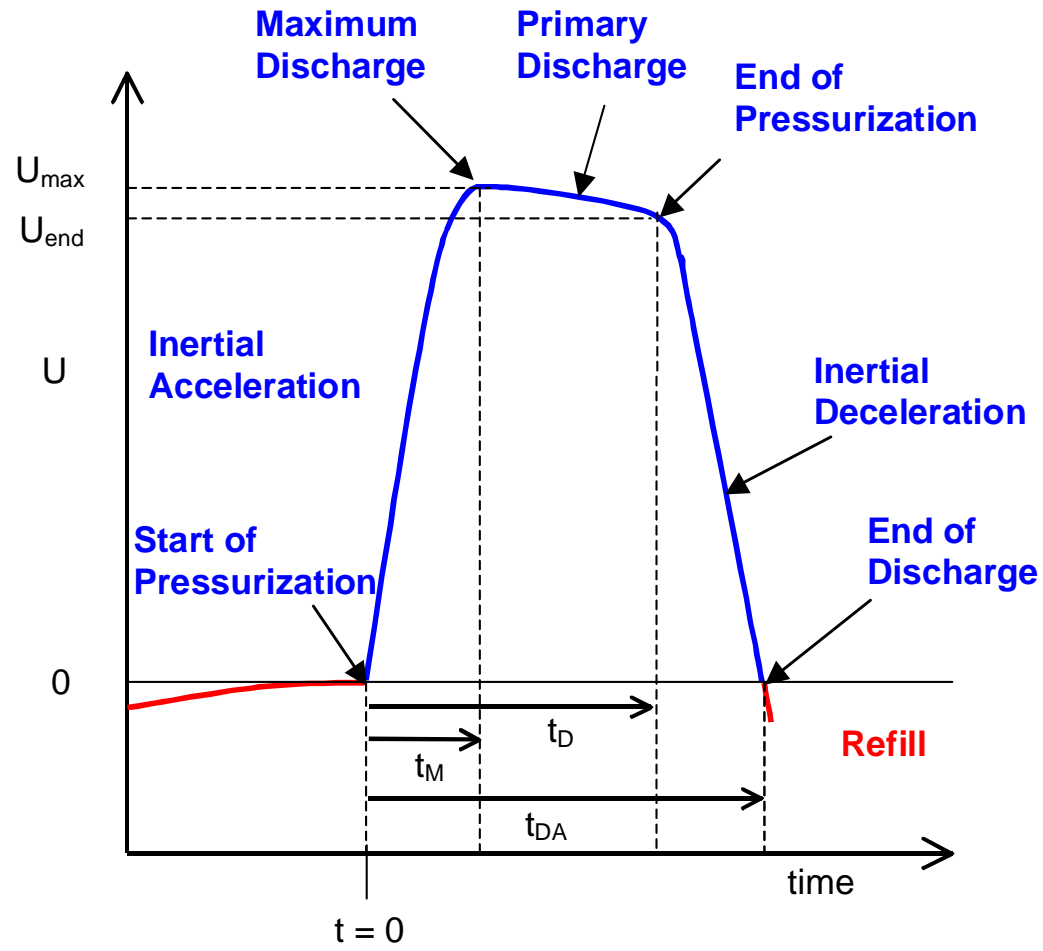

Figure A- 2. Illustration of Temporal Variation of Velocity during PJM Operation

\section{A-3 IMPORTANT PROPERTIES, PARAMETERS, AND NON-DIMENSIONAL GROUPS}

The following is a list of pertinent waste properties and system parameters to be used in forming non-dimensional parameter groups:

- Waste properties
$\rho \quad$ slurry density $\left(\mathrm{kg} / \mathrm{m}^{3}\right)$ (assumes well-mixed slurry with no settling)
$\tau_{\mathrm{s}} \quad$ slurry shear strength $(\mathrm{Pa})$
$\tau_{0} \quad$ laminar flow yield stress $(\mathrm{Pa})$ (from Bingham plastic fit of waste rheogram)
$\mathrm{K}$ laminar flow consistency (mPa-s) (assumed to be effective Newtonian viscosity $(\mu)$ in turbulent region)
$t_{\text {rel }} \quad$ slurry relaxation time ( $s$ ) (characteristic response time of gelled slurry to an impulse)


- Physical parameters

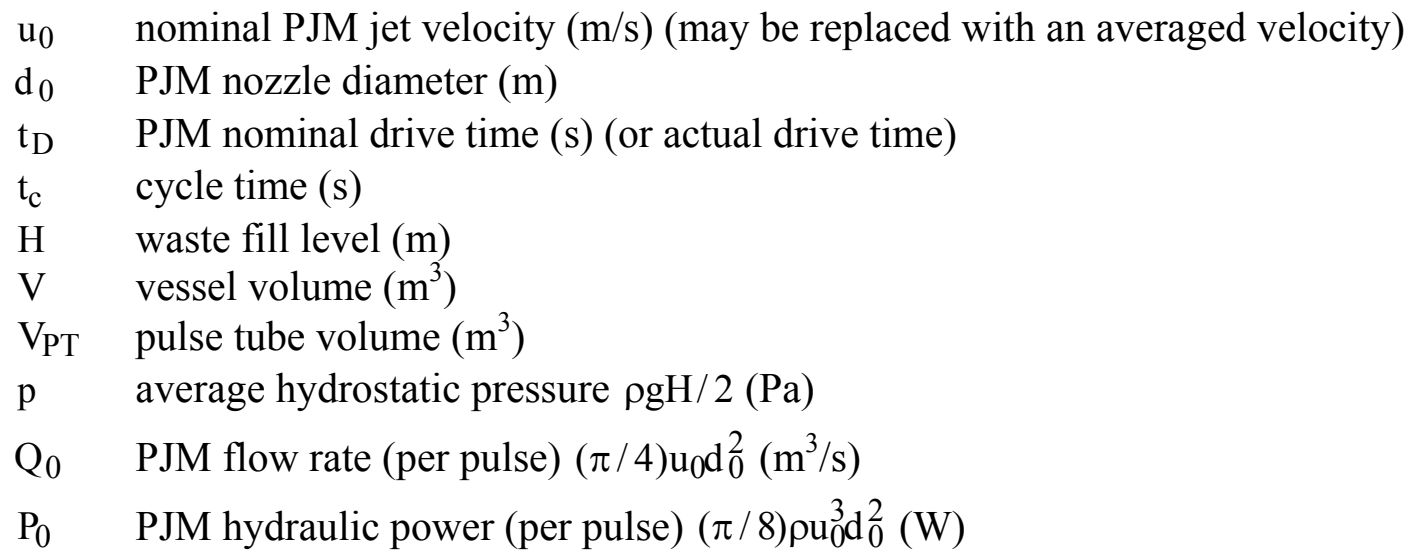

The relevant non-dimensional parameter groups for the physical system are as follows:

Yield Reynolds number: $\quad \operatorname{Re}_{Y}=\frac{\rho u_{0}^{2}}{\tau_{s}}$

This is the ratio of dynamic stress to slurry strength which directly affects size of the mixing cavern. It is considered a dominant non-dimensional parameter.

Jet Reynolds number: $\quad \operatorname{Re}_{0}=\frac{\rho u_{0} \mathrm{~d}_{0}}{\mu}$

This is the ratio of dynamic stress to viscous stress. It affects the degree of turbulence in the mixed region as well as weakly affecting stresses at the cavern and boundary layers. It is considered a secondary non-dimensional parameter.

Strouhal number: $\quad \mathrm{S}_{0}=\frac{\mathrm{t}_{\mathrm{D}} \mathrm{u}_{0}}{\mathrm{~d}_{0}}$

This is the ratio of pulse time to flow time scale. It affects the degree to which flow approaches steady jet behavior and is considered a primary non-dimensional parameter. In the limit of steady jet flows, the Strouhal Number become infinite, and the effects of pulsation are no longer present. For small Strouhal number, the mixing behavior will be highly dominated by pulsation effects.

Non-Newtonian stress ratio: $\quad \mathrm{N}_{\tau}=\frac{\tau_{\mathrm{s}}}{\tau_{0}}$

This is the ratio of shear strength to Bingham yield stress. It may affect boundary layer structure and possibly the friction coefficient at the cavern boundary. 


\section{A-4 GEOMETRIC SCALING APPROACH}

The non-Newtonian test program uses geometric scaling. We define the geometric scale factor $\mathrm{s}$ as

Equation A- $7 \quad \mathrm{~s}=\frac{\mathrm{L}_{\mathrm{L}}}{\mathrm{L}_{\mathrm{S}}}$

where $\mathrm{L}_{\mathrm{L}}$ is any characteristic linear dimension of the large-scale system (such as tank diameter, nozzle diameter, waste level, etc.). At small scale, every linear dimension, $\mathrm{L}_{\mathrm{S}}$, is reduced or scaled by s (i.e., $\mathrm{d}_{0_{\mathrm{S}}}=\mathrm{d}_{0_{\mathrm{L}}} / \mathrm{s}, \mathrm{D}_{\mathrm{T}_{\mathrm{S}}}=\mathrm{D}_{\mathrm{T}_{\mathrm{L}}} / \mathrm{s}, \mathrm{H}_{\mathrm{S}}=\mathrm{H}_{\mathrm{L}} / \mathrm{s}$ ). Hence the ideal smallscale test is an exact geometric miniature of the large system, with all areas scaled according to
Equation A- 8
$\mathrm{A}_{\mathrm{S}}=\frac{1}{\mathrm{~s}^{2}} \mathrm{~A}_{\mathrm{L}}$

and all volumes scaled according to
Equation A- 9

$$
\mathrm{V}_{\mathrm{s}}=\frac{1}{\mathrm{~s}^{3}} \mathrm{~V}_{\mathrm{L}}
$$

Typically in scaled fluid mixing tests, scale factors up to about 10 are considered acceptable, that is, much of the important physics can be captured at small scale. For the non-Newtonian test program, conservative scale factors in the range of 4 to 5 were selected due to the relatively new nature of the tests and the importance of the outcome.

When testing at small scale, one must determine how to scale velocity (i.e., PJM drive velocity $\mathrm{u}_{0}$ ). One choice is to scale velocity by the scale factor. This is problematic, however, because it tends to reduce the Reynolds number by $1 / \mathrm{s}^{2}$ and introduce further difficulties with the scaling of time. A better choice is to keep jet velocity constant at both scales:

\section{Equation A- 10}


With geometric scaling and constant velocity scaling, nozzle flow rates per pulse scale according to
Equation A- 11

$$
\mathrm{Q}_{0_{\mathrm{S}}}=\mathrm{Q}_{0_{\mathrm{L}}} / \mathrm{s}^{2}
$$

Jet hydraulic power also scales similarly. However, power per unit volume scales according to

$$
\text { Equation A- } \left.\left.12 \quad \frac{\mathrm{P}_{0}}{\mathrm{~V}}\right)_{\mathrm{S}}=\mathrm{s} \frac{\mathrm{P}_{0}}{\mathrm{~V}}\right)_{\mathrm{L}}
$$

For steady jet mixing, time does not come into play. However, PJM operation is a periodic process. Therefore, the scaling of time must be addressed.

If velocity is held constant and the geometry is scaled, then it follows that all imposed time scales must be reduced at small scale. Similarly, to keep the jet discharge velocity the same while scaling pulse volume geometrically, the pulse time will be reduced by the scale factor according to

$$
\text { Equation A- } 13
$$

Hence the PJM drive time (as well as refill time and cycle time) are all reduced by s at small scale.

\section{A-5 SCALING NON-DIMENSIONAL PARAMETERS}

In general, for a given non-Newtonian PJM mixing test, the non-dimensional cavern position should depend on all of the non-dimension parameter groups:

\section{Equation A- 14}

$$
\frac{\mathrm{H}_{\mathrm{C}}}{\mathrm{D}_{\mathrm{T}}}=\mathrm{f}\left(\operatorname{Re}_{\tau}, \operatorname{Re}_{0}, \mathrm{~N}_{\tau}, \mathrm{S}_{0}, \mathrm{D}_{0}, \mathrm{~F}_{0}\right)
$$

Similarly, non-dimensional mixing time (time to steady cavern formation, time to break through, or time to full mobilization) should depend on the same parameters:

Equation A- 15

$$
\frac{\mathrm{t}_{\mathrm{M}}}{\mathrm{t}_{\mathrm{D}}}=\mathrm{g}\left(\operatorname{Re}_{\tau}, \operatorname{Re}_{0}, \mathrm{~N}_{\tau}, \mathrm{S}_{0}, \mathrm{D}_{0}, \mathrm{~F}_{0}\right)
$$


The ideal small-scale test is one where the measured non-dimensional cavern height and mixing time are the same as those at full scale. Hence, the extent to which the nondimensional parameters scale will determine the success of the small scale test approach.

To this end, we consider how each of the non-dimensional parameters scale with the geometric scale factor $\mathrm{s}$ :

Yield Reynolds Number: $\quad \quad \operatorname{Re}_{\tau_{\mathrm{S}}}=\operatorname{Re}_{\tau_{\mathrm{L}}}$

The yield Reynolds number will be the same at both scales so long as the simulant used has the same shear strength $\tau_{\mathrm{s}}$ :

Jet Reynolds Number: $\quad \operatorname{Re}_{0_{\mathrm{S}}}=\frac{1}{\mathrm{~S}} \operatorname{Re}_{0 \mathrm{~L}}$

The Reynolds number at small scale is reduced by the geometric scale factor. This should introduce only minor differences in test results since the Reynolds numbers in both tests are quite large. Whether the reduction in Reynolds number produces conservative results (i.e., lower caverns) at small scale is not clear due to the competing effects of Reynolds number on jet structure and friction coefficients. The potential need for a minor Reynolds number correction to small-scale results should be evident from the scaling tests. If necessary, the Reynolds number can be matched at small scale by reducing the consistency or viscosity by the factor $1 / \mathrm{s}$.

Non-Newtonian stress ratio: $\quad \mathrm{N}_{\tau_{\mathrm{S}}}=\mathrm{N}_{\tau_{\mathrm{L}}}$

The non-Newtonian stress ratio will be the same at both scales if the same simulant is used.

Strouhal number: $\quad \mathrm{S}_{0 \mathrm{~S}}=\mathrm{S}_{0 \mathrm{~L}}$

The Strouhal number will be the same at both scales.

\section{A-6 SUMMARY OF SCALED TEST APPROACH}

By way of summary, the primary non-dimensional parameters required for small-scale testing are the yield Reynolds number $\mathrm{Re}_{\tau}$, and the Strouhal number $\mathrm{S}_{0}$. If these are matched at large and small scale, then we expect, to first order, non-dimensional cavern heights and mixing times to be the same:

Equation A- 16

$$
\left.\left.\frac{\mathrm{H}_{\mathrm{C}}}{\mathrm{D}_{\mathrm{T}}}\right)_{\mathrm{S}} \approx \frac{\mathrm{H}_{\mathrm{C}}}{\mathrm{D}_{\mathrm{T}}}\right)_{\mathrm{L}}
$$

and 
Equation A- $\left.\left.17 \quad \frac{t_{M}}{t_{D}}\right)_{S} \approx \frac{t_{M}}{t_{D}}\right)_{L}$

Given that full-scale cavern heights are adequately predicted by reduced-scale testing, it follows that specification of PJM operation parameters sufficient to achieve complete mixing (no stagnant regions) at reduced scale will produce designs that also provide complete mixing at full-scale. Further, testing at reduced scale will provide a degree of conservatism so long as the consistency, $\mathrm{k}$, of the simulant is the same as the full-scale bounding value. This is true since the jet Reynolds number will be smaller in the scaled-test than in the fullscale system:

\section{Equation A- 18}

$$
\operatorname{Re}_{0_{\mathrm{S}}}=\frac{1}{\mathrm{~s}} \operatorname{Re}_{0 \mathrm{~L}}
$$

If adequate mixing is achieved in a reduced-scale test, then it can be expected that the degree of turbulence will be greater in the full-scale vessel due the associated effect of increased jet Reynolds number. 
WSRC-TR-2004-00398, REVISION 0

SRNL-RPP-2004-00060, REVISION 0

This page intentionally left blank. 
WSRC-TR-2004-00398, REVISION 0

SRNL-RPP-2004-00060, REVISION 0

\section{APPENDIX B. NOZZLE VELOCITY VALIDATION AND VERIFICATION}

A primary parameter for applying results from the scaled CRV to the full scale plant is the pulse jet nozzle velocity. During testing, this velocity is set as the maximum change in liquid level height inside the PJM as measured by the level probe divided by the drive time or pressure pulse time. This is called the average velocity (Equation A-3) or the nominal velocity. However, the actual, measured nozzle velocity is deemed necessary for accurate application of the scaling method.

Since the pressure pulse is only an input to the fluid mass-force system inside the PJM, the true nozzle velocity must be characterized by the response of the liquid level. Investigation of the actual level probe response for two nozzle velocities, Figure B- 1(a) and Figure B- 1(b), indicates that liquid level curve is slowly changing at the start and end of the transient, due to inertial effects. The true average nozzle velocity, Equation A- 6, can vary as much as $20 \%$ depending on where the start and stop points are determined to be. Also, the start of the slurry level drop is delayed by as much as 1.55 seconds from the start of the pressure pulse. In Figure B- 1(a), the set drive time was $2.9 \mathrm{sec}$, and in Figure B- 1(b), the set drive time was $2.0 \mathrm{sec}$. The measured drive times correspond to the set times if the pressure pulse time starts at zero pressure during the initial pressure ramp and ends when the pressure starts to decay after maximum pressure is reached. The instantaneous maximum velocities (derived by differentiating the level curve), $48.6 \mathrm{fps}$ and $40 \mathrm{fps}$, have a 1.22 ratio, which is less than the nominal velocity ratio of $(39 / 26)$ of 1.5 .

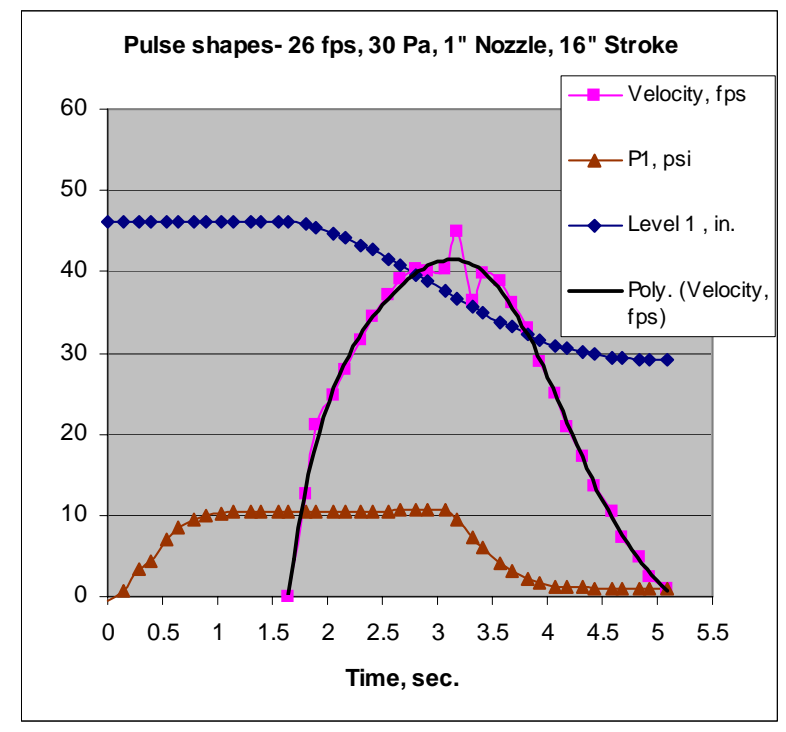

(a)

26 fps

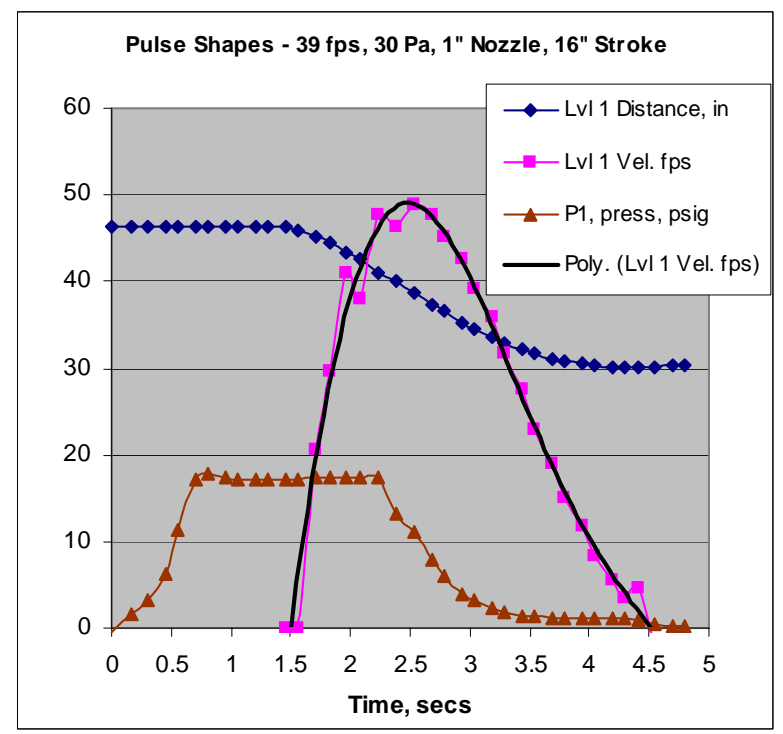

(b)

Figure B- 1. Pulse Shapes for VVV Run - Nozzle Velocity, 30 Pa, 16” Stroke 
Consequently, there was a need to Validate and Verify the nozzle Velocity (VVV). The technique used was to utilize three Leica Disto Pro laser distance sensors to measure the tank liquid level during pulsing and relating this to the nozzle velocity. This was accomplished by first calibrating the tank volume (by mass measurement) outside the PJMs as a function of tank level, which provided an effective tank area. The nozzle velocity via the laser sensors is the laser velocity times the ratio of the tank area to total nozzle area. Due to wave action along the liquid surface, the laser light would often be reflected away from the senor, dropping the signal. To resolve this problem, the laser lights were reflected off Styrofoam discs that floated on top of the liquid surface and guided to move vertically (without tilting) through the use of guide rods inserted through a hole in each disc, respectively. This minimized loss of laser data. The laser sensors and Styrofoam discs were located opposite PJMs 2, 3, and 5. The laser data was analyzed by performing a linear fit on the displacement data (10 to 20 readings) for tank surface levels below the top of the PJMs. Above this level, the data became nonlinear due to the change in tank cross-section. The laser measured velocities correspond to the area-averaged velocity, Equation A- 5, where the rising and falling periods are not included.

VVV tests were run for two nozzle velocities, $26 \mathrm{fps}$ and $39 \mathrm{fps}$, two Kaolin slurry yield stresses, 30 and $6 \mathrm{~Pa}$, and two drive distances, 16 and 27-inches. The 16-inch drive distance for the 8-inch PJM used simulated the same drive volume of a 6-inch PJM, as used in some of the mixing tests. Further tests were performed with water and intermediate and slower nozzle velocities, $32.8 \mathrm{fps}$, and $13.1 \mathrm{fps}$, to further elucidate the capacitance level probe response.

\section{6-inch Stroke Tests}

Table B- 1 gives the results for $30 \mathrm{~Pa}$ Kaolin/bentonite simulant for a 16-inch stroke, simulating the same delivered volume of a 6-inch PJM. This table shows that the maximum velocities obtained from the capacitance probe readings were from 1.32 to 1.15 times the calculated nozzle velocities from the laser sensors. The nominal velocities were within 10\% of the laser readings.

\section{Table B- 1. Comparison of Calculated Nozzle Velocities by Various Methods for $30 \mathrm{~Pa}$ and 16" Stroke}

\begin{tabular}{|l|c|c|c|c|}
\hline \multicolumn{5}{|c|}{ 30 Pa Kaolin slurry, 16-inch stroke } \\
\hline & Measured velocity & \multicolumn{2}{|c|}{ Ratios (Cap. Probe vel./Laser vel.) } \\
\hline Target velocity & $26 \mathrm{fps}$ & $39 \mathrm{fps}$ & $26 \mathrm{fps}$ & $39 \mathrm{fps}$ \\
\hline Nominal velocity, fps & 29.2 & 39.4 & 0.91 & 0.93 \\
\hline $\begin{array}{l}\text { Cap. Probe -Upper } \\
\text { peak velocity, fps }\end{array}$ & 42.6 & 48.6 & 1.32 & 1.15 \\
\hline $\begin{array}{l}\text { Laser - Average } \\
\text { velocity, fps }\end{array}$ & 32.2 & 42.2 & 1 & 1 \\
\hline
\end{tabular}


WSRC-TR-2004-00398, REVISION 0

SRNL-RPP-2004-00060, REVISION 0

Table B- 2 gives the results for a 6 Pa simulant for the same 16-inch stroke. The capacitance probe readings were still high compared to the laser readings, while the nominal velocities were within $3 \%$ of the laser readings.

Table B- 2. Comparison of Calculated Nozzle Velocities by Various Methods for 6 Pa and 16" Stroke

\begin{tabular}{|l|c|c|c|c|}
\hline \multicolumn{5}{|c|}{ 6 Pa Kaolin slurry, 16-inch stroke } \\
\hline & \multicolumn{2}{|c|}{ Measured velocity } & \multicolumn{2}{|c|}{ Ratios (Cap. Probe vel./Laser vel.) } \\
\hline Target velocity & $26 \mathrm{fps}$ & $39 \mathrm{fps}$ & $26 \mathrm{fps}$ & $39 \mathrm{fps}$ \\
\hline Nominal velocity, fps & 28 & 40.1 & 0.97 & 1.01 \\
\hline $\begin{array}{l}\text { Cap. Probe -Upper } \\
\text { peak velocity, fps }\end{array}$ & 38.2 & 45.4 & 1.32 & 1.15 \\
\hline $\begin{array}{l}\text { Laser - Average } \\
\text { velocity, fps }\end{array}$ & 29 & 39.6 & 1 & 1 \\
\hline
\end{tabular}

\section{7-inch Stroke Tests}

The question is why the capacitance probe velocities were higher than the nominal or laser velocities. In Figure B- 1(a) and Figure B- 1(b), the drop in capacitance probe readings were delayed 1.3 seconds after the pressure reached its full value. The instantaneous velocity then started to decrease immediately after the pressure started to decrease. The VVV tests with the longer 27-inch stroke may provide further insight into the response of the capacitance probe under fast transients. If there was any wave action on the surface of the slurry due to the jet of air coming from the inlet pipe, this would be damped down at the later stage of the long stroke. The effects of an electronic time delay due to the capacitance of the probe would also be mitigated for long pulses such as with a $13 \mathrm{fps}$ nominal velocity. Table B- 3 and Table B- 4 provide results with a 27-inch stroke at $28 \mathrm{~Pa}$ and $6 \mathrm{~Pa}$ yield stresses, respectively.

Table B- 3. Comparison of Calculated Nozzle Velocities by Various Methods for 26 Pa and 27" Stroke

\begin{tabular}{|l|c|c|c|c|c|c|}
\hline \multicolumn{7}{|c|}{ 26 Pa Kaolin slurry, 27-inch stroke } \\
\hline & \multicolumn{7}{|c|}{ Measured velocity } & \multicolumn{2}{c|}{ Ratios (Cap. Probe vel./Laser vel.) } \\
\hline Target velocity & $13 \mathrm{fps}$ & $32.8 \mathrm{fps}$ & $39 \mathrm{fps}$ & $26 \mathrm{fps}$ & $32.8 \mathrm{fps}$ & $39 \mathrm{fps}$ \\
\hline Nominal velocity, fps & 13.1 & 27.1 & 39.5 & 0.91 & 0.99 & 1.06 \\
\hline $\begin{array}{l}\text { Cap. Probe Upper peak } \\
\text { velocity, fps }\end{array}$ & 20.1 & 36.8 & 49.4 & 1.40 & 1.35 & 1.33 \\
\hline $\begin{array}{l}\text { Cap. Probe-Lower peak } \\
\text { velocity, fps }\end{array}$ & 11.2 & NA & NA & 0.78 & NA & NA \\
\hline $\begin{array}{l}\text { Laser - Average velocity, } \\
\text { fps }\end{array}$ & 14.4 & 27.3 & 37.2 & 1 & 1 & 1 \\
\hline
\end{tabular}


WSRC-TR-2004-00398, REVISION 0

SRNL-RPP-2004-00060, REVISION 0

Table B- 4. Comparison of Calculated Nozzle Velocities by Various Methods for 6 Pa and 27" Stroke

\begin{tabular}{|l|c|c|c|c|c|c|}
\hline \multicolumn{7}{|c|}{ 6 Pa Kaolin slurry, 27-inch stroke } \\
\hline & \multicolumn{7}{|c|}{ Measured velocity } & \multicolumn{2}{|c|}{ Ratios (Cap. Probe vel./Laser vel.) } \\
\hline Target velocity & $26 \mathrm{fps}$ & $32.8 \mathrm{fps}$ & $39 \mathrm{fps}$ & $26 \mathrm{fps}$ & $32.8 \mathrm{fps}$ & $39 \mathrm{fps}$ \\
\hline Nominal velocity, mps & 24.8 & 32.9 & 40.1 & 1.00 & 1.06 & 1.13 \\
\hline $\begin{array}{l}\text { Cap. Probe -Upper peak } \\
\text { velocity, mps }\end{array}$ & 38.3 & 43.2 & 47.8 & 1.54 & 1.39 & 1.35 \\
\hline $\begin{array}{l}\text { Cap. Probe-Lower peak } \\
\text { velocity, mps }\end{array}$ & 24.9 & NA & NA & 1.00 & NA & NA \\
\hline $\begin{array}{l}\text { Laser - Average velocity, } \\
\text { mps }\end{array}$ & 24.8 & 31 & 35.5 & 1.00 & 1.00 & 1.00 \\
\hline
\end{tabular}

In Table B- 3 and Table B- 4 for the case of a 27-inch stroke, nominal velocities were within $13 \%$ of the laser based velocities, similar to those for the case of a 16-inch stroke. The ratio of the peak capacitance probe based velocities to the laser based velocities got worse compared to the shorter stroke. Pulse shapes for the 27-inch stroke runs are shown in Figure B- 2(a) - (c). Laser readings are included, but were not synchronized to the capacitance probe readings because these were recorded on separate laptop computers.

In the case of the $13 \mathrm{fps}(26 \mathrm{~Pa})$ run, the capacitance probe velocity curve shows an initial upper peak followed by a lower peak which is closer to the laser based velocity (Table B- 4) than the upper peak. For the $26 \mathrm{fps}$ run (Figure B- 2(b)), the capacitance probe velocity shows a hint of a lower peak, the velocity dropping quickly as the pressure input decayed to zero. The laser readings did not show a similar change in velocity so that this effect is probably not due to a liquid level change. The higher $39 \mathrm{fps}$ velocity run, (Figure B- 2(c)) where the transient is much shorter, does not show this lower peak. 
WSRC-TR-2004-00398, REVISION 0

SRNL-RPP-2004-00060, REVISION 0

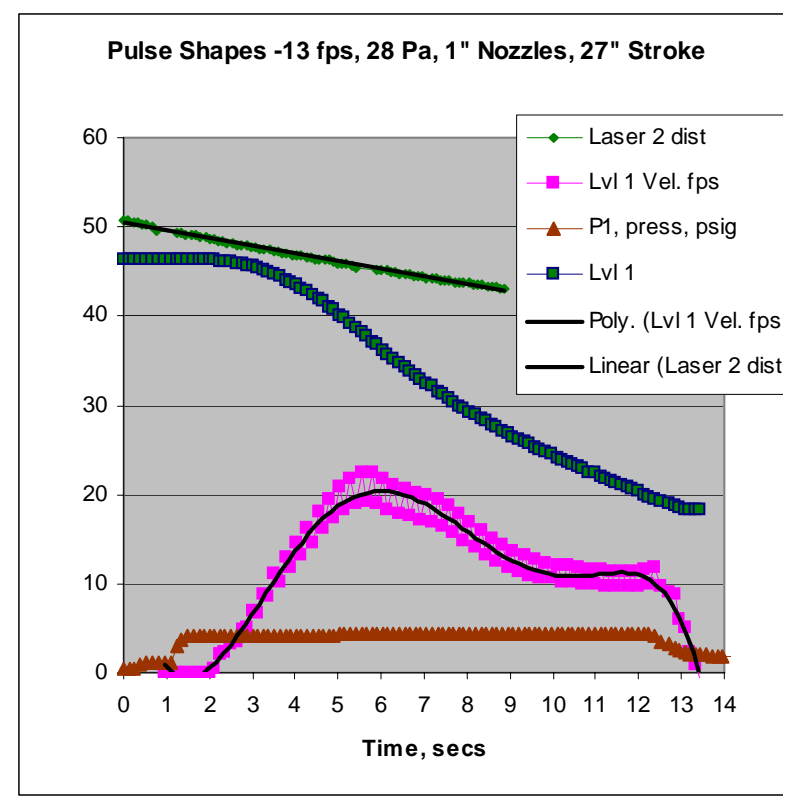

(a)

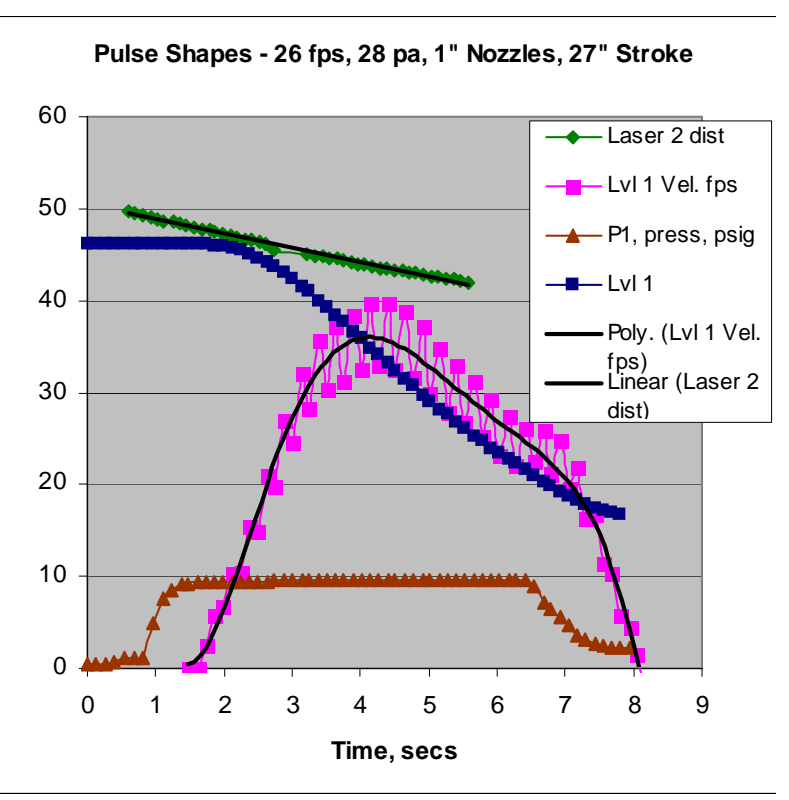

(b)

13 fps

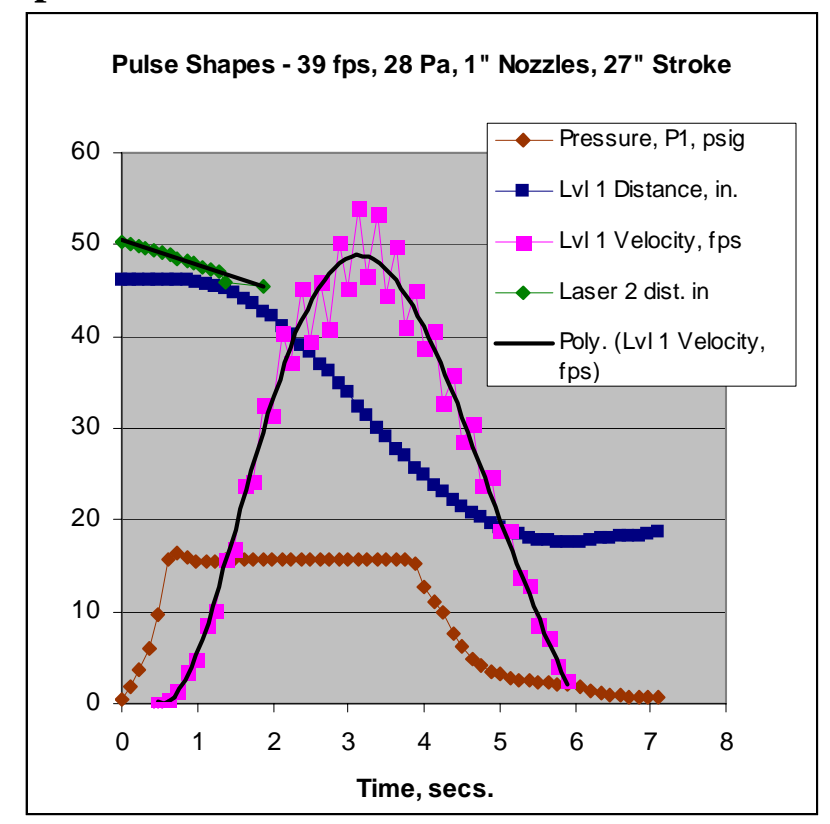

(c)

39 fps

Figure B- 2. Pulse Shapes for VVV Run - Nozzle Velocity, 26 Pa, 27” Stroke 


\section{Water Runs}

Calibration runs were also performed with water as simulant, for 16-inch and 27-inch strokes and for $13 \mathrm{fps}$ and $26 \mathrm{fps}$ nominal velocities. The results are given in Table B- 5. The nominal velocities are within $10 \%$ of the laser based velocities. The capacitance probe peak velocity also comes close to the laser based velocities, to within $12 \%$. Plots of the pressure, capacitance probe level, laser level, and calculated capacitance probe velocity are given in Figure B- 3 and Figure B- 4. The laser sensor readings were synchronized with the capacitance probe readings for these cases by recording both sets of readings on the same data acquisition computer. The plots show that the capacitance probe readings with water media do not have the large delay as evident with the runs with Kaolin.

In summary, the validation and verification tests shows that using the nominal velocity gives accurate average PJM nozzle velocity to within 13\%. Using the capacitance probe instantaneous velocity would provide erroneous answers. This capacitance probe error is probably due to a delay in drainage of the Kaolin slurry coating surrounding the capacitance probe relative to the true level inside the PJM. Thus with a coating above the slurry level, the effective level recorded by the capacitance probe can be higher than the true level change. When the coating has caught up with the PJM level, then the probe velocity will tend towards the laser velocity, as indicated with the lower peak and the runs with water.

\section{Table B- 5. Comparison of Calculated Nozzle Velocities by Various Methods for Water Runs for 16" and 27" Stroke}

\begin{tabular}{|l|c|c|c|c|}
\hline \multicolumn{5}{|c|}{ Measured Velocities in Water (Ratio rel. to Laser Vel.) } \\
\hline & \multicolumn{2}{|c|}{16 -in. Stroke } & \multicolumn{2}{c|}{ 27-in. Stroke } \\
\hline Target velocity & $13 \mathrm{fps}$ & $39 \mathrm{fps}$ & $13 \mathrm{fps}$ & $39 \mathrm{fps}$ \\
\hline Nominal velocity, fps & $14.2(0.90)$ & $41.5(1.03)$ & $13.5(0.94)$ & $39.5(0.97)$ \\
\hline $\begin{array}{l}\text { Cap. Probe -Upper peak } \\
\text { velocity, fps }\end{array}$ & $16.4(1.04)$ & $36.6(0.91)$ & $13.9(0.96)$ & $36.8(0.88)$ \\
\hline $\begin{array}{l}\text { Laser - Average } \\
\text { velocity,fps }\end{array}$ & $15.8(1)$ & $40.1(1)$ & $14.4(1)$ & $40.8(1)$ \\
\hline
\end{tabular}


WSRC-TR-2004-00398, REVISION 0

SRNL-RPP-2004-00060, REVISION 0

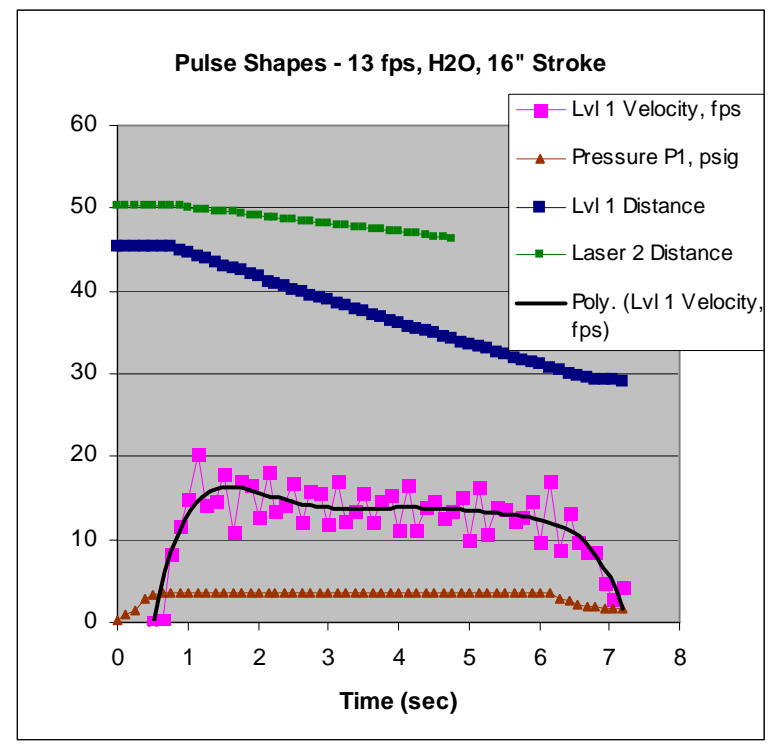

(a)

13 fps

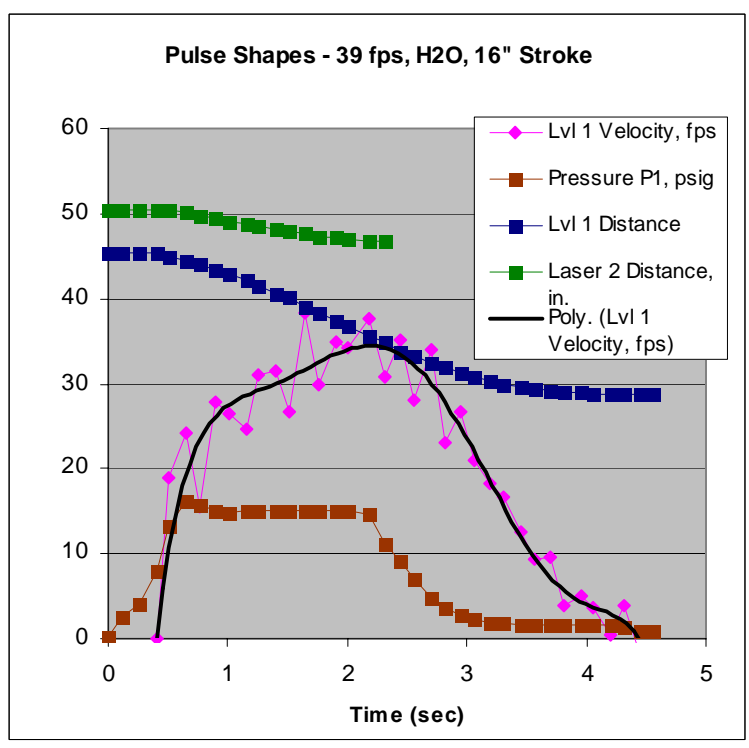

(b)

Figure B- 3. Pulse Shapes for Water VVV Run - Nozzle Velocity, 16” Stroke

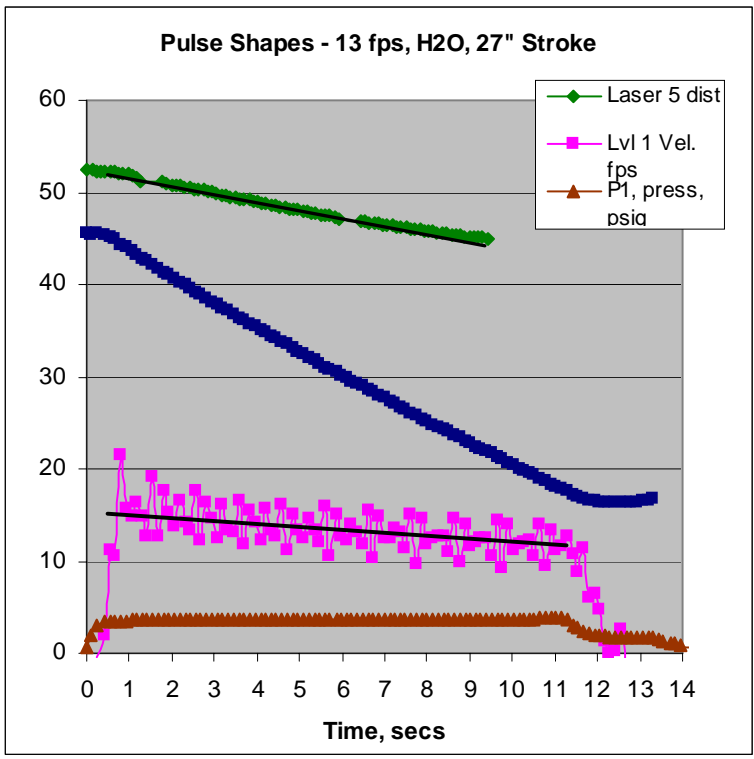

(a)

$13 \mathrm{fps}$

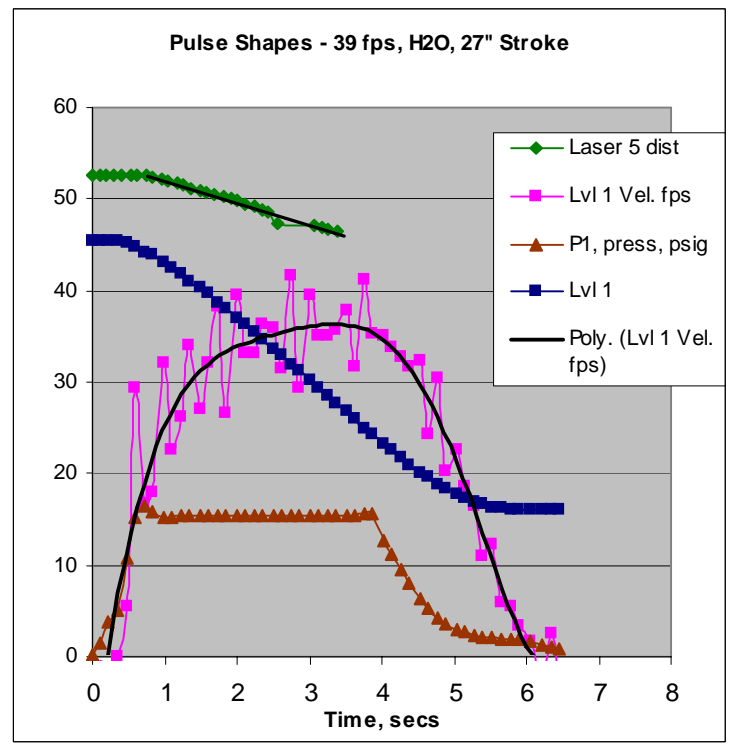

(b)

39 fps

Figure B- 4. Pulse Shapes for Water VVV Run - Nozzle Velocity, 27” Stroke 
WSRC-TR-2004-00398, REVISION 0

SRNL-RPP-2004-00060, REVISION 0

This page intentionally left blank. 


\section{APPENDIX C. DYE METHOD AND RESULTS}

\section{C-1 DYE METHOD DESCRIPTION}

The concentration of dye [in this case Food Dye Color No. 1, (Brilliant Blue FCF) (BB FCF)] in an aqueous sample was determined through the correlation shown in Figure C-1. This correlation follows Beer's law, which says that the dye concentration is proportional to the optical absorbance value of the dye at the mode wavelength. The mode wavelength for BB FCF is approximately $633 \mathrm{~nm}$. The results are only valid over a certain region of dye concentration. From visual inspection of Figure $\mathrm{C}$ - 1 , the linear region is present up to an absorbance value of 1.5 ( $\sim 9$ ppm FCD1). When the dye concentration is above this level the sample must be diluted with water and remeasured. The original dye concentration can be calculated by knowing the quantity of water used for the dilution.

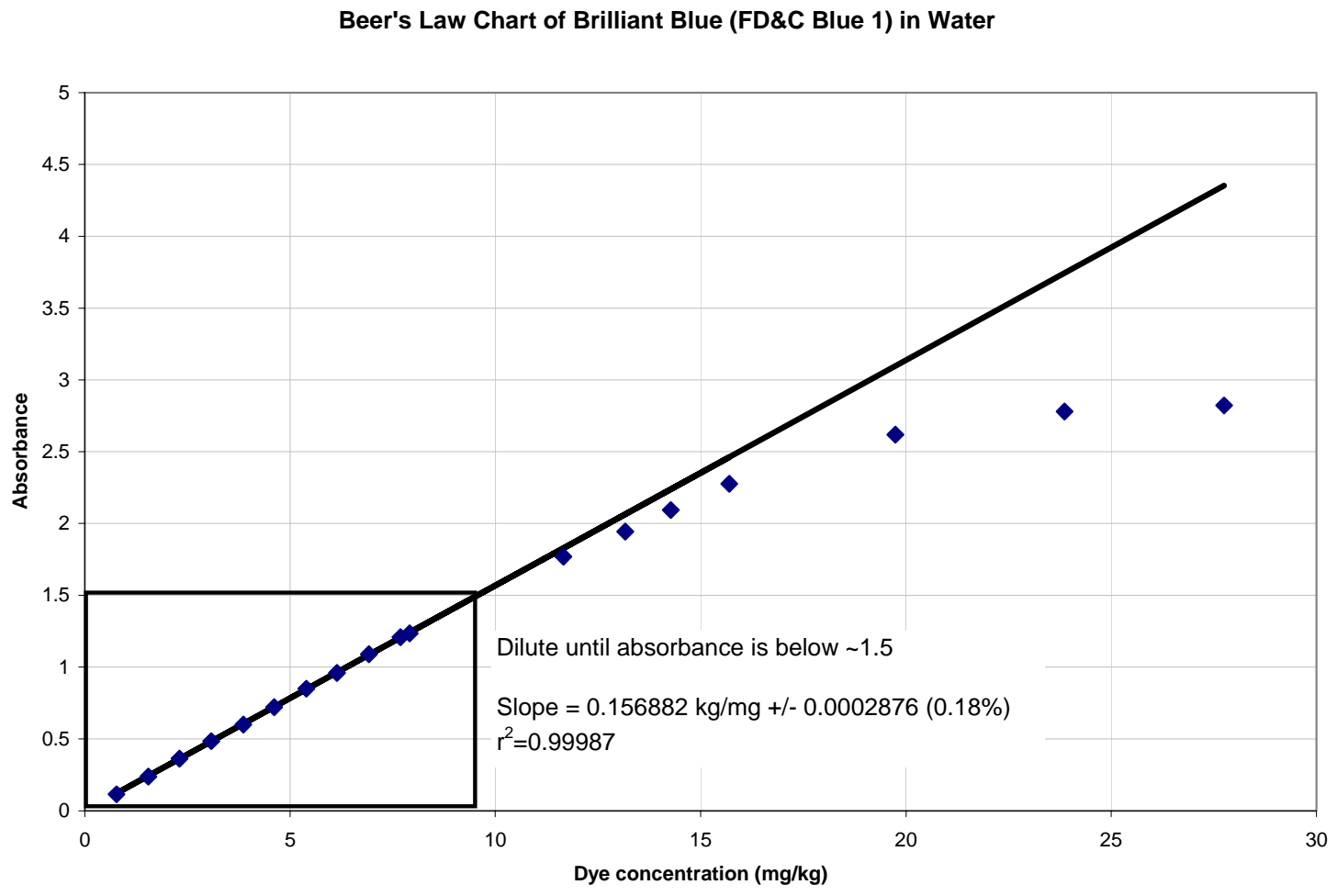

Figure C- 1. Beer's Law Correlation of Optical Absorbance to BB FCF Dye Concentration in Water 
Absorption of dye onto the surface of the clay particles can be estimated through a linear approximation. This correlation is shown in Figure $\mathrm{C}-2$, where the dye concentration in the liquid phase is plotted against the dye concentration in the solid phase. Due to batch to batch variations of the clay composition, small differences in the amount of dye absorbed were measured from sample to sample. The linear isotherm assumption allows for the use of Equation C- 1 to calculate percent mixed in a PJM test.

Equation C- 1

$$
X_{j}=\frac{A_{f}-A_{0}}{A_{j}-A_{0}}
$$

where

$X_{j} \quad$ is the fraction mixed of the $\mathrm{j}$-th tank sample

$A_{f} \quad$ is the optical absorbance of the final homogenized simulant

$A_{0} \quad$ is the optical absorbance of the initial baseline simulant

$A_{j} \quad$ is the optical absorbance of the $\mathrm{j}$-th tank sample

Linear Approximation of Isotherm in Operational Dye Concentration Range

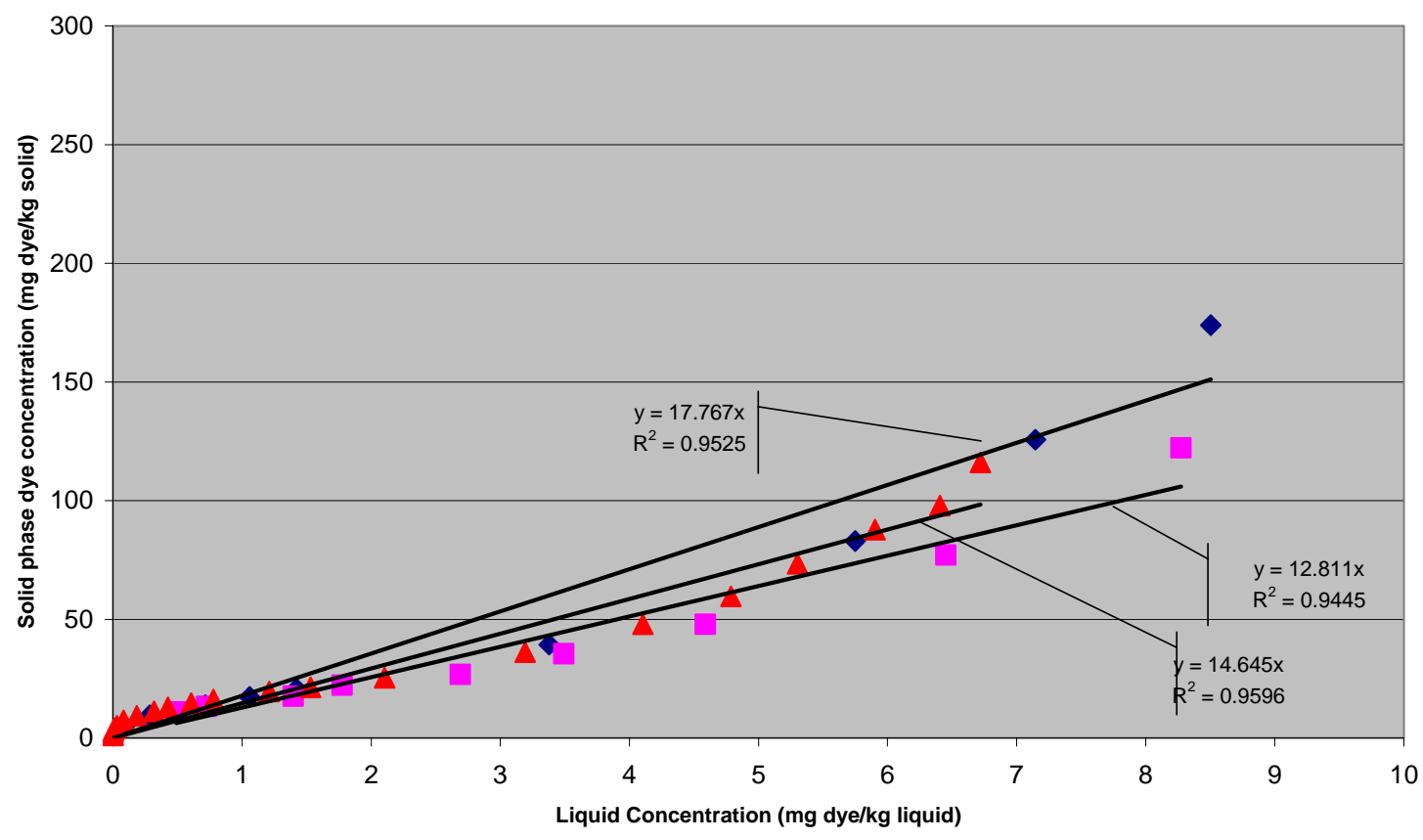

Sample Set $35 \square$ Sample Set $44 \Delta$ Sample Set 52 - Linear (Sample Set 44) 一 Linear (Sample Set 52) - Linear (Sample Set 35)

Figure C- 2. Linear Fit of Isotherm Data over the Linear Beer's Law Region 
A polynomial fit to one of the isotherm data sets is shown in Figure C- 3. Use of this fit allows for an estimation of the error incurred through the assumption of a linear isotherm. This error is estimated by calculating the difference in the percent mixed between Equation C- 1 and Equation C- 2. To perform this calculation the correlation shown in Figure C- 3 is used to calculate the $K_{d}$ values of each sample in the calculation. A conservative estimation of the solids loading in each sample is assumed at $30 \mathrm{wt} \%$ solids $70 \mathrm{wt} \%$ liquid.

Equation C- 2

$$
X_{j}=\frac{Y_{l}\left(A_{f}-A_{o}\right)+Y_{s}\left(K_{d f} A_{f}-K_{d o} A_{o}\right)}{Y_{l}\left(A_{j}-A_{o}\right)+Y_{s}\left(K_{d j} A_{j}-K_{d o} A_{o}\right)}
$$

where

$K_{d f}$ is the distribution coefficient at the homogenized tank tracer concentration

$K_{d o}$ is the distribution coefficient at the initial baseline tracer concentration

$K_{d j}$ is the distribution coefficient at the $\mathrm{j}$-th tank sample tracer concentration

Linear Approximation of Isotherm in Operational Dye Concentration Range

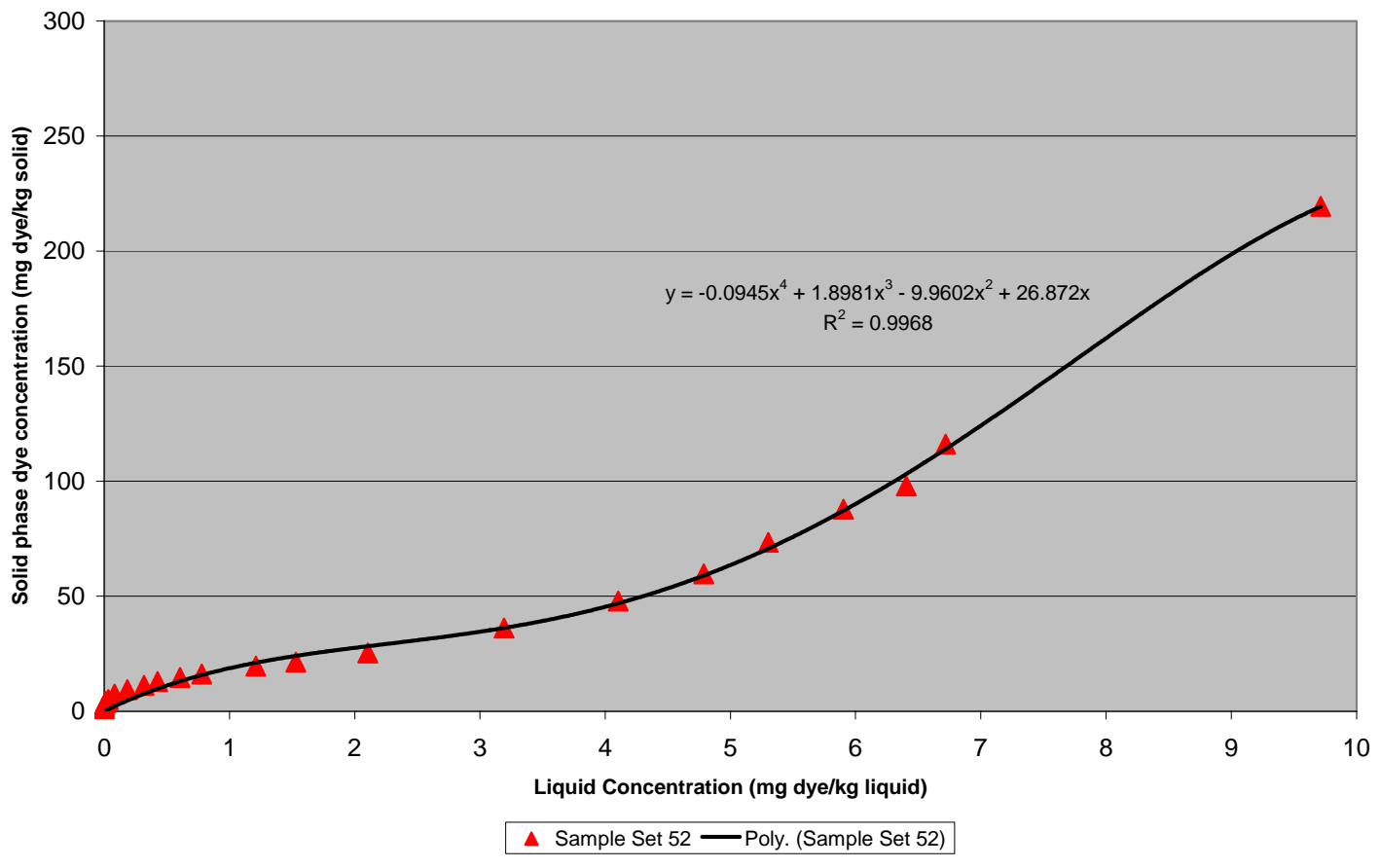

Figure C- 3. Polynomial Fit of Isotherm Data over the Linear Beer's Law Region 
During prototype testing, Equation C- 1 was used to calculate a fraction mixed for each sample at each sample location. These samples were drawn from different locations in the testing vessel. Sample locations 1, 2, and 3 were located near the tank wall at low elevations; Sample location 4 was also near the tank wall at a high elevation. During a test run of an experimental condition, e.g., $8 \mathrm{~m} / \mathrm{s}$ nozzle velocity, the sample lines were first purged by running the peristaltic pump at full speed until the sample line has been completely replaced. Then samples from all locations were taken approximately every 10 minutes after completion of dye injection. After 50 minutes of operation, the next run experimental condition, e.g., $12 \mathrm{~m} / \mathrm{s}$, was employed. The absorbance from each sample and the average fraction of the tank mixed calculated from all samples are given in the following figures.

As discussed, the error associated with the linear isotherm approximation is estimated through the use of Equation C- 2. In the worst case, typical errors due to this assumption are approximately less than \pm 0.15 fraction mixed; the error goes to zero as the fraction mixed approaches unity.

\section{C-2 DYE TEST RESULTS}

In this section, plots of absorbances (Figure C- 4 through Figure C-19) from samples taken at different tank locations are plotted as functions of sample number or test condition (nozzle velocity, air sparger flows. When possible, the calculated percent tank mixed volume is also plotted vs. test condition.

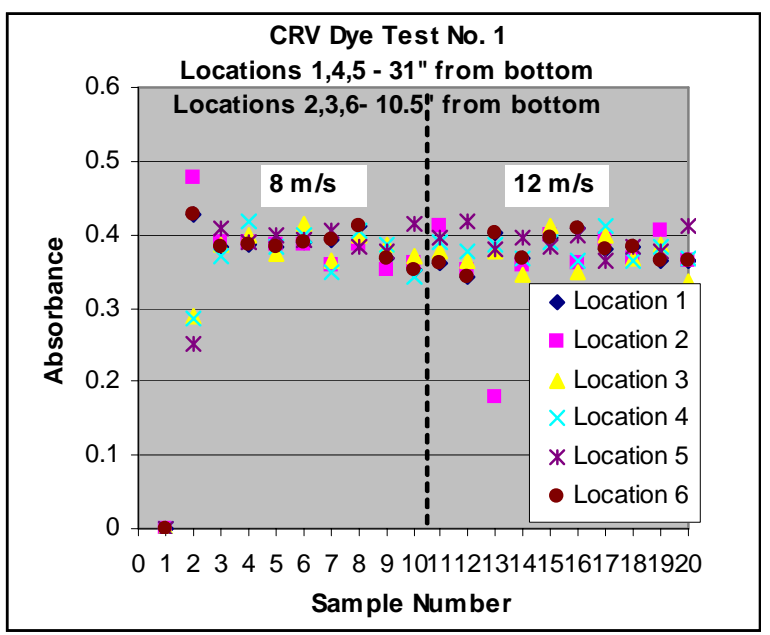

CRV Dye Test A-1

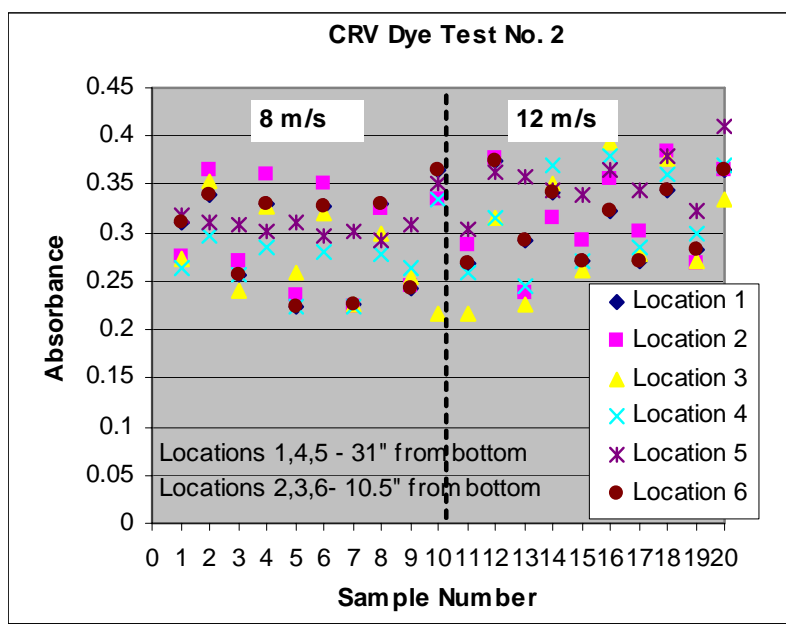

CRV Dye Test A-2

Figure C- 4. Absorbances 
WSRC-TR-2004-00398, REVISION 0

SRNL-RPP-2004-00060, REVISION 0

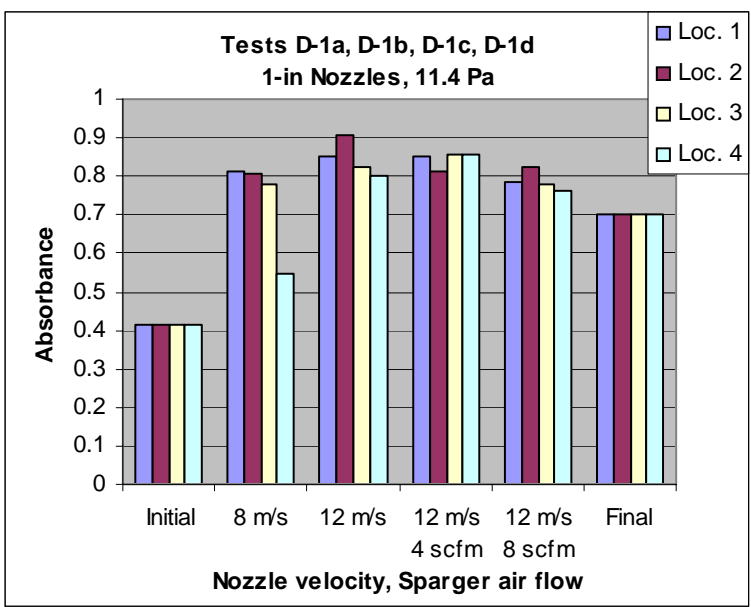

Absorbances

Figure C- 5. Test D-1a, 1b, 1c, 1d

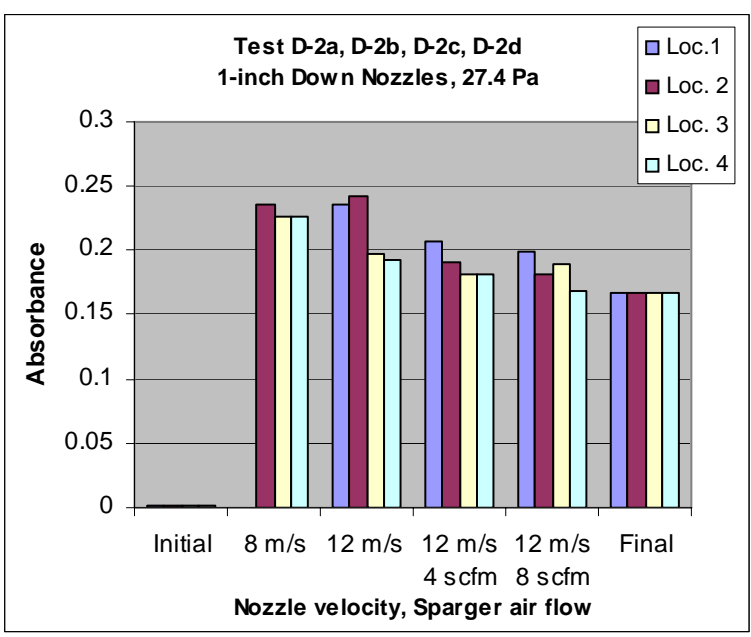

Absorbances

Figure C- 6. Test D-2a, 2b, 2c, 2d

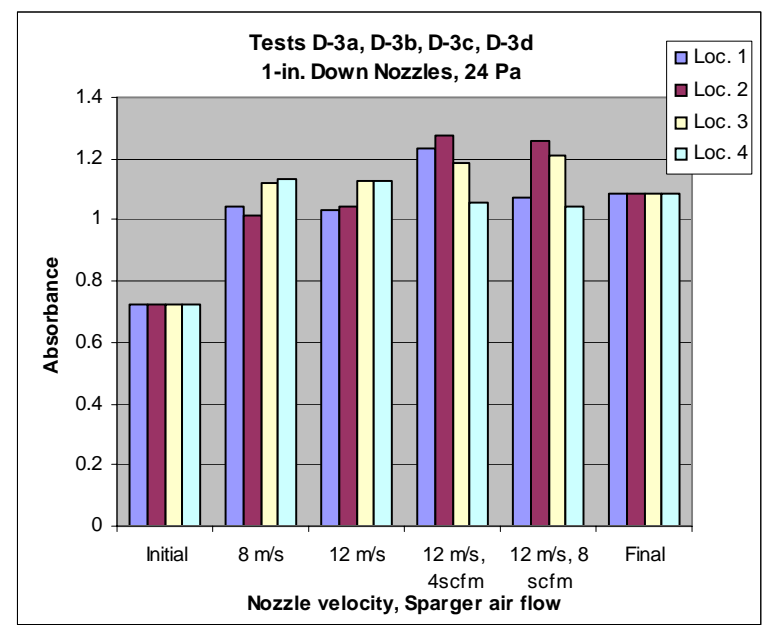

Absorbances

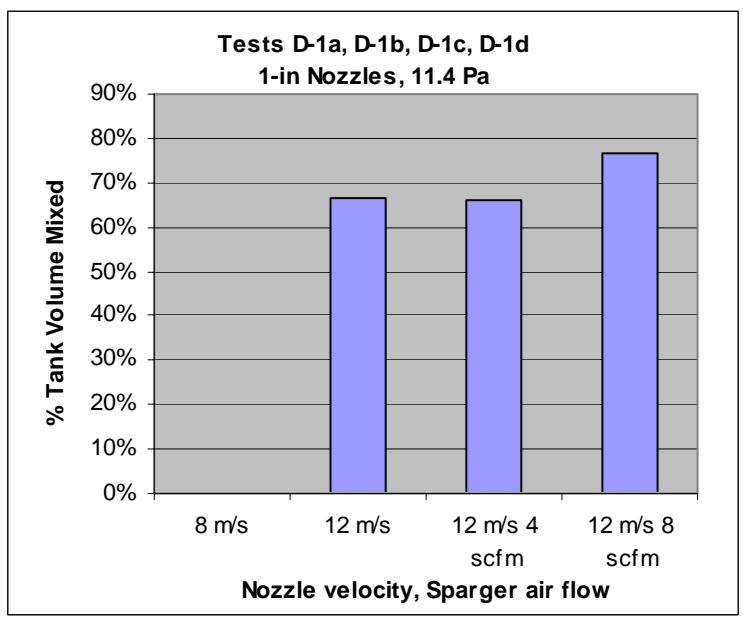

Tank Mixed Volumes

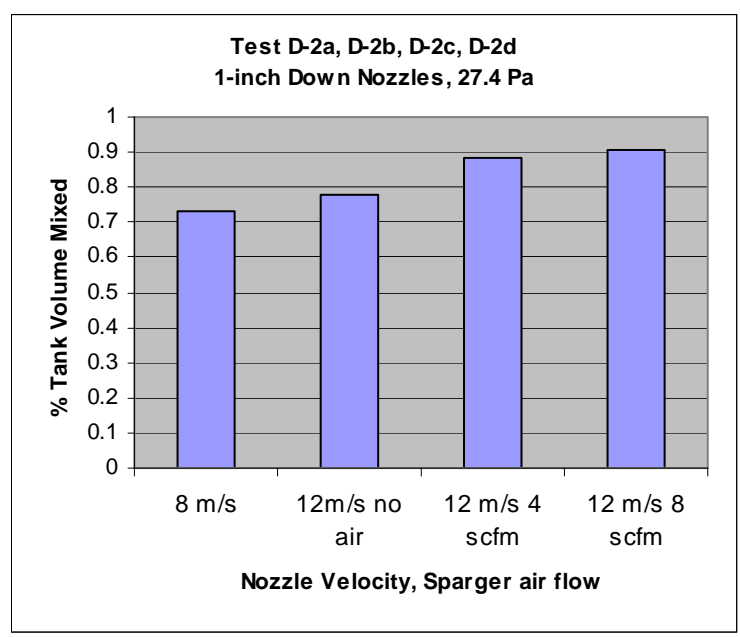

Tank Mixed Volumes

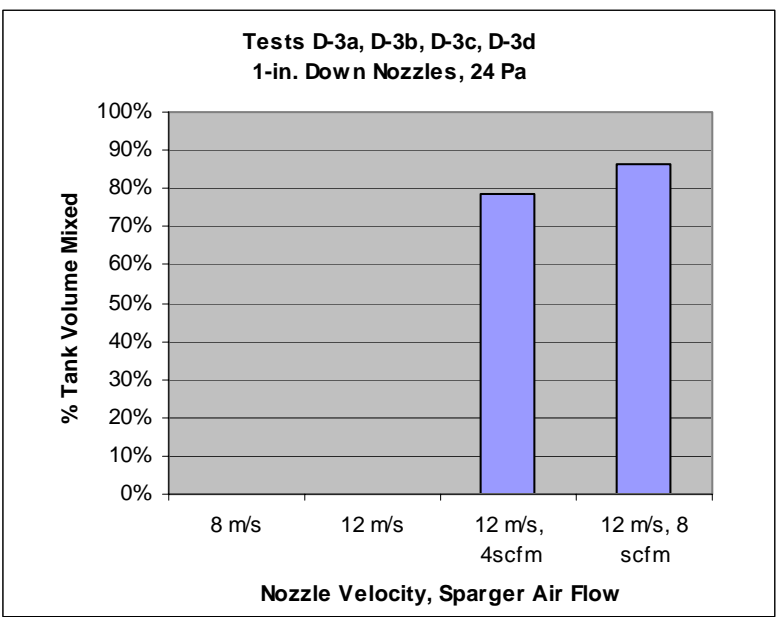

Tank Mixed Volumes

Figure C- 7. Test D-3a, 3b, 3c, 3d 
WSRC-TR-2004-00398, REVISION 0

SRNL-RPP-2004-00060, REVISION 0

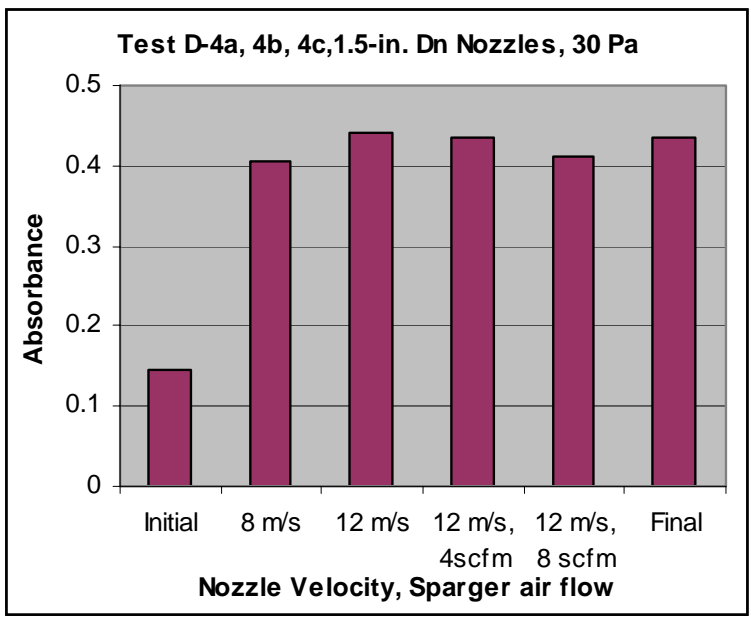

Absorbances

Figure C- 8. Test D-4a, 4b, 4c, 4d

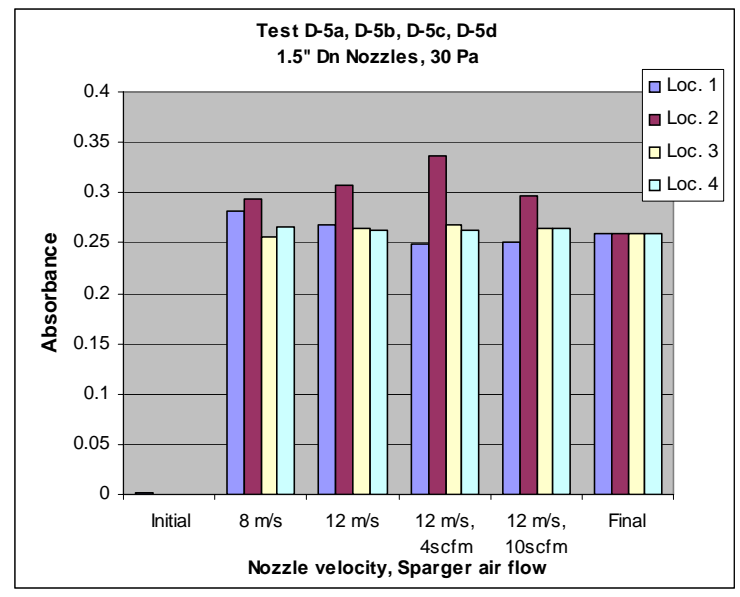

Absorbances

Figure C- 9. Test D-5a, 5b, 5c, 5d

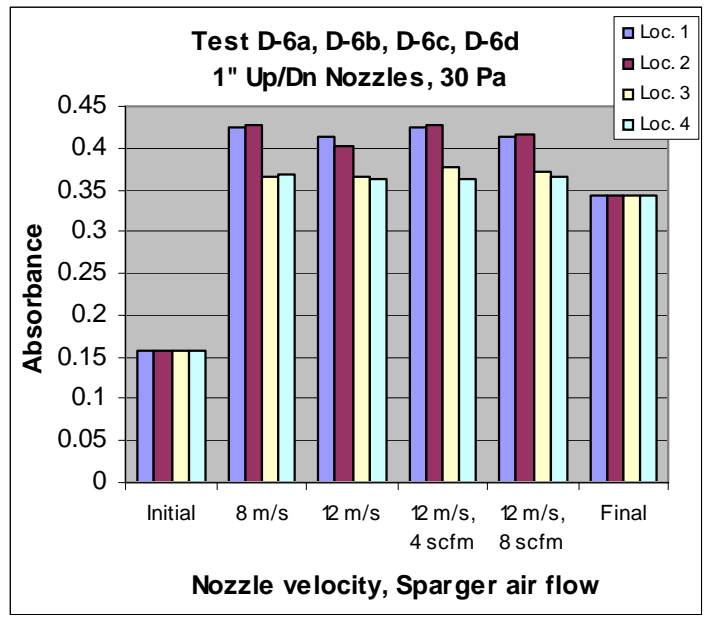

Absorbances

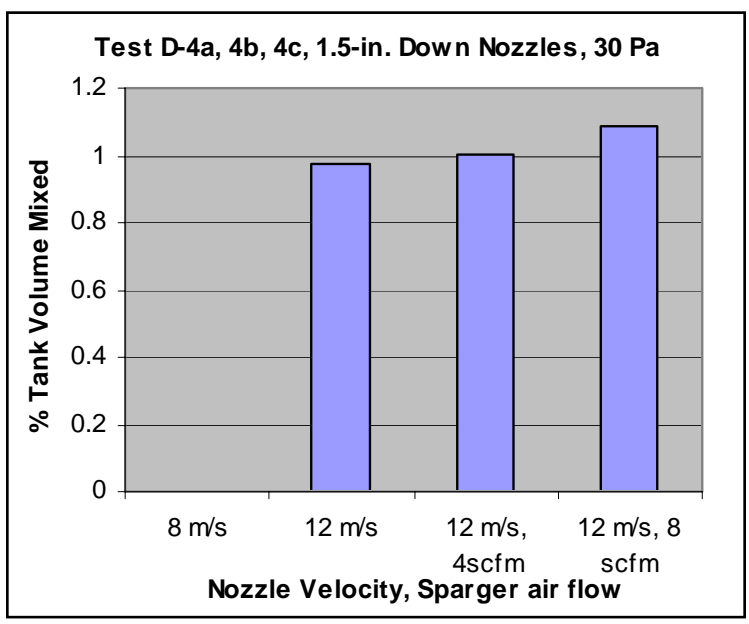

Tank Mixed Volumes

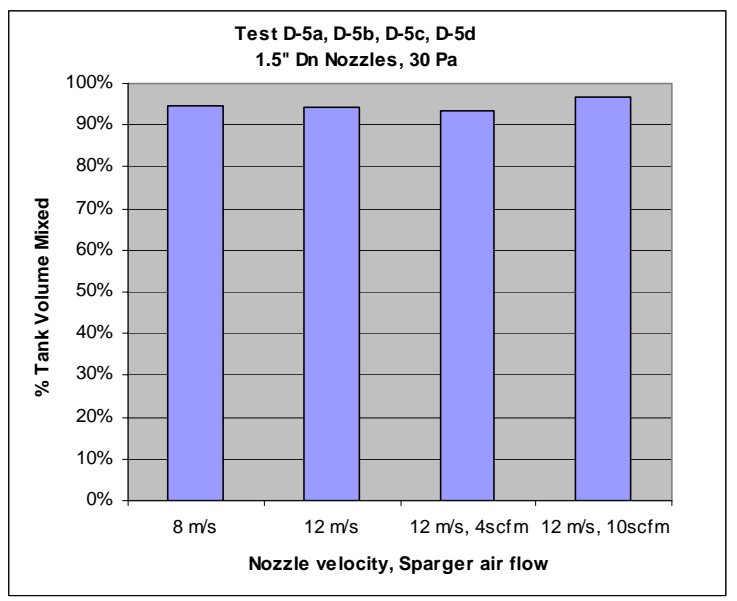

Tank Mixed Volumes

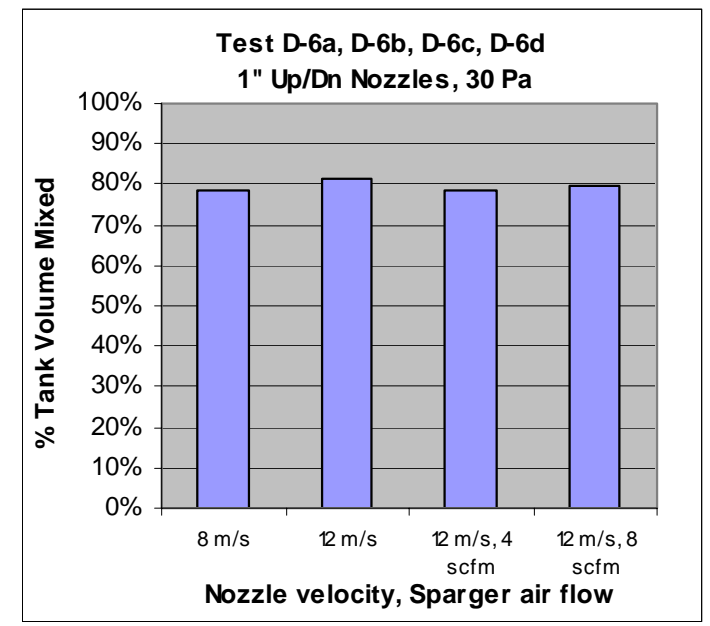

Tank Mixed Volumes

Figure C- 10. Test D-6a, 6b, 6c, 6d 
WSRC-TR-2004-00398, REVISION 0

SRNL-RPP-2004-00060, REVISION 0

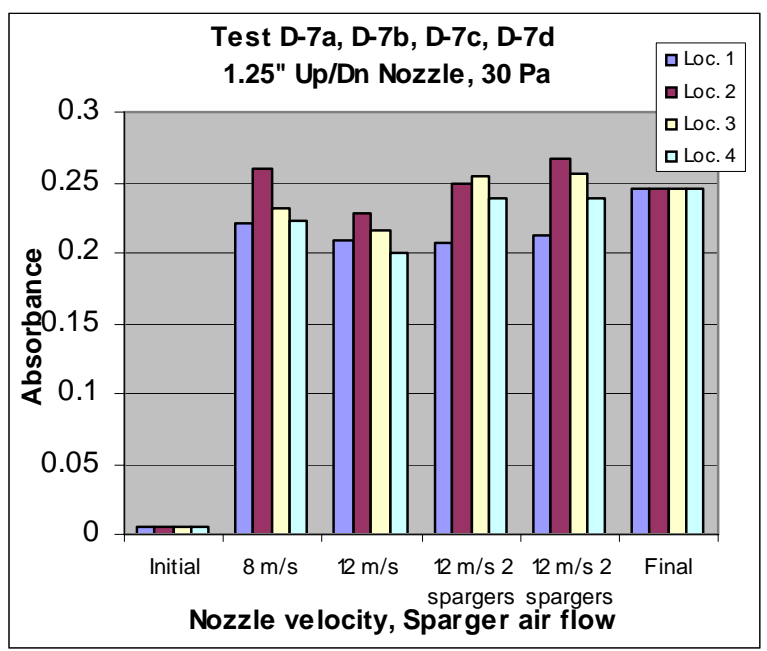

Absorbances

Figure C- 11. Test D-7a, 7b, 7c, 7d

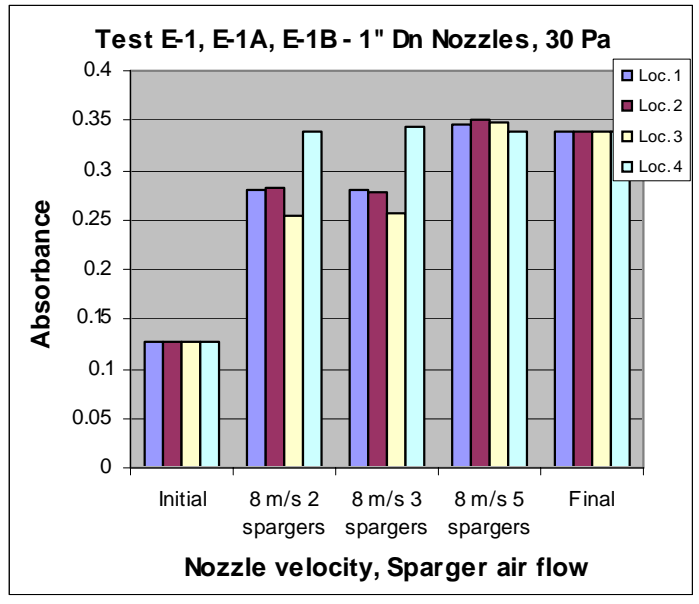

Absorbances

Figure C- 12. Test E-1, 1A, 1B

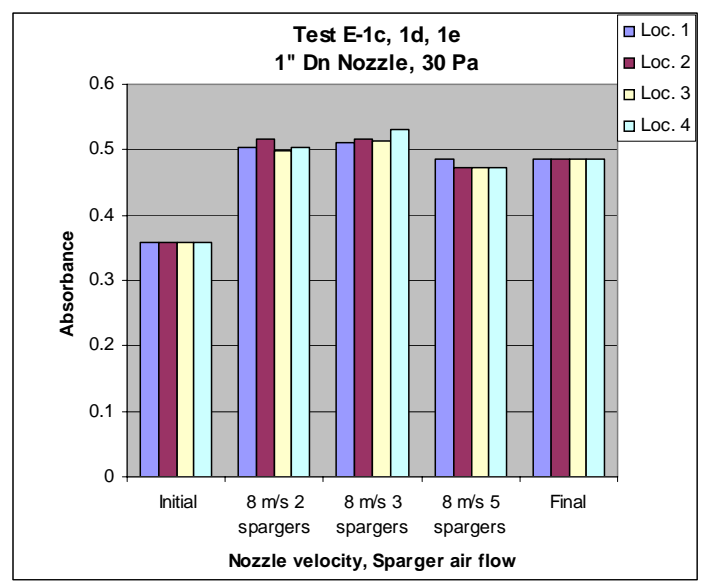

Absorbances

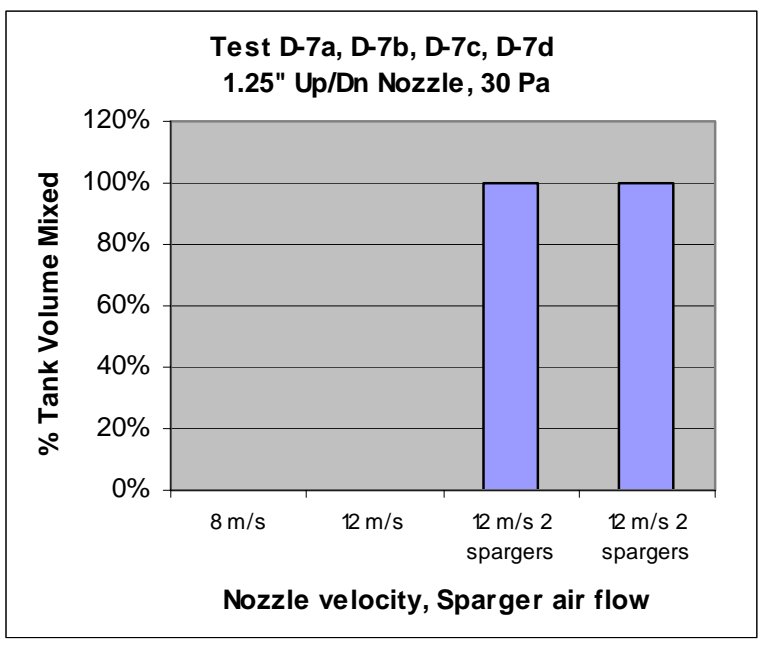

Tank Mixed Volumes

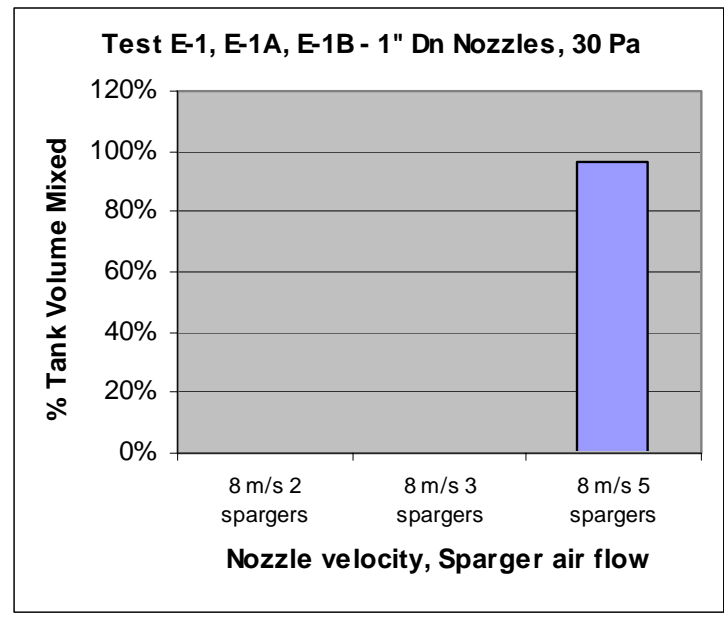

Tank Mixed Volumes

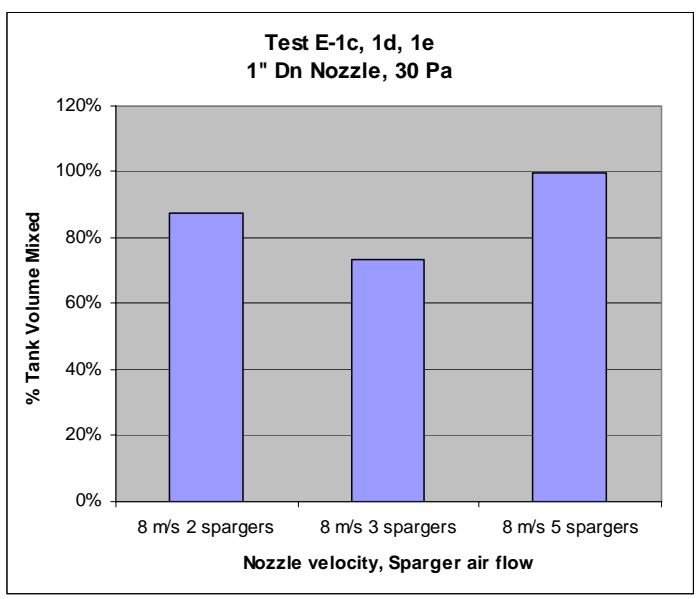

Tank Mixed Volumes

Figure C- 13. Test E-1C, 1D, 1E 
WSRC-TR-2004-00398, REVISION 0

SRNL-RPP-2004-00060, REVISION 0

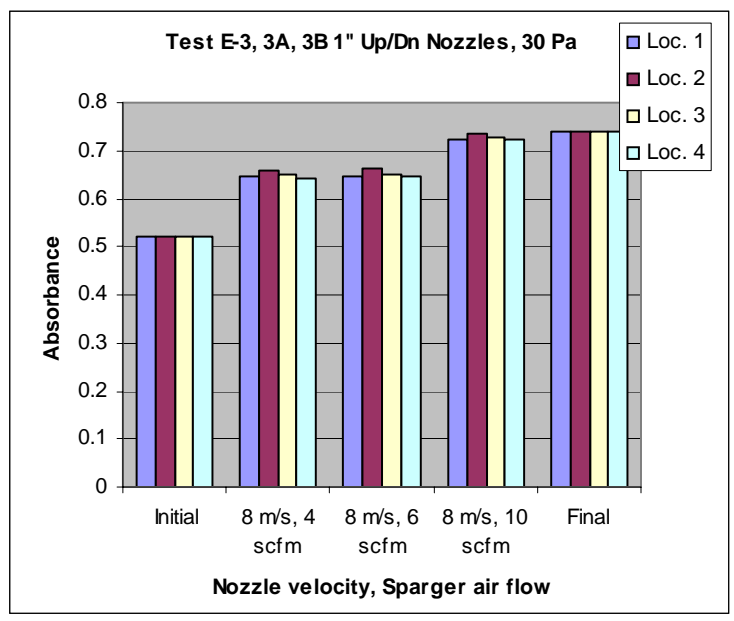

Absorbances

Figure C- 14. Test E-3, 3A, 3B

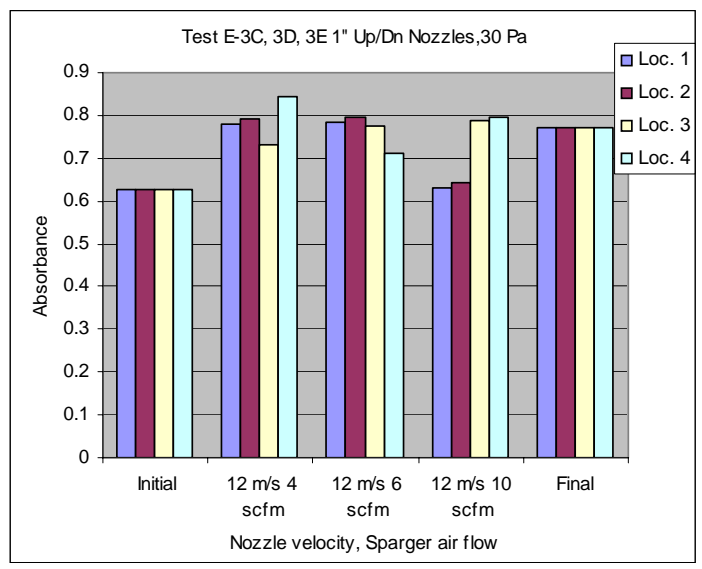

Absorbances

Figure C- 15. Test E-3C, 3B, 3C, 3D

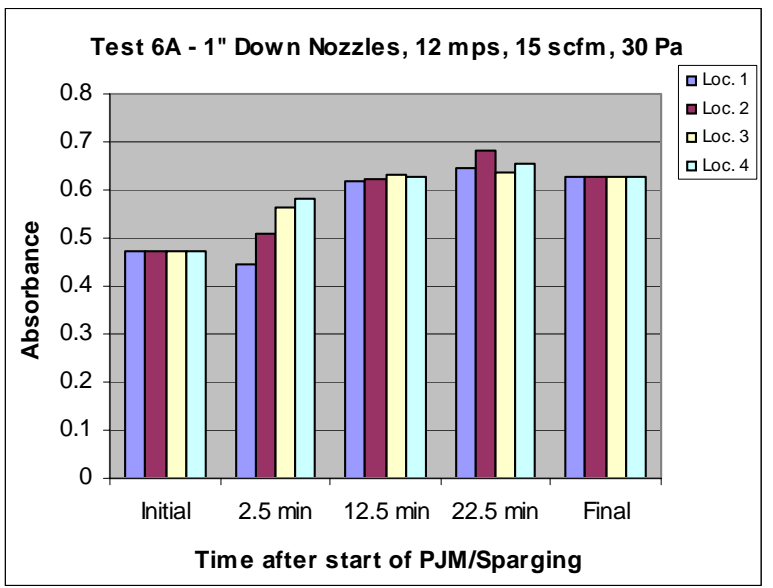

Absorbances

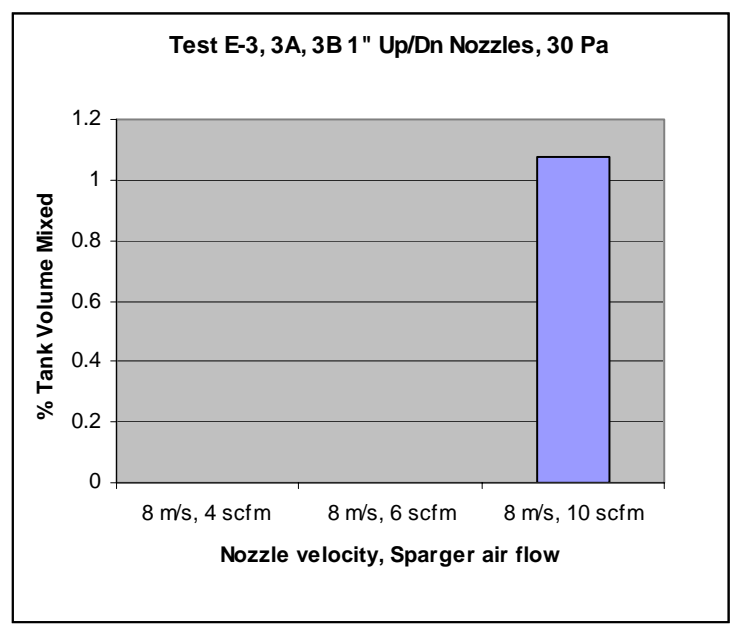

Tank Mixed Volumes

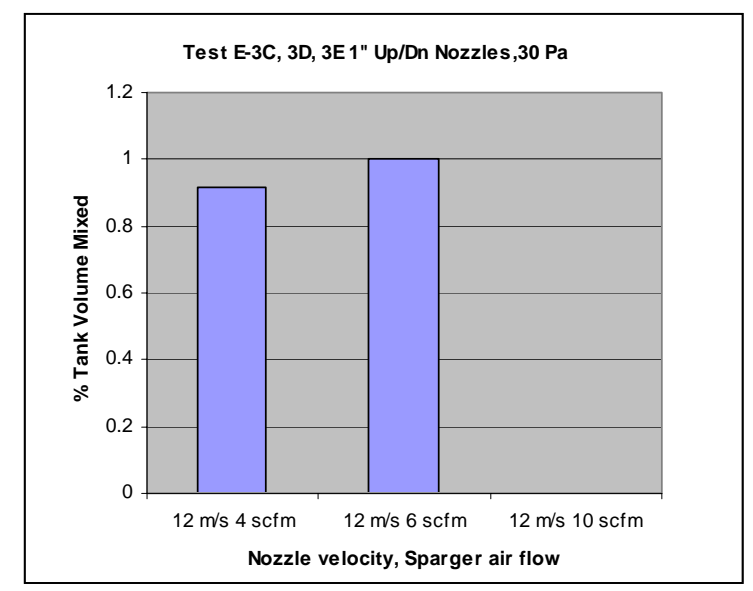

Tank Mixed Volumes

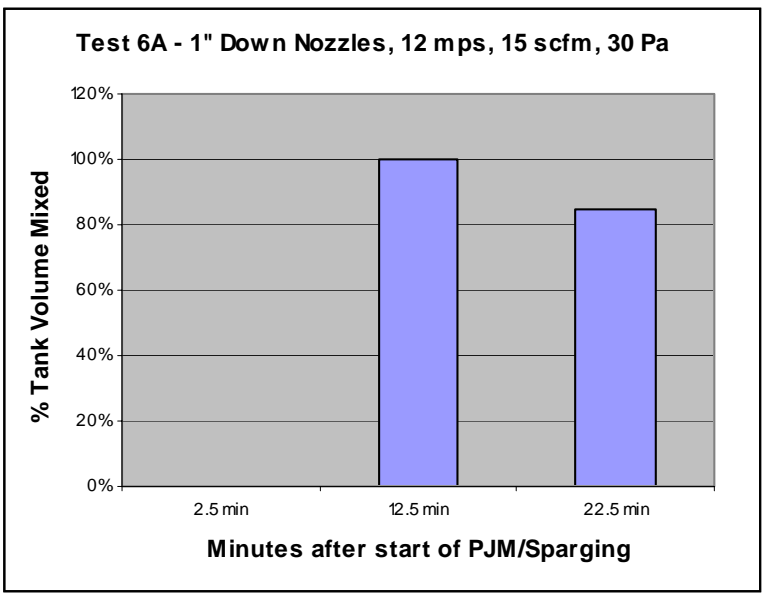

Tank Mixed Volumes

Figure C- 16. Test E-6A 
WSRC-TR-2004-00398, REVISION 0

SRNL-RPP-2004-00060, REVISION 0

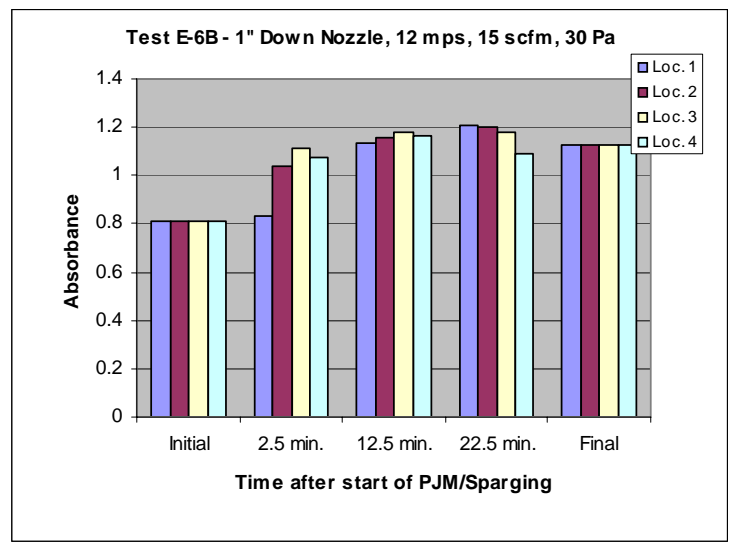

Absorbances

Figure C- 17. Test E-6B

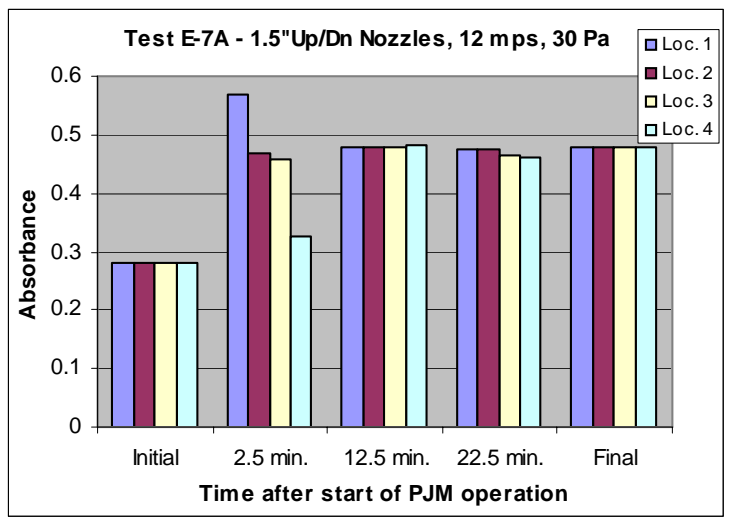

Absorbances

Figure C- 18. Test E-7A

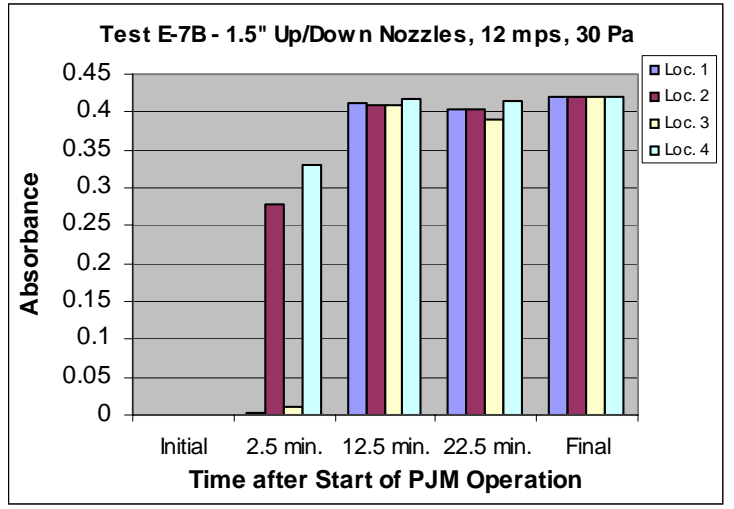

Absorbances

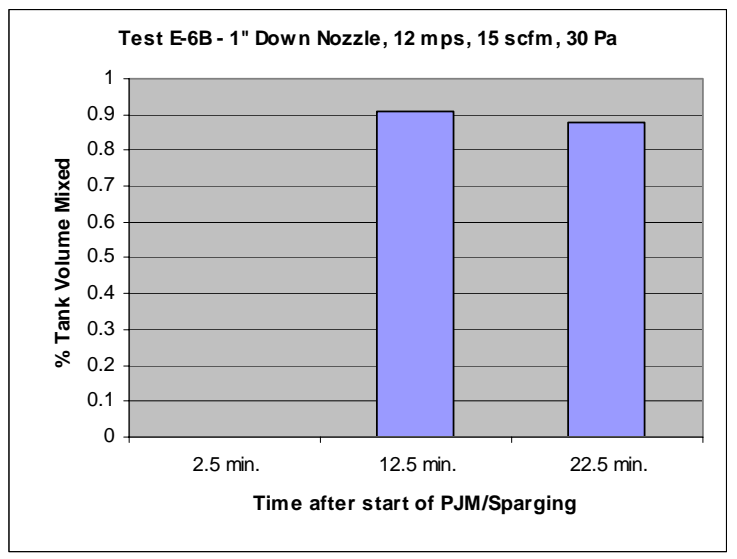

Tank Mixed Volumes

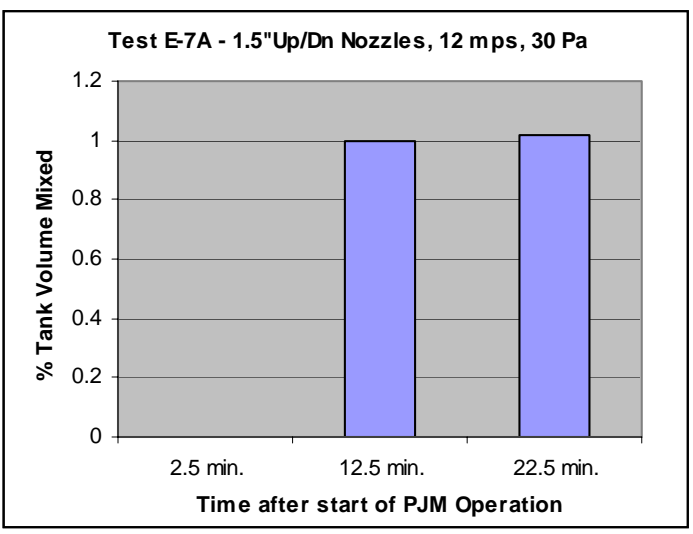

Tank Mixed Volumes

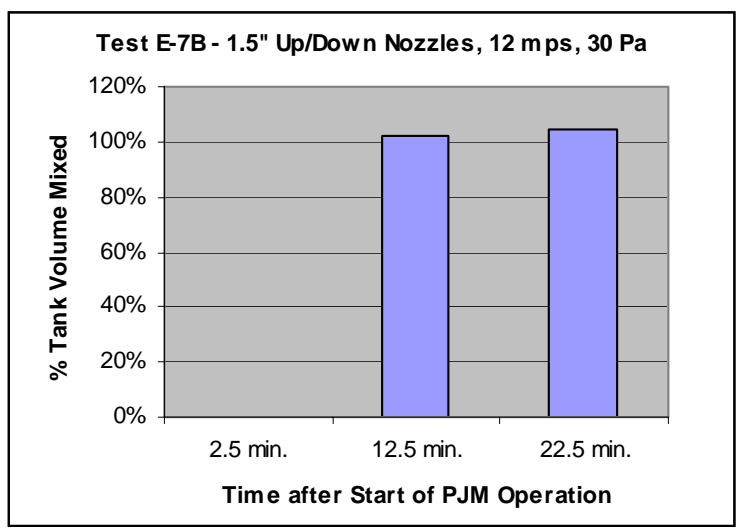

Tank Mixed Volumes

Figure C- 19. Test E-7B 
WSRC-TR-2004-00398, REVISION 0

SRNL-RPP-2004-00060, REVISION 0

This page intentionally left blank. 
WSRC-TR-2004-00398, REVISION 0

SRNL-RPP-2004-00060, REVISION 0

\section{APPENDIX D. \\ ULTRASONIC VELOCITY PROBE}

The principle of the Ultrasonic Velocity Probe (UVP) is described in reference to Figure D- 1, as follows:

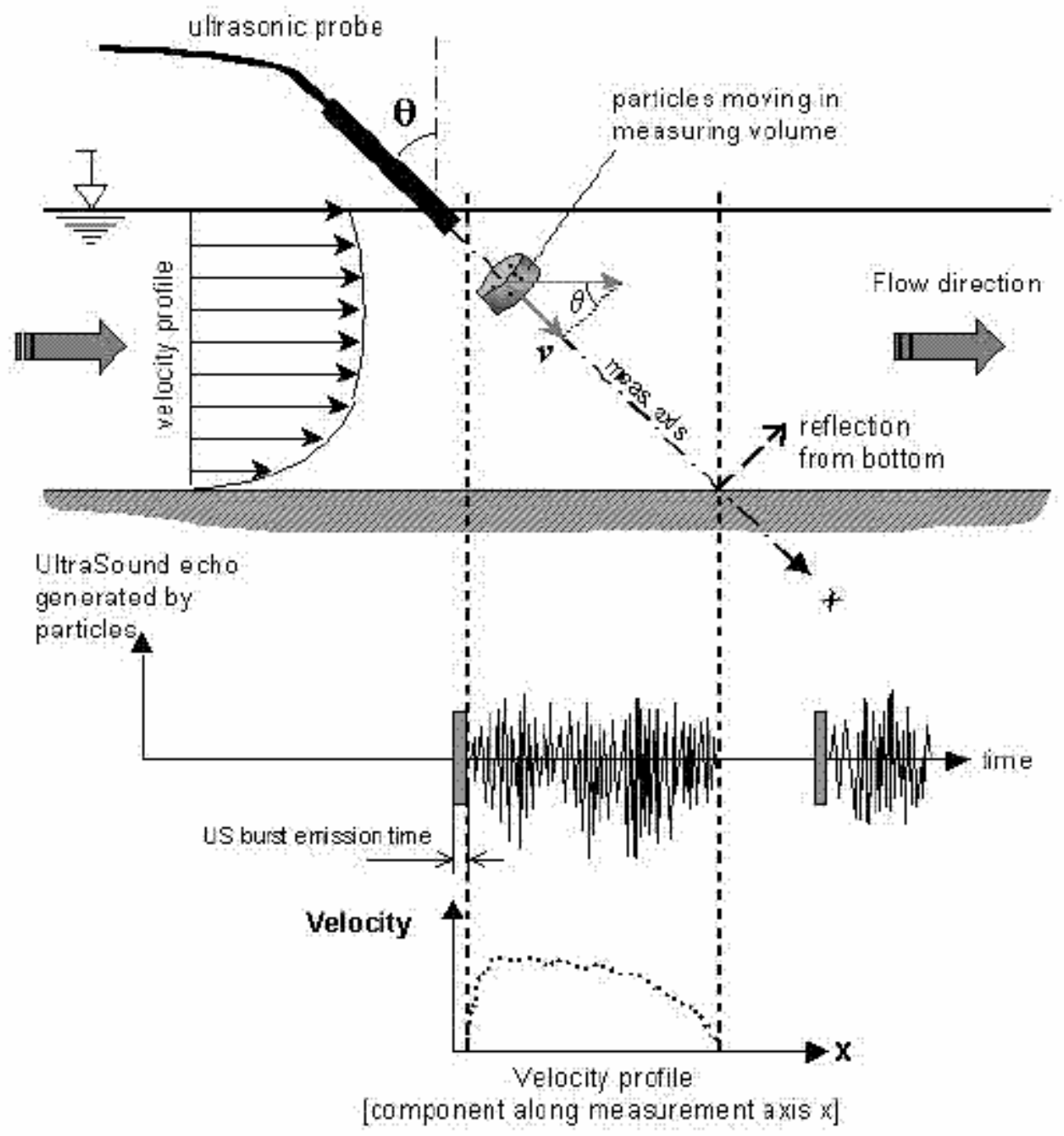

Figure D- 1. Schematic Picture of UVP Velocity Profile Measurement on a Flow with Free Surface 
An ultrasonic transducer transmits a short emission of ultrasound (US), which travels along the measurement axis Lm, and then switches over to receiving (listening). When the US pulse hits a small particle in the liquid, part of the US energy scatters on the particle and echoes back. The echo reaches the transducer after a time delay.

Equation D- 1

$$
t=\frac{2 x}{c}
$$

where $t$ time delay between transmitted and received signal [s]

$x \quad$ distance of scattering particle from transducer [m]

$c \quad$ speed of sound in the liquid $[\mathrm{m} / \mathrm{s}]$

If the scattering particle is moving with non-zero velocity component into the acoustic axis Lm of the transducer, Doppler shift of echoed frequency takes place, and received signal frequency becomes Doppler-shifted. The velocity of the particle is then given by:

$$
\begin{aligned}
& \text { Equation D- } 2 \quad v=\frac{f_{d}}{2 f_{o}} c \\
& \text { where } v \quad \text { velocity component into transducer axis }[\mathrm{m} / \mathrm{s}] \\
& c \quad \text { sound velocity in liquid }[\mathrm{m} / \mathrm{s}] \\
& f_{d} \quad \text { Doppler shift [Hz] } \\
& f_{0} \quad \text { transmitting frequency }[\mathrm{Hz}]
\end{aligned}
$$

In Equation D- 2, both source of oscillations (transducer) and observer (also the transducer) are stationary, and the reflector moves. One Doppler shift is created by relative movement of reflector to source, and additional Doppler shift is created by relative movement of reflector to observer. Hence, twice as high Doppler shift results.

If the UVP succeeds to measure the delay $t$ and Doppler shift $f_{d}$, it is then possible to calculate both position and velocity of a particle. Thus, the principle of the UVP is similar to the radar gun. Many ultrasonic probes are on the market, but the Met-Flow UVP DUO was used in this application due to its ability to measure the velocity profile along the measurement axis and the ability to use probes of different frequencies.

Figure D- 2 gives a graphic illustration of the propagation of an ultrasonic wave in a medium. The UVP starts collecting Doppler shift data after an initial time delay corresponding to the travel time of the wave to the first measurement volume and stores the data for that measurement volume in a register or channel. This first volume is called the starting channel. The UVP continues collecting data at specified time intervals to correspond to a given depth, channel width, and channel distance. There are certain tradeoffs between the transducer frequencies, measurement window or maximum measurable depth, and velocity resolutions. The reader is referred to the Met-Flo UVP-DUO Measurement Guide for these aspects of the UVP operation. 
WSRC-TR-2004-00398, REVISION 0

SRNL-RPP-2004-00060, REVISION 0

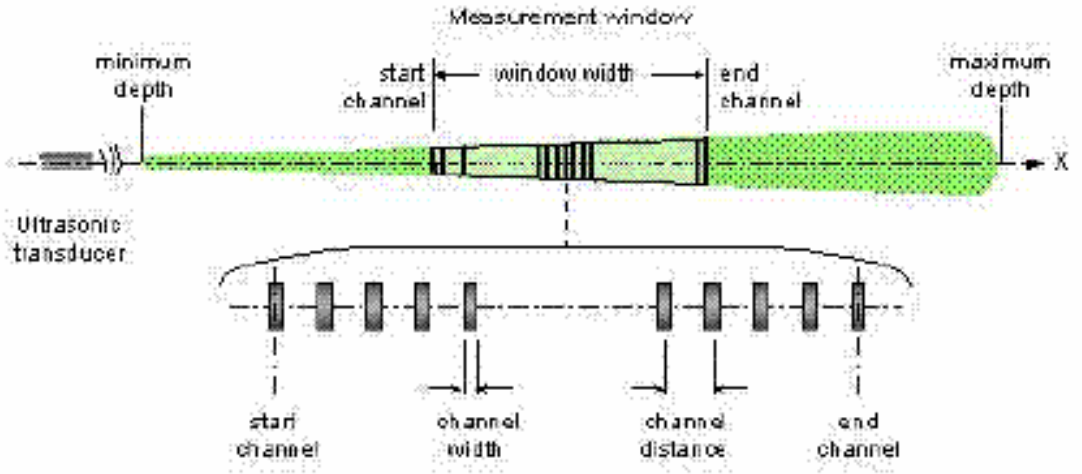

Figure D- 2. Illustration of How the UVP Measures Velocity at Many Different Points

A principal difficulty in using ultrasonic probes in the kaolin/bentonite slurry simulant was the highly attenuating nature of the slurry to ultrasonic waves. For this reason, 1 and $2 \mathrm{MHz}$ probes were used, which generally provided maximum measurable distances of about 4 inches in the slurry. The Doppler velocity method works on first principles if an independent method of measuring speed of sound can be established, such as the back-scatter method. However, this was difficult to do in the slurry/simulant due to high attenuation of the signal resulting in large uncertainties. Consequently, the UVP was calibrated against a magnetic flowmeter in a flow loop that contained the simulant. A speed of sound in the simulant was backed out of the calibration and then used in the software to measure fluid velocities during the tests. This provided a direct calibration of the UVP probe. A speed of sound of $1430 \mathrm{~m} / \mathrm{s}$ in the $30 \mathrm{~Pa}$ simulant was measured, using this method.

Figure D- 3 is a typical time-series plot of the velocity with the probe looking downwards at the 16-inch elevation in the region between the sampling vessels and the PJMs. This is where the lowest flows are expected. The negative velocities indicate that the flow is going toward the probe or upwards. The velocities for four cycles are captured and the peak velocities for four pulses are averaged. Thus in this example, the average peak velocity is approximately $500 \mathrm{~mm} / \mathrm{sec}$ between small charge vessels and PJMs at the 16-inch elevation, Test E-1c. Figure D.4 is a typical time-series velocity plot for a horizontally directed probe in the region between the small charge vessels and the PJMs at an elevation of 25 inches for Test Run E-1c. Here, some of the mostly upward jet energy is converted to a horizontal component, as the flow nears the cavern boundary. 
WSRC-TR-2004-00398, REVISION 0

SRNL-RPP-2004-00060, REVISION 0

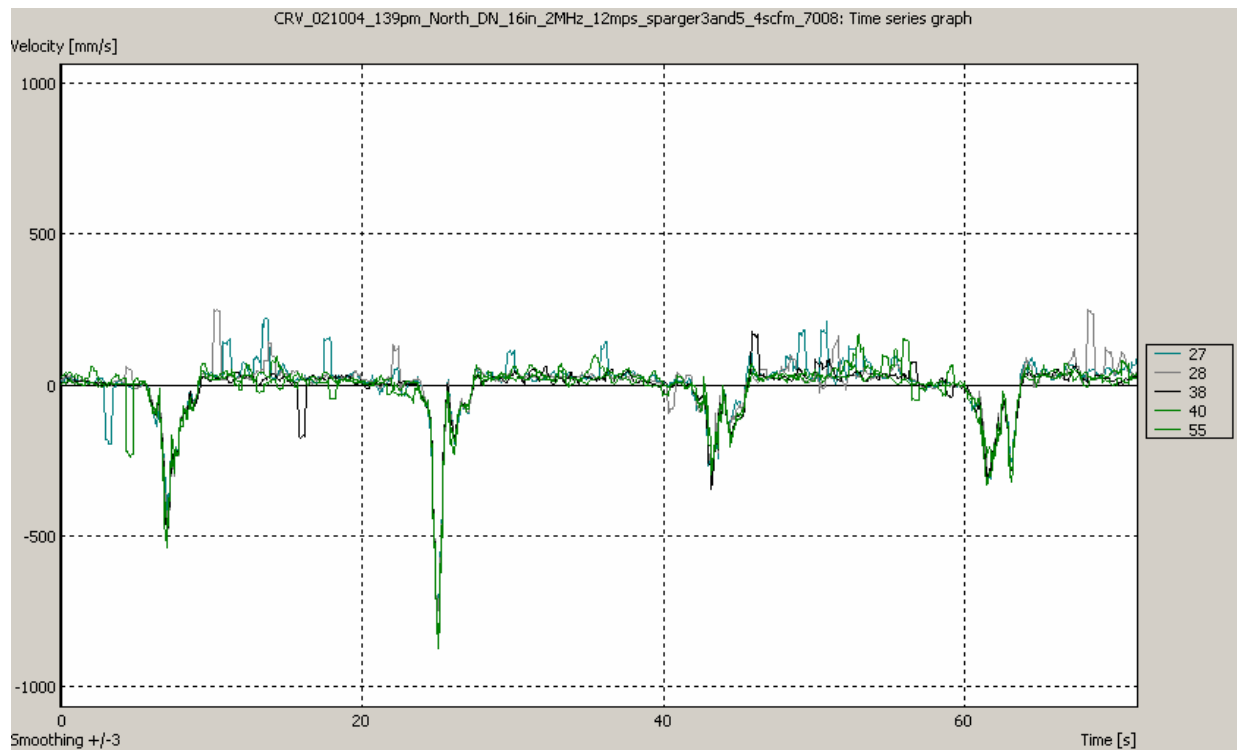

Figure D- 3. UVP Velocity Measurements for a Downward-Looking Probe in the Region

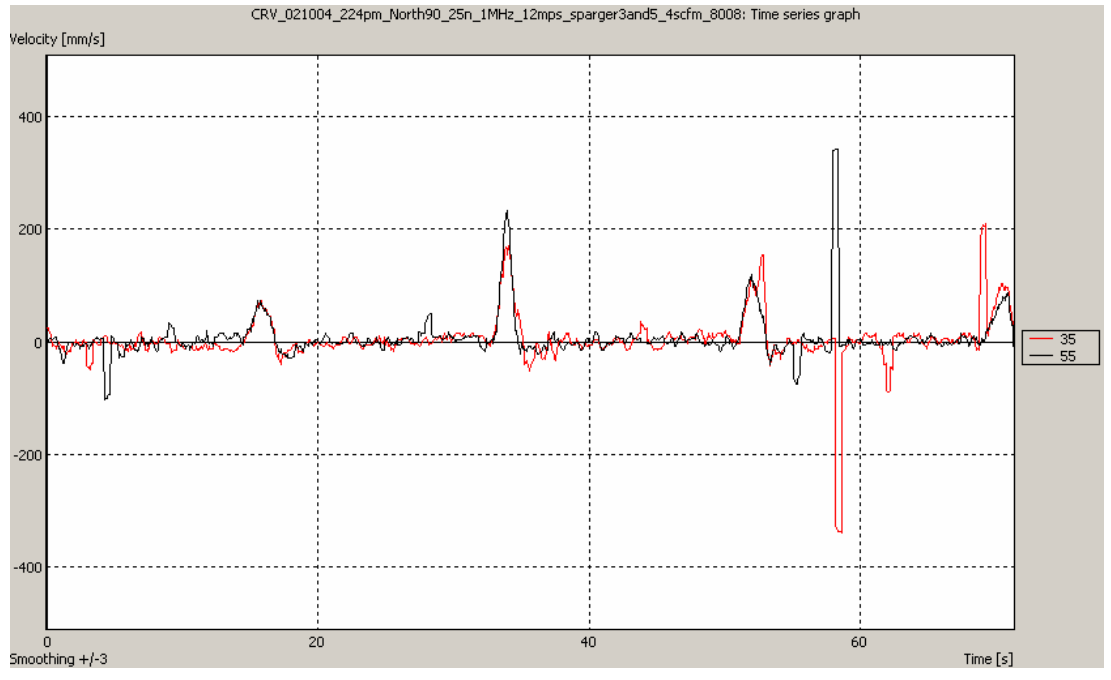

Figure D- 4. UVP Velocity Measurements for a Horizontal Probe in the Region between Small Charge Vessels and PJMs at the 25-inch Elevation, Test E-1c

Figure D- 5 is a typical time-series plot of the measured velocity near the top of the vessel (35-inch elevation) for the case of sparging with air flows of approximately $3 \mathrm{scfm}$ per sparger ( 5 spargers total) at the same radial location as in Figure D- 1 and Figure D- 2. This was for the case of 1.5 inch J-nozzles (upwards pointing), which is not considered in this report. However, this low flow region at this elevation is hardly affected by the J-nozzles. 
WSRC-TR-2004-00398, REVISION 0

SRNL-RPP-2004-00060, REVISION 0

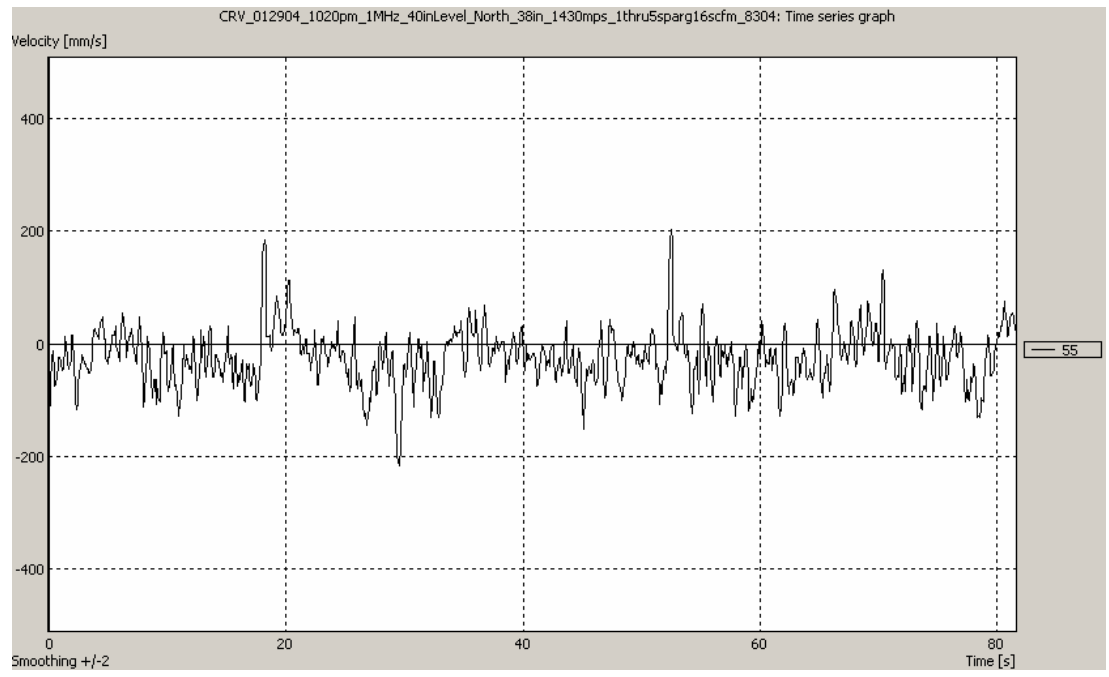

Figure D- 5. UVP Velocity Measurements for a Horizontal Probe in the Region between Small Charge Vessels and PJMs at the 35-inch Elevation, with 5 spargers (J-nozzle case)

Figure D- 6 gives the locations of the UVP probe for the UVP measurements in Figures D.7 through D.14.

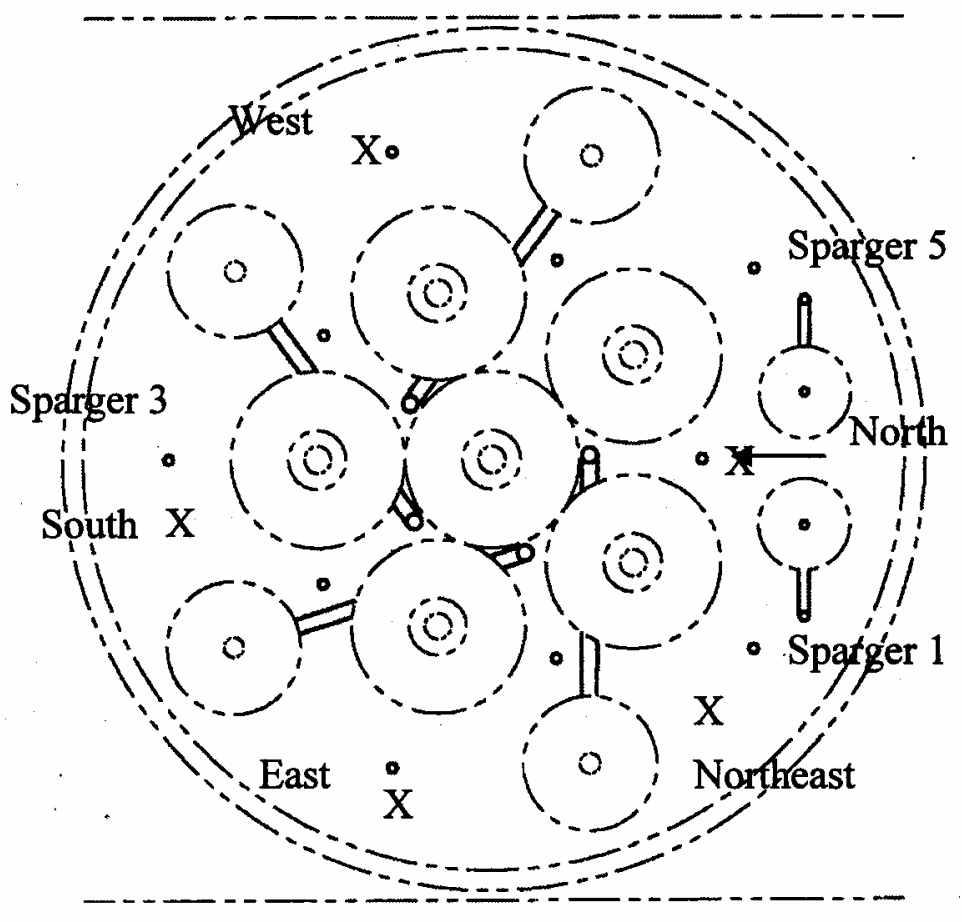

Figure D- 6. UVP Probe Locations 
Figure D- 7 is a plot of the average peak velocity for two probes, one looking downwards, and the other 90 degrees to the first or horizontal towards the tank center at a location away from the spargers. The criteria for indicating a cavern is when the horizontal probe reading is of the order of $80 \mathrm{~mm} / \mathrm{s}$, which for this case is 30 inches. The downward looking probe still indicates a high level above $100 \mathrm{~mm} / \mathrm{s}$, but this is mostly a plug type of flow with low radial flow component. 
WSRC-TR-2004-00398, REVISION 0

SRNL-RPP-2004-00060, REVISION 0

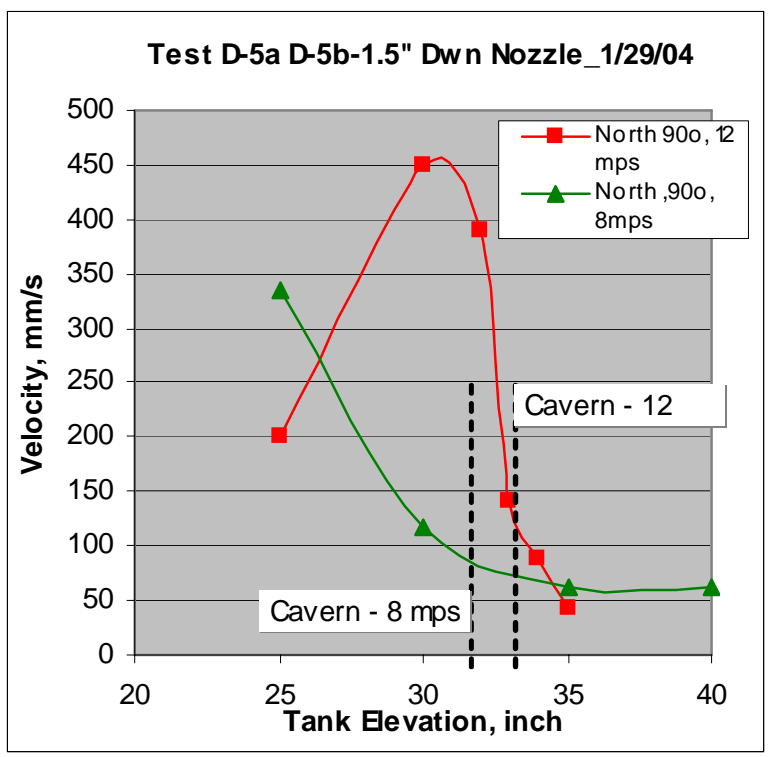

(a)

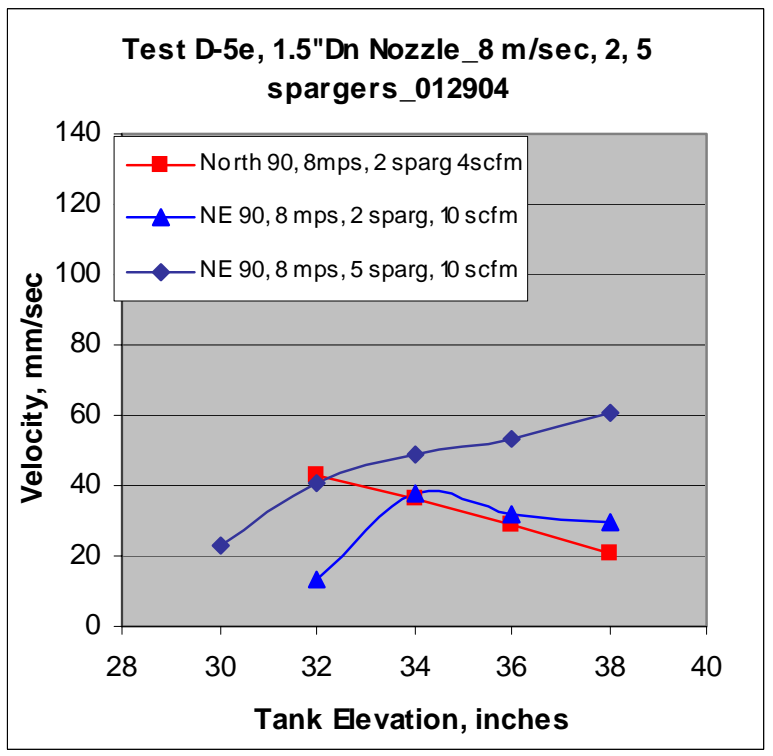

(c)

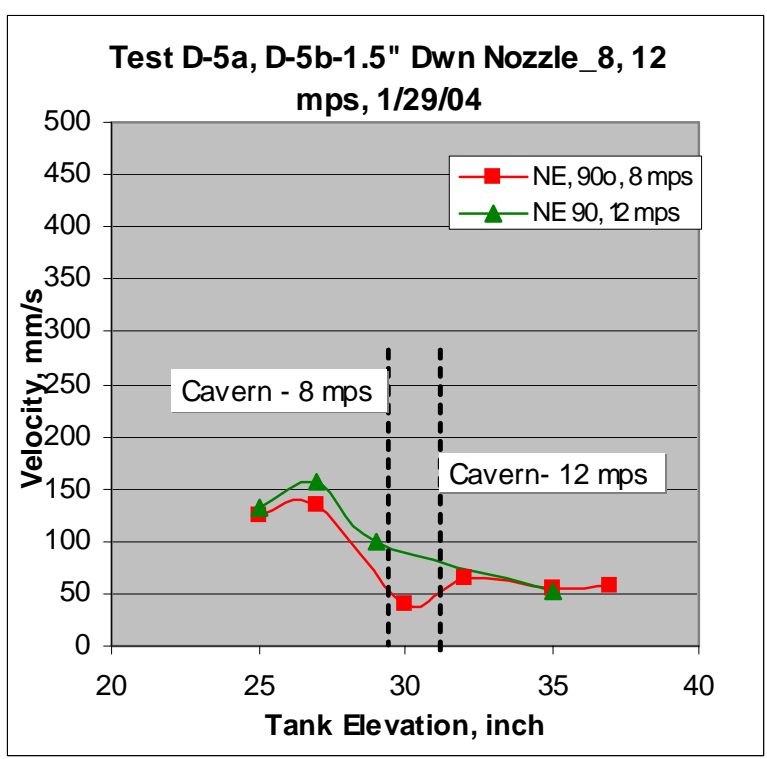

(b)

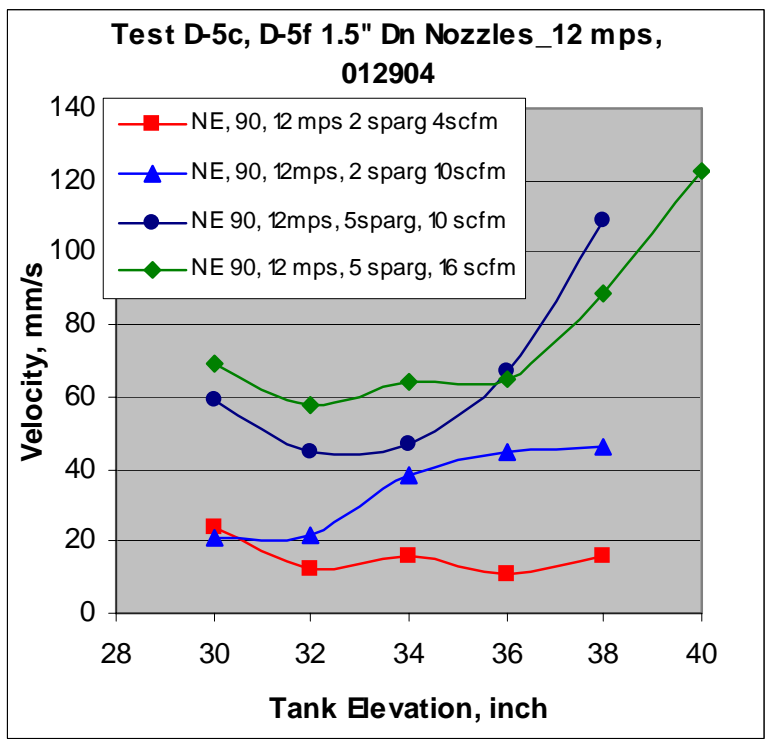

(d)

Figure D- 7. UVP Measurements for Test D-5a and D-5b for (a) North $-8 \mathrm{~m} / \mathrm{s}$, (b) Northeast-8 m/s, (c) North-12m/s; and (d) Northeast-12 m/s 
WSRC-TR-2004-00398, REVISION 0

SRNL-RPP-2004-00060, REVISION 0

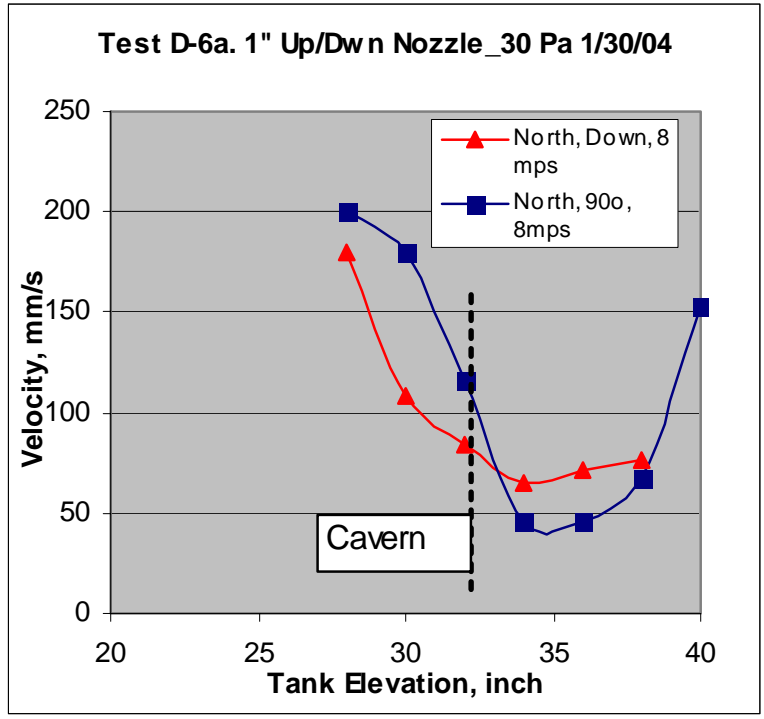

(a)

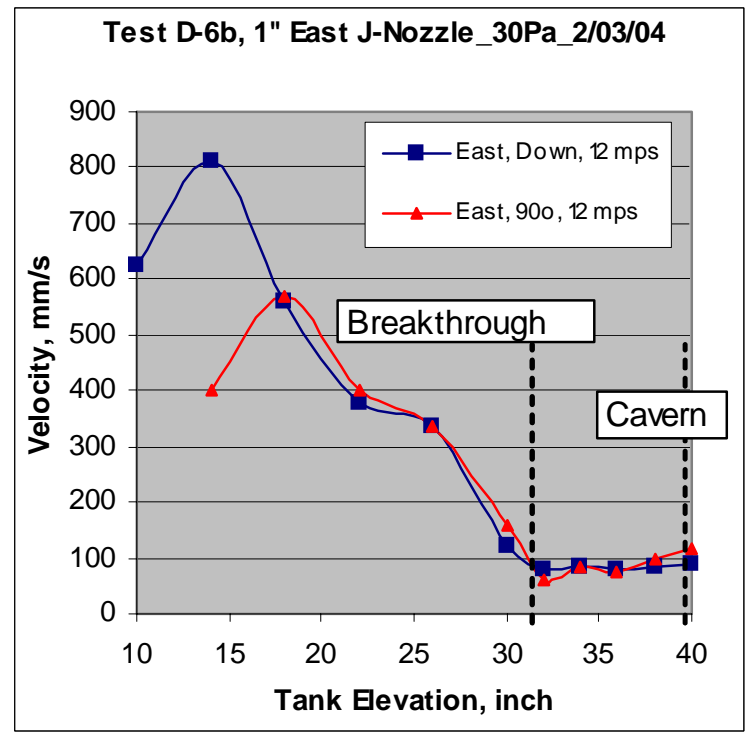

(c)

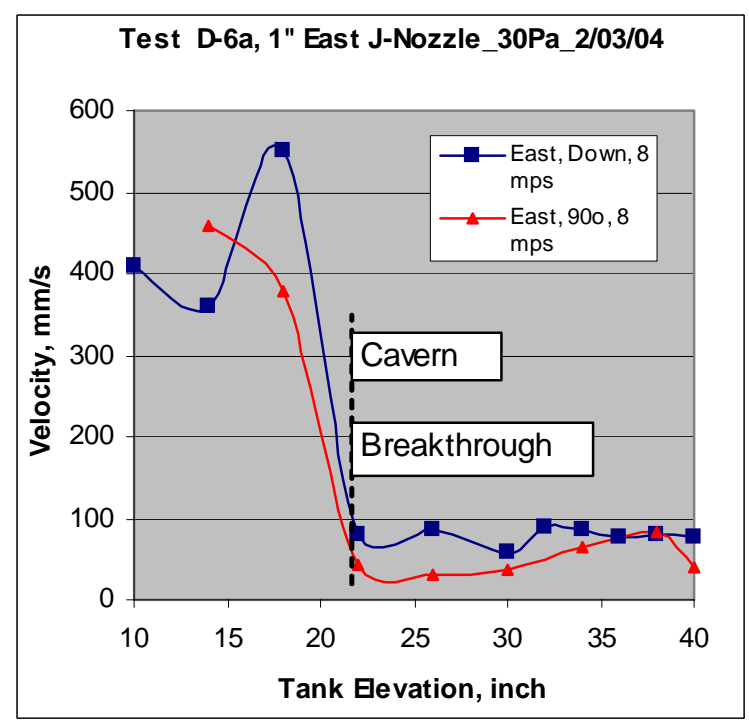

(b)

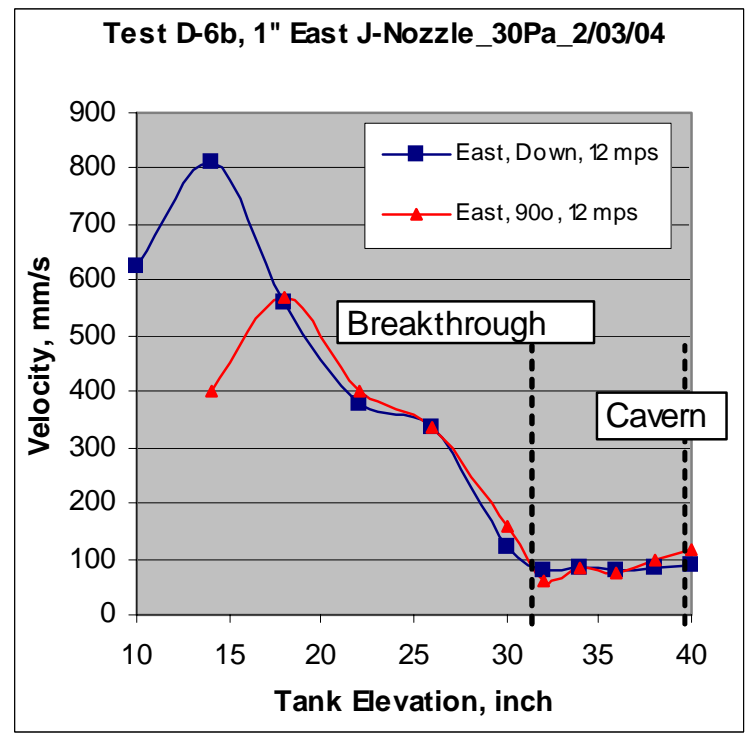

(d)

Figure D- 8. UVP Measurements for Test D-6a and D-6b for (a) North $-8 \mathrm{~m} / \mathrm{s}$, (b) East-8 m/s, (c) North-12m/s; and (d) East-12 m/s 
WSRC-TR-2004-00398, REVISION 0

SRNL-RPP-2004-00060, REVISION 0

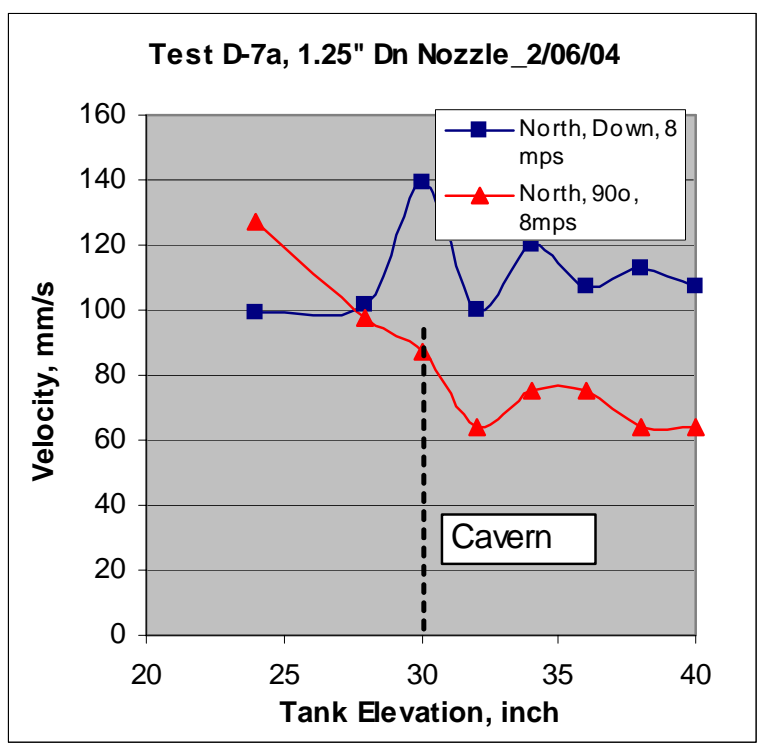

(a)

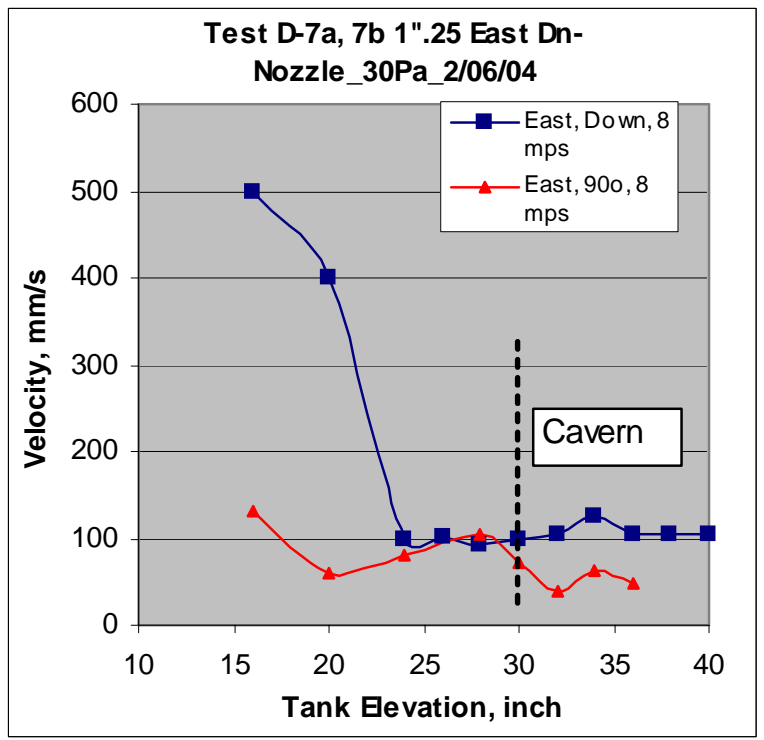

(c)

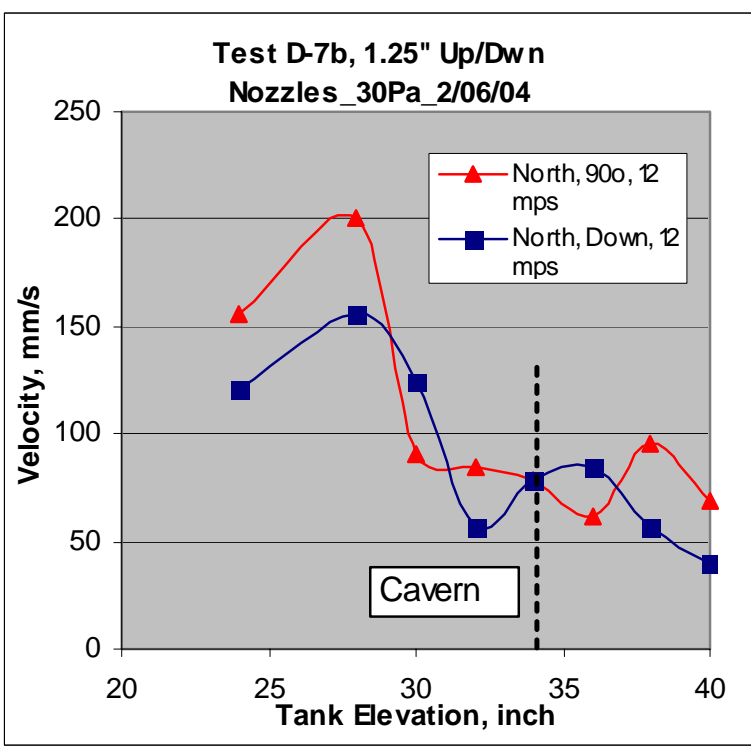

(b)

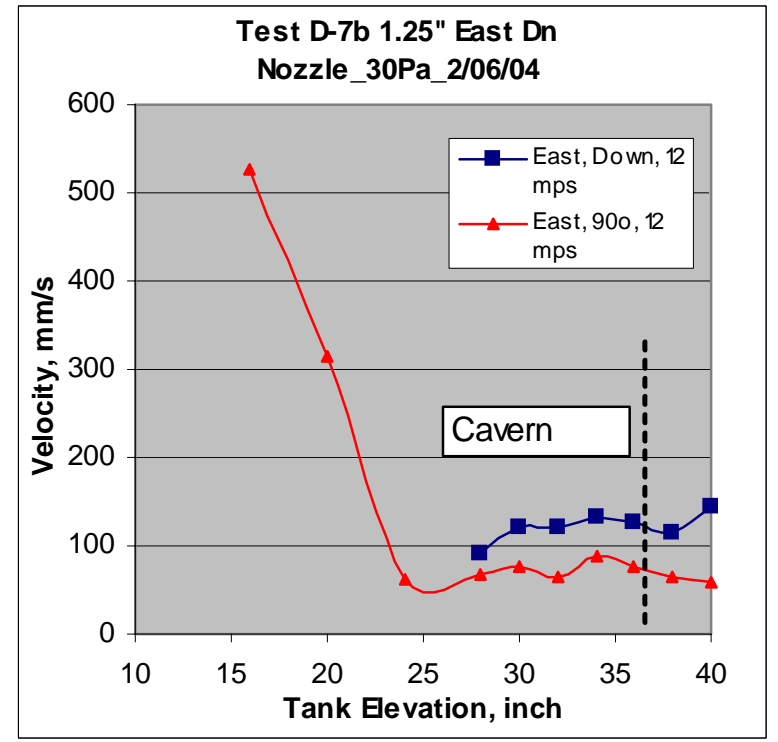

(d)

Figure D- 9. UVP Measurements for Test D-7a and D-7b for (a) North $-8 \mathrm{~m} / \mathrm{s}$, (b) North-12 m/s, (c) East-8m/s; and (d) East-12 m/s 
WSRC-TR-2004-00398, REVISION 0

SRNL-RPP-2004-00060, REVISION 0

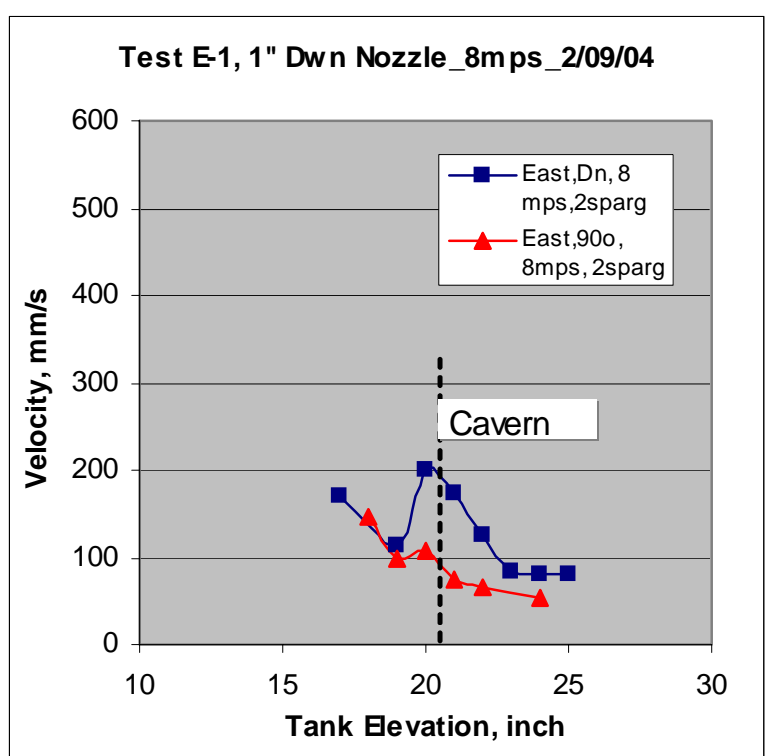

(a)

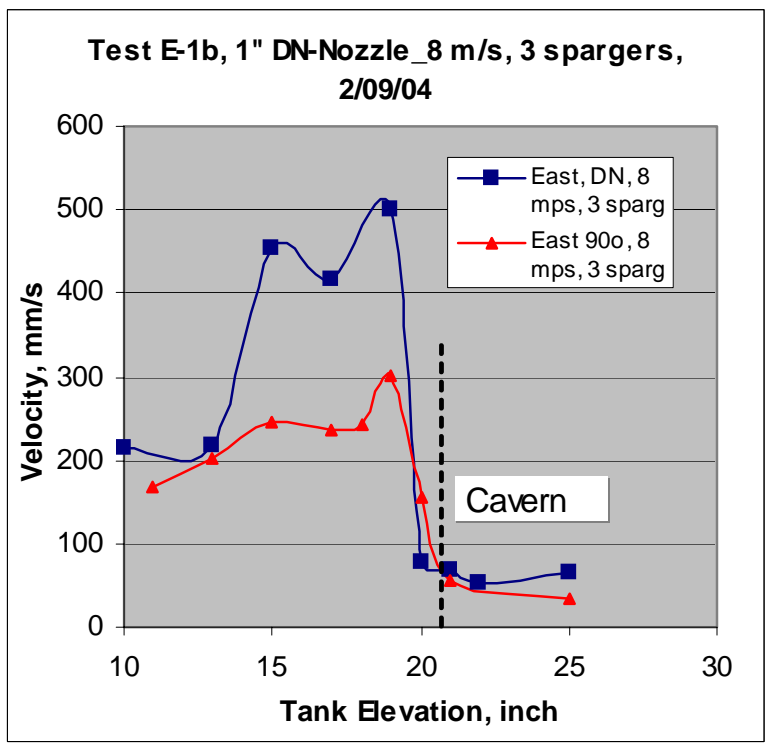

(c)

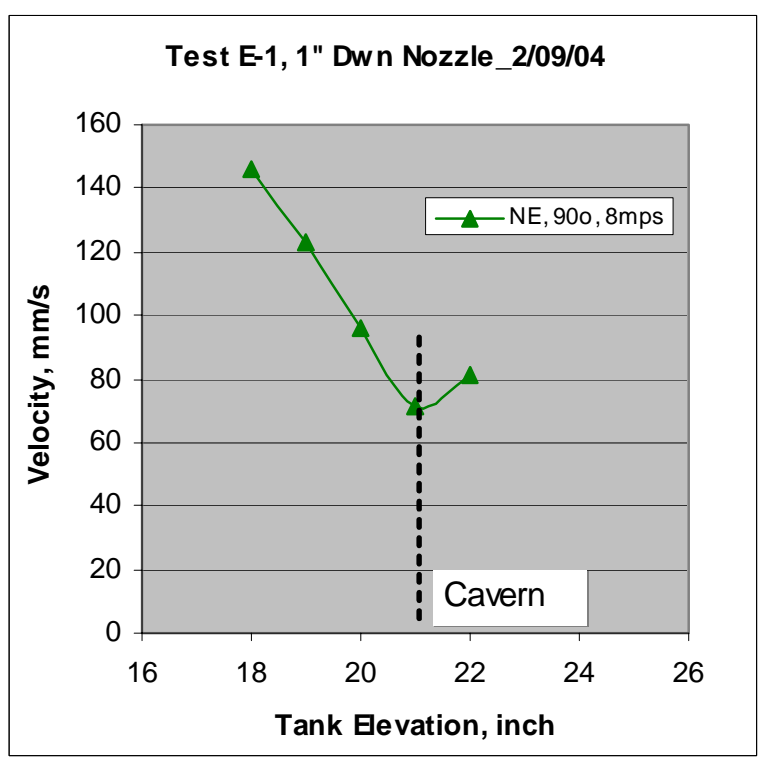

(b)

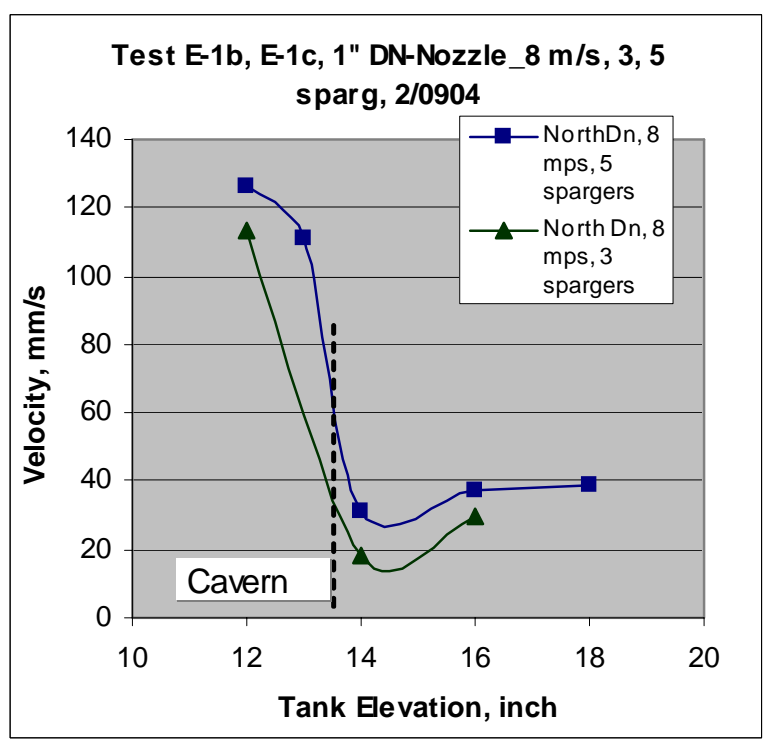

(d)

Figure D- 10. UVP Measurements for Test E-1 (a) East - 8m/s and (b) Northeast-8 m/s, (c) Test E-1b-East-8m/s; and Test E-1c(d) North-8 m/s 
WSRC-TR-2004-00398, REVISION 0 SRNL-RPP-2004-00060, REVISION 0

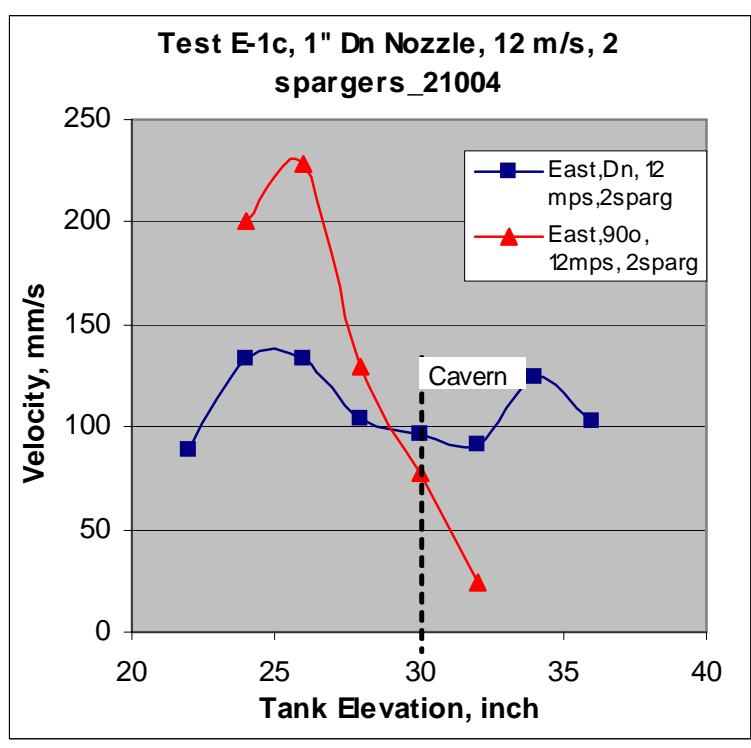

(a)

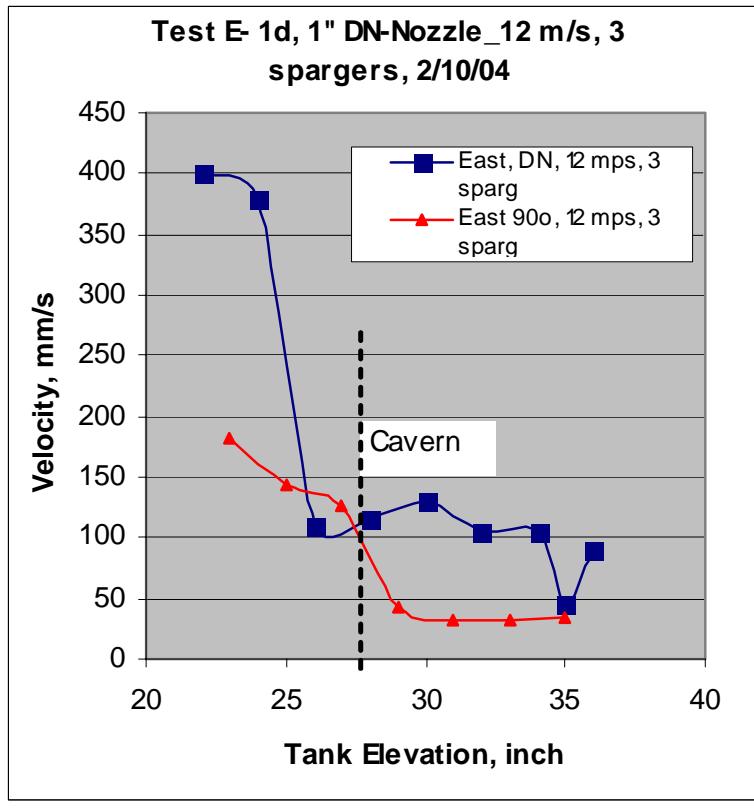

(c)

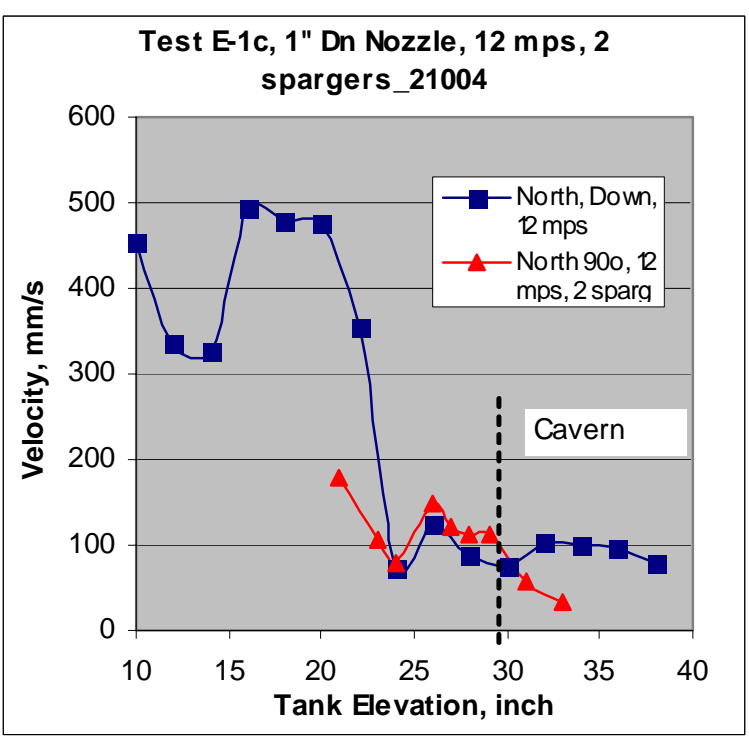

(b)

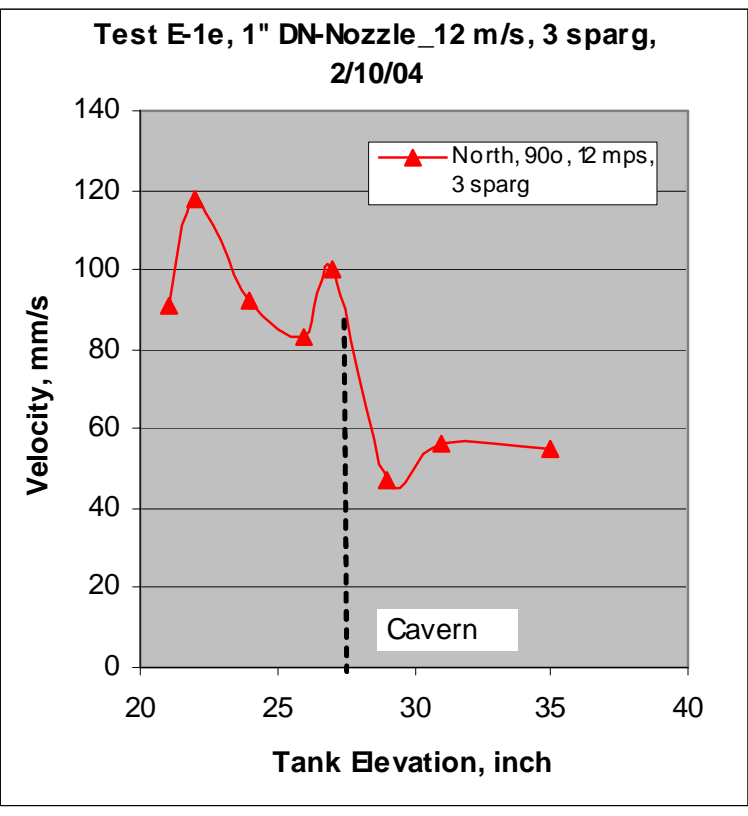

(d)

Figure D- 11. UVP Measurements for Test E-1c (a) East - 12m/s and (b) North-12 m/s, (c) Test E-1d-East-12 m/s; and Test E-1e (d) North-12 m/s 
WSRC-TR-2004-00398, REVISION 0

SRNL-RPP-2004-00060, REVISION 0

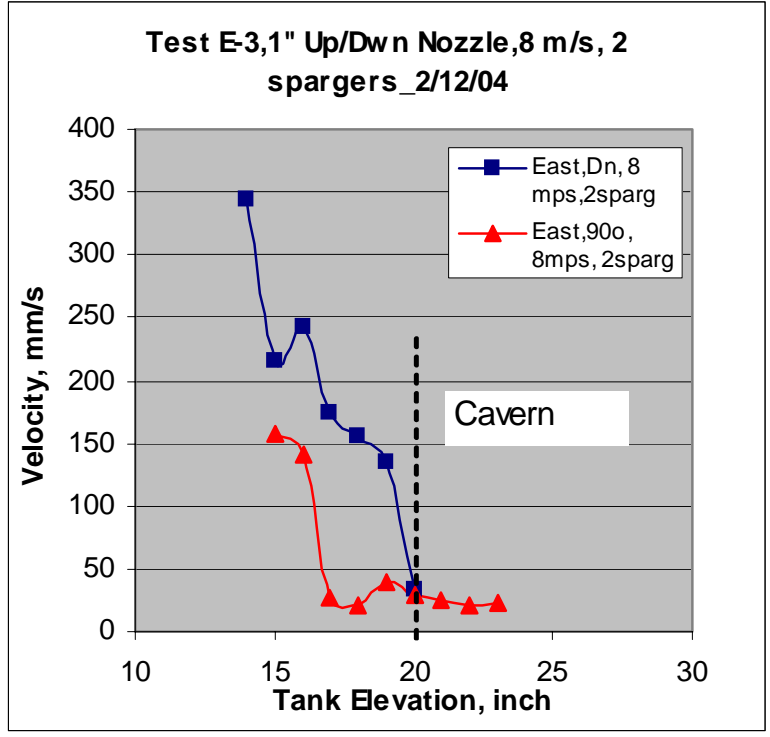

(a)

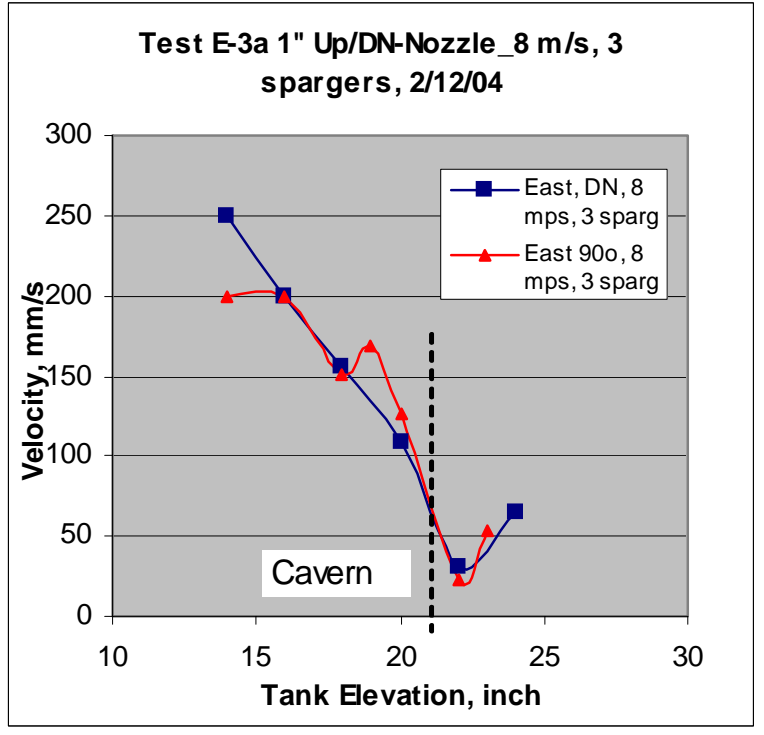

(c)

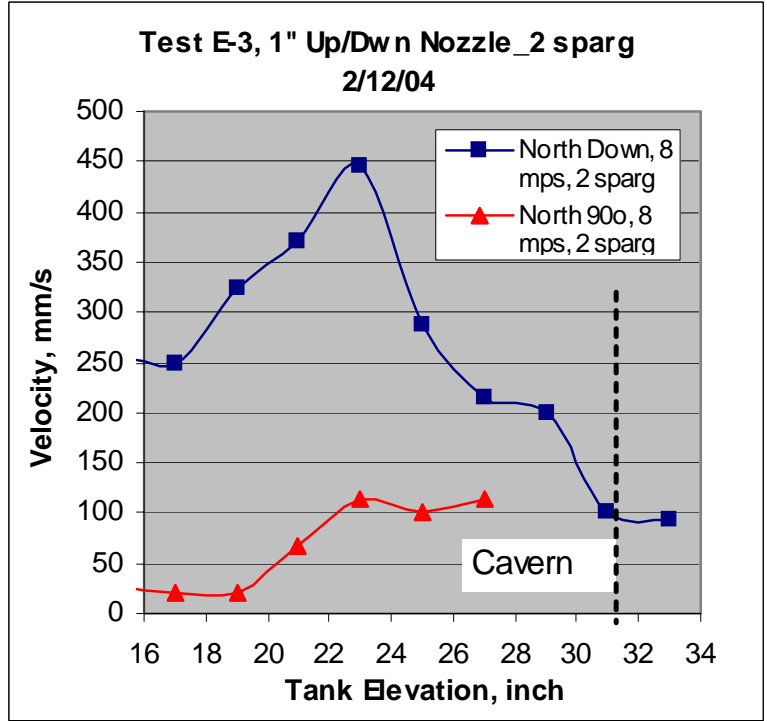

(b)

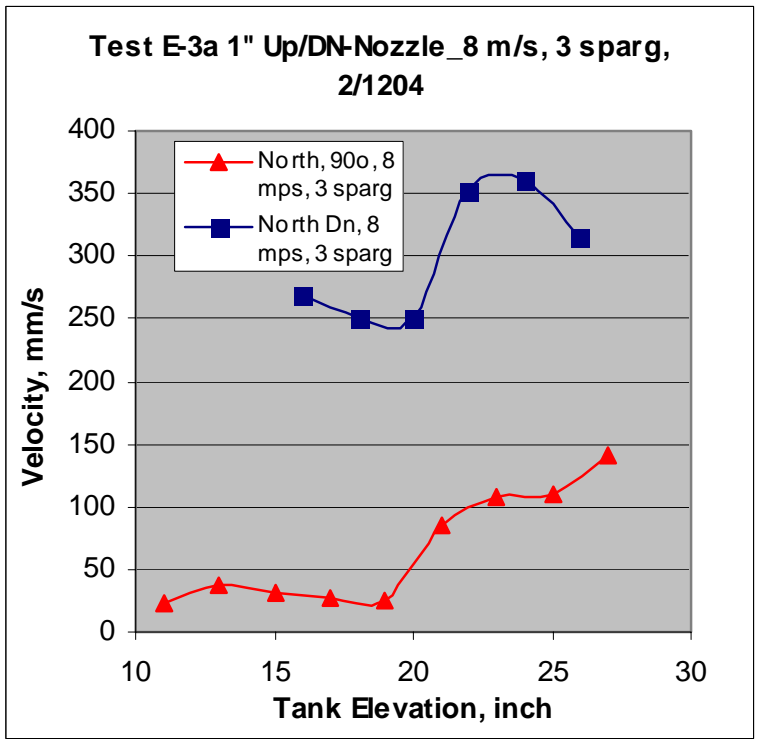

(d)

Figure D- 12. UVP Measurements for Test E-3 (a) East $-8 \mathrm{~m} / \mathrm{s}$ and (b) North-8 m/s, Test E-3a (c) East-8m/s; and (d) North-8 m/s 
WSRC-TR-2004-00398, REVISION 0

SRNL-RPP-2004-00060, REVISION 0

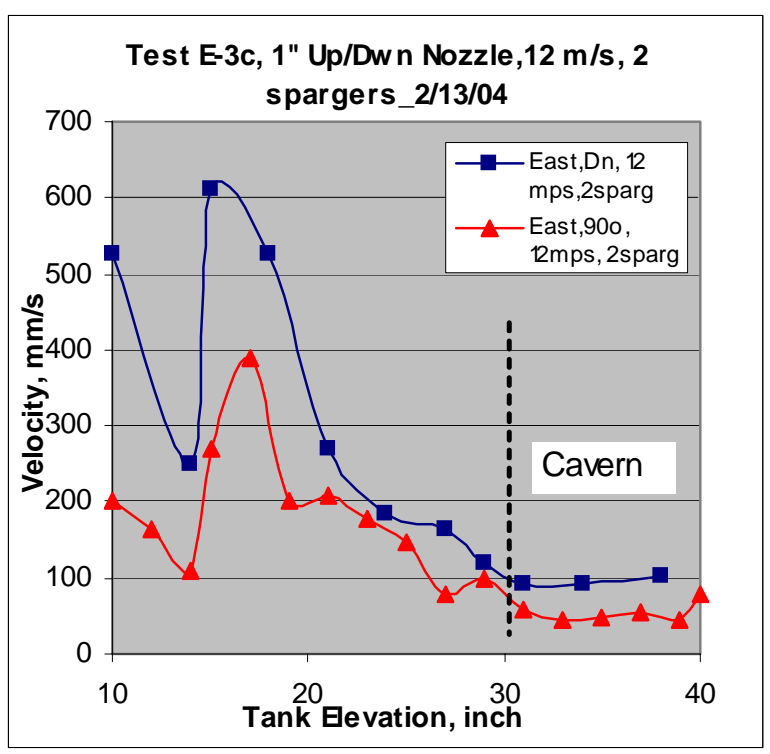

(a)

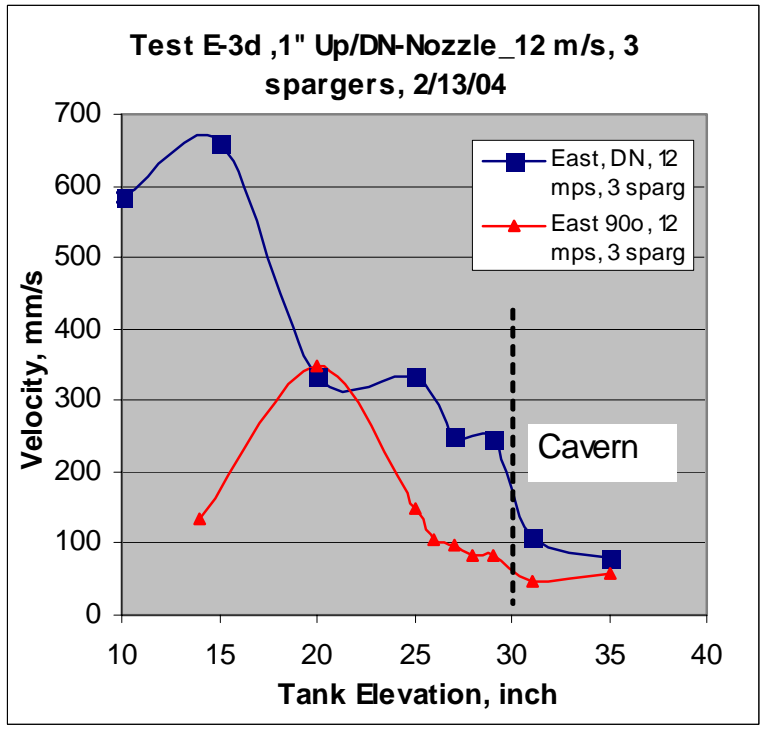

(c)

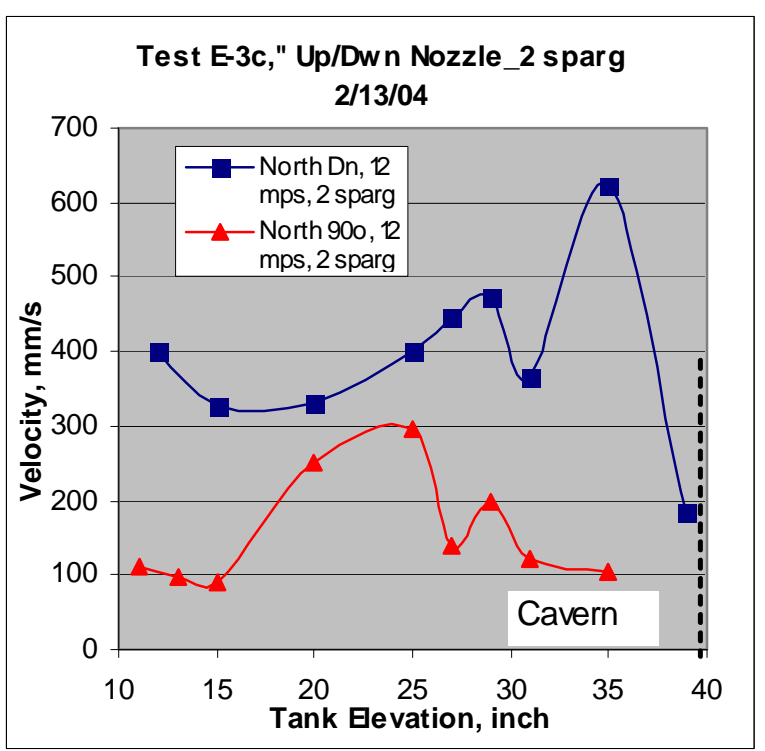

(b)

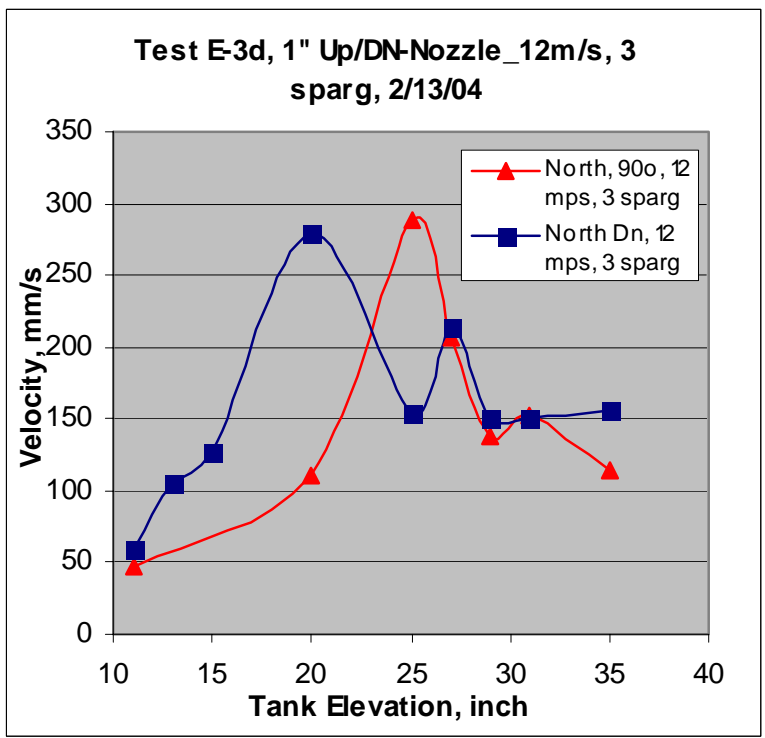

(d)

Figure D- 13. UVP Measurements for Test E-3c (a) East $-12 \mathrm{~m} / \mathrm{s}$ and (b) North-12 m/s, Test E-3d (c) East-12m/s; and (d) North-8 m/s 
WSRC-TR-2004-00398, REVISION 0 SRNL-RPP-2004-00060, REVISION 0

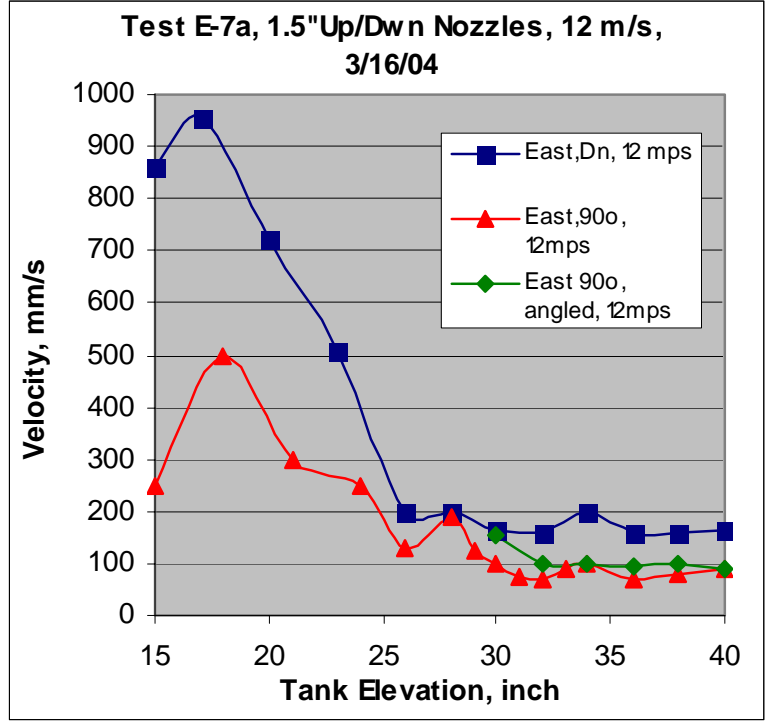

(a)

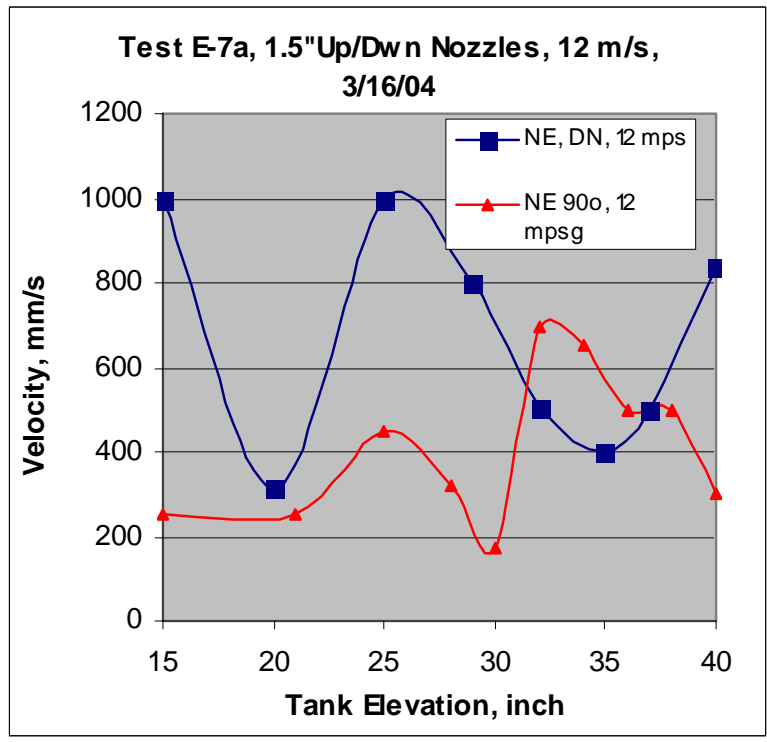

(c)

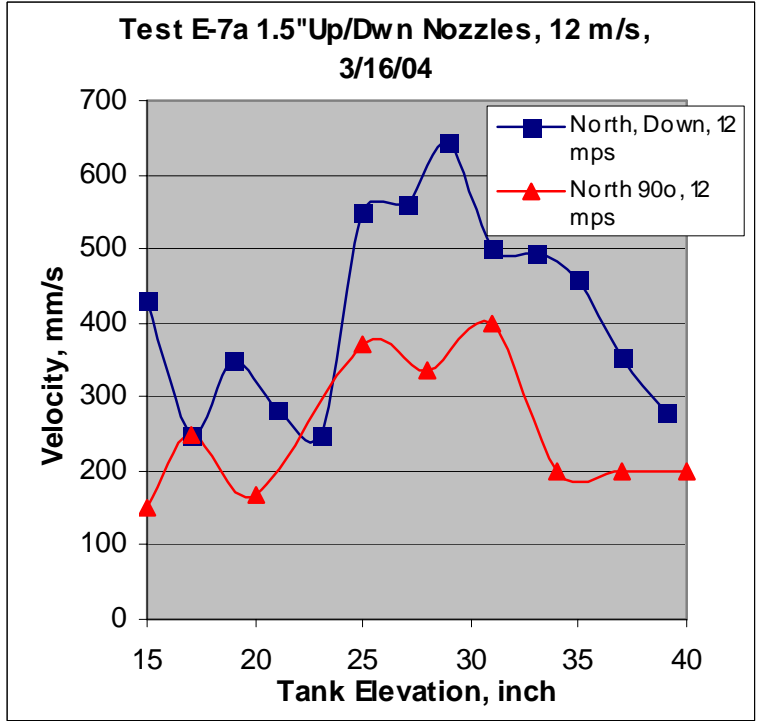

(b)

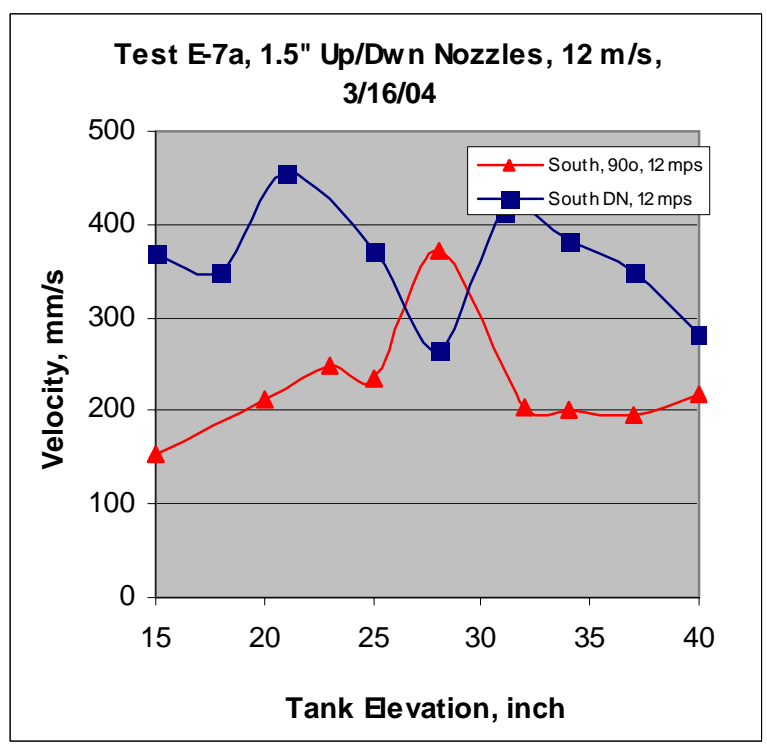

(d)

Figure D- 14. UVP Measurements for Test E-3c (a) East $-12 \mathrm{~m} / \mathrm{s}$ and (b) North-12 m/s, Test E-3d (c) East-12m/s; and (d) North-8 m/s 
WSRC-TR-2004-00398, REVISION 0

SRNL-RPP-2004-00060, REVISION 0

\section{APPENDIX E. STATISTICAL ANALYSIS OF SOLIDS MIXING TESTS}

Appendix E provides statistical comparisons of the data across sampling locations for the $30 \mathrm{~Pa}$ and $6 \mathrm{~Pa}$ tests, Tests E-6A and E-6B, conducted during the Solids Mixing Tests. The statistical comparisons were conducted using JMP ${ }^{\circledR}$ Version 5.0, a commercially available, statistical package from SAS Institute, Inc. [E-1].

Exhibit E- 1 presents the results from Test E-6A with involved the $30 \mathrm{~Pa}$ simulant. The first plot of the exhibit presents the solids wt $\%$ values by sampling location. Also, shown on this plot is a $95 \%$ confidence diamond for the mean solids $w t \%$ at each of these locations. The estimate of the standard error for each of these means is derived by pooling the sample standard deviations of the three locations (i.e., the variances in the values across the three locations are assumed to be the same, and the data are pooled to estimate this common variance).

Below this plot are the results of an analysis of variance (ANOVA) that is used to determine if there is an indication of a statistical difference in the mean solids $\mathrm{wt} \%$ values among the sampling locations. A p-value for Prob $>F$ less than or equal to 0.05 would indicate that the hypothesis of no difference in these means can be rejected with $95 \%$ confidence. Since the p-value in Exhibit B1 is 0.0084 , the hypothesis of no difference in the mean solids wt $\%$ of the heel, high grab, and low grab is rejected with $95 \%$ confidence. Thus, the data indicate a difference in these means. Note that the approach used in this analysis assumes that the variances in the values at each sampling location are the same (i.e., a pooled estimate of the error variance is used). The values for the confidence diamonds plotted in this exhibit are provided in the next table (titled "Means for Oneway Anova") of this exhibit.

The table under the heading "Summary Statistics" provides the sample means and standard deviations as well as $95 \%$ confidence intervals for the means. In this table the confidence intervals for the means are derived using the sample variance at each location (i.e., no pooling of variances is conducted).

The next plot and two tables of information in the exhibit are associated with statistical tests regarding the hypothesis that the underlying variances of the solids $\mathrm{wt} \%$ values at the sampling locations are the same. Note that in the above ANOVA an assumption was made that the variances are the same. The results presented in this part of the exhibit check on that assumption. The plot shows the standard deviations by sampling location. The first table below the plot lists these values along with some other descriptive information regarding the relationship between spread and central tendency of these data. The next table presents a series of statistical tests of the hypothesis of equal variances across the three sampling locations of Test 1. For the purposes of this analysis, Levene's test will be used to assess this hypothesis. If the p-value for Prob $>\mathrm{F}$ for Levene's test is 0.05 or smaller, then the hypothesis of equal variances can be rejected with at least $95 \%$ confidence. For the data of Exhibit B1, the $\mathrm{p}$-value is 0.2141 , and the hypothesis cannot be rejected. Thus, there is no indication from these data that the assumption of equal variances is not appropriate. 
If there were an indication of a difference in the variances of the solids $\mathrm{wt} \%$ values across the sampling location, then there would be a need for a statistical test for differences in the mean values that does not rely on pooling the variances. Such a test is provided in the next table of the exhibit - the table with the heading of "Welch Anova testing Means Equal, allowing Std Devs Not Equal." If the p-value in this table for Prob $>F$ is 0.05 or less, then the hypothesis of equal means can be rejected with at least $95 \%$ confidence.

For ANOVA results such as those above where there is an indication of a statistical difference in the mean solids $\mathrm{wt} \%$ among sampling locations, there is a need for additional insight into which means are different. This insight is provided in the last part of the exhibit under the heading of "Means Comparisons." In the first of the tables associated with these comparisons, the differences among the sampling means across various pairs of locations are given. Statistical differences are identified at an overall significance (Alpha) level of 0.05 (as indicated in the exhibit) using the Tukey-Kramer HSD test. The results of this test are provided in a symmetric matrix that shows a positive entry at a row and column pair (a pair of sampling locations) that is statistically different. Finally, the results are also provided in a table, in which location means that are not connected by the same letter are significantly different. For Exhibit E- 1, these mean comparisons indicate that the mean solids $w t \%$ for the heel is different from the mean values for the high and low grab locations.

So, in summary, the ANOVA results of Exhibit E- 1 suggest that the means are different, and the means comparisons indicate that the heel mean is different from the means of the other two locations.

For Exhibit E- 2, which covers the results from Test E-6B involving the $6 \mathrm{~Pa}$ simulant, the ANOVA results suggest an indication of a difference in the mean glass beads wt $\%$ across the three sampling locations at slightly above a 5\% significance level. However, Levene's test suggests that the variances of the data across the three locations are not the same, and Welch's test concludes that the means are different with at least $95 \%$ confidence. For the variances, it appears that the variance of the heel is greater than those of the low and high grab data. The Tukey-Kramer comparisons among the means show a significant difference between the low grab and heel. Figure E- 1 shows an ANOVA providing a comparison between just the low grab and high grab results. The results presented in this figure suggest that there is a statistically significant difference between the mean values for the high and low grab locations for the $6 \mathrm{~Pa}$ test. 
WSRC-TR-2004-00398, REVISION 0

SRNL-RPP-2004-00060, REVISION 0
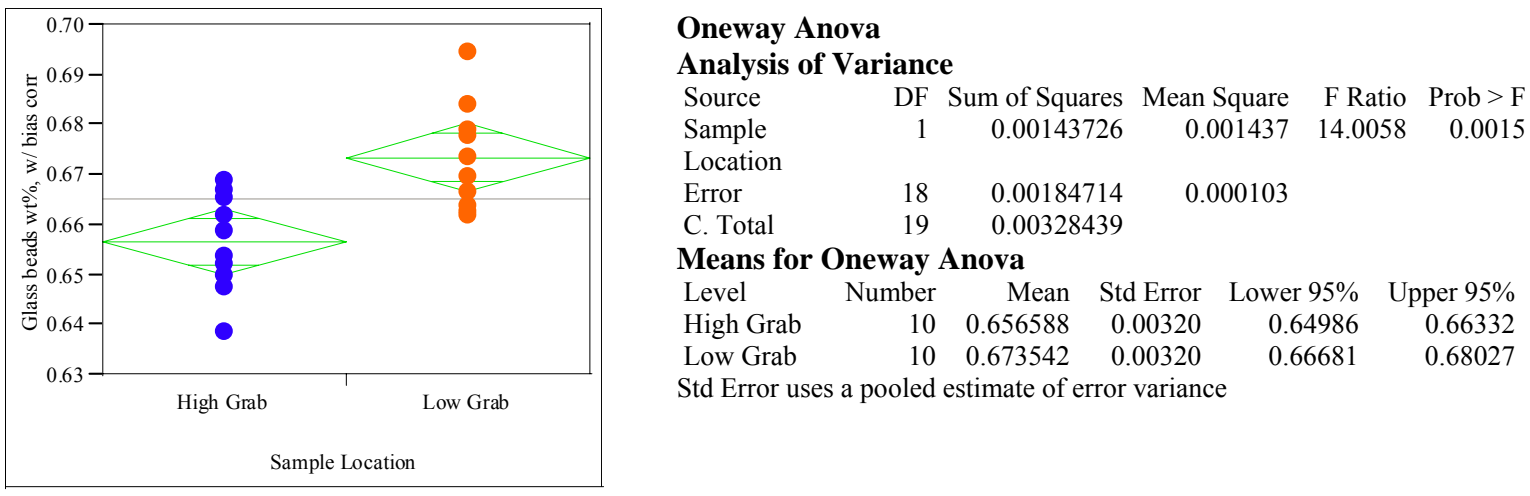

Figure E- 1. ANOVA Providing a Comparison Between just the Low Grab and High Grab Results

\section{Results of Statistical Comparisons Using Screened Data}

In Test E-6B, a potential outlier was identified, removed, and the statistical tests were repeated to determine if the potential outlier significantly affected the conclusions form Exhibit E- 2. For Exhibit E3, which covers the screened results from Test E-6B involving the $6 \mathrm{~Pa}$ simulant, the ANOVA results suggest a difference in the mean solids $\mathrm{wt} \%$ values across the three sampling locations at a confidence level of over $90 \%$. Levene's test suggests that the variances of the data across the three locations are not the same, and Welch's test concludes that the means are different with at least $95 \%$ confidence. The Tukey-Kramer comparisons among the means show no significant differences at the $95 \%$ confidence level in line with the ANOVA results. However, the results from Figure E- 1 still apply and suggest a statistically significant difference between the High Grab and Low Grab means.

\section{REFERENCES:}

E-1. SRT-SCS-2004-00016, "A Statistical Review of Data from a Series of EDL Solids Mixing Tests (U),” by T. B. Edwards, draft version, April 16, 2004.

E-2. JMP®: Statistics and Graphics Guide, Version 5.0, SAS Institute, Inc., Cary, NC, 2002. 
WSRC-TR-2004-00398, REVISION 0

SRNL-RPP-2004-00060, REVISION 0

Exhibit E- 1. Test E-6A (30 Pa simulant)

Oneway Analysis of Solids Wt\% By Sample Location

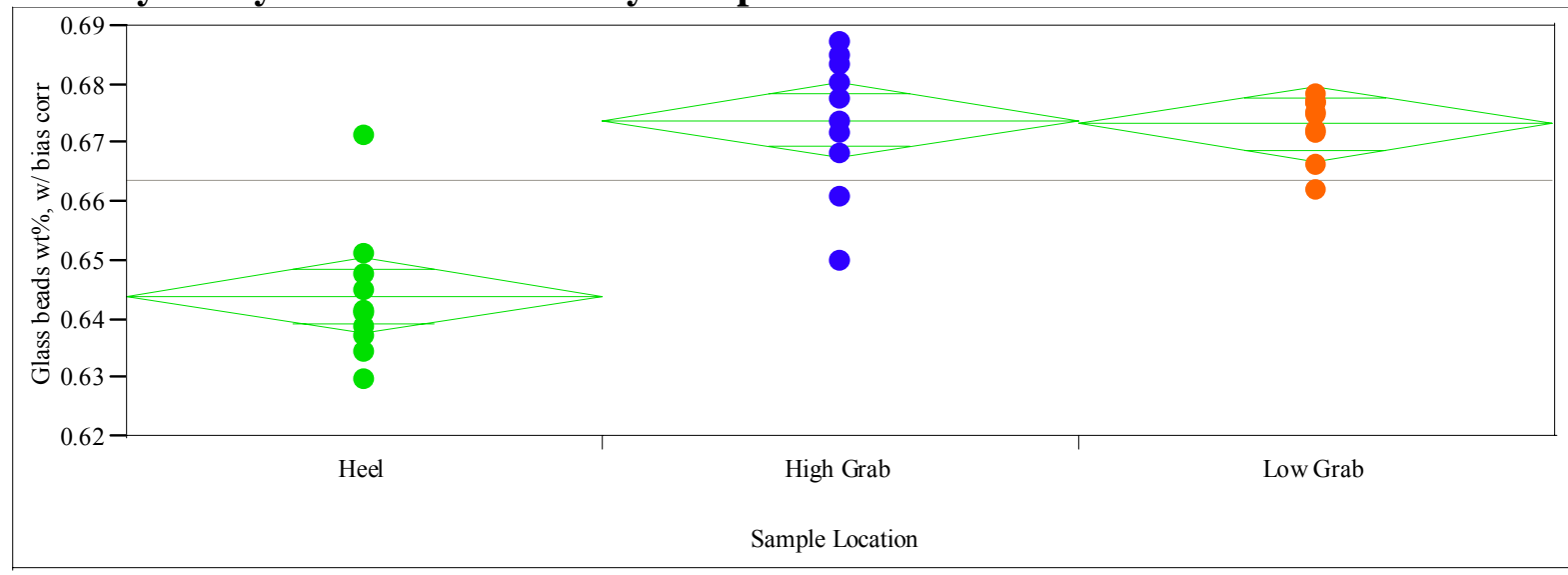

\section{Oneway Anova}

Summary of Fit

Summary of Fit
\begin{tabular}{|l|r|}
\hline & \\
\hline Rsquare & 0.685855 \\
\hline Adj Rsquare & 0.662585 \\
\hline Root Mean Square Error & 0.009961 \\
\hline Mean of Response & 0.663751 \\
\hline Observations (or Sum Wgts) & 30 \\
\hline
\end{tabular}

Analysis of Variance

\begin{tabular}{|l|r|r|r|r|r||}
\hline \hline Source & DF & Sum of Squares & Mean Square & F Ratio & Prob $>$ F \\
\hline Sample Location & 2 & 0.00584883 & 0.002924 & 29.4738 & $<.0001$ \\
\hline Error & 27 & 0.00267896 & 0.000099 & & \\
\hline C. Total & 29 & 0.00852779 & & & \\
\hline
\end{tabular}

Means for Oneway Anova

\begin{tabular}{|l|r|r|r|r|r||}
\hline Level & Number & Mean & Std Error & Lower 95\% & Upper 95\% \\
\hline Heel & 10 & 0.644008 & 0.00315 & 0.63755 & 0.65047 \\
\hline High Grab & 10 & 0.673965 & 0.00315 & 0.66750 & 0.68043 \\
\hline Low Grab & 10 & 0.673279 & 0.00315 & 0.66682 & 0.67974 \\
\hline
\end{tabular}

Std Error uses a pooled estimate of error variance

\section{Summary Statistics}

Means and Std Deviations

\begin{tabular}{|l|r|r|r|r|r|r||}
\hline Level & Number & Mean & Std Dev & Std Err Mean & Lower 95\% & Upper 95\% \\
\hline Heel & 10 & 0.644008 & 0.011552 & 0.00365 & 0.63574 & 0.65227 \\
\hline High Grab & 10 & 0.673965 & 0.011662 & 0.00369 & 0.66562 & 0.68231 \\
\hline Low Grab & 10 & 0.673279 & 0.005313 & 0.00168 & 0.66948 & 0.67708 \\
\hline
\end{tabular}


WSRC-TR-2004-00398, REVISION 0

SRNL-RPP-2004-00060, REVISION 0

Exhibit E-1. Test E-6A (30 Pa simulant) - continued

\section{Tests that the Variances are Equal}

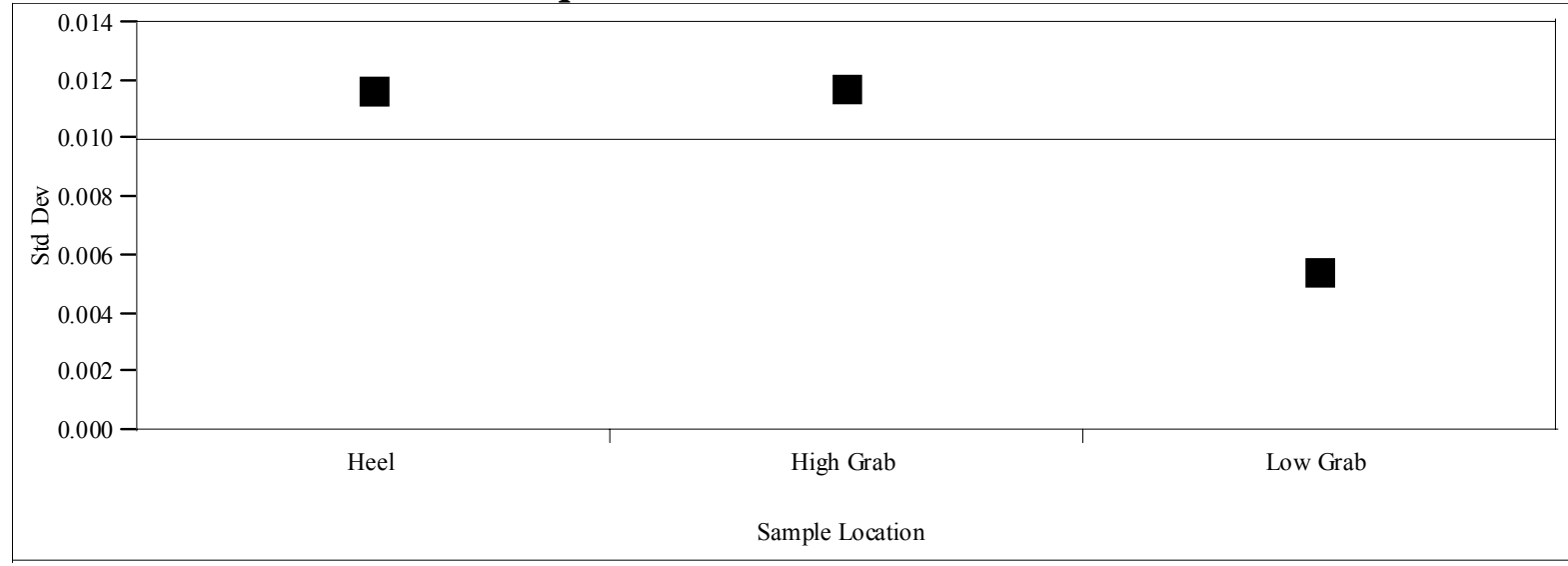

\begin{tabular}{|l|r|r|r|r||}
\hline Level & Count & Std Dev & MeanAbsDif to Mean & MeanAbsDif to Median \\
\hline Heel & 10 & 0.0115519 & 0.0079982 & 0.0075434 \\
\hline High Grab & 10 & 0.0116616 & 0.0088921 & 0.0088921 \\
\hline Low Grab & 10 & 0.0053125 & 0.0040912 & 0.0037641 \\
\hline
\end{tabular}

\begin{tabular}{|l|r|r|r|r||}
\hline Test & F Ratio & DFNum & DFDen & Prob > F \\
\hline O'Brien[.5] & 0.9538 & 2 & 27 & 0.3979 \\
\hline Brown-Forsythe & 1.4612 & 2 & 27 & 0.2497 \\
\hline Levene & 1.6279 & 2 & 27 & 0.2150 \\
\hline Bartlett & 2.7685 & 2 &. & 0.0628 \\
\hline
\end{tabular}

\section{Welch Anova testing Means Equal, allowing Std Devs Not Equal}

\begin{tabular}{||r|r|r|r||}
\hline \hline F Ratio & DFNum & DFDen & Prob $>$ F \\
\hline 26.4222 & 2 & 15.582 & $<.0001$ \\
\hline \hline
\end{tabular}

\section{Means Comparisons}

\begin{tabular}{||l|r|r|r|}
\hline Dif=Mean[i]-Mean[j] & High Grab & Low Grab & Heel \\
\hline High Grab & 0.00000 & 0.00069 & 0.02996 \\
\hline Low Grab & -0.00069 & 0.00000 & 0.02927 \\
\hline Heel & -0.02996 & -0.02927 & 0.00000 \\
\hline
\end{tabular}

Alpha $=$

0.05

Comparisons for all pairs using Tukey-Kramer HSD

\begin{tabular}{|r|r|}
\hline $\mathrm{q}^{*}$ & Alpha \\
\hline 2.47942 & 0.05 \\
\hline
\end{tabular}


Exhibit E-1. Test E-6A (30 Pa simulant) - continued

\begin{tabular}{||l|r|r|r||}
\hline \hline Abs(Dif)-LSD & High Grab & Low Grab & Heel \\
\hline High Grab & -0.01105 & -0.01036 & 0.01891 \\
\hline Low Grab & -0.01036 & -0.01105 & 0.01823 \\
\hline Heel & 0.01891 & 0.01823 & -0.01105 \\
\hline
\end{tabular}

Positive values show pairs of means that are significantly different.

\begin{tabular}{|l|l|l|r|}
\hline Level & & & Mean \\
\hline High Grab & A & & 0.67396465 \\
\hline Low Grab & A & & 0.67327938 \\
\hline Heel & & B & 0.64400831 \\
\hline
\end{tabular}

Levels not connected by same letter are significantly different 
WSRC-TR-2004-00398, REVISION 0

SRNL-RPP-2004-00060, REVISION 0

Exhibit E- 2. Test E-6B (6 Pa simulant)

Oneway Analysis of Solids Wt\% By Sample Location

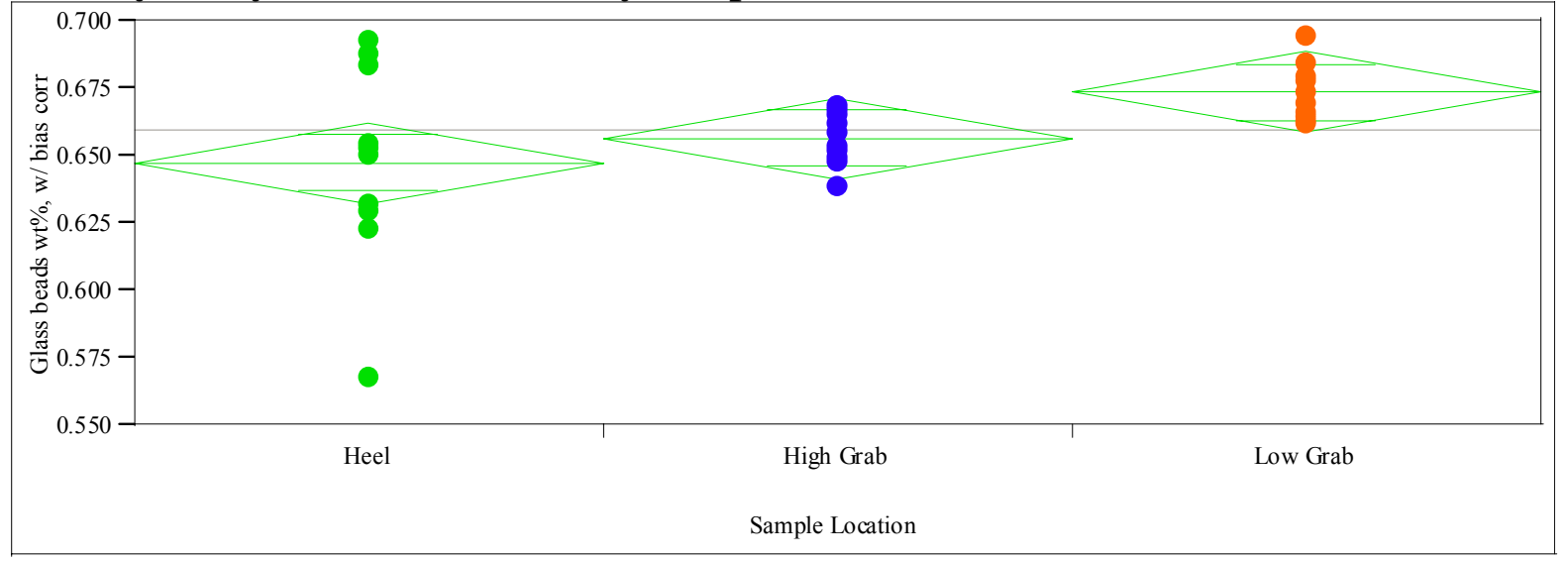

\section{Oneway Anova}

Summary of Fit
\begin{tabular}{||l|r|}
\hline & \\
\hline Rsquare & 0.195788 \\
\hline Adj Rsquare & 0.136216 \\
\hline Root Mean Square Error & 0.023099 \\
\hline Mean of Response & 0.659191 \\
\hline Observations (or Sum Wgts) & 30 \\
\hline
\end{tabular}

Analysis of Variance

\begin{tabular}{|l|r|r|r|r|r||}
\hline Source & DF & Sum of Squares & Mean Square & F Ratio & Prob > F \\
\hline Sample Location & 2 & 0.00350722 & 0.001754 & 3.2866 & 0.0528 \\
\hline Error & 27 & 0.01440615 & 0.000534 & & \\
\hline C. Total & 29 & 0.01791337 & & & \\
\hline \hline
\end{tabular}

Means for Oneway Anova

\begin{tabular}{|l|r|r|r|r|r||}
\hline Level & Number & Mean & Std Error & Lower 95\% & Upper 95\% \\
\hline Heel & 10 & 0.647444 & 0.00730 & 0.63246 & 0.66243 \\
\hline High Grab & 10 & 0.656588 & 0.00730 & 0.64160 & 0.67158 \\
\hline Low Grab & 10 & 0.673542 & 0.00730 & 0.65855 & 0.68853 \\
\hline
\end{tabular}

Std Error uses a pooled estimate of error variance

\section{Summary Statistics}

Means and Std Deviations

\begin{tabular}{|l|r|r|r|r|r|r||}
\hline Level & Number & Mean & Std Dev & Std Err Mean & Lower 95\% & Upper 95\% \\
\hline Heel & 10 & 0.647444 & 0.037356 & 0.01181 & 0.62072 & 0.67417 \\
\hline High Grab & 10 & 0.656588 & 0.009689 & 0.00306 & 0.64966 & 0.66352 \\
\hline Low Grab & 10 & 0.673542 & 0.010552 & 0.00334 & 0.66599 & 0.68109 \\
\hline \hline
\end{tabular}


WSRC-TR-2004-00398, REVISION 0

SRNL-RPP-2004-00060, REVISION 0

Exhibit E-2. Test E-6B (6 Pa simulant) - continued

\section{Tests that the Variances are Equal}

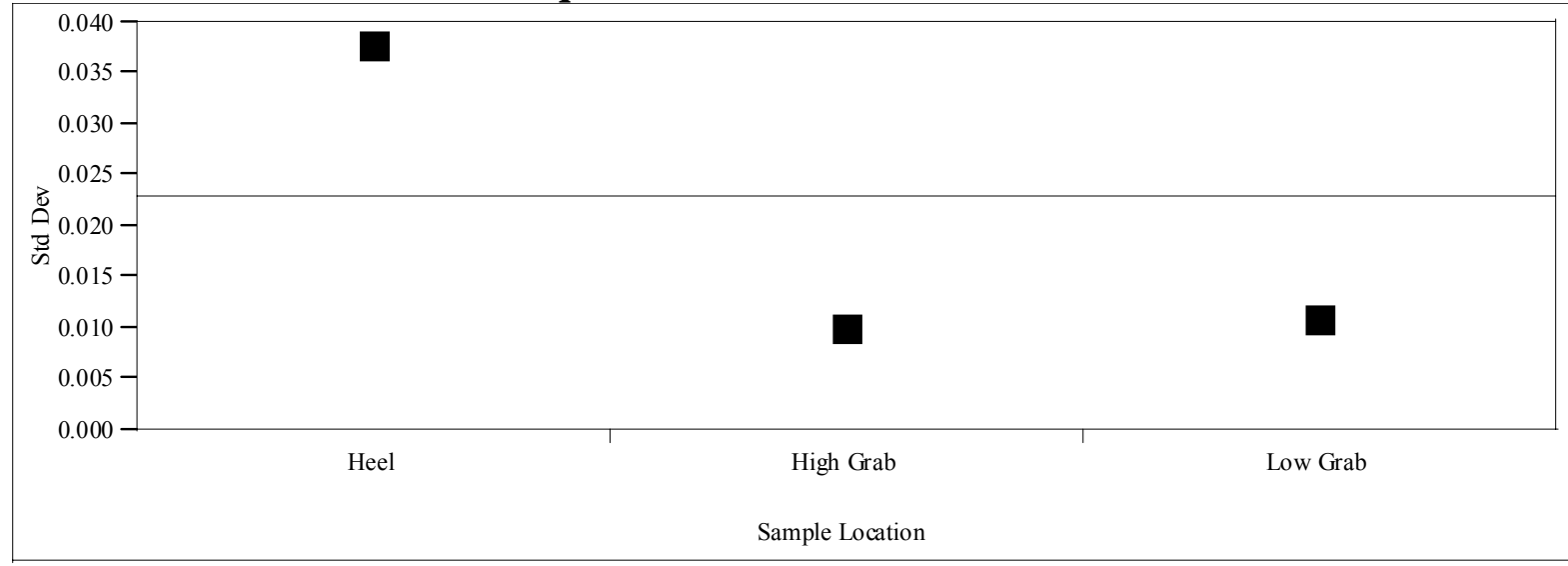

\begin{tabular}{|l|r|r|r|r|}
\hline Level & Count & Std Dev & MeanAbsDif to Mean & MeanAbsDif to Median \\
\hline Heel & 10 & 0.0373557 & 0.0274856 & 0.0269208 \\
\hline High Grab & 10 & 0.0096894 & 0.0080072 & 0.0080072 \\
\hline Low Grab & 10 & 0.0105524 & 0.0083876 & 0.0083876 \\
\hline
\end{tabular}

\begin{tabular}{|l|r|r|r|r||}
\hline Test & F Ratio & DFNum & DFDen & Prob > F \\
\hline O'Brien[.5] & 3.2344 & 2 & 27 & 0.0551 \\
\hline Brown-Forsythe & 5.2406 & 2 & 27 & 0.0119 \\
\hline Levene & 6.0820 & 2 & 27 & 0.0066 \\
\hline Bartlett & 10.0473 & 2 &. & $<.0001$ \\
\hline
\end{tabular}

\section{Welch Anova testing Means Equal, allowing Std Devs Not Equal}

\begin{tabular}{|r|r|r|r|}
\hline F Ratio & DFNum & DFDen & Prob > F \\
\hline 7.6767 & 2 & 16.326 & 0.0045 \\
\hline \hline
\end{tabular}

\section{Means Comparisons}

\begin{tabular}{||l|r|r|r||}
\hline Dif=Mean[i]-Mean[j] & Low Grab & $\begin{array}{r}\text { High } \\
\text { Grab }\end{array}$ & Heel \\
\hline Low Grab & 0.00000 & 0.01695 & 0.02610 \\
\hline High Grab & -0.01695 & 0.00000 & 0.00914 \\
\hline Heel & -0.02610 & -0.00914 & 0.00000 \\
\hline
\end{tabular}

Alpha $=$

0.05

Comparisons for all pairs using Tukey-Kramer HSD

\begin{tabular}{|r|r|}
\hline $\mathrm{q}^{*}$ & Alpha \\
\hline 2.47942 & 0.05 \\
\hline
\end{tabular}


WSRC-TR-2004-00398, REVISION 0

SRNL-RPP-2004-00060, REVISION 0

Exhibit E-2. Test E-6B (6 Pa simulant) - continued

\begin{tabular}{||l|r|r|r||}
\hline \hline Abs(Dif)-LSD & Low Grab & $\begin{array}{r}\text { High } \\
\text { Grab }\end{array}$ & Heel \\
\hline Low Grab & -0.02561 & -0.00866 & 0.00049 \\
\hline High Grab & -0.00866 & -0.02561 & -0.01647 \\
\hline Heel & 0.00049 & -0.01647 & -0.02561 \\
\hline
\end{tabular}

Positive values show pairs of means that are significantly different.

\begin{tabular}{|l|l|l|r|}
\hline Level & & & Mean \\
\hline Low Grab & A & & 0.67354215 \\
\hline High Grab & A & B & 0.65658775 \\
\hline Heel & & B & 0.64744412 \\
\hline
\end{tabular}

Levels not connected by same letter are significantly different 